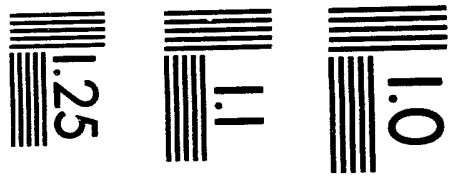

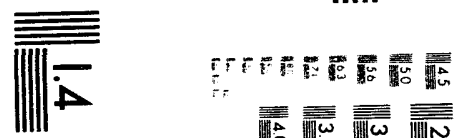

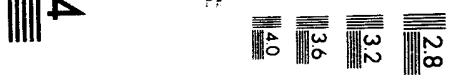

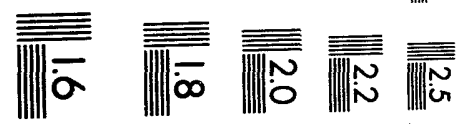



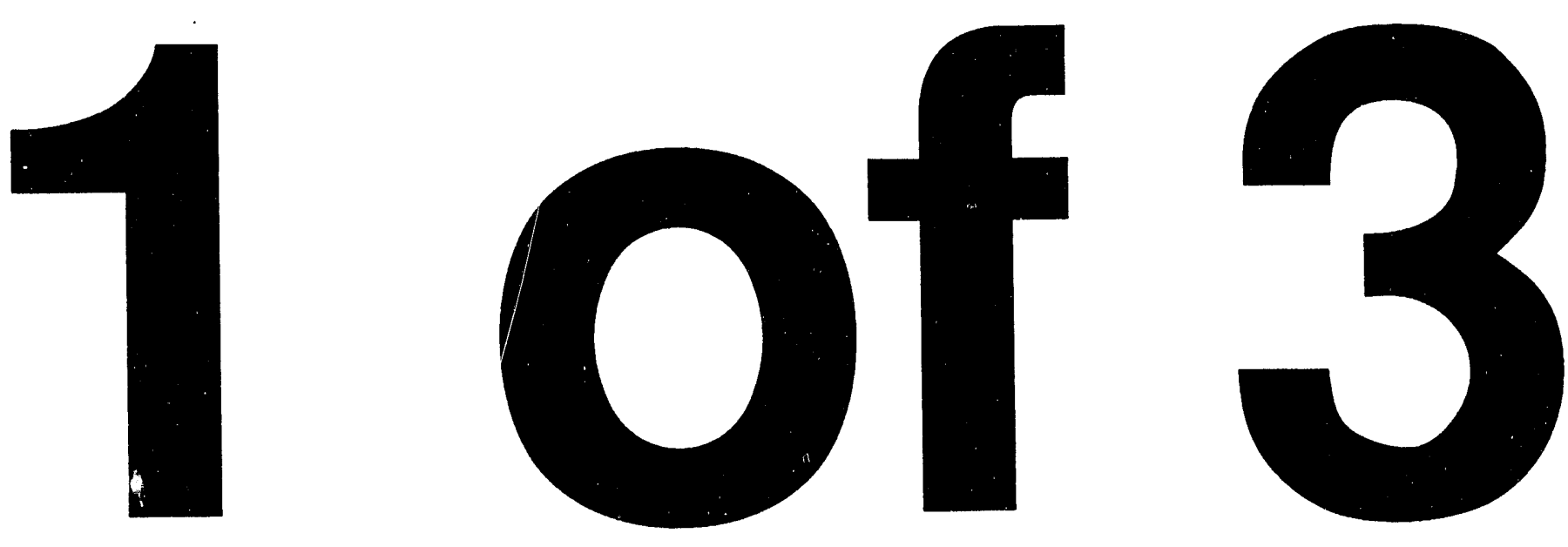


\title{
Intermedia Transfer Factors for Fifteen Toxic Pollutants Released to Air Basins in California
}

\author{
Prepared by: \\ Thomas E. McKone \\ Jeffrey I. Daniels \\ Health and Ecological Assessments Division \\ Lawrence Livermore National Laboratory \\ with Contributions from \\ Florence F. Chiao \\ Dennis P.H. Hsieh \\ University of California, Davis
}

Prepared for:

The California Air Resources Board

and

The Office of Environmental Health Hazard Assessment

California Environmental Protection Agency

October 1993

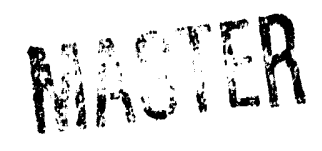




\section{FORWARD AND ACKNOWLEDGEMENTS}

As part of an effort to improve the Health Risk Assessment (HRA) computer program developed by the State of California Air Resources Board (ARB), the scientific objectives of this project are to develop for toxic chemical emissions to air the intermedia transfer factors (ITFs) to be used for estimating contaminant partitioning between air, soil, water, sediments, and biota. These ITFs will be compatible with both current and improved versions of the HRA model as well as other models that require ITF inputs.

This work was performed under the auspices of the U.S. Department of Energy (DOE) through Lawrence Livermore National Laboratory (LLNL) under Contract W-7405-Eng-48 with funding provided by the ARB through Contract Agreement A147-111. The work here represents part of a joint effort between LLNL and the University of California, Davis, (UCD) to address scientific problems related to risk assessment through the LLNL-UCD Risk Sciences Program. Funding for work at the University of California, Davis was provided in part by the State of California Department of Toxic Substances Control and by an LLNL LaboratoryDirected Research and Development Grant . 


\section{TABLE OF CONTENTS}

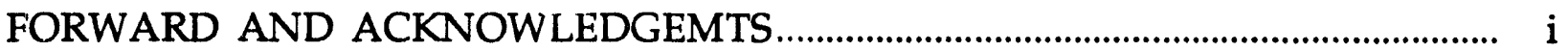

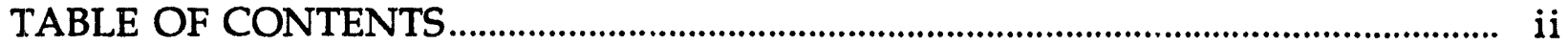

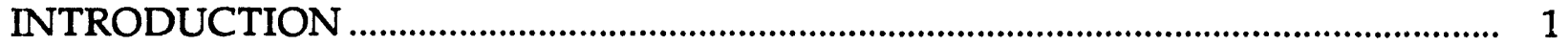

PART I: SUMMARY DEFINITION OF ITFs .................................................................. 2

Definitions of Intermedia Transfer Factors...................................................................... 2

The Basic Exposure Model and ITFs........................................................................... 2

Molecular Weight............................................................................................................. 3

Melting Point............................................................................................................... 3

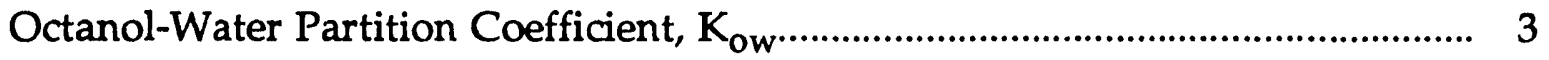

Vapor Pressure, VP......................................................................................... 4

Water Solubility, WS............................................................................................... 4

Henry's Law Constant, $\mathrm{H}$......................................................................................... 4

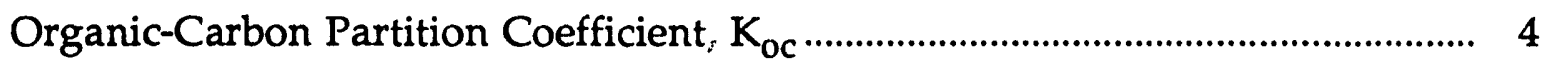

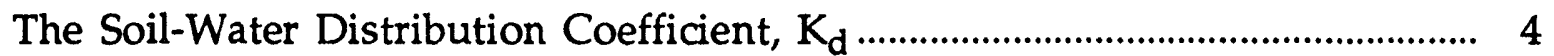

Diffusion Coefficients in Air and Water .................................................................. 5

Bioconcentration Factors (BCFs)......................................................................... 5

Biotransfer Factors ................................................................................................... 5

Biodegradation Factors .................................................................................................... 5

Media-Specific Half Lives........................................................................................ 6

Intermedia Transfer Factors: ........................................................................................ 6

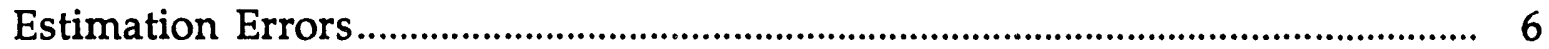

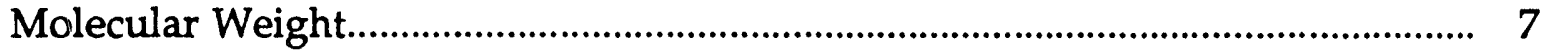

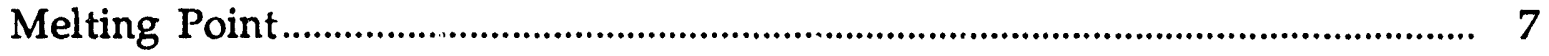

Octanol-Water Partition Coefficient, Kow ………................................................... 7

Vapor Pressure at Standard Temperature, VP ......................................................... 7

Solubility in Water, WS.................................................................................... 8

Henry's Law Constant.................................................................................... 8

Organic-Carbon Partition Coefficient, $K_{o c}$ and Sorption Coefficients, $K_{d} \ldots . . . . . .9$

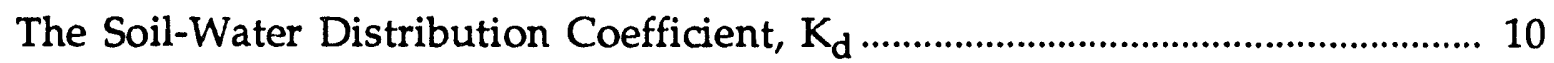

Molecu: r Diffusion Coefficients ...................................................................... 10

Diffusion in Water ..................................................................................... 10

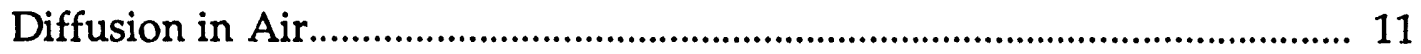


Plant-Soil Partition Coefficients, $\mathrm{K}_{\mathrm{ps}}^{\mathrm{rain}}, \mathrm{K}_{\mathrm{ps}}$ and $\mathrm{K}_{\mathrm{ps}}($ roots).............................. 11

Plant-Air Partition Coefficients ...................................................................... 14

Bioconcentration Factors (BCFs) in Fish........................................................ 15

Biotransfer Factors for Meat, Milk, and Eggs .................................................. 16

Contaminant Biodegradation Factors in Soil......................................................... 18

Media-Specific Half Lives............................................................................... 19

References for Part I............................................................................................. 19

PART II: INTERMEDIA TRANSFER FACTORS FOR 15 CHEMICALS.................... 23

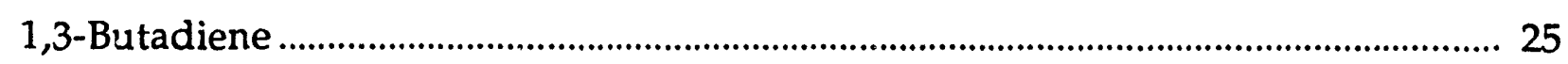

References for 1,3-Butadiene............................................................................. 34

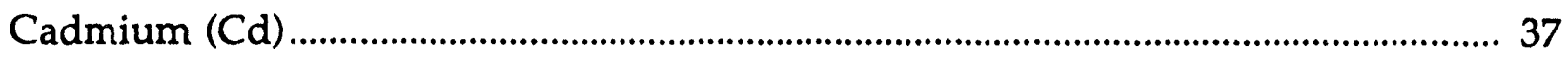

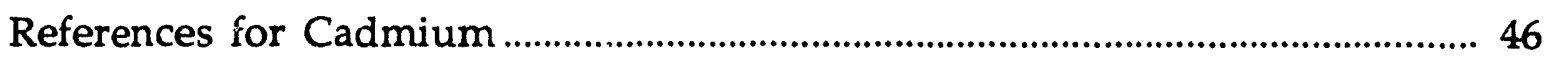

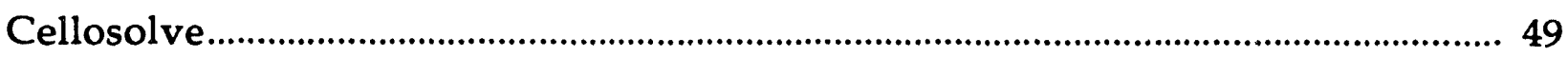

References for Cellosolve...................................................................................... 56

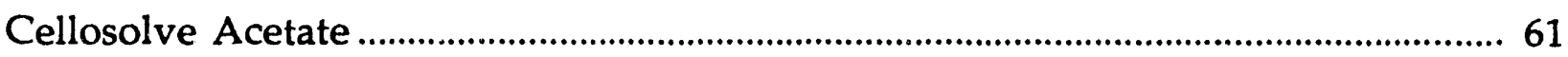

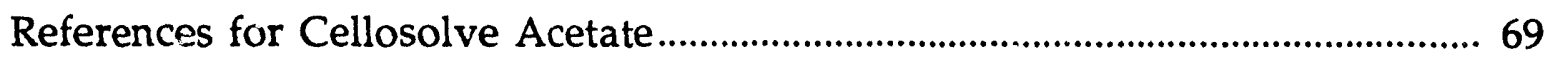

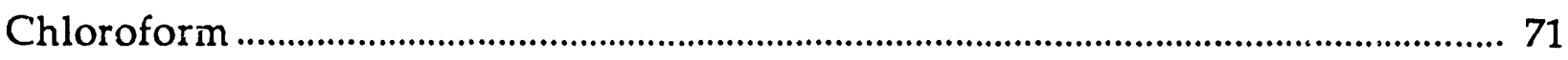

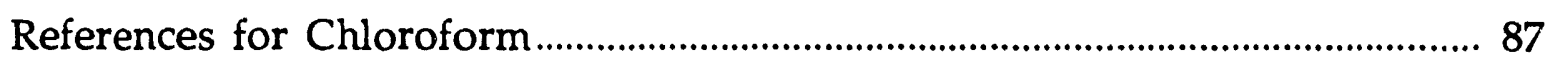

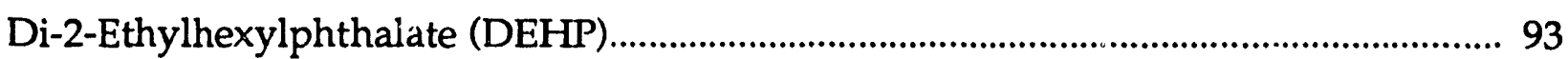

References for Di(2-ethylhexyl)phthalate (DEHP) ...................................................103

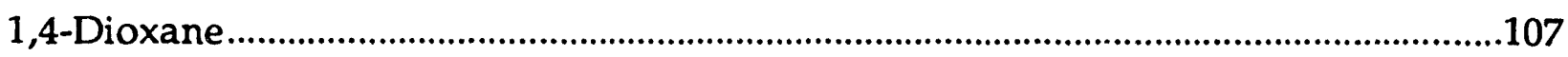

References for 1,4-Dioxane................................................................................116

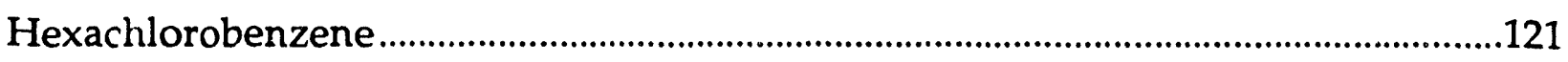

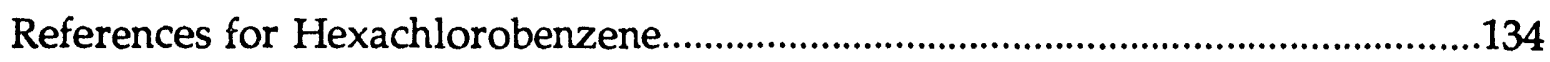

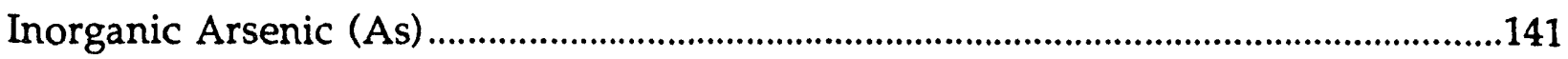

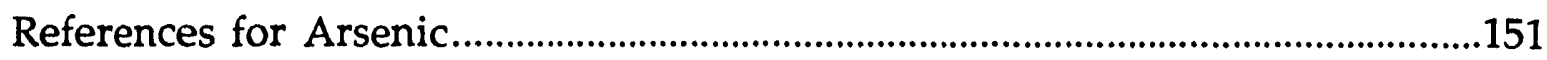

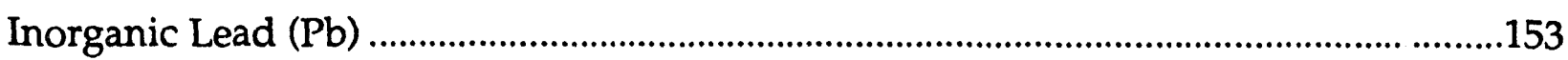

References for Inorganic Lead ..............................................................................162

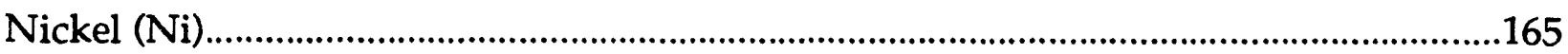

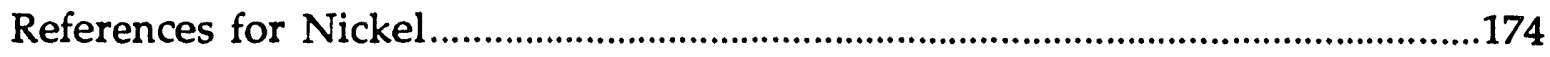

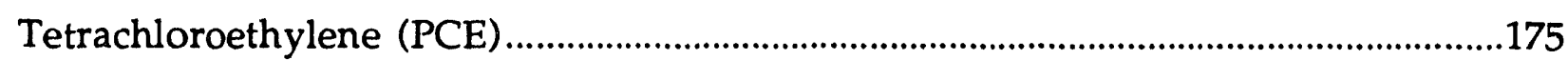

References for Tetrachloroethylene (PCE)............................................................191

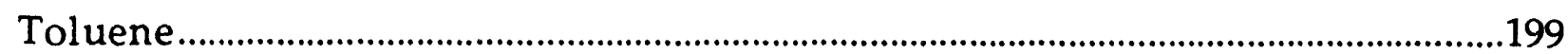




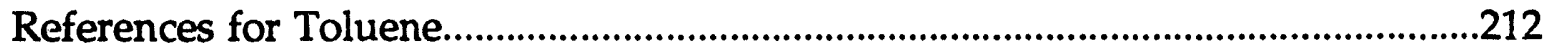

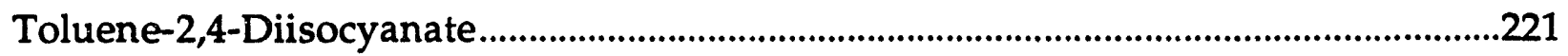

References for Toluene-2,4-diisocyanate ..............................................................229

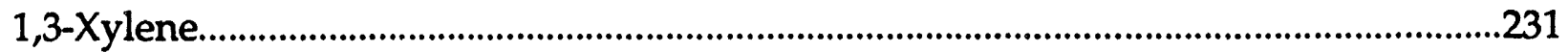

References for 1,3-Xylene ........................................................................................243 


\section{INTRODUCTION}

The purpose of this report is to provide intermedia-transfer factors (ITFs) for 15 chemicals. For these chemicals we have carried out a critical review of the existing literature in order to identify a range and best estimate values for the following ITFs:

molecular weight

melting point

octanol-water partition coefficient $\left(\mathrm{K}_{\mathrm{ow}}\right)$

vapor pressure at standard temperature (VP)

solubility in water (WS)

Henry's law constant $(\mathrm{H})$

organic-carbon partition coefficient $\left(\mathrm{K}_{\mathrm{oc}}\right)$

soil-water and/or sediment-water partition coefficient $\left(\mathrm{K}_{\mathrm{d}}\right)$

diffusion coefficient in water $\left(D_{\text {water }}\right)$

diffusion coefficient in air $\left(D_{\text {air }}\right)$

Bioconcentration factors for plant tissue concentration relative to soil concentration $\left(\mathrm{K}_{\mathrm{ps}}\right)$

Bioconcentration factors for plant leaf concentration relative to air concentration $\left(\mathrm{K}_{\mathrm{pa}}\right)$

Bioconcentration factors for fish-tissue concentration relative to water/or sediment concentrations (BCF)

Steady-state biotransfer factors for milk or dairy-product concentration relative to contaminant intake by cattle $\left(B_{k}\right)$

Steady-state biotransfer factors for meat concentration relative to contaminant intake by cattle, pigs, and chickens $\left(B_{t}\right)$

Steady-state biotransfer factors for egg concentration relative to contaminant intake by chickens $\left(B_{e}\right)$

Contaminant biodegradation factors in soil

Media-specific half lives for air, soil, and surface water

For factors that are not directly available from the literature, including references such as Lyman et al. (1990), Verschuereri (1983), Howard (1989), Howard et al. (1990, 1991) and Mackay et al. (1992a, 1992b, 1993); we discuss here methods to calculate these factors. 
This report is divided into two parts, in the first part we provide a summary definition of the ITFs, discuss methods for estimating these parameters in the absence of measured values, and consider the estimation errors inherent in these estimation methods. In the second part, we provide a detailed summaries of measured and estimated ITF values for 15 air contaminants and make recommendations regarding the expected value and variance in these values for use in exposure models.

\section{PART I: SUMMARY DEFINITION OF ITFs}

\section{DEFINITIONS OF INTERMEDIA TRANSFER FACTORS}

The use of any multimedia transport model relating contaminant concentrations in air to those in soil, water, and biota, requires that we determine the intermedia transfer factors (ITFs) that define concentration relationships between an exposure medium and the environmental medium that provides contaminant to the exposure medium. In this section, we consider how ITFs are used in a generalized exposure model and we define the ITFs for which values are presented in Part II of this report.

\section{The Basic Exposure Model and ITFs}

The exposure-assessment process relates contaminant concentrations in environmental media-air, surface soil, root-zone soil, surface water, and ground water, etc.-to contaminant concentrations in the exposure media with which a human population has contact (personal air, tap water, foods, household dusts and soils, etc.). Average daily dose within an exposed population is the product of the exposure concentrations in these contact media and an intake or uptake factor that relates the concentrations to the distributions of potential dose by the inhalation, ingestion, and dermal contact routes within the population. Thus, the populationaveraged potential dose during a period of time when environmental concentrations remain constant is expressed as an average daily dose rate (ADD), in $\mathrm{mg} / \mathrm{kg}-\mathrm{d}$,

$$
A D D=\left[\frac{C_{i}}{C_{k}}\right] \times\left[\frac{I U_{i}}{B W}\right] \times \frac{E F \times E D}{A T} \times C_{k}
$$


where $\left[C_{i} / C_{k}\right]$ is the intermedia concentration ratio, which expresses the ratio of contaminant concentration in the exposure medium $i$ to the concentration in an environmental medium $k ;\left[\mathrm{IU}_{\mathrm{i}} / \mathrm{BW}\right]$ is the intake or uptake factor per unit body weight associated with the exposure medium $i, \mathrm{EF}$ is the exposure frequency for the exposed population, in days per year; ED is the exposure duration for the exposed population, in years; AT is the averaging time for the exposed population, in days; and $\mathrm{C}_{\mathrm{k}}$ is the contaminant concentration in environmental medium $k$. For exposure through the ingestion route, $\left[\mathrm{IU}_{\mathrm{i}} / \mathrm{BW}\right]$ is the intake rate per unit body weight of the exposure medium such as $\mathrm{kg}$ (vegetables) $/ \mathrm{kg}-\mathrm{d}, \mathrm{L}$ (milk)/ $\mathrm{kg}-\mathrm{d}$, or $\mathrm{kg}$ (meat) $/ \mathrm{kg}$-d. The calculation of the intermedia concentration ratio, $\mathrm{C}_{\mathrm{i}} / \mathrm{C}_{\mathrm{k}}$, requires the use of the ITFs described in the sections below. The reliability of the intermedia concentration ratio is directly dependent on the reliability in the measured and estimated values of the ITFs which are used to calculate this ratio.

\section{Molecular Weight}

Molecular weight is the mass of one gram-mole of and element or compound, that is the mass of $6.02252 \times 10^{23}$ atoms or molecules.

\section{Melting Point}

The melting point the temperature at which a compound makes the transition from a solid to a liquid phase. It is typically measured at atmospheric pressure.

\section{Octanol-Water Partition Coefficient, $\mathrm{K}_{\mathrm{ow}}$}

The octanol-water partition coefficient provides a measure of the extent of chemical partitioning between water and octanol at equilibrium. The greater the $\mathrm{K}_{\mathrm{ow}}$, the more likely a chemical is to partition to octanol than to water. The octanol-water partition coefficient is used as a basis for estimating organic carbon partitioning in soils and sediments, bioconcentration factors in aquatic organisms, root-soil and leaf-air partition coefficients in land vegetation, and fat-diet partition coefficients in terrestrial animals. 


\section{Vapor Pressure, VP}

Vapor pressure is a saturation property in that it is a measure of the maximum capacity that a gas phase medium has for a chemical. VP is the pressure exerted by a chemical vapor in equilibrium with its solid or liquid phase. It is used to calculated the rate of volatilization of contaminant from soil or water and for estimating the Henry's law constant for low-srslubility chemicals. The higher the vapor pressure, the more likely a chemical is to exist in the gas phase.

\section{Water Solubility, WS}

Water solubility is also a saturation property in that it is a measure of the capacity of the water phase to hold a contaminant. WS is the upper limit on a chemical's dissolved concentration in pure water at a specified temperature.

\section{Henry's Law Constant, $\mathrm{H}$}

This factor is a measure at equilibrium of the ratio of chemical activity in the gas above a liquid to chemical activity in the liquid. It is the basis for estimating airwater partition coefficients and is often expressed as the partial pressure of chemical in the gas phase divided by the concentration in the water phase. For chemicals with a low solubility limit in water, the Henry's law constant can be estimated as the vapor pressure of the pure chemical divided by the solubility limit in water. The higher the Henry's law constant, the more likely a chemical is to exist in the gaseous state than remain dissolved in water.

\section{Organic-Carbon Partition Coefficient, $\mathrm{K}_{\mathrm{oc}}$}

The organic-carbon partition coefficient provides a measure of chemical partitioning between organic carbon (in soils and sediments) and water. The higher the $\mathrm{K}_{\mathrm{oc}}$, the more likely a chemical is to bind to the solid phase of soil or sediment than to the liquid phase. When $\mathrm{K}_{\mathrm{oc}}$ is multiplied by the fraction organic carbon in a soil or sediment, we obtain an estimate of the soil/water or sediment/water partition coefficient.

\section{The Soil-Water Distribution Coefficient, $\mathbf{K}_{\mathbf{d}}$}

$\mathrm{K}_{\mathrm{d}}$ represents the distribution or sorption coefficient, which is the ratio at equilibrium of chemical concentration attached to particles $(\mathrm{mol} / \mathrm{kg})$ to chemical concentration in the solution, $\mathrm{mol} / \mathrm{L}$. 


\section{Diffusion Coefficients in Air and Water}

Diffusion coefficients describe the movement of a molecule in a liquid or gas medium as a result of differences in concentration. They are used to calculate the dispersive component of chemical transport. The higher the diffusion coefficient, the more likely a chemical is to move in response to concentration gradients. Diffusive mass transfer at compartment boundaries is often modeled using a boundary layer model. The flux of contaminant from the surface to the bulk fluid is proportional to the difference in concentration between the surface and the bulk fluid. This approach is used for mass transfer between air and soil, air and surface water, and surface water and sediments. In order to carry out this approach, one needs estimates of the diffusion coefficients of a chemical in both pure air and pure water.

\section{Bioconcentration Factors (BCFs)}

Bioconcentration factors provide a measure of chemical partitioning between a biological medium such as fish tissue or plant tissue and an external medium such as water (for fish) or air (for plants). The higher the BCF the more likely partitioning in biota is likely to be high. BCFs have been expressed for fish/sediment, fish/water, plant-leaf/air, plant-root/soil, and animal-fat/diet partitioning.

\section{Biotransfer Factors}

Biotransfer factors are the steady-state contaminant concentration in fresh meat, milk, dairy products and eggs divided by the animals' daily contaminant intake and have units of $(\mathrm{mg} / \mathrm{kg}) /(\mathrm{mg} / \mathrm{d})$ or $\mathrm{d} / \mathrm{kg}$. Unlike bioconcentration factors, which express steady-state concentration ratios between animal tissue and a specific environmental medium, biotransfer factors express the steady-state relationship between intake and tissue or food-product concentrations. For terrestrial animals that are exposed to contaminants from multiple media (such as air, water, forage, soil, etc.), the biotransfer factor has more utility for assessing the effects of multimedia contamination on food contamination.

\section{Biodegradation Factors}

The transformation of organic and inorganic compounds by microorganisms that are present in environmental media can have a profound influence on their 
persistence and toxicity. Due to their broad range of enzymatic capabilities, microorganisms are capable of transforming many inorganic and organic compounds. Such transformations can result in the partial degradation of a compound (e.g., conversion of DDT to DDE), mineralization (i.e., complete transformation to carbon dioxide and water), or synthesis of a stable product (e.g., formation of methyl arsenicals from arsenate). While these processes generally result in the detoxification of the parent compound, other toxic products may also be formed. For example, the microbial metabolism of aromatic amines can result in the formation of mutagenic byproducts.

\section{Media-Specific Half Lives}

A medium-specific half life provides a relative measure of the persistence of a chemical in a given medium such as soil or water. This measure accounts for the sum of all loss mechanisms, both transport and transformation. The greater the half-life in a medium, the more persistent a chemical is likely to be in that medium.

\section{INTERMEDIA TRANSFER FACTORS:}

\section{MEASURED VALUES AND ESTIMATION METHODS}

\section{Estimation Errors}

For all the ITFs presented here the value of the ITF is described both by an arithmetic mean value and a coefficient of variation, which is the arithmetic standard deviation divided by the arithmetic mean and abbreviated as CV. The CV is used to described measurement variance for properties that are measured and estimation error for properties that are estimated.

Estimates of many ITF properties are often based on regression equations that relate these ITFs to some measure of structure or activity associated with the contaminant. These methods are referred to as quantitative structure-activity relationship (QSAR) methods. It should be recognized that the reliability of an exposure model will be limited by the precision of these QSAR estimates. When these chemical properties are then used to estimate ITFs, the associated estimation errors are often not reported (see for example Travis and Arms, 1988).

Our estimate of precision in ITFs is based on calculating, $\mathrm{S}_{\mathrm{e}}$, the standard error of the estimate (or standard deviation of the residuals) in the regression equations and fragment models used to derive an ITF. The $S_{e}$ for an ITF, such as the organic-carbon partition coefficient $\left(\mathrm{K}_{\mathrm{oc}}\right)$ derived from a regression or 
correlation analysis can be estimatea according to the following formula (Hamburg, 1970),

$$
S_{\mathrm{e}} \text { of } \log K_{\alpha c}^{\mathrm{est}}=\sqrt{\frac{1}{(n-2)} \sum_{i=1}^{\mathrm{n}}\left[\log K_{o c}^{\mathrm{msd}}-\log K_{o c}^{\mathrm{est}}\right]_{i}^{2}}
$$

where $\mathrm{n}$ is the number of chemicals used in the estimation protocol and $\mathrm{K}_{o c}^{\text {est }}$ refers to the estimated property ( $\mathrm{K}_{\mathrm{oc}}$ in this case) and $\mathrm{K}_{\propto}^{\mathrm{msd}}$ refers to the corresponding measured values used to carry out the regression.

\section{Molecular Weight}

For most organic and inorganic compounds, the molecular weight can be reliably obtained from a number of common references. The precision with which molecular weights can be measured is as high as ITF.

\section{Melting Point}

The melting point is a measured parameter and available for most compounds in the literature. Methods for estimating the melting point in the absence of measured values are describe by Lyman et al. (1990).

\section{Octanol-Water Partition Coefficient, $\mathbf{K}_{\mathbf{~ o w}}$}

Measured values of $\mathrm{K}_{\mathrm{ow}}$ are available for many compounds. Experimental methods for measuring $K_{o w}$ involve the determination of chemical concentration in water and octanol phases. This process is typically carried out using shake-flask or generator-column methods. Details of experimental methods are described in several papers, most notably in Fujita et al. (1964), Leo et al. (1971), Chiou et al. (1982), and De Bruijn et al. (1989). Literature reviews of measured and calculated values of $\mathrm{K}_{\mathrm{ow}}$ for many contaminants are available in Howard (1989), Howard et al. (1990), Mackay et al. (1992a, 1992b, 1993), and Verschueren (1983). Methods for estimating $K_{o w}$ are summarized in Lyman et al. (1990) and Verschueren (1983).

\section{Vapor Pressure at Standard Temperature, VP}

Measured values for vapor pressure are widely available. One of the earliest and most extensive compilations of vapor pressure for both organic and inorganic chemicals are those of Stull (1947a, 1947b). 
In principal the determination of vapor pressure involves the measurement of saturation concentration or pressure of the solute in a gas phase. The most reliable methods involve direct determination of these concentrations but convenient indirect methods are also available. based on an evaporation rate measurement or chromatographic retention times. Vapor pressures are strongly dependent on temperature. Vapor pressure data are often regressed against temperature using and Antoine equation.

Literature reviews of measured values of VP for many contaminants are available in Boublik et al. (1984), Howard (1989), Howard et al. (1990), Mackay et al. (1992a, 1992b, 1993), Stull (1947a, 1947b), and Verschueren (1983). Methods for measuring VP are summarized in Lyman et al. (1990) and Mackay et al. (1992a, 1992b, 1993).

\section{Solubility in Water, WS}

Measured values for the solubility limit in water are also widely available. For most organic chemicals, the solubility is reported at a defined temperature in distilled water. Literature reviews of measured values of WS for many contaminants are available in Horvath (1982), Howard (1989), Howard et al. (1990), Mackay et al. (1992a, 1992b, 1993), Stephen and Stephen (1963), and Verschueren (1983). Methods for estimating WS in the absence of measure values are described in Lyman et al. (1990). Methods for measuring WS are described in Lyman et al. (1990) and Mackay et al. (1992a, 1992b, 1993).

\section{Henry's Law Constant}

The Henry's law constant is essentially an air-water partition coefficient that can be determined by measurement of solute concentrations in both phases. Literature reviews of measured values of $\mathrm{H}$ for many contaminants are available in Mackay and Shiu (1981), Howard (1989), Howard et al. (1990), Mackay et al. (1992a, 1992b, 1993), and Verschueren (1983). Methods for estimating $H$ in the absence of measure values are summarized in Lyman et al. (1990). Methods for measuring $\mathrm{H}$ are summarized and described in Lyman et ai. (1990) and Mackay et al. (1992a, 1992b, 1993). 


\section{Organic-Carbon Partition Coefficient, $\mathbf{K}_{\mathrm{oc}}$, and Sorption Coefficients, $\mathbf{K}_{\mathbf{d}}$}

The organic-carbon partition coefficient provides a measure of chemical partitioning between organic carbon (in soils and sediments) and water. The higher the $\mathrm{K}_{\mathrm{oc}}$, the more likely a chemical is to bind to the solid phase of soil or sediment than to the liquid phase.

As reported in Lyman et al. (1990), Kenaga and Goring (1980) developed a regression for $\mathrm{K}_{\mathrm{oc}}$ based on $\mathrm{K}_{\mathrm{ow}}$ for a wide variety of compounds including many pesticides. This regression takes the form,

$$
\log K_{o c}=0.544 \log K_{o w}+1.377 \text { (45 compounds, many pesticides). }
$$

Karickhoff (1985) has described several empirical estimation methods for obtaining $\mathrm{K}_{\mathrm{oc}}$ from $\mathrm{K}_{\mathrm{ow}}$.

$$
\begin{aligned}
& \log K_{\mathrm{oc}}=0.72 \log K_{\mathrm{ow}}+0.49 \text { (methylated and halogenated benzenes) } \\
& \log K_{\mathrm{oc}}=1.029 \log K_{\mathrm{ow}}-0.18 \text { (13 pesticides) } \\
& \log K_{\mathrm{oc}}=0.989 \log K_{\mathrm{ow}}-0.346 \text { (5 poly-nuclear aromatics [PNAs]) } \\
& \log K_{\mathrm{oc}}=\log K_{\mathrm{ow}}-0.317 \text { (22 PNAs and substituted PNAs) }
\end{aligned}
$$

These estimation equations can estimate $\mathrm{K}_{\mathrm{oc}}$ with a $\mathrm{CV}$ of about 1 . This estimation error does not include uncertainty in the value of $\mathrm{K}_{\mathrm{ow}}$. These estimation methods are intended for nonionic organic compounds. A larger CV should be expected when the estimation is applied to ionic species and a correction for acid dissociation should be made.

Chiou et al. (1977) have related $\mathrm{K}_{\mathrm{oc}}$ to water solubility, $\mathrm{S}^{\prime}$ in $\mu \mathrm{mol} / \mathrm{L}$, as

$$
\log K_{\mathrm{oc}}=4.277-0.557 \log S^{\prime} \quad(15 \text { chlorinated hydrocarbons })
$$

Kenega (1980b) has related $\mathrm{K}_{\mathrm{oc}}$ to water solubility (WS) in ppm

$$
\log K_{\mathrm{oc}}=3.64-0.55 \log W S \text { (358 compounds, mostly pesticides). }
$$


Meylan et al (1992) have related $\mathrm{K}_{\mathrm{oc}}$ to the molecular connectivity index $\left({ }^{1} \chi\right)$.

\section{The Soil-Water Distribution Coefficient, $K_{d}$}

$\mathrm{K}_{\mathrm{d}}$ represents the distribution or sorption coefficient, which at equilibrium is the ratio of chemical concentration attached to soil or sediment particles $(\mathrm{mol} / \mathrm{kg})$ to chemical concentration in the solution, mol/L. When $\mathrm{K}_{\mathrm{oc}}$ for an organic compound is multiplied by the fraction of organic carbon in a soil or sediment, we obtain an estimate of the soil/water or sediment/water partition coefficient, $\mathrm{K}_{\mathrm{d}}$ (Karickhoff, 1985). The $\mathrm{CV}$ in this estimation is dominated by the estimation error in $\mathrm{K}_{\mathrm{oc}}$ and equal to 1.0. For inorganic chemicals, values of $K_{d}$ can is based on measured values or on estimation methods both of which are discussed in Bodek et al. (1988).

\section{Molecular Diffusion Coefficients}

Molecular diffusion is the net transport of a molecule in a liquid or gas phase and is the result of intermolecular collisions rather than turbulence or bulk transport. Mass transport via molecular diffusion is driven by concentration gradients. A diffusion coefficient depends on properties of both the chemical species being transported and the phase or phases through which it is transported.

\section{Diffusion in Water}

Reid et al. (1987) and Lyman et al. (1990) have also reviewed several methods for estimating liquid diffusion coefficients and found these methods are all based on the Stokes-Einstein equation relating diffusivity to the temperature and viscosity of the solvent and the molecular radius of the solute. As noted by Reid et al. (1987), one of the oldest but still widely used empirical estimation methods for binary diffusion in liquids is that of Wilke and Chang (1955),

$$
D_{\mathrm{xy}}=\frac{6.5 \times 10^{-7}\left(\phi M_{\mathrm{y}}\right)^{1 / 2} \mathrm{~T}}{\eta_{\mathrm{y}} V_{\mathrm{x}}^{0.6}} \text {, }
$$

where $D_{x y}$ is the diffusion coefficient in of solute $x$ in solvent $y, \mathrm{~m}^{2} / \mathrm{d} ; \phi$ is the association factor of solvent $y$, no units; $\mathrm{M}_{\mathrm{y}}$ is the molecular weight of the solvent, $\mathrm{g} / \mathrm{mol} ; \mathrm{T}$ is the temperature of the solute-solvent system, $\mathrm{K} ; \eta_{\mathrm{y}}$ is the viscosity of the 
solvent $y, c P$; and $\mathrm{V}_{\mathrm{x}}$ is molecular volume of the solute at its normal boiling temperature, $\mathrm{cm}^{3} / \mathrm{mol}$. Wilke and Chang (1955) report an average estimation error of 10 per cent in predicting diffusion coefficients for 251 solute-solvent systems. They recommend an association factor of 2.6 when the solvent is water. The viscosity of water is $0.79 \mathrm{cP}$ at $30^{\circ} \mathrm{C}$. Molecular volume can be estimated by the LeBas incremental method as described in Lyman et al. (1990). For many organic compounds, $D_{\text {water }}$ is in the range of $10^{-5}$ to $10^{-4} \mathrm{~m}^{2} / \mathrm{d}$.

\section{Diffusion in Air}

Analytical methods for estimating the diffusion coefficient of a binary gas system have been reviewed by Reid et al. (1987) and Lyman et al. (1990). These methods have their foundations in a theoretical relationship referred to as the Chapman-Enskog model for dilute gases at low pressures (Chapman and Cowling, 1939; Reid et al., 1987). Based on accuracy and ease of use, Lyman et al. (1990) recommend two methods for use under ambient environmental conditions. When applied at atmospheric pressure, the most straightforward of these two methods relates diffusion in air to the molecular weight of the compound as

$$
D_{\text {air }}=8.6 \times 10^{-3} \mathrm{~T}^{1.75} \frac{\sqrt{\frac{\left(29+\mathrm{M}_{\mathrm{x}}\right)}{29 \mathrm{M}_{\mathrm{x}}}}}{\left[2.7+\left(V_{\mathrm{x}}\right)^{1 / 3}\right]^{2}},
$$

where $D_{\text {air }}$ is the diffusion coefficient in air for compound $x$ in $\mathrm{m}^{2} / \mathrm{d}, \mathrm{T}$ is the air temperature in $\mathrm{K}, \mathrm{M}_{\mathrm{x}}$ is the molecular weight of compound $x$ in $\mathrm{g} / \mathrm{mol}$, and $\mathrm{V}_{\mathrm{x}}$ is the molecular volume of the compound $x$ in $\mathrm{cm}^{3} / \mathrm{mol}$. The values 29 and 2.7 represent the molecular weight and cubic root of molecular volume, respectively, for air. Methods for estimating molecular volumes are reviewed in Lyman et al. (1990). For many organic compounds, $D_{\text {air }}$ is in the range of 0.1 to $1 \mathrm{~m}^{2} / \mathrm{d}$.

\section{Plant-Soil Partition Coefficients, $K_{\mathrm{ps}}^{\text {rain }}, K_{\mathrm{ps} \text {, and }} K_{\mathrm{ps}}$ (roots)}

The plant-soil partition coefficients express the ratio of contaminant concentration in plant parts, both pasture and food, in $\mathrm{mg} / \mathrm{kg}$ (plant fresh mass) to concentration in dry soil in $\mathrm{mg} / \mathrm{kg}$. We consider separately plant-soil partition coefficients for surface soil, which is roughly the top $1 \mathrm{~cm}$ of soil and for which the 
mechanisms of transport from soil to plant are particle resuspension by wind and by rainsplash, and for root-zone soil, which is the soil layer from the bottom of the surface soil layer to the depth to which food crops and pasture crops extend their roots and is equal to roughly $1 \mathrm{~m}$.

The transfer from surface soil to plant surfaces by wind erosion and subsequent deposition of contaminants attached to soil particles in the air is covered by the combination of contaminant concentration in air and the partition factor $\mathrm{K}_{\mathrm{pa}}^{\mathrm{pt}}$ described above. Thus, the only factor we include in the partition factor from surface soil to edible plant parts is the rainsplash partition factor, $\mathrm{K}_{\mathrm{ps}}^{\text {rain }}$. Dreicer et al. (1984) have shown that the value of the ratio of contaminant concentration on plant surfaces in $\mathrm{mg} / \mathrm{kg}$ (plant dry mass) to contaminant concentration in soil is $1.7 \times 10^{-2}$ with a geometric standard deviation of approximately 2.5. We adjust this to a fresh mass ratio (assuming that the plant dry-mass fraction equals 0.2 ) to obtain $\mathrm{K}_{\mathrm{ps}}^{\text {rain }}$ equal to $3.4 \times 10^{-3}$ with a $C V$ i $\hat{1}$. This partition factor applies to both organic and inorganic contaminants.

The partition coefficient $K_{p s}$ expresses the ratio of contaminant concentration $(\mathrm{mg} / \mathrm{kg})$ in the fresh mass of the edible portion of vegetation and pasture to the contaminant concentration in the root zone. This partition coefficient actually involves two partition factors, one between roots and soil and a second between edible plant parts and roots. When consideration is given to root crops, the second of these is unity. What is meant by the "concentration in a plant" can be difficult to define in larger plants where roots, stems, and leaves each may have different chemical concentrations. Recent studies on the bioconcentration of nonionic organic chemicals has focused on correlations between partition factors and known chemical properties, such as Henry's law constants $(\mathrm{H})$ and octanol-water partition coefficients $\left(\mathrm{K}_{\mathrm{ow}}\right)$ (Bacci et al., 1990; Briggs et al., 1982; Briggs et al., 1983; Travis and Hattemer-Frey, 1988; Travis and Arms, 1988). Ryan et al. (1988) and Riederer (1990) report the potential unreliability of simple plant/soil partition coefficients. McFarlane et al. (1987) have demonstrated experimentally that chemicals with similar values of $\mathrm{K}_{\mathrm{ow}}$ can have drastically different long-term partitioning, probably due to differences in metabolism. Nonetheless, the plant-soil partition coefficient provides a simple and useful method for assessing poteritial dose. We use it here, recognizing its potentially large uncertainties. Briggs et al. $(1982,1983)$ have developed an estimation equation for uptake of contaminants by roots from soil solution. They refer to this partition coefficient as the root concentration factor, 
$\mathrm{RCF}$. It represents the ratio of contaminant concentration in root, $\mathrm{mg} / \mathrm{kg}$ (fresh mass), to contaminant concentration in soil solution, $\mathrm{mg} / \mathrm{L}$, and it takes the form

$$
\mathrm{RCF}=0.82+0.03 \mathrm{~K}_{\mathrm{ow}}^{0.77}
$$

When this factor is divided by the sorption coefficient, $\mathrm{K}_{\mathrm{D}}=\mathrm{f}_{\mathrm{OC}} \times \mathrm{K}_{\mathrm{oc}}=$ $0.02 \times 0.411 \times \mathrm{K}_{\mathrm{ow}}$ (from above), we obtain the ratio of contaminant concentration in roots, $\mathrm{mg} / \mathrm{kg}$ (fresh mass) to contaminant concentration in soil solids, $\mathrm{mg} / \mathrm{kg}$, which we refer to as $K_{p s}$ (roots) and estimate as

$$
\mathrm{K}_{\mathrm{ps}}(\text { roots })=100 \mathrm{~K}_{\mathrm{ow}}^{-1}+3.7 \mathrm{~K}_{\mathrm{ow}}^{-0.23}
$$

Based on studies of carbon-14-labeled organic chemicals in barley and cress, Topp et al. (1986) developed a correlation for the root-soil pertition coefficient in terms of $\mathrm{K}_{\mathrm{oc}}$

$$
\mathrm{K}_{\mathrm{ps}}(\text { roots })=664 \mathrm{~K}_{\mathrm{\alpha c}}^{-0.622}
$$

with our substitution of $\mathrm{K}_{\mathrm{oc}}=0.411 \mathrm{~K}_{\mathrm{ow}}$ from above gives

$$
\mathrm{K}_{\mathrm{ps}}(\text { roots })=273 \mathrm{~K}_{\mathrm{ow}}^{-0.622}
$$

Based on a review of reported measurements of bioconcentration for 29 persistent organochlorines in plants, Travis and Arms (1988) have correlated plant-soil bioconcentration (on a dry-mass basis) in above-ground plant parts with octanolwater partition coefficients. This bioconcentration factor, $B_{v}$, on a dry-weight basis is expressed as

$$
\log B_{v}=1.58-0.58 \log K_{o w} \pm 0.73\left(n=29, r^{2}=0.525\right)
$$

We calculated the error term, \pm 0.73 , from the mean square error of the estimator for this regression from the data provided by Travis and Arms (1988). The geometric standard deviation in this estimate of $B_{v}$ is $10^{(0.73)}(=5.4)$. This estimation error corresponds to a $\mathrm{CV}$ of 4 . When adjusted to a fresh-mass basis, equation [16] gives 
the plant-soil partition coefficient, $\mathrm{K}_{\mathrm{ps}}$, expressing the ratio of contaminant concentration in $\mathrm{mg} / \mathrm{kg}$ in above-ground plant fresh relative to contaminant concentration in $\mathrm{mg} / \mathrm{kg}$ (dry soil) in the root-zone soil,

$$
\mathrm{K}_{\mathrm{ps}}=7.7 \mathrm{~K}_{\mathrm{ow}}^{-0.58}
$$

We recommend equation [17] to estimate the partitioning of organic contaminants between root-zone soil and above ground plant parts in order to calculate contaminant exposures for exposed produce. Because the estimates of $K_{\mathrm{ps}}$ from equations [13] and [15] do not differ by more that a factor of 3 over $10^{3}<\mathrm{Kow}<10^{6}$, and because equation [15] differs from equation [17] almost exactly a factor of 35, we estimate the partitioning of organic contaminants between root-zone soil and roots as

$$
\mathrm{K}_{\mathrm{ps}}(\text { roots })=35 \mathrm{~K}_{\mathrm{ps}}=270 \mathrm{~K}_{\mathrm{ow}}^{-0.58}
$$

and recommend this as a basis for estimating contaminant concentrations in the edible root crops and other protected produce.

Bodek et al. (1988) have reviewed estimation methods for obtaining plant-soil partition coefficients for inorganic chemicals. For some inorganic chemicals, the literature on radionuclides is often a useful source for plant-soil partition factors (for example, see $\mathrm{Ng}$, 1982). Regional scale biogeochemical partitioning between soil and plants as described by Bowen (1979) is useful for making preliminary estimates of plant-soil partitioning for some inorganic contaminants.

\section{Plant-Air Partition Coefficients}

The intermedia-transfer factors $K_{\mathrm{pa}}^{\mathrm{gs}}$ and $K_{\mathrm{pa}}^{\mathrm{pt}}$ the chemical-specific plant-air partition coefficients, represent the ratio of contaminant concentration in aboveground plant parts, in $\mathrm{mg} / \mathrm{kg}$ (fresh mass), to contaminant concentration in, respectively, the gas-phase of the atmosphere (gs) and particles suspended in the atmosphere (pt), both in $\mathrm{mg} / \mathrm{m}^{3}$ (air).

For contaminants in the gas phase of the atmosphere, $\mathrm{K}_{\mathrm{pa}}^{\mathrm{gs}}$ represents the foliar-uptake and expresses the partitioning between contaminant concentration in leaf fresh mass, $\mathrm{mg} / \mathrm{kg}$, and contaminant concentration in air, $\mathrm{mg} / \mathrm{m}^{3}$. Trapp et al. 
(1990) have used barley plants in growth chambers to demonstrate that chemicals in the roots of the barley plants reach equilibrium with the soil, whereas chemicals in the shoots are in equilibrium with the air. Riederer (1990) reports that a full description of steady-state partitioning within plant foliage requires a model that includes rates of uptake from and loss to aqueous and solid phases at the surface of the cuticle and the rates of translocation, metabolism, and dilution due to growth. Riederer (1990) has shown that, for foliar uptake of gases, the most general form of a steady-state plant-air partition model is

$$
K_{p a}^{g s}=\left[f_{p a}+\left(f_{p w}+f_{p l} \times K_{o w}\right) \times \frac{R T}{H}\right] \times \frac{1}{\rho_{p}}
$$

where $f_{p a}$ is the fraction of the plant tissue volume that is air; $f_{p w}$ is the of plant tissue volume that is water; $f_{p l}$ is the fraction of the plant tissue volume that is lipid; $\mathrm{R}$ is the universal gas constant, $8.31 \mathrm{~Pa}-\mathrm{m}^{3} / \mathrm{mol}-\mathrm{k}$; $\mathrm{T}$ is the temperature, kelvins (293 K); $\mathrm{H}$ is the Henry's law constant in Pa-m $\mathrm{m}^{3} / \mathrm{mol}$; and $\rho_{\mathrm{p}}$ is the density of plant tissues in $\mathrm{kg} / \mathrm{m}^{3}$. Based on azalea-leaf experiments with five chemicals, Bacci et al. (1990) have developed a correlation of leaf-air bioconcentration factors with air-water and octanol-water partition coefficients and have shown that $f_{\mathrm{pl}}$ is on the order of 0.01. Paterson and Mackay (1989) have estimated that $f_{p a}$ is 0.5 . This implies that the remainder of the plant volume fraction, 0.49 , is either water or nonlipid solids. Based on our observation above that $80 \%$ of plant mass is water (i.e., bio $_{\mathrm{dm}}=0.2$ ), we set $\mathrm{f}_{\mathrm{pa}}$ equal to 0.4 . We use $1000 \mathrm{~kg} / \mathrm{m}^{3}$ as the density of plant tissue, and recommend the following expression to estimate the plant-air partition coefficient.

$$
\mathrm{K}_{\mathrm{pa}}^{\mathrm{gs}}=\left[0.5+\left(0.4+0.01 \times \mathrm{K}_{\mathrm{ow}}\right) \times \frac{\mathrm{RT}}{\mathrm{H}}\right] \times 10^{-3} \frac{\mathrm{m}^{3}}{\mathrm{~kg}}
$$

We could find no study in which the estimation error of this partition coefficient has been considered, but we assume the $\mathrm{CV}$ associated with it is on the order of 1 .

\section{Bioconcentration Factors (BCFs) in Fish}

Bioconcentration factors provide a measure of chemical partitioning between a biological medium, such as fish tissue, and an external medium, such as water. The higher the BCF the more likely is partitioning to biota. The transfer of a 
contaminant in water, sediment, and/or food to an aquatic organism is governed by three basic processes, namely, the uptake from the contact media, distribution to target tissue, and elimination via excretion and/or metabolic transformation. Normally, biotransfers of contaminants are measured or estimated for steady-state conditions in which intakes are equal to losses. For fish, the BCF is taken as the ratio of concentration of a xenobiotic substance in fish flesh (or lipids) to the contaminant's concentration in water (Mackay, 1982). The BCF for neutral organic compounds can be estimated from regression equations based on selected physicochemical properties, particularly a compound's $\mathrm{K}_{\mathrm{ow}}$ or aqueous solubility. Mackay (1982) recommends,

$$
\mathrm{BCF}=0.048 \mathrm{~K}_{\mathrm{ow}}
$$

and reports that the estimation error in this expression has a GSD of 1.8 or a CV of 0.6. Regression equations for BCFs are also discussed by Van Gestel et al. (1985) and Isnard and Lambert (1988). It should be noted that there are cases in which the measured levels of organic or inorganic substances in fish are considerably higher than the values predicted from BCF equations such as that above. This occurs as a result of bioaccumulation, which refers to the accumulation of a substance in fish from both water (i.e., bioconcentration) and the consumption of contaminated foods. Thus, a substance that bioaccumulates will usually occur at its highest concentrations in fish occupying the top trophic levels in a food chain. Generally, only those substances that are lipophiiic and persistent will bioaccumulate. Models for simulating these bioaccumulation processes have been presented by Thomann (1989) and Barber et al. (1991).

\section{Biotransfer Factors for Meat, Milk, and Eggs}

The biotransfer factors $B_{t}, B_{k}$ and $B_{e}$ are the steady-state contaminant concentrations in, respectively, fresh meat, milk, and eggs divided by the animals' daily contaminant intake, and are expressed in units of $(\mathrm{mg} / \mathrm{kg}) /(\mathrm{mg} / \mathrm{d})$ or $\mathrm{kg} / \mathrm{d}$. Unlike bioconcentration factors, which express steady-state concentration ratios between animal tissue and a specific environmental medium, biotransfer factors express the steady-state relationship between intake and tissue or food-product concentrations. For terrestrial animals that are exposed to contaminants from multiple media (such as air, water, forage, soil, etc.), the biotransfer factor has more utility for assessing the effects of multimedia contamination on the contamination 
of food. Based on a review of biotransfer factors for 28 organic chemicals in milk and 36 chemicals in meat, Travis and Arms (1988) developed the following geometric-mean regressions for $B_{t}$ and $B_{k}$ based on the octanol-water partition coefficient, $\mathrm{K}_{\mathrm{ow}}$

$$
\begin{aligned}
& \log B_{t}=\log K_{o w}-7.6 \pm 0.95 \quad\left(n=36, r^{2}=0.67\right) \text { and } \\
& \log B_{k}=\log K_{o w}-8.1 \pm 0.84 \quad\left(n=28, r^{2}=0.55\right)
\end{aligned}
$$

Using the data provided by Travis and Arms (1988), we calculated the error terms, \pm 0.95 and \pm 0.84 , from the mean square error of the estimator for these regressions. These estimation errors correspond, respectively, to CVs of 11 and 6.

The transfer of organic chemicals from diet to food has also been expressed in terms of the fat-diet partition coefficient, $\mathrm{K}_{\mathrm{fd}}$, which is the steady-state ratio of contaminant concentration in animal fat (or lipid) to contaminant concentration in animal diet with units $\mathrm{kg}$ (diet) $/ \mathrm{kg}$ (fat). Kenaga (1980b) reviewed cattle-dietary feeding studies for 23 chemicals, and from these studies derived the following fatdiet equation relating $\mathrm{K}_{\mathrm{fd}}$ to $\mathrm{K}_{\mathrm{ow}}$,

$$
\log K_{f d}=0.5 \log K_{o w}-3.457 \pm 1 \quad\left(n=23, r^{2}=0.62\right) .
$$

The estimation error in this expression, \pm 1 , was calculated by Kenaga (1980b).

There are so few measurements of diet-egg partitioning, that it is impractical at this time to develop an estimation equation. Thus, to develop a biotransfer factor for transfer of organic chemicals from chicken diet to eggs, we consider possible proxy values of $\mathrm{K}_{\mathrm{fd}}$ for chickens. The correlations of Travis and Arms (1988) can be converted from biotransfer factors to fat-diet partition coefficients by multiplying the milk biotransfer factor, $B_{k}$, by the fat content of cow's milk and feed intake of dairy cattle and by multiplying the meat biotransfer factor, $B_{t}$, by the fat content of beef and feed intake of beef cattle. We did this using fat contents and feed intakes from Table IV and developed the following geometric least squared regression of $\mathrm{K}_{\mathrm{fd}}$ with $\mathrm{K}_{\mathrm{ow}}$ using the 64 biotransfer factors reported by Travis and Arms (1988),

$$
\log \mathrm{K}_{\mathrm{fd}}=\log \mathrm{K}_{\mathrm{ow}}-4.9 \pm 1 \quad\left(\mathrm{n}=64, \mathrm{r}^{2}=0.61\right)
$$


For $K_{o w}$ in the range $10^{2}$ to $10^{6}$, equations [24] and [25] are within a factor of 10 of each other, which is within the range of the estimation error associated with either equation. For $\mathrm{K}_{\mathrm{ow}}$ in the range $10^{4}$ to $10^{5}$, equations [24] and [25] are within a factor of two of each other.

Based on measurements of polychlorodibenzodioxins (PCDDs) and polychlorodibenzofurans (PCDFs) concentrations in soil versus concentrations in egg fat and adipose tissue of foraging chickens and concentrations in the adipose tissue of grazing cattle, Stephens, et al. (1990) have shown that contaminant concentrations in animal fat correlate with soil concentrations and that the fat-soil partition factor in chicken fat is roughly six times higher than the fat-soil partition factor in cattle. However, the fraction of total intake represented by soil in the chicken diet is higher than in the cattle diet. Based on these observation and what is discussed above, we (a) assume that the fat-diet partition factor in chickens is similar to that in cattle, (b) use equation [25] to estimate the $K_{\mathrm{fd}}$ for chickens, and (c) use the fat content of eggs (0.08) and feed intake of chickens $(0.12 \mathrm{~kg} / \mathrm{d}$ [fresh mass]) to obtain the following estimate of a biotransfer factor, $B_{e}$, from chicken diet to eggs with units $\mathrm{d} / \mathrm{kg}$ (eggs),

$$
\log B_{e}=\log K_{o w}-5.1 \pm 1
$$

We estimate the $\mathrm{CV}$ in this expression as 14 .

There are no general estimation methods for approximating the biotransfer factors of inorganic chemicals. The literature on radionuclides is often a useful source for biotransfer factors (see, for example, $\mathrm{Ng}, 1982)$. Stevens $(1991,1992)$ has reported on milk and meat biotransfer factors for toxic metals. Bowen (1979) has some limited data on transfers of elements from vegetation and soil to animal tissues.

\section{Contaminant Biodegradation Factors in Soil}

The transformation of organic and inorganic compounds by microorganisms that are present in soil can result in substantial degradation. Howard et al. (1991) have provide a review of the literature on contaminant degradation in soil due to both aerobic and anaerobic biodegradation. 


\section{Media-Specific Half Lives}

A medium-specific half life provides a relative measure of the persistence of a chemical in a given medium such as soil or water. Media-specific half lives for many organic contaminants in air, soil, and surface water are summarized in Howard et al. (1991).

\section{REFERENCES FOR PART I}

Bacci, E, D. Calamari, G. Gaggi, and M. Vighi (1990), "Bioconcentration of Chemical Vapors in Plant Leaves: Experimental Measures and Correlation," Environ. Sci. Technol. 24, 885-889.

Barber, M. C., L. A. Suarez, and R. R. Lassiter (1991), "Modelling Bioaccumulation of Organic Pollutants in Fish with an Application to PCBs in Lake Ontario Salmonids," Can. J. Fish. Aquat. Sci. 48, 318-337.

Bodek, I, W.J. Lyman, W.F. Reehl, and D.H. Rosenblatt (1988), Environmental Inorganic Chemistry Properties, Processes and Estimation Methods (Pergamon Press, New York).

Boublík, T., Fried, V., and Hála, E. (1984), The Vapour Pressures of Pure Substances: Selected Values of the Temperature Dependence of the Vapour Pressures of Some Pure Substances in the Normal and Low Pressure Region (Second Revised Edition), Physical sciences data; 17 (Elsevier Science Publishers, Amsterdam, The Netherlands).

Bowen, H.J.M. (1979), Environmental Chemistry of the Elements (Academic Press, New York City, NY).

Briggs, G. G., R. H. Bromilow, and A. A. Evans (1982), "Relationship Between Lipophilicity and Root Uptake and Translocation of Non-Ionized Chemicals by Barley," Pestic. Sci. 13, 495-504.

Briggs, G. G., R. H. Bromilow, A. A. Evans, and M. Williams (1983), "Relationships Between Lipophilicity and the Distribution of Non-Ionized Chemicals in Barley Shoots Following Uptake by the Roots," Pestic. Sci. 14, 492-500.

Chapman, S., and T.G. Cowling (1939), The Mathematical Theory of Nonuniform Gases (Cambridge University Press, New York, NY).

Chiou, C. T., V. H. Freed, D.W. Schmedding, and R. L. Kohnert (1977), "Partition Coefficient and Bioaccumulation of Selected Organic Chemicals," Environ. Sci. Technol. 11(5), 475-478.

Chiou, C. T., D. W. Schmedding, and M. Manes (1982), "Partitioning of Organic Compounds in Octanol-Water System," Environ. Sci. Technol. 16, 4-10. 
De Bruijn, J., F. Busser, W. Seinen, and J. Hermens (1989), "Determination of Octanol/Water Partition Coefficients for Hydrophobic Organic Chemicals with the 'Slow-Stirring' Method," Environ. Toxicol. Chem. 8, 499-512.

Dreicer, M., T.E. Hakonson, G.C. White, and F.W. Whicker (1984), "Rainsplash as a Mechanism for Soil Contamination of Plant Surfaces," Health Phys. 46, 177-187.

Fujita, T., J. Iwasa, and C. Hansch (1964), "A New Substituent Constant 'pi' derived from Partition Coefficients," J. Am. Chem. Soc. 86, 5175-5180.

Hamburg, M. (1970). Statistical Analysis for Decision Making. Harcourt Brace Jovanovich, Inc., San Diego, California.

Horvath, A. L. (1982), Halogenated Hydrocarbons, Solubility-Miscibility with Water (Marcel Dekker, Inc., New York City, NY).

Howard, P.H., Ed. (1989), Handbook of Environmental Fate and Exposure Data for Organic Chemicals, Volume I (Lewis Publishers, Chelsea, MI).

Howard, P.H., G.W. Sage, W.F. Jarvis, and D.A. Gray, Eds. (1990), Handbook of Environmental Fate and Exposure Data for Organic Chemicals. Volume II. Solvents (Lewis Publishers, Inc., Chelsea, MI).

Howard, P. H., R. S. Boethling, W. F. Jarvis, W. M. Meylan, and E. M. Michalenko, Eds. (1991), Handbook of Environmental Degradation Rates (Lewis Publishers, Inc, Chelsea, MI).

Isnard, P., and S. Lambert (1988), "Estimating Bioconcentration Factors from Octanol-Water Partition Coefficient and Aqueous Solubility," Chemosphere 17, 2134.

Karickhoff, S.W. (1985), "Chapter 3. Pollutant Sorption in Environmental Systems," in Environmental Exposure From Chemicals, Volume I., W. B. Neely and G.E. Blau, Eds. (CRC Press, Inc., Boca Raton, FL), pp. 49-64.

Kenaga, E. E. (1980a), "Predicted Bioconcentration Factors and Soil Sorption Coefficients of Pesticides and Other Chemicals," Ecotoxicol. Environ. Saf. 4, 26-38.

Kenaga, E. E. (1980b), "Correlation of Bioconcentration Factors of Chemicals in Aquatic and Terrestrial Organisms with Their Physical and Chemical Properties," Environ. Sci. Technol. 14, 553-556.

Kenaga, E. E., and C. A. I. Goring (1980), "Relationship Between Water Solubility, Soil Sorption, Octanol-Water Partitioning, and Concentration of Chemicals in Biota," in Aquatic Toxicology, ASTM STP 707, J. G. Eaton, P. R. Parrish, and A. C. Hendricks, Eds. (American Society for Testing and Materials, Philadelphia, PA) pp. 78-115.

Leo, A., C. Hansch, and D. Elkins (1971), "Partition Coefficients and their Uses," Chem. Rev. 71(6) 525-616. 
Lyman, W.J., W.F. Reehl, and D.H. Rosenblatt (1990), Handbook of Chemical Property Estimation Methods (American Chemical Society, Washington, D.C.).

McFarlane, J. C., T. Pfleeger, and J. Fletcher (1987), "Transpiration Effect on the Uptake and Distribution of Bromacil, Nitrobenzene, and Phenol in Soybean Plants," J. Environ. Qual. 16, 372-376.

Mackay, D. (1982), "Correlation of Bioconcentration Factors," Environ. Sci. Technol. 16, 274-278.

Mackay, D., and W.-Y. Shiu (1981), "A Critical Review of Henry's law Constants for Chemicals of Environmental Interest," J. Phys. Chem. Ref. Data 10, 1175-1199.

Mackay, D., W.Y. Shiu, and K.C. Ma (1992a), Illustrated Handbook of PhysicalChemical Properties and Environmental Fate for Organic Chemicals, Volume I Monoaromatic Hydrocarbons, Chlorobenzenes, and PCBs (Lewis Publishers, Chelsea, MI).

Mackay, D., W.Y. Shiu, and K.C. Ma (1992b), Illustrated Handbook of PhysicalChemical Properties and Environmental Fate for Organic Chemicals, Volume II, Polynuclear Aromatic Hydrocarbons, Polychlorinated Dioxins, and Dibenzo Furans (Lewis Publishers, Chelsea, MI).

Mackay, D., W.Y. Shiu, and K.C. Ma (1993), Illustrated Handbook of PhysicalChenical Properties and Environmental Fate for Organic Chemicals, Volume III Volatile Organic Compounds (Lewis Publishers, Chelsea, MI).

Meylan, W., P.H. Howard, and R.S. Boethling (1992), "Molecular Topology/Fragment Contribution Method for Predicting Soil Sorption Coefficients," Environ. Sci. Technol. 26, 1560-1567.

$\mathrm{Ng}$, Y.C. (1982), "A Review of Transfer Factors for Assessing the Dose from Radionuclides in Agricultural Products," Nucl. Saf. 23, 57-71.

Paterson, S., and D. Mackay (1989), "Modeling the Uptake and Distribution of Organic Chemicals in Plants," in Intermedia Pollutant Transport Modeling and Field Measurements D.T. Allen, Y. Cohen, and I.R. Kaplan (eds.), Plenum Press, New York.

Reid, R. C., J. M. Prausnitz, and B. E. Poling (1987), The Properties of Gases and Liquids (McGraw Hill, New York City, NY), 4th ed.

Reiderer, M. (1990), "Estimating Partitioning and Transport of Organic Chemicals in the Foliage/Atmosphere System: Discussion of a Fugacity-Based Model," Erviron. Scil. Technol. 24, 829-837.

Ryan, J. A., R. M. Bell, J. M. Davidson, and G. A. O'Connor (1988), "Plant Uptake of Non-Ionic Organic Chemicals From Soils," Chemosphere 17, 2299-2324.

Stephen, H., and T. Stephen (1963), Solubilities of Inorganic and Organic Compounds, Vols. 1 and 2, Pergamon, Oxford, UK. 
Stephens, R.D., M.Harnly, G.G. Haywood, R.R. Chang, J. Flattery, M.X. Petreas, and L. Goldman (1990), "Bioaccumulation of Dioxins in Food Animals II: Controlled Exposure Studies," Chemosphere 20, 1091-1096.

Stevens, J.B. (1991), "Disposition of Toxic Metals in the Agricultural Food Chain. 1. Steady-State Bovine Milk Biotransfer Factors," Environ. Sci. Technol. 25, 12891294.

Stevens, J.B. (1992), 'Disposition of Toxic Metals in the Agricultural Food Chain. 2. Steady-State Bovine Tissue Biotransfer Factors," Environ. Sci. Technol. 26, 19151921.

Stull, D. R. (1947a), "Vapor Pressure of Pure Substances: Organic Compounds," Ind. Eng. Chem. 39, 517-540.

Stull, D. R. (1947b), "Vapor Pressure of Pure Substances: Inorganic Compounds," Ind. Eng. Chem. 39, 540-550.

Thomann, R. V. (1989), "Bioaccumulation Model of Organic Chemical Distribution in Aquatic Food Chains," Environ. Sci. Technol. 23, 699-707.

Topp, E. I. Scheunert, A. Attar, and F. Korte (1986), "Factors Affecting the Uptake of 14C-Labeled Organic Chemicals by Plants from Soil," Ecotoxicol. Environ. Saf. 11, 219-228.

Trapp, S., M. Matthies, I. Scheunert, and E.M. Topp (1990), "Modeling the Bioconcentration of Organic Chemicals in Plants," Environ. Sci. Technol. 24, 12461252.

Travis, C.C. and Arms, A.D. (1988). Bioconcentration of organics in beef, milk, and vegetation. Environ. Sci. Technol. 22, 271-274.

Travis, C. C., and H. A. Hattemer-Frey (1988), "Uptake of Organics by Aerial Plant Parts: A Call for Research," Chemosphere 17, 277-284.

Van Gestel, C. A. M., K. Otermann, and J. H. Canton (1985), "Relation Between Water Solubility, Octanol/Water Partition Coefficients, and Bioconcentration of Organic Chemicals in Fish: A Review," Regul. Toxicol. Pharmacol. 5, 422-431.

Verschueren, K. (1983), Handbook of Environmental Data on Organic Chemicals, (Van Nostrand Reinhold, New York, NY).

Wilke, C.R., and P. Chang (1955), "Correlation of Diffusion Coefficients in Dilute Solutions," AIChE J. 1, 264-270. 


\section{PART II}

INTERMEDIA TRANSFER FACTORS FOR 15 CHEMICALS 
Summary Definition of ITFs

$-24-$ 


\section{1,3-Butadiene}

Other names: vinylethylene, divinyl, bivinyl, pyrrolylene, biethlylene, erythrene CAS Registry Number: 106-99-0

1,3-butadiene is a gas at most environmental temperatures and very volatile even at low temperatures. It is produced largely from petroleum gasses by catalytic dehydrogenation of butene or butene-butane mixtures. Once released to the atmosphere, it will photoxidize by reaction primarily with hydroxyl radicals.

Formula: $\mathrm{C}_{4} \mathrm{H}_{6}$

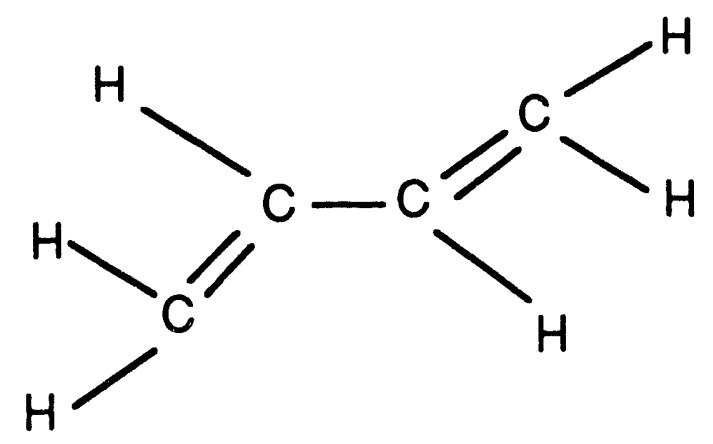

Molecular weight

54.09 (Weast et al., 1986; Windholz et al., 1983; Howard, 1989; Verschueren, 1983)

\section{Melting Point}

$-108.9^{\circ} \mathrm{C}$ (Howard, 1989; Verschueren, 1983)

Octanol-water partition coefficient $\left(K_{o w}\right)$

97.7 derived from a $\log \mathrm{K}_{\mathrm{ow}}$ of 1.99 reported by Hansch and Leo (1987). This value is based on unpublished measurements carried out by Hansch and his colleagues. Also derived from a $\log \mathrm{K}_{\mathrm{ow}}$ of 1.99 reported in Howard(1989) based on the value published by Hansch and Leo (1985).

$$
\begin{gathered}
\text { Recommended value: } \\
\log \mathrm{K}_{\mathrm{ow}}=1.99 \\
\mathrm{~K}_{\mathrm{ow}}=97.7
\end{gathered}
$$




\section{Vapor pressure at standard temperatures}

An extensive review of measured vapor pressures for organic compounds is reported in Stull (1947), who reports the following values for 1,3-butadiene in the range of temperatures likely to be found in the environment.

\begin{tabular}{|c|c|c|}
\hline Temperature $(\mathrm{C})$ & Vapor Pressure $(\mathrm{mm})$ & Vapor Pressure $(\mathrm{Pa})$ \\
\hline-19.3 & 400 & $5.33 \times 10^{4}$ \\
-4.5 & 760 & $1.01 \times 10^{5}$ \\
15.3 & 1520 & $2.03 \times 10^{5}$ \\
47 & 3800 & $5.07 \times 10^{5}$ \\
\hline
\end{tabular}

Interpolating from this data gives VP at $25^{\circ} \mathrm{C}=275 \mathrm{kPa}$. These values are also given in Windholz et al. (1983).

Verschueren (1983) reports the following vapor pressures for 1,3-butadiene:

\begin{tabular}{|c|c|c|}
\hline Temperature $(\mathrm{C})$ & Vapor Pressure $(\mathrm{mm})$ & Vapor Pressure $(\mathrm{Pa})$ \\
\hline-4.4 & 760 & $5.33 \times 10^{4}$ \\
20 & 1900 & $2.53 \times 10^{5}$ \\
30 & 2508 & $3.34 \times 10^{5}$ \\
\hline
\end{tabular}

Interpolating from this data gives VP at $25^{\circ} \mathrm{C}=290 \mathrm{kPa}$

Wilhoit and Zwolinski (1971), Dean (1985), Boublick et al. (1984) have compiled data on vapor pressure and temperature for a number of organic compounds and have fit this data to the Antoine equation relating vapor pressure to absolute temperature for 1,3-butadiene.

$$
\begin{aligned}
& \log _{10}(\mathrm{VP})=5.975-\frac{932}{239.3+\mathrm{T}}, \text { from Boublik et al. (1984), and } \\
& \log _{10}(\mathrm{VP})=5.975-\frac{930.5}{238.9+\mathrm{T}}, \text { from Wilhoit and Zwolinski (1971). }
\end{aligned}
$$

Both estimation equations above provide VP in $\mathrm{kPa}$ based on $\mathrm{T}$ in ${ }^{\circ} \mathrm{C}$ and both equations give $\mathrm{VP}=281 \mathrm{kPa}$ at $25^{\circ} \mathrm{C}$.

$$
\log _{10}(V P)=6.850-\frac{930.5}{238.8+T} \text {, from Dean (1985) }
$$

This third equation gives VP in torr and gives VP $=2102$ torr or $280 \mathrm{kPa}$ at $25^{\circ} \mathrm{C}$.

The fitted Antoine equation for 1,3-butadiene from Boublik et al. (1984) is plotted below. 
Recommended value:

$\mathrm{VP}=281 \mathrm{kPa}(2100$ torr $)$ at $25^{\circ} \mathrm{C}$

$\log _{10}(\mathrm{VP})=5.975-\frac{932}{239.3+\mathrm{T}} \mathrm{kPa}$ in the range -10 to $40^{\circ} \mathrm{C}$

\section{Vapor pressure versus temperature}

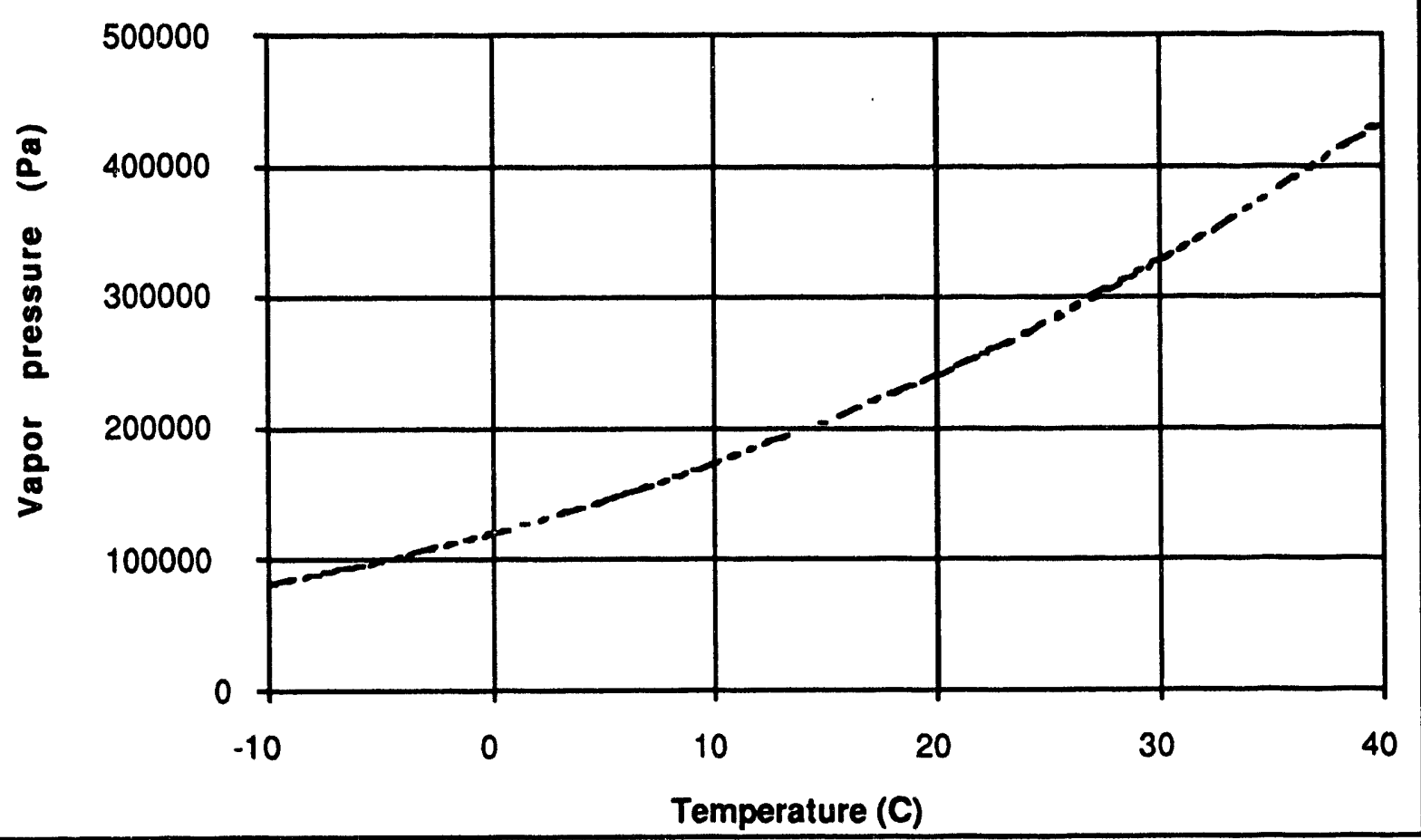

Solubility in water

$735 \mathrm{mg} / \mathrm{L}$ at $25^{\circ} \mathrm{C}$ measured and reported by McAuliffe (1966)

$735 \mathrm{mg} / \mathrm{L}$ at $20^{\circ} \mathrm{C}$ reported by Verschueren (1983)

$735 \mathrm{mg} / \mathrm{L}$ at $25^{\circ} \mathrm{C}$ reported by Howard (1989), who attributes this value to McAuliffe (1966).

$600 \mathrm{mg} / \mathrm{L}$ at $38^{\circ} \mathrm{C}$ as interpolated from the measured data of Reed and McKetta (1959).

Recommended value:

WS $=735 \mathrm{mg} / \mathrm{L}$ at $25^{\circ} \mathrm{C}$ 
Henry's law constant

2.57 dimensionless Henry's law constant (\{mol/L[air]\}/\{mol/L[water]\}) reported in Howard (1989) based on a value reported in Hine and Mookerjee (1975). However, there appears to be an error in the reported value of $\log \mathrm{H}$ reported in Hine and Mookerjee (1974). They report the $\log$ of the equilibrium air concentration, $\log c_{g^{\prime}}$ as -1.39 and the $\log$ of the equilibrium water concentration, $\log c_{w}$ as -1.87 (which corresponds to a water solubility of $730 \mathrm{mg} / \mathrm{L})$. They report $\log (\mathrm{H} / \mathrm{RT})$, the difference, $\log c_{g}-\log c_{w}$, as 0.41 (corresponding to $H / R T=2.57$ ) when it is actually 0.48 (corresponding to $H / R^{\prime} T=3.02$ ).

3.02 at $25^{\circ} \mathrm{C}$ based on the actual values for vapor pressure and solubility reported in Hine and Mookerjee (1975) (and not on the reported ratio). This value is also obtained from ratio of VP to WS values reported above. Shown below is the estimated variation of the dimensionless Henry's law constant versus temperature for 1,3-butadiene. It should be noted that the vapor pressure of 1,3-butadiene cannot exceed atmospheric pressure in the air above a water solution.

\section{Dimensionless Henry's law versus temperature}

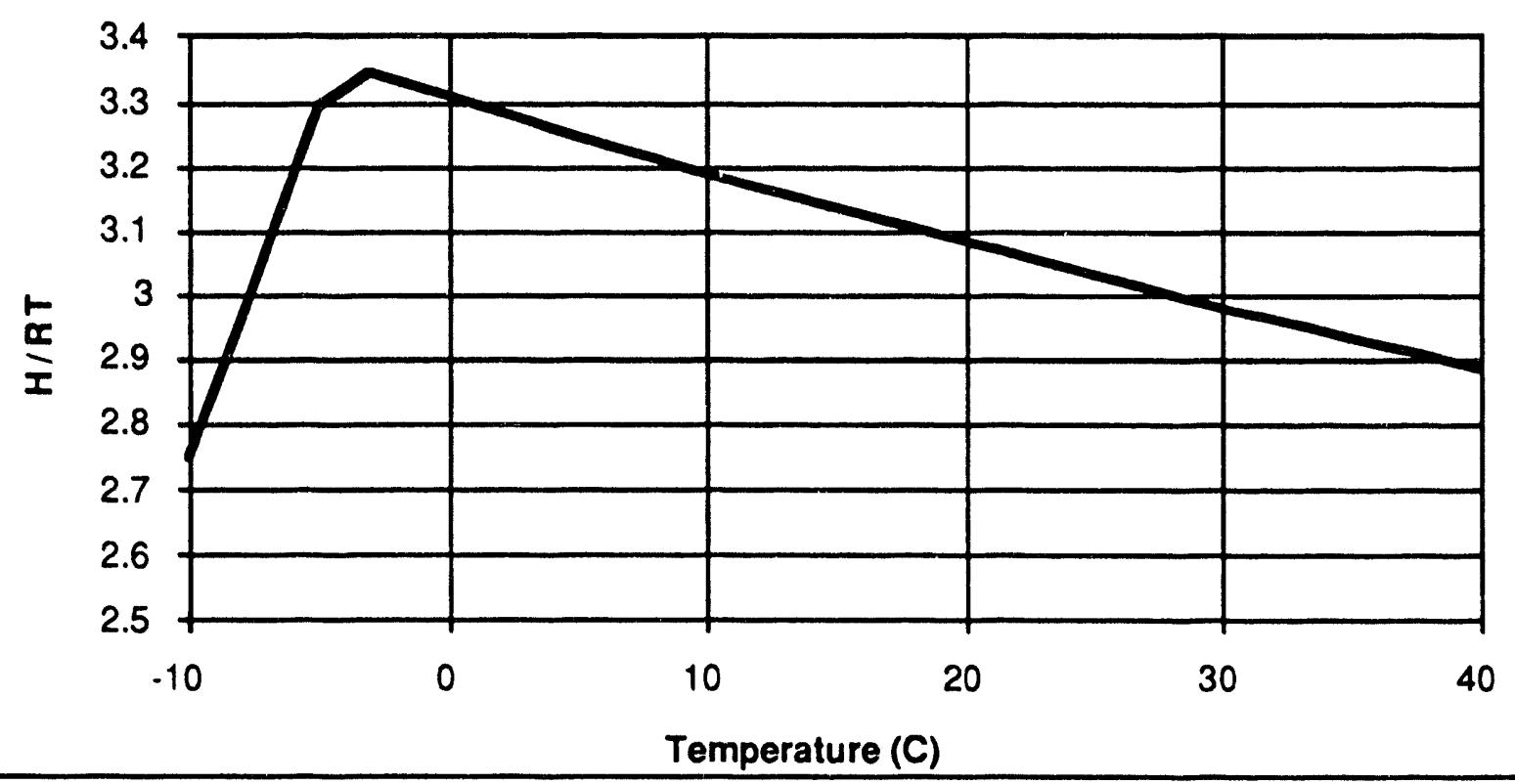

Recommended dimensionless value:

$\mathrm{H} / \mathrm{RT}=3.02 @ 25^{\circ} \mathrm{C}$ 
Organic-carbon partition coefficient $\left(K_{o c}\right)$

No reported measurements of $K_{o c}$ or $K_{d}$ for 1,3-butadiene in soils or sediments are available in the current literature. Estimation methods for $K_{o c}$ produce the following values for $\mathrm{K}_{\mathrm{oc}}$

283 as derived from the $\mathrm{K}_{\mathrm{oc}}$ estimation method proposed by Kenaga and Goring (1980) and referred to in Lyman et al. (1990)

83.7, 73.7, 41.9 , and 47 as derived from the four regression equations relating $\mathrm{K}_{\mathrm{oc}}$ to $\mathrm{K}_{\mathrm{ow}}$ in Karickhoff (1985).

112 as derived from the regression of $\mathrm{K}_{\mathrm{oc}}$ with solubility proposed by Chiou et al. (1977)

116 as derived from the regression of $\mathrm{K}_{\mathrm{oc}}$ with solubility proposed by Kenaga (1980)

162 as derived from the regression of $K_{o c}$ with the molecular connectivity index $\left({ }^{1} \chi=3\right)$ as proposed by Meylan et al (1992).

Recommended value based on the log mean of the predicted values above:

$$
\begin{aligned}
& \log \mathrm{K}_{\mathrm{oC}}=2.0 \pm 0.25 \\
& \mathrm{~K}_{\mathrm{oC}}=100 \times \text { or } \div 1.8
\end{aligned}
$$

Diffusion coefficient in water

Based on the Wilke and Chang (1955) method described in Reid et al. (1987), the diffusion coefficient in $\mathrm{m}^{2} / \mathrm{d}$ in water is given by

$$
D_{x y}=\frac{6.5 \times 10^{-7}\left(\phi M_{y}\right)^{1 / 2} \mathrm{~T}}{\eta_{y} V_{x}^{0.6}}
$$

The molecular weight, $M_{y}$, of water is $18 \mathrm{~g} / \mathrm{mol}$. Wilke and Chang (1955) recommend an association factor, $\phi$, of 2.6 when the solvent is water. The viscosity of water, $\eta_{y}$, is $1.0 \mathrm{cP}$ at $20^{\circ} \mathrm{C}$. Molecular volume can be estimated by the LeBas incremental method as described in Lyman et al. (1982). With the molecular volume $V_{x}$ of 1,2-butadiene equal to $77.9 \mathrm{~cm}^{3} / \mathrm{mol}$, this expression gives 
$D_{\text {water }}=3.7 \times 10^{-7} \mathrm{~T} \mathrm{~m}^{2} / \mathrm{d}=1.1 \times 10^{-4} \mathrm{~m}^{2} / \mathrm{d}$ or $1.3 \times 10^{-9} \mathrm{~m}^{2} / \mathrm{s} @ 293 \mathrm{~K}$

Diffusion coefficient in air

Based on the Fuller et al. (1966) method described in Lyman et al. (1990), the diffusion coefficient in $\mathrm{m}^{2} / \mathrm{d}$ in air is given by

$$
D_{\text {air }}=8.6 \times 10^{-3} \mathrm{~T}^{1.75} \frac{\sqrt{\frac{\left(29+\mathrm{M}_{\chi}\right)}{29 \mathrm{M}_{x}}}}{\left[2.7+\left(V_{x}\right)^{1 / 3}\right]^{2}}
$$

With the molecular volume, $V_{x}$, of 1,3-butadiene equal to $77.9 \mathrm{~cm}^{3} / \mathrm{mol}$ and a molecular weight of $54.09 \mathrm{~g} / \mathrm{mol}$, the above expression gives

$$
D_{\text {air }}=4.7 \times 10^{-5} \mathrm{~T}^{1.75} \mathrm{~m}^{2} / \mathrm{d}=0.84 \mathrm{~m}^{2} / \mathrm{d} \text { or } 9.8 \times 10^{-6} \mathrm{~m}^{2} / \mathrm{s} @ 293 \mathrm{~K}
$$

Bioconcentration factors for plant tissue concentration relative to soil concentration

No reported measurements of plant-root bioconcentration for 1,3-butadiene in soils are available in the current literature. Estimation methods for this parameter are considered below.

The partition factor from surface soil to edible plant parts due to rainsplash, $\mathrm{K}_{\mathrm{ps}}^{\text {rain }}$ is equal to $0.0034 \mathrm{~kg}$ (soil) $/ \mathrm{kg}$ (plant) with a CV of 1 (Dreicer et al. 1984). This partition factor relates plant fresh mass concentration to soil concentration.

Based on the Briggs et al. $(1982,1983)$ estimation equation for uptake of contaminants by roots from soil solution, we calculate the RCF (which represents the ratio of contaminant concentration in root, $\mathrm{mg} / \mathrm{kg}$ [fresh mass], to contaminant concentration in soil solution, $\mathrm{mg} / \mathrm{L}$ ) for 1,3-butadiene as

$$
\mathrm{RCF}=1.84
$$

When this factor is divided by the sorption coefficient, $\mathrm{K}_{\mathrm{d}}=\mathrm{f}_{\mathrm{oc}} \times \mathrm{K}_{\mathrm{oc}}=(0.01$ to $0.02) \times \mathrm{K}_{\mathrm{oc}}$ (from above), we obtain the ratio of contaminant concentration in roots, $\mathrm{mg} / \mathrm{kg}$ (fresh mass) to contaminant concentration in soil solids, $\mathrm{mg} / \mathrm{kg}$, which we refer to as $K_{p s}$ (roots) and estimate it as being in the range 


$$
\mathrm{K}_{\mathrm{ps}} \text { (roots) }=0.32 \text { to } 4.4
$$

Based the regression of $K_{p s}$ (roots) with $K_{o c}$ from Topp et al. (1986), and based on the range of $\mathrm{K}_{\mathrm{oc}}$ values listed above, we obtain

$$
\mathrm{K}_{\mathrm{ps}} \text { (roots) }=4.5 \text { to } 15 \text { (recommended range for root crops) }
$$

Based on the Travis and Arms (1988) correlation for plant-soil bioconcentration we obtain for total plant (not just roots) the following soil/plant partition coefficient.

$$
\mathrm{K}_{\mathrm{ps}}=0.54 \times \text { or }+5.4 \text { (recommended value for exposed produce) }
$$

Bioconcentration factors for plant leaf concentration relative to air concentration

No reported measurements of plant-air bioconcentration for 1,3-butadiene in air are available in the current literature. Estimation methods for this parameter are considered below.

Based on the model of Riederer (1990) for foliar uptake of gases in plant leaves, we estimate a steady-state plant-air coefficient of

$$
\mathrm{K}_{\mathrm{pa}}^{\mathrm{gs}}=\left[0.5+\left(0.4+0.01 \times \mathrm{K}_{\mathrm{ow}}\right) \times \frac{\mathrm{RT}}{\mathrm{H}}\right] \times 10^{-3} \frac{\mathrm{m}^{3}}{\mathrm{~kg}}=0.63 \text { (recommended value) }
$$

We could find no study in which the estimation error of this partition coefficient has been considered, but we assume the $\mathrm{CV}$ associated with it is on the order of 1 .

Bioconcentration factors for fish concentration relative to water/or sediment concentrations

No information on the bioconcentration factor for 1,3-butadiene could be found in the literature. However, based our recommended $\mathrm{K}_{\mathrm{ow}}$ value, we estimate bioconcentration factor (BCF) is 4.6 based on the correlation of Mackay (1982). Howard (1989) reports a bioconcentration factor estimated from $\mathrm{K}_{\mathrm{ow}}$ of 19.

$$
\mathrm{BCF}=4.6 \quad \text { (recommended value) }
$$


Steady-state biotransfer factors for milk or dairy-product concentration relative to contaminant intake by cattle

No reported measurements of milk-diet biotransfer for 1,3-butadiene are available in the current literature. Estimation methods for this parameter are considered below.

Based on the geometric mean regression of milk-to-diet biotransfer against $\mathrm{K}_{\mathrm{ow}}$ developed by Travis and Arms (1988), we estimate the milk biotransfer factor for 1,3-butadiene as

$\log B_{k}=-6.1 \pm 0.84$ (recommended value)

The estimation error in this expression corresponds to a CV of 6 .

Steady-state biotransfer factors for meat concentration relative to contaminant intake by cattle, pigs, and chickens

No reported measurements of meat-diet biotransfer for 1,3-butadiene are available in the current literature. Estimation methods for this parameter are considered below.

Based on the geometric mean regression of meat-to-diet biotransfer against $\mathrm{K}_{\mathrm{ow}}$ developed by Travis and Arms (1988) we estimate the meat biotransfer factor for 1,3-butadiene as

$\log B_{t}=-5.6 \pm 0.95$ (recommended value)

The estimation error in this expression corresponds to a CV of 11 .

Steady-state biotransfer factors for egg concentration relative to contaminant intake by chickens

No reported measurements of egg-diet biotransfer for 1,3-butadiene are available in the current literature. An estimation method value for this parameter is considered below.

Based on the geometric mean regression of egg-to-diet biotransfer against $\mathrm{K}_{\mathrm{ow}}$ developed above, we estimate the egg biotransfer factor for 1,3-butadiene as

$$
\log B_{e}=-3.1 \pm 1 \text { (recommended value) }
$$

The estimation error in this expression corresponds to a CV of 14 . 
Contaminant biodegradation factors in soil

Howard et al. (1991) have estimated the half-life of 1,3-butadiene in soil duc to aerobic biodegradation to be in the range of 7 to 28 days.

Recommended value, based on log mean and log variance of the range of the soil half lives given above:

Soil biodegradation rate constant $=0.05 \mathrm{~d}^{-1} \times$ or $\div 1.5$

Media-specific half lives for air, soil, and surface water

Air. Howard et al. (1991) estimate the half life of 1,3-butadiene in lower atmosphere is in the range of 1 to 8 hours ( 0.042 to 0.33 days) and that removal from air is due primarily to reaction with hydroxyl radicals.

Soil Howard et al. (1991) have estimated the half-life of 1,3-butadiene in soil due to aerobic biodegradation to be in the range of 7 to 28 days.

Water. When released to water, 1,3-butadiene evaporates rapidly with a half life estimated to be several hours; it does not hydrolyze appreciably, but may be subject to some biodegradation (Howard et al., 1991).

Recommended half-lives (in days), based on the log mean of the half lives and geometric range of the values:
Air $\quad 0.12 \times$ or $\div 1.8$
Soil $\quad 14 \times$ or $\div 3.5$
Water $\quad 0.12 \times$ or $\div 1.5$ 


\section{References for 1,3-Butadiene}

Boublik, T., Fried, V., and Hála, E. (1984), The Vapour Pressures of Pure Substances: Selected Values of the Temperature Dependence of the Vapour Pressures of Some Pure Substances in the Normal and Low Pressure Region (Second Revised Edition), Physical sciences data; 17 (Elsevier Science Publishers, Amsterdam, The Netherlands).

Briggs, G.G., R.H. Bromilow, and A.A. Evans (1982), "Relationships Between Lipophilicity and Root Uptake and Translocation of Non-Ionized Chemicals by Barley," Pestic. Sci. 13, 495-504.

Briggs, G.G., R.H. Bromilow, A.A. Evans, and M. Williams (1983), "Relationships Between Lipophilicity and the Distribution of Non-Ionized Chemicals in Barley Shoots Following Uptake by the Roots," Pestic. Sci. 14, 492-500.

Chiou, C. T., V. H. Freed, D.W. Schmedding, and R. L. Kohnert (1977), "Partition Coefficient and Bioaccumulation of Selected Organic Chemicals," Environ. Sci. Technol. 11(5), 475-478.

Dean, J.D., Ed. (1985), Lang's Handbook of Chemistry (McGraw-Hill, Inc., New York City, NY, 13th ed.

Dreicer, M., T.E. Hakonson, G.C. White, and F.W. Whicker (1984), "Rainsplash as a Mechanism for Soil Contamination of Plant Surfaces," Health Phys. 46, 177-187.

Fuller, E.N., P.D. Schettler, and J.C. Giddings (1966), "A New Method for Prediction of Binary Gas-Phase Diffusion Coefficients," Ind. Eng. Chem. 58, 19-27.

Hansch, C., A. Leo (1985), "The Log P and Related Parameters Database, created and updated by the Medicinal Chemistry Project at Pomona College under the direction of Corwin Hansch and Albert Leo - 1985 Printout," in Medchem Project Issue N‥ 26, Pomona College, Claremont, CA.

Hansch, C., and A. Leo (1987), "The Log P and Related Parameters Database," created and updated by the Medicinal Chemistry Project at Pomona College, Claremont, CA, under the direction of Corwin Hansch and Albert Leo - 1987 Printout.

Hine, J. and P.K. Mookerjee (1975), "The Intrinsic Hydrophilic Character of Organic Compounds. Correlations in Terms of Structural Contributions," J. Org. Chem. 40, 292-298.

Howard, P.H., Ed. (1989), Handbook of Fate and Exposure Data for Organic

Chemicals. Vol. I . Large Production and Priority Pollutants (Lewis Publishers, Inc., Chelsea, MI).

Howard, P. H., R. S. Boethling, W. F. Jarvis, W. M. Meylan, and E. M. Michalenko, Eds. (1991), Handbook of Environmental Degradation

Rates (Lewis Publishers, Inc, Chelsea, MI). 
Karickhoff, S.W. (1985), "Chapter 3. Pollutant Sorption in Environmental Systems," in Environmental Exposure From Chemicals, Volume I., W. B. Neely and G.E. Blau, Eds. (CRC Press, Inc., Boca Raton, FL), pp. 49-64.

Kenaga, E. E. (1980), "Predicted Bioconcentration Factors and Soil Sorption Coefficients of Pesticides and Other Chemicals," Ecotoxicol. Environ. Saf. 4, 26-38.

Kenaga, E. E., and C.A.I. Goring (1980), "Relationship Between Water Solubility, Soil Sorption, Octanol-Water Partitioning, and Concentration of Chemicals in Biota," in Aquatic Toxicology, ASTM STP 707, J. G. Eaton, P. R. Parrish, and A. C. Hendricks, Eds. (American Society for Testing and Materials, Philadelphia, PA) pp. 78-115.

Lyman, W. J., W. F. Reehl, and D. H. Rosenblatt (1990), Handbook of Chemical Property Estimation Methods: Environmental Behavior of Organic Compounds (American Chemical Society, Washington, DC).

Mackay, D. (1982), "Correlation of Bioconcentration Factors," Environ. Sci. Technol. 16, 274-278.

McAuliffe, C. (1966), "Solubility in Water of Paraffin, Cycloparaffin, Olegin, Acetylene, Cycloolefin, and Aromatic Hydrocarbons," J. Phys. Chem. 70, 1267-1275.

Meylan, W., P.H. Howard, and R.S. Boethling (1992), "Molecular Topology/Fragment Contribution Method for Predicting Soil Sorption Coefficients," Environ. Sci. Technol. 26, 1560-1567.

Reed, C.D., and J.J. McKetta (1959), "Solubility of 1,3-Butadiene in Water," J. Chem. Eng. 4(4), 294-295; "Correction to Fig. 3," J. Chem. Eng. 5(1), 41 (January 1960).

Reid, R. C., J. M. Prausnitz, and B. E. Poling (1987), The Properties of Gases and Liquids (McGraw Hill, New York City, NY), 4th ed.

Reiderer, M. (1990), "Estimating F'artitioning and Transport of Organic Chemicals in the Foliage/Atmosphere System: Discussion of a Fugacity-Based Model," Environ. Scil. Technol. 24, 829-837.

Stull, D. R. (1947), "Vapor Pressure of Pure Substances: Organic Compounds," Ind. Eng. Chem. 39, 517-540.

Topp, E., I. Scheunert, A. Attar, and F. Korte (1986), "Factors Affecting the Uptake of 14C-Labeled Organic Chemicals by Plants From Soil," Ecotoxicol. Environ. Saf. 11, 219-228.

Travis, C. C., and A. D. Arms (1988), "Bioconcentration of Organics in Beef, Milk, and Vegetation," Environ. Sci. Technol. 22, 271-274.

Verschueren, K. (1983), Handbook of Environmental Data on Organic Chemicals, Second Edition (Van Nostrand Reinhold Company Inc., New York City, NY). 
Weast, R. C., M. J. Astle, and W. H. Beyer, Eds. (1986), CRC Handbook of Chemistry and Physics: A Ready Reference Book of Chemical and Physical Data, 67th Edition (CRC Press, Inc., Boca Raton, FL).

Wilhoit, R.C., and B.J. Zwolinski (1971), Handbook of Vapor Pressures and Heats of Vaporization of Hydrocarbons and Related Compounds, Thermodynamics Research Center, Texas A\&M University, College Station, TX.

Wilke, C.R., and P. Chang (1955), "Correlation of Diffusion Coefficients in Dilute Solutions," AIChE J. 1, 264-270.

Windholz, M., S. Budavari, R. F. Blumetti, and E. S. Otterbein, Eds. (1983), The Merck Index: An Encyclopedia of Chemicals, Drugs, and Biologicals, 10th Edition (Merck \& Co., Inc., Rahway, NJ). 


\section{Cadmium (Cd)}

Cadmium typically occurs in nature in association with zinc ores, such as sphalerite $(\mathrm{ZnS})$. Greenockite ( $\mathrm{Cu}$ ) is the only mineral of any consequence bearing cadmium (Weast et al., 1986). Almost all cadmium used industrially is obtained as a by-product in the treatment of zinc, copper, and lead ores. Cadmium has a only one valance state, +2 . Cadmium forms a number of salts, including cadmium chloride $\left(\mathrm{CdCl}_{2}\right)$, cadmium sulfate $\left(\mathrm{CdSO}_{4}\right)$, and cadmium sulfide (CdS). Cadmium sulfate is the most common salt. Cadmium has a relatively high bioavailability. It is accumulated and retained in the human body.

\section{Molecular and atomic weights}

$112.41 \mathrm{~g} / \mathrm{mol}$, atomic weight of $\mathrm{Cd}$ (Weast et al., 1986).

$112.4 \mathrm{~g} / \mathrm{mol}$, atomic weight of $\mathrm{Cd}$ (Bowen, 1979).

$183.32 \mathrm{~g} / \mathrm{mol}$, molecular weight of cadmium chloride, $\mathrm{CdCl}_{2}$ (Weast et al., 1986).

$208.47 \mathrm{~g} / \mathrm{mol}$, molecular weight of cadmium sulfate, $\mathrm{CdSO}_{4}$ (Weast et al., 1986).

$144.47 \mathrm{~g} / \mathrm{mol}$, molecular weight of cadmium sulfide, CdS (Weast et al., 1986).

\section{Melting points}

$321{ }^{\circ} \mathrm{C}$ for cadmium metal, Cd (Stull, 1947).

$568{ }^{\circ} \mathrm{C}$ for cadmium chloride, $\mathrm{CdCl}_{2}$ (Stull, 1947).

$1000{ }^{\circ} \mathrm{C}$ for cadmium sulfate, $\mathrm{CdSO}_{4}$ (Weast et al., 1986). cadmium sulfide, CdS, boils before it melts (Weast et al., 1986).

\section{Vapor pressure}

$765{ }^{\circ} \mathrm{C}$ is the boiling point of pure cadmium, $\mathrm{Cd}$ (Stull, 1947).

$967{ }^{\circ} \mathrm{C}$ is the boiling point of cadmium chloride, $\mathrm{CdCl}_{2}$, reported by Stull (1947).

$960{ }^{\circ} \mathrm{C}$ is the boiling point of cadmium chloride, $\mathrm{CdCl}_{2}$, reported by (Weast et al., 1986).

$980{ }^{\circ} \mathrm{C}$ is the boiling point of cadmium sulfide, $\mathrm{CdS}$, reported by (Weast et al., 1986). 
Stull (1947) reports the following vapor pressures for cadmium metal (Cd).

$\begin{array}{ccc}\text { Temperature }\left({ }^{\circ} \mathrm{C}\right) & \text { Vapor Pressure }(\mathrm{mm}) & \text { Vapor Pressure }(\mathrm{kPa}) \\ 394 & 1 & 0.133 \\ 455 & 5 & 0.667 \\ 484 & 10 & 1.33 \\ 516 & 20 & 2.67 \\ 553 & 40 & 5.33 \\ 578 & 60 & 8.00 \\ 611 & 100 & 13.3 \\ 658 & 200 & 26.7 \\ 711 & 400 & 53.3 \\ 765 & 760 & 101\end{array}$

Interpolating from this data using an Antoine equation gives VP at $25^{\circ} \mathrm{C}=1.7 \times 10^{-8} \mathrm{~Pa}$

Stull (1947) reports the following vapor pressures for cadmium chloride $\left(\mathrm{CdCl}_{2}\right)$.

Temperature $\left({ }^{\circ} \mathrm{C}\right) \quad$ Vapor Pressure $(\mathrm{mm})$ Vapor Pressure $(\mathrm{kPa})$

$\begin{array}{lrc}618 & 5 & 0.667 \\ 656 & 10 & 1.33 \\ 695 & 20 & 2.67 \\ 736 & 40 & 5.33 \\ 762 & 60 & 8.00 \\ 797 & 100 & 13.3 \\ 847 & 200 & 26.7 \\ 908 & 400 & 53.3 \\ 967 & 760 & 101\end{array}$

Interpolating from this data using an Antoine equation gives $\mathrm{VP}$ at $25^{\circ} \mathrm{C}=0.95 \mathrm{~Pa}$ Recommended value:

No recommended vapor pressure for cadmium because the speciation of its compounds makes vapor pressure unimportant for characterizing environmental transport 
Solubility in water

In aqueous systems, water hardness along with $\mathrm{pH}$ determine the speciation of cadmium. In fresh water at typical environmental $\mathrm{pH}$ values of 6 to $8, \mathrm{Cd}^{+2}$ is the predominant species (Bodek et al., 1988). The only oxidation state of importance for cadmium under environmental conditions is +2 . In the presence of sulfide ions and under reducing conditions, cadmium sulfide is formed over a wide $\mathrm{pH}$ range. The resulting precipitation of cadmium sulfide in reducing environments can serve to control the effective solubility of cadmium in natural waters.

metal cadmium, Cd, is insoluble in water (Weast et al., 1986).

$1,680,000 \mathrm{mg} / \mathrm{L}\left(9170 \mathrm{~mol} / \mathrm{m}^{3}\right)$ of cadmium chloride $\left(\mathrm{CdCl}_{2}\right)$, at $20^{\circ} \mathrm{C}$ (Weast et al., 1986).

$2,160,000 \mathrm{mg} / \mathrm{L}\left(11,790 \mathrm{~mol} / \mathrm{m}^{3}\right)$ of cadmium chloride $\left(\mathrm{CdCl}_{2}\right)$, at $100^{\circ} \mathrm{C}$ (Weast et al., 1986).

$755,000 \mathrm{mg} / \mathrm{L}\left(3620 \mathrm{~mol} / \mathrm{m}^{3}\right)$ of cadmium sulfate $\left(\mathrm{CdSO}_{4}\right)$, at $0{ }^{\circ} \mathrm{C}$ (Weast et al., 1986).

$608,000 \mathrm{~g} / \mathrm{L}\left(2920 \mathrm{~mol} / \mathrm{m}^{3}\right)$ of cadmium sulfate $\left(\mathrm{CdSO}_{4}\right)$, at $100^{\circ} \mathrm{C}$ (Weast et al., 1986).

$1.3 \mathrm{mg} / \mathrm{L}\left(9.0 \mathrm{~mol} / \mathrm{m}^{3}\right)$ of cadmium sulfide (CdS), at $18^{\circ} \mathrm{C}$ (Weast et al., 1986).

Recommended values:

$\mathrm{WS}(\mathrm{Cd}$ metal $)=\sim 0$

$\mathrm{WS}\left(\mathrm{Cd}^{+2}\right)=9$ to $12,000 \mathrm{~mol} / \mathrm{m}^{3}$ depending on the presence of sulfate and sulfide ions and the Eh of the water.

\section{Henry's law constant}

Because of their almost complete speciation in water and extremely low vapor pressures, most cadmium compounds do not have measurable or predicted Henry's law constants. However, at low concentrations, the ratio of air to water concentration in air and water environments that are in contact can be estimated as

$$
\mathrm{C}_{\mathrm{w}} / \mathrm{C}_{\mathrm{a}}=\mathrm{A} \times \mathrm{v}_{\mathrm{d}} /\left(\mathrm{V}_{\mathrm{w}} \times \mathrm{R}_{\mathrm{w}}\right)
$$

where $C_{w}$ is the cadmium concentration in a given water body, $m o l / \mathrm{m}^{3} ; \mathrm{C}_{\mathrm{a}}$ is the cadmium concentration in air above the water body, $\mathrm{mol} / \mathrm{m}^{3} ; \mathrm{v}_{\mathrm{d}}$ is the 
deposition velocity that represents the rate of cadmium transfer from air to water, $\mathrm{m} / \mathrm{d} ; \mathrm{A}$ is the contact area between the air and water, $\mathrm{m}^{2} ; \mathrm{V}_{\mathrm{w}}$ is the volume of the water body, $\mathrm{m}^{3}$; and $R_{w}$ is the first-order rate constant that accounts for all cadmium removals from water (i.e. precipitation and deposition), day-1.

Partition coefficients in soils and sediments

1.2 -2.5 L/kg reported by Bodek et al. (1988) as the range of $K_{d}$ values observed for Cd in sediments.

Bodek et al. (1988) list ranges of Freundlich isotherms parameters for modeling sorption of cadmium in four different soil types. The following Freundlichisotherm derived distribution coefficients, $K_{d}$, bracket the range of isotherms developed by Bodek et al. (1988),

$$
\begin{aligned}
& \mathrm{K}_{\mathrm{d}}=\mathrm{S} / \mathrm{C}=0.63 \mathrm{C}^{0.95} / \mathrm{C}[\mathrm{L} / \mathrm{kg}] \\
& \mathrm{K}_{\mathrm{d}}=\mathrm{S} / \mathrm{C}=23.2 \mathrm{C} 0.63 / \mathrm{C}[\mathrm{L} / \mathrm{kg}]
\end{aligned}
$$

where $S$ is the sorbed cadmium concentration, $\mathrm{mg} / \mathrm{kg}$, and $\mathrm{C}$ is cadmium concentration in water, $\mathrm{mg} / \mathrm{L}$. The solid lines in the figure below illustrate the dependence of the distribution coefficient for cadmium on cadmium concentration in the water phase based on these Freundlich isotherms.

Bodek et al. (1988) also list ranges of Langmuir constants for cadmium in sediments. These equations give the following estimates of the distribution coefficient $K_{d}$ in river sediments.

$$
\mathrm{K}_{\mathrm{d}}=\mathrm{S} / \mathrm{C}=\mathrm{A}_{\mathrm{m}} \mathrm{K}_{\mathrm{L}} /\left(1+\mathrm{K}_{\mathrm{L}} \mathrm{C}\right)[\mathrm{L} / \mathrm{kg}]
$$

where

$\mathrm{S}$ is the cadmium sorbed to soil, $\mathrm{mol} / \mathrm{kg}$;

$\mathrm{C}$ is the cadmium concentration in sediment water, $\mathrm{mol} / \mathrm{L}$;

$A_{m}$ is the maximum amount of cadmium that can be absorbed by soil and ranges from 0.002 to $0.17 \mathrm{~mol} / \mathrm{kg}$ for sediments; and

$\mathrm{K}_{\mathrm{L}}$ is the measure of bond strength holding the sorbed cadmium to the soil surface and ranges from 25,000 to $10^{7} \mathrm{~L} / \mathrm{mol}$ for sediments.

The two dotted lines in the figure below represent this range of distribution coefficients associated with the range of Langmuir constants quoted above for sediments. 
Recommended value of $\mathrm{K}_{\mathrm{d}}$ for cadmium in soils and in sediments based on the geometric mean and geometric standard deviation of values considered above:

$$
\begin{aligned}
& 1 \leq K_{d} \leq 9,000 \text { in soils } \\
& 200 \leq K_{d} \leq 160,000 \text { in sediments } \\
& \log K_{d}=2.00 \pm 1.1 \text { in soils } \\
& \log K_{d}=3.75 \pm 0.83 \text { in sediments } \\
& K_{d}=200 \times \text { or }+12.6 \text { in soils } \\
& K_{d}=5600 \times \text { or } \div 6.9 \text { in sediments }
\end{aligned}
$$

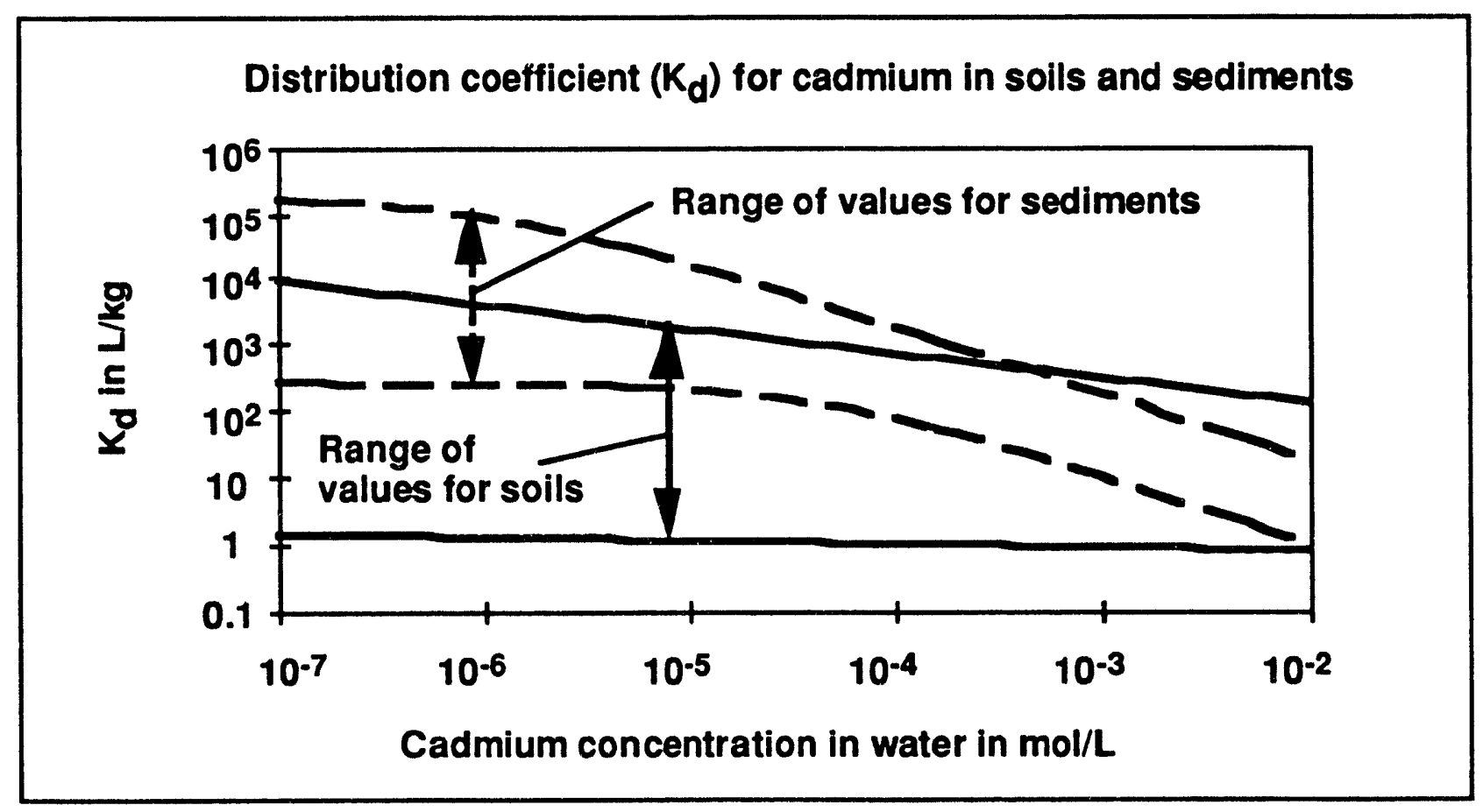

Diffusion coefficient in water

In dilute solutions of ionized species, such as cadmium compounds, in which there are no rapid chemical reactions and the solution is isothermal, Bodek et al. (1988) have shown that diffusion coefficients for the anions and cations in solution do not vary greatly and are on the order of $1.5 \times 10^{-9} \mathrm{~m}^{2} / \mathrm{s}$. The 
diffusion coefficients of many simple salts generally do not vary by more than a factor of 2 over a range of concentrations and temperatures even though their conductivities can vary greatly (Bodek et al., 1988).

Recommended value:

$$
D_{\text {water }}=1.3 \times 10^{-4} \mathrm{~m}^{2} / \mathrm{d} \text { or } 1.5 \times 10^{-9} \mathrm{~m}^{2} / \mathrm{s} \times \text { or }+2 \text { for } 0^{\circ} \mathrm{C} \leq \mathrm{T} \leq 40^{\circ} \mathrm{C}
$$

\section{Diffusion coefficient in air}

Because of the extremely low vapor pressure of cadmium and inorganic cadmium compounds, these chemical species are not likely to be found in the gas phase of the environment. There is no need for a diffusion coefficient in air and, thus no value is recommended.

Bioconcentration factors for plant tissue relative to soil concentration $\mathrm{kg}\left(\right.$ soil) $/ \mathrm{kg}$ (plant fresh mass), $K_{p s}$

Cadmium is considered a potential essential trace element for plants and animals (Mertz, 1981). Root uptake of cadmium as $\mathrm{Cd}^{+2}$ in plants is passive and occurs though uptake by roots of $\mathrm{Cd}$ dissolved in water; cadmium is highly mobile in plants and readily translocated to other plant parts (Bodek et al. (1988).

0.055 to 0.17 based on a soil-to-plant-dry-mass coefficient of 0.55 used by Baes et al. (1984) for the vegetative portion of food crops and our assumed plant dry mass fraction in the range 0.1 to 0.3 .

0.015 to 0.045 based on soil-to-plant-dry-mass coefficient of 0.15 used by Baes et al. (1984) for the non-vegetative (reproductive) portion of food crops and our assumed plant dry-mass fraction in the range 0.1 to 0.3 .

0.029 to 2.1 based on a $0.35 \mathrm{mg} / \mathrm{kg}$ as the geosphere average of soil cadmium concentration and 0.1 to $2.4 \mathrm{mg} / \mathrm{kg}$ (dry mass) as a geosphere average of land-plant cadmium concentration reported by Bowen (1979) and our assumed plant dry-mass fraction in the range 0.1 to 0.3 .

$0.5 \times$ or $\div 9$ based on a 0.01 to $1 \mathrm{mg} / \mathrm{kg}$ as the range of background soil cadmium levels and 0.1 to $0.8 \mathrm{mg} / \mathrm{kg}$ (dry mass) as the range of background soil plant levels reported by Bodek et al. (1988) and our assumed plant drymass fraction in the range 0.1 to 0.3 .

$0.0034 \times$ or +2.2 is the partition factor from surface soil to edible plant parts due to rainsplash, $\mathrm{K}_{\mathrm{ps}}^{\mathrm{rain}}$ (Dreicer et al. 1984). 
Recommended value of $K_{\mathrm{ps}}$ based on the log mean of the ranges of values considered above (excluding rainsplash),

$$
\begin{aligned}
& \log K_{p s}=-0.88 \pm 0.89 \\
& K_{p s}=0.13(\times \text { or } \div 7.8) \mathrm{kg}(\text { soil }) / \mathrm{kg} \text { (plant fresh mass) }
\end{aligned}
$$

Steady-state bioconcentration factors for plant leaf concentration relative to air concentration

According to Bodek et al. (1988), airborne deposition is believed to contribute to concentrations of cadmium found in plant leaves. At low concentrations, the ratio of plant leaf concentration to air concentration when air and plant environments are in contact, can be estimated as

$$
C_{p} / C_{a}=A \times v_{d} /\left(V_{p} \times R_{p}\right)
$$

where $C_{p}$ is cadmium concentration in the plants in contact with contaminated air, $\mathrm{mol} / \mathrm{m}^{3} ; \mathrm{C}_{\mathrm{a}}$ is the cadmium concentration in air above the plants, $\mathrm{mol} / \mathrm{m}^{3}$; $v_{d}$ is the deposition velocity that represents the rate of cadmium transfer from air to plant surfaces, $\mathrm{m} / \mathrm{d} ; \mathrm{A}$ is the contact area between the air and plants, $\mathrm{m}^{2}$; ' $V_{p}$ is the volume of the plants compartment, $\mathrm{m}^{3}$; and $R_{p}$ is the first-order rate constant that accounts for all cadmium removals from plants (i.e. wash-off, biodegradation, etc.), day ${ }^{-1}$.

Bioconcentration factors for fish concentration relative to water or sediment concentrations

50,000 reported by Bodek et al. (1988) as a typical concentration ratio in marine invertebrates relative to water concentration.

3,000 reported by Bodek et al. (1988) as a typical concentration ratio in marine fish relative to water concentration.

2,000 reported by Bodek et al. (1988) as a typical concentration ratio in freshwater invertebrates relative to water concentration.

200 reported by Bodek et al. (1988) as a typical concentration ratio in freshwater fish relative to water concentration.

200 to 6000 based on $0.0001 \mathrm{mg} / \mathrm{L}$ as a geosphere average of ocean-water cadmium concentration and 0.1 to $3 \mathrm{mg} / \mathrm{kg}$ (dry mass) as an average of marinefish cadmium concentration reported by Bowen (1979) and our assumed fish dry mass fraction of 0.2 . 
Recommended $\mathrm{BCF}$ value, based on the geometric mean and geometric standard deviation reflecting the range of BCF values described above:

$$
\begin{aligned}
& \log B C F(\text { fish })=3.3 \pm 0.91 \\
& B C F(\text { fish })=2000 \times \text { or }+8.1
\end{aligned}
$$

Steady-state biotransfer factors for milk or dairy-product concentration relative to contaminant intake by cattle, $B_{k}$

$1.5 \times 10^{-3} \mathrm{~d} / \mathrm{L}$ is uptake to milk from feed based on radioisotope studies reported by $\mathrm{Ng}$ (1982).

Stevens (1991) evaluated several studies investigating the concentration of soluble forms of cadmium (Cd) in milk relative to the $\mathrm{Cd}$ intake in feed.

0.56 to $6.3 \times 10^{-6} \mathrm{~d} / \mathrm{L}$ is the range of values Stevens (1991) identified in studies investigating the concentration of soluble forms of cadmium (Cd) in milk, relative to the $\mathrm{Cd}$ intake in feed.

$1.3 \times 10^{-6} \mathrm{~d} / \mathrm{L}$ was derived from a study by Vreman et al. (1986) by Stevens (1991) who recommended this estimate of this biotransfer factor.

Recommended biotransfer factor, $B_{k}$, for milk based on the geometric mean and geometric standard deviation reflecting the range of values above:

$$
\begin{aligned}
& \log B_{k}=-5.0 \pm 1.5 \\
& B_{k}=5 \times 10^{-5} \times \text { or } \div 32
\end{aligned}
$$

Steady-state biotransfer factors for meat concentration relative to contaminant intake by cattle, pigs, and chickens

Stevens (1992) evaluated several studies investigating the concentration of soluble forms of cadmium (Cd) in meat from cattle, relative to the $\mathrm{Cd}$ intake in feed by these cattle.

1 to $10 \times 10^{-4} \mathrm{~d} / \mathrm{kg}$ is the range of values Stevens (1992) identified in studies investigating the concentration of cadmium (Cd) in bovine muscle relative to the $C d$ intake in feed. 
7.7 to $48 \times 10^{-3} \mathrm{~d} / \mathrm{kg}$ is the range of values Stevens (1992) identified in studies investigating the concentration of cadmium (Cd) in bovine kidney relative to the $C d$ intake in feed.

4.7 to $19 \times 10^{-2} \mathrm{~d} / \mathrm{kg}$ is the range of values Stevens (1992) identified in studies investigating the concentration of cadmium (Cd) in bovine liver relative to the $\mathrm{Cd}$ intake in feed.

$1.7 \times 10^{-4} \mathrm{~d} / \mathrm{kg}$ is the value considered by Stevens (1992) to be the most reasonable estimate of a steady-state biotransfer factor for cadmium to bovine muscle.

$4.8 \times 10^{-2} \mathrm{~d} / \mathrm{kg}$ is the value considered by Stevens (1992) to be the most reasonable estimate of a steady-state biotransfer factor for cadmium to bovine liver.

$1.9 \times 10^{-1} \mathrm{~d} / \mathrm{kg}$ is the value considered by Stevens (1992) to be the most reasonable estimate of a steady-state biotransfer factor for cadmium to bovine kidney.

Recommended biotransfer factor, $\mathrm{B}_{\mathrm{t}}$, for meat based on the geometric mean and geometric standard deviation reflecting the range of values above:

$$
\begin{aligned}
& \log B_{t}=-2.00 \pm 1.26 \\
& B_{t}=0.01 \times \text { or } \div 18
\end{aligned}
$$

Steady-state biotransfer factors for egg concentration relative to contaminant intake by chickens

No reported measurements of egg-diet biotransfer for cadmium are available in the current literature.

$\mathrm{Ng}$ (1982) has shown that for the seven elements strontium, rubidium, iodine, cesium, cerium, plutonium, and americium, the ratio of egg contents biotransfer to beef biotransfer is $60 \times$ or +13 . Based on this observation, the meat biotransfer above can be used to make an estimate of egg contents biotransfer of $0.6 \times$ or +19 where the larger GSD mostly reflects the uncertainty in the meat biotransfer factor. 
Recommended biotransfer factor, $\mathrm{B}_{\mathrm{e}}$, for eggs:

$\log B_{e}=-0.22 \pm 1.28$

$B_{e}=0.6 \times$ or +19

Contaminant biodegradation factors in soil

There is no evidence of biodegradation of inorganic cadmium in soils and sediments (Bodek et al. 1988). Thus, there is no recommended biodegradation factor for inorganic cadmium compounds in soils.

Media-specific half lives for air, soil, and surface water

There is no evidence that inorganic cadmium compounds react in air, soil, or water in such a way as to increase an existing physical removal of cadmium from these compartments. Thus the half lives of cadmium species in these compartments will depend entirely upon the removal rate due to natural physical processes such as deposition and erosion.

Recommended half-lives:

Air deposition half life

Soil erosion half life

Water suspended particle half life

\section{References for Cadmium}

Baes, III, C.F., R.D. Sharp, A.L. Sjoreen, and R.W. Shor (1984), A Review and Analysis of Parameters for Assessing Transport of Environmentally Released Radionuclides Through Agriculture, Oak Ridge National Laboratory, Oak Ridge, TN, ORNL-5786/NTIS DE85-000287.

Bodek, I., W.J. Lyman, W.F. Reehl, and D.H. Rosenblatt, Eds. (1988), Environmental Inorganic Chemistry: Properties, Processes, and Estimation Methods (Pergamon Press, New York City, NY.) 
Bowen, H.J.M. (1979), Environmental Chemistry of the Elements (Academic Press, New York City, NY).

Dreicer, M., T.E. Hakonson, G.C. White, and F.W. Whicker (1984), "Rainsplash as a Mechanism for Soil Contamination of Plant Surfaces," Health Phys. 46, 177-187.

Mertz, W. (1981), "The Essential Trace Elements," Science 213, 1332-1338.

$\mathrm{Ng}$, Y.C. (1982), "A Review of Transfer Factors for Assessing the Dose from Radionuclides in Agricultural Products," Nucl. Saf. 23, 57-71.

Stevens, J.B. (1991), "Disposition of Toxic Metals in the Agricultural Food Chain. 1. Steady-State Bovine Milk Biotransfer Factors," Environ. Sci. Technol. 25, 1289-1294.

Stevens, J.B. (1992), "Disposition of Toxic Metals in the Agricultural Food Chain. 2. Steady-State Bovine Tissue Biotransfer Factors," Environ. Sci. Technol. 26, 1915-1921.

Stull, D.R. (1947), "Vapor Pressure of Pure Substances: Inorganic Compounds," Ind. Eng. Chem. 39, 540-550.

Vreman, K., N.G. van der Veen, E.J. van der Molen, W.G. de Ruig (1986), Neth. J. Agric. Sci. 34, 129.

Weast, R.C., M.J. Astle, and W.H. Beyer, Eds. (1986), CRC Handbook of Chemistry and Physics: A Ready Reference Book of Chemical and Physical Data, 67th Edition (CRC Press, Inc., Boca Raton, FL). 
Cadmium

-48 - 


\section{Cellosolve}

Other names: Ethylene glycol monoethyl ether, ethoxol, ethylglycol, glycolmonoethylether, 2-ethoxyetanol, Dowanol EE, Jeffersol EE, Oxitol, Ethyl cellosolve.

\section{CAS Registry Number: 110-80-5}

Cellosolve is released into the atmosphere as a result of its use as a evaporative solvent in the preparation of a variety of products. Approximately $50 \%$ of cellosolve produced is utilized for cellosolve acetate production (IPCS, 1990). It is used as a solvent for nitrocellulose; for natural and synthetic resins for surface coatings; and for dyes in textile and leather finishing. It is also used as a general solvent in varnish removers and cleansing solutions. Cellosolve is used in dry cleaning compounds and as a solvent in ink formulations for printing, photographic and photolithographic processes (Windholz et al., 1983; Howard et al., 1990; Verschueren, 1983).

Formula: $\mathrm{C}_{4} \mathrm{H}_{10} \mathrm{O}_{2}$

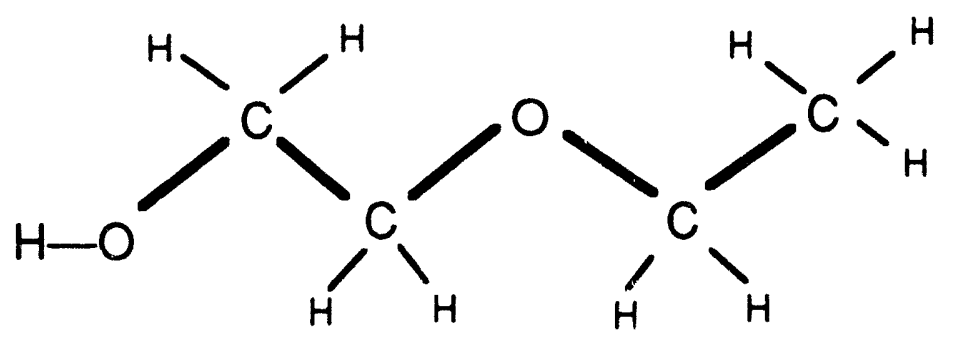

Molecular weight

90.12 (Howard et al., 1990 )

90.1 (Verschueren, 1983; Weast et al., 1986; Windholz et al., 1983)

Recommended molecular weight for cellosolve: 90.1

\section{Melting Point}

not available

Octanol-water partition coefficient $\left(K_{o w}\right)$

0.288 derived from a $\log \mathrm{K}_{\mathrm{ow}}$ of -0.54 reported by Hansch and Leo (1987) based on the value measured by Collander (1951). 
0.288 derived from a $\log \mathrm{K}_{\mathrm{ow}}$ of -0.54 reported by Verschueren (1983) and apparently taken from and earlier edition of Hansch and Leo (1987).

0.447 derived from a $\log \mathrm{K}_{\mathrm{ow}}$ of -0.35 reported by Hansch and Leo (1987) based on the measured value they attribute to Funasaki et al. (1984).

0.794 derived from a $\log \mathrm{K}_{\mathrm{ow}}$ of -0.10 reported by Hansch and Leo (1987) based on the value measured by Korenman and Udalova (1974) [This value is also cited by Howard (1990).

Recommended value, based on the log-mean value of the 3 measured values reported above:

$$
\begin{aligned}
& \log \mathrm{K}_{\mathrm{ow}}=-0.33 \pm 0.22 \\
& \mathrm{~K}_{\mathrm{ow}}=0.47 \times \text { or } \div 1.6
\end{aligned}
$$

\section{Vapor pressure at standard temperatures}

$0.507 \mathrm{~Pa}$ based on a VP of $3.8 \mathrm{~mm} \mathrm{Hg}$ at $20^{\circ} \mathrm{C}$ reported in IPCS (1990) attributed to Rowe and Wolf (1982).

$0.707 \mathrm{~Pa}$ based on a VP of $5.3 \mathrm{~mm} \mathrm{Hg}$ at $25^{\circ} \mathrm{C}$ reported in Howard et al. (1990) and attributed to the Dow Chemical Company Glycol Ethers Handbook (1981).

$0.767 \mathrm{~Pa}$ based on a VP of $5.75 \mathrm{~mm} \mathrm{Hg}$ at $25^{\circ} \mathrm{C}$ reported in Rowe and Wolf (1982).

$0.933 \mathrm{~Pa}$ based on a VP of $7 \mathrm{~mm} \mathrm{Hg}$ at $30^{\circ} \mathrm{C}$ reported in Verschueren (1983).

The following Antoine equation has been published for estimating the vapor pressure of cellosolve in $\mathrm{kPa}$

$\log _{10}(\mathrm{VP}$ in $\mathrm{kPa})=6.972-\frac{1825}{232.483+\mathrm{T}}$ for $63^{\circ} \mathrm{C}<\mathrm{T}<134^{\circ} \mathrm{C}$ from

Boublik et al. (1984),

which gives $\mathrm{VP}(\mathrm{kPa})=0.765=$ at $25^{\circ} \mathrm{C}$.

The Antoine equation above proposed by Boublik et al. (1984) for VP versus temperature is plotted below in the temperature range $-10^{\circ} \mathrm{C}<\mathrm{T}<40^{\circ} \mathrm{C}$. 
Recommended value for the temperature range -10 to $40^{\circ} \mathrm{C}$, based on the Antoine equation of Boublik et al. (1984) above:

$$
\operatorname{VP}(\mathrm{kPa})=10^{[6.972-1825 /(232.483+\mathrm{T})]} \pm 0 . ? ? \text { for }-10^{\circ} \mathrm{C}<\mathrm{T}<40^{\circ} \mathrm{C}
$$

Recommended value at $25^{\circ} \mathrm{C}$, based on the mean of the three values above:

$$
\mathrm{VP}(\mathrm{kPa})=0.75 \pm 0.034 @ 25^{\circ} \mathrm{C}
$$

\section{Vapor pressure versus temperature for Cellosolve}

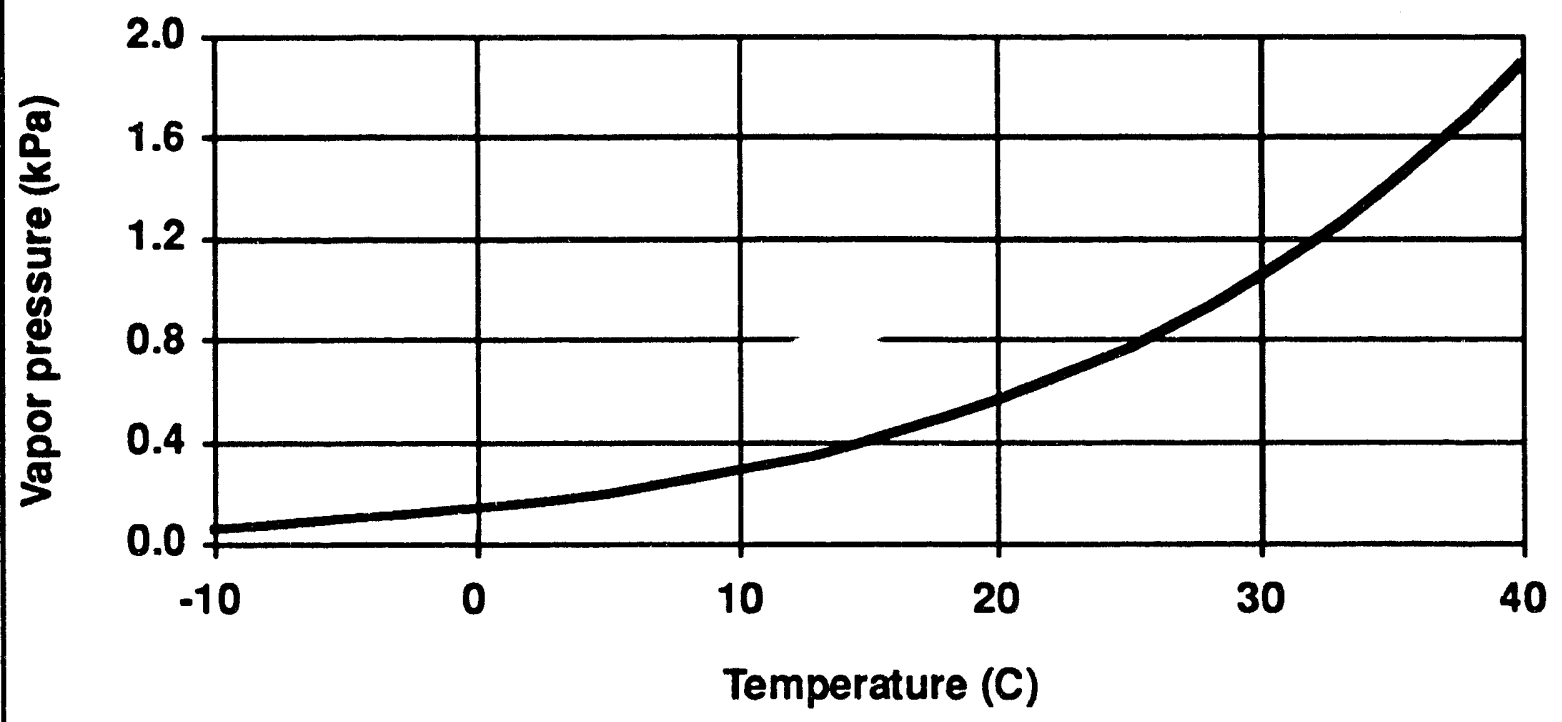

Solubility in water

Miscible with water (Howard et al., 1990; Rowe and Wolf, 1982).

Henry's law constant (dimensionless form)

2.1 based on $5.2 \times 10^{3} \mathrm{~Pa}-\mathrm{m} 3 / \mathrm{mole}$ (or $5.13 \times 10^{3} \mathrm{~atm}-\mathrm{m}^{3} / \mathrm{mole}$ ) reported by Howard et al. (1990). 
Organic-carbon partition coefficient $\left(K_{o c}\right)$

No reported measurements of $\mathrm{K}_{\mathrm{oc}}$ or $\mathrm{K}_{\mathrm{d}}$ for cellosolve in soils or sediments are available in the current literature. With $\mathrm{K}_{\mathrm{ow}}=$ to 0.47 , estimation methods for $\mathrm{K}_{\mathrm{oc}}$ produce the following values for $\mathrm{K}_{\mathrm{oc}}$

16 as derived from the regression equation relating $\mathrm{K}_{\mathrm{oc}}$ to $\mathrm{K}_{\mathrm{ow}}$ in Kenaga and Goring (1980) and referred to in Lyman et al. (1990).

$1,8,0.30,0.21$, and 0.23 as derived from the four regression equations relating $\mathrm{K}_{\mathrm{oc}}$ to $\mathrm{K}_{\mathrm{ow}}$ in Karickhoff (1985).

1.8 as derived from the regression as proposed by Meylan et al (1992) of $\mathrm{K}_{\mathrm{oc}}$ with the molecular connectivity index $\left({ }^{1} \chi=2.91\right)$ and a correction factor of -2.528 for the aliphatic-ether and aliphatic-alcohol $\mathrm{C}-\mathrm{O}$ bonds.

Recommended value, based on the log-mean value of the 6 values reported above:

$$
\begin{aligned}
& \log K_{O C}=-0.02 \pm 0.74 \\
& K_{O C}=0.95 \times \text { or } \div 5.5
\end{aligned}
$$

\section{Diffusion coefficient in water}

Based on the Wilke and Chang (1955) method described in Reid et al. (1987), the diffusion coefficient in $\mathrm{m}^{2} / \mathrm{d}$ in water is given by

$$
D_{x y}=\frac{6.5 \times 10^{-7}\left(\phi M_{\mathrm{y}}\right)^{1 / 2} \mathrm{~T}}{\eta_{\mathrm{y}} V_{\mathrm{x}}^{0.6}} .
$$

The molecular weight $\mathrm{M}_{\mathrm{y}}$ of water is $18 \mathrm{~g} / \mathrm{mol}$. Wilke and Chang (1955) recommend an association factor, $\phi$, of 2.6 when the solvent is water. The viscosity of water, $\eta_{y}$, is $0.89 \mathrm{cP}$ at $25^{\circ} \mathrm{C}$. Molecular volume can be estimated by the LeBas incremental method as described in Lyman et al. (1990). With the molecular volume $V_{x}$ cellosolve equal to $101 \mathrm{~cm}^{3} / \mathrm{mol}$, this expression gives

$$
\begin{aligned}
& \text { Recommended value: } \\
& \mathrm{D}_{\text {water }}=3.1 \times 10^{-7} \mathrm{~T} \mathrm{~m}^{2} / \mathrm{d}=9.3 \times 10^{-5} \mathrm{~m}^{2} / \mathrm{d} \text { or } 1.0 \times 10^{-9} \mathrm{~m}^{2} / \mathrm{s} @ 25^{\circ} \mathrm{C}
\end{aligned}
$$




\section{Diffusion coefficient in air}

Based on the Fuller et al. (1966) method described in Lyman et al. (1990), the diffusion coefficient in $\mathrm{m}^{2} / \mathrm{d}$ in air is given by

$$
D_{\text {air }}=8.6 \times 10^{-3} \mathrm{~T}^{1.75} \frac{\sqrt{\frac{\left(29+\mathrm{M}_{\mathrm{x}}\right)}{29 \mathrm{M}_{\mathrm{x}}}}}{\left[2.7+\left(V_{\mathrm{x}}\right)^{1 / 3}\right]^{2}}
$$

With the molecular volume, $\mathrm{V}_{\mathrm{x}}$, of cellosolve of $101 \mathrm{~cm}^{3} / \mathrm{mol}$ and a molecular weight of $90.1 \mathrm{~g} / \mathrm{mol}$, the above expression gives (with $\mathrm{T}$ in kelvins)

$$
\begin{aligned}
& \text { Recommended value: } \\
& \mathrm{D}_{\text {air }}=3.4 \times 10^{-5} \mathrm{~T}^{1.75} \mathrm{~m}^{2} / \mathrm{d}=0.73 \mathrm{~m}^{2} / \mathrm{d} \text { or } 8.4 \times 10^{-6} \mathrm{~m}^{2} / \mathrm{s} @ 25^{\circ} \mathrm{C}
\end{aligned}
$$

Bioconcentration factors for plant root concentration relative to soil concentration

No reported measurements of plant-root bioconcentration for in soils are available in the current literature. Estimation methods for this parameter are considered below.

The partition factor from surface soil to edible plant parts due to rainsplash, $\mathrm{K}_{\mathrm{ps}}^{\text {rain }}$ is equal to $0.0034 \mathrm{~kg}$ (soil) $/ \mathrm{kg}$ (plant) with a CV of 1 (Dreicer et al. 1984). This partition factor applies plant fresh mass concentration relative to soil concentration.

Based on the Briggs et al. $(1982,1983)$ estimation equation for uptake of contaminants by roots from soil solution, we calculate the RCF (which represents the ratio of contaminant concentration in root, $\mathrm{mg} / \mathrm{kg}$ [fresh mass], to contaminant concentration in soil solution, $\mathrm{mg} / \mathrm{L}$ ) for cellosolve as

$\mathrm{RCF}=0.82+0.03 \mathrm{~K}_{\mathrm{ow}}^{0.77}=0.84$

When this factor is divided by the sorption coefficient, $\mathrm{K}_{\mathrm{d}}=\mathrm{f}_{\mathrm{oc}} \times \mathrm{K}_{\mathrm{oc}}=(0.01$ to $0.02) \times K_{o c}$ (from above), we obtain the ratio of contaminant concentration in roots, $\mathrm{mg} / \mathrm{kg}$ (fresh mass) to contaminant concentration in soil solids, $\mathrm{mg} / \mathrm{kg}$, which we refer to as $K_{p s}$ (roots) and estimate it as being in the range

$$
\mathrm{K}_{\mathrm{ps}}(\text { roots })=44 \text { to } 88 \times \text { or } \div 5.5 \text { (reflecting the error in } \mathrm{K}_{\mathrm{oc}} \text { ) }
$$


Based the regression of $\mathrm{K}_{\mathrm{ps}}$ (roots) with $\mathrm{K}_{\mathrm{oc}}$ from Topp et al. (1986), and based on the range of $\mathrm{K}_{\mathrm{oc}}$ values listed above, we obtain

$$
\begin{aligned}
& \text { (recommended range for root crops) } \\
& \mathrm{K}_{\mathrm{ps}}(\text { roots })=664 \mathrm{~K}_{\mathrm{oc}}^{-0.622}=685 \times \text { or }+5.5 \text { (reflecting the error in } \mathrm{K}_{\mathrm{oc}} \text { ) }
\end{aligned}
$$

Based on the Travis and Arms (1988) correlation for plant-soil bioconcentration we obtain for total plant (not just roots) the following soil/plant partition coefficient

$$
\begin{array}{r}
\left.\mathrm{K}_{\mathrm{ps}}=7.7 \mathrm{~K}_{\mathrm{ow}}^{-0.58}=12 \times \text { or } \div 1.6 \begin{array}{c}
(\text { recommended value for exposed } \\
\text { produce reflecting the error in } \mathrm{K}_{\mathrm{ow}}
\end{array}\right)
\end{array}
$$

Bioconcentration factors for plant leaf concentration relative to air concentration

No reported measurements of plant-air bioconcentration for cellosolve in air are available in the current literature. Estimation methods for this parameter are considered below.

Based on the model of Riederer (1990) for foliar uptake of gases in plant leaves, we estimate a steady-state plant-air coefficient of

$$
\mathrm{K}_{\mathrm{pa}}^{\mathrm{gs}}=\left[0.5+\left(0.4+0.01 \times \mathrm{K}_{\mathrm{ow}}\right) \times \frac{\mathrm{RT}}{\mathrm{H}}\right] \times 10^{-3} \frac{\mathrm{m}^{3}}{\mathrm{~kg}}=0.0013 \text { (recommended value) }
$$

We could find no study in which the estimation error of this partition coefficient has been considered, but we assume the $\mathrm{CV}$ associated with it is on the order of 1 (or GSD=2.3).

Bioconcentration factors for fish concentration relative to water/or sediment concentrations

No information on the bioconcentration factor for cellosolve could be found in the literature. However, based on its $\mathrm{K}_{\mathrm{ow}}$ value, its estimated bioconcentration factor is 0.02 based on the correlation of Mackay (1982).

Steady-state biotransfer factors for milk or dairy-product concentration relative to contaminant intake by cattle

No reported measurements of milk-diet biotransfer for cellosolve are available in the current literature. Estimation methods for this parameter are considered below. 
Based on the geometric mean regression of milk-to-diet biotransfer against $\mathrm{K}_{\mathrm{ow}}$ developed by Travis and Arms (1988) we estimate the milk biotransfer factor for cellosolve as

$$
\mathrm{B}_{\mathrm{k}}=7.9 \times 10^{-9} \mathrm{~K}_{\mathrm{oW}} \times 10^{( \pm 0.84)}=3.7 \times 10^{-9} \times \text { or } \div 7 \text { (recommended value) }
$$

The estimation error in this expression corresponds to a CVs of 6 .

Steady-state biotransfer factors for meat concentration relative to contaminant intake by cattle, pigs, and chickens

No reported measurements of meat-diet biotransfer for cellosolve are available in the current literature. Estimation methods for this parameter are considered below.

Based on the geometric mean regression of meat-to-diet biotransfer against $\mathrm{K}_{\mathrm{ow}}$ developed by Travis and Arms (1988) we estimate the meat biotransfer factor for cellosolve as

$$
B_{t}=2.5 \times 10^{-8} K_{o w} \times 10^{( \pm 0.952)}=1.2 \times 10^{-8} \times \text { or } \div 9 \text { (recommended value) }
$$

The estimation error in this expression corresponds to a CV of 11.

Steady-state biotransfer factors for egg concentration relative to contaminant intake by chickens

No reported measurements of egg-diet biotransfer for cellosolve are available in the current literature. An estimation method value for this parameter is considered below.

Based on the geometric mean regression of egg-to-diet biotransfer against $\mathrm{K}_{\mathrm{ow}}$ developed above, we estimate the egg biotransfer factor for cellosolve as

$$
\mathrm{B}_{\mathrm{e}}=7.9 \times 10^{-6} \mathrm{~K}_{\mathrm{ow}} \times 10^{( \pm 1)}=3.7 \times 10^{-6} \times \text { or } \div 10 \text { (recommended value) }
$$

The estimation error in this expression corresponds to a CV of 14 .

\section{Contaminant biodegradation factors in soil}

Based on experiments by Bogan and Sawyer (1955) Howard et al. (1991) have estimated the half-live of cellosolve in soil due to aerobic biodegradation to be in the range of 7 to 28 days. 
Recommended value, based on log mean and log variance of the range of the soil half lives given above:

$$
\text { Soil biodegradation rate constant }=0.05 \mathrm{~d}^{-1} \times \text { or }+1.5
$$

Media-specific half lives for air, soil, and surface water

Air. Based on measurements of the photooxidation half-life in air by Atkinson (1987), Howard et al. (1991) estimate the half life of cellosolve in the lower atmosphere to be in the range 5.4 to 54 hours ( 0.23 to 2.3 days) with removal from air is due primarily to reaction with hydroxyl radicals and nitrogen dioxides.

Soil Howard et al. (1991) have estimated that cellosolve is not expected to bound to soil tightly. It is expected to leach to ground water and volatilize. Biodegradation may be significant. Their estimate of its half-life in soil is in the range 7 to 28 days due primarily to biodegradation.

Water. When released to water, cellosolve volatilizes rapidly with no estimation of half-life. It may be subject to significant biodegradation (Howard et al., 1991). Its photooxidation half-life in water is on the order of years. Based on aerobic biodegradation, (Howard et al., 1991) estimate the half-life of cellosolve in surface water to be in the range of 7 to 28 days.

Recommended half-lives (in days), based on the log mean of the half lives and geometric range of the values:

$$
\begin{array}{ll}
\text { Air } & 0.73 \times \text { or } \div 1.9 \text { days } \\
\text { Soil } & 14 \times \text { or } \div 3.5 \text { days } \\
\text { Water } & 14 \times \text { or } \div 3.5 \text { days }
\end{array}
$$

\section{References for Cellosolve}

Anbar, M., and P. Neta,(1967), "A compilation of Specific Bimolecular Rate Constants for the Reactions of Hydrated Electrons, Hydrogen Atoms, and Flydrosyl Radicals with Inorganic and Organic compounds in Aqueous Solution," Int. J. of Appl. Radiation and Isotopes 18, 493-523. 
Atkinson, R. (1987), "Structure-Activity Relationship for the Estimation of Rate Constants for the Gas-Phase Reactions of OH Radicals with Organic Compounds," Int. J. Chem. Kinetics 19, 799-828.

Bogan, R.H. and C.N. Sawyer (1955), "Biochemical Degradation of Synthetic Detergents. II. Studies on the Relation between Chemical Structure and Biochemical Oxidation," Sew. Ind. Wastes 27, 917-928.

Boublík, T., Fried, V., and Hála, E. (1984), The Vapour Pressures of Pure Substances: Selected Values of the Temperature Dependence of the Vapour Pressures of Some Pure Substances in the Normal and Low Pressure Region (Second Revised Edition), Physical sciences data; 17 (Elsevier Science Publishers, Amsterdam, The Netherlands).

Briggs, G.G., R.H. Bromilow, and A.A. Evans (1982), "Relationships Between Lipophilicity and Root Uptake and Translocation of Non-Ionized Chemicals by Barley," Pestic. Sci. 13, 495-504.

Briggs, G.G., R.H. Bromilow, A.A. Evans, and M. Williams (1983), "Relationships Between Lipophilicity and the Distribution of Non-Ionized Chemicals in Barley Shoots Following Uptake by the Roots," Pestic. Sci. 14, 492-500.

Collander, R. (1951), ACTA Chem. Scandin. 5, 774.

Dow Chemical Company (1981), The Glycol Ethers Handbook, (Dow Chemical Company, Midland MI).

Dreicer, M., T.E. Hakonson, G.C. White, and F.W. Whicker (1984), "Rainsplash as a Mechanism for Soil Contamination of Plant Surfaces," Health Phys. 46, 177-187.

Fuller, E.N., P.D. Schettler, and J.C. Giddings (1966), "A New Method for Prediction of Binary Gas-Phase Diffusion Coefficients," Ind. Eng. Chem. 58, 19-27.

Funasaki, N., S. Hada, S. Neya, and K. Machida (1984), "Intramolecular Hydrophobic Association of Two Alkyl Chains of Oligoethylene Glycol Diethers and Diesters in Water," J. Phys. Chem. 88, 5786-5790.

Hansch, C., and A. Leo (1987), "The Log P and Related Parameters Database," created and updated by the Medicinal Chemistry Project at Pomona College, Claremont, CA, under the direction of Corwin Hansch and Albert Leo - 1987 Printout.

Hine, J. and P.K. Mookerjee (1975), "The Intrinsic Hydrophilic Character of Organic Compounds. Correlations in Terms of Structural Contributions," J. Org. Chem. 40, 292-298.

Howard, P.H., G.W. Sage, W.F. Jarvis, and D.A. Gray, Eds. (1990), Handbook of Environmental Fate and Exposure Data for Organic Chemicals. Volume II. Solvents (Lewis Publishers, Inc., Chelsea, MI). 
IPCS (1990), International Programme on Chemical Safety Environmental Health, Criteria 115, 2-Methoxyethanol, 2-Ethoxyethanol, and their Acetates, International Programme on Chemical Safety Environmental Health.

Karickhoff, S.W. (1985), "Chapter 3. Pollutant Sorption in Environmental Systems," in Environmental Exposure From Chemicals, Volume I., W. B. Neely and G.E. Blau, Eds. (CRC Press, Inc., Boca Raton, FL), pp. 49-64.

Kenaga, E. E., and C.A.I. Goring (1980), "Relationship Between Water Solubility, Soil Sorption, Octanol-Water Partitioning, and Concentration of Chemicals in Biota," in Aquatic Toxicology, ASTM STP 707, J. G. Eaton, P. R. Parrish, and A. C. Hendricks, Eds. (American Society for Testing and Materials, Philadelphia, PA) pp. 78-115.

Korenman and Udalova (1974), cited in Hansch and Leo (1987), full citation not available.

Lyman, W. J., W. F. Reehl, and D. H. Rosenblatt (1990), Handbook of Chemical Property Estimation Methods: Environmental Behavior of Organic Compounds (American Chemical Society, Washington, DC).

Mackay, D. (1982), "Correlation of Bioconcentration Factors," Environ. Sci. Technol. 16, 274-278.

Meylan, W., P.H. Howard, and R.S. Boethling (1992), "Molecular Topology/Fragment Contribution Method for Predicting Soil Sorption Coefficients," Environ. Sci. Technol. 26, 1560-1567.

Reid, R. C., J. M. Prausnitz, and B. E. Poling (1987), The Properties of Gases and Liquids (McGraw Hill, New York City, NY), 4th ed.

Reiderer, M. (1990), "Estimating Partitioning and Transport of Organic Chemicals in the Foliage/Atmosphere System: Discussion of a Fugacity-Based Model," Environ. Scil. Technol. 24, 829-837.

Rowe, V.K., and M.A. Wolf (1982), "Derivatives of Glycols," in G.D. Clayton and F.E. Clayton Eds., Patty's Industrial Hygiene Toxicology, Vol 2C, Third Revised Edition, (John Wiley and Sons, New York, p. 3912).

Topp, E., I. Scheunert, A. Attar, and F. Korte (1986), "Factors Affecting the Uptake of 14C-Labeled Organic Chemicals by Plants From Soil," Ecotoxicol. Environ. Saf. 11, 219-228.

Travis, C. C., and A. D. Arms (1988), "Bioconcentration of Organics in Beef, Milk, and Vegetation," Environ. Sci. Technol. 22, 271-274.

Verschueren, K. (1983), Handbook of Environmental Data on Organic Chemicals, Second Edition (Van Nostrand Reinhold Company Inc., New York City, NY).

Weast, R. C., M. J. Astle, and W. H. Beyer, Eds. (1986), CRC Handbook of Chemistry and Physics: A Ready Reference Book of Chemical and Physical Data, 67th Edition (CRC Press, Inc., Boca Raton, FL). 
Wilke, C.R., and P. Chang (1955), "Correlation of Diffusion Coefficients in Dilute Solutions," AIChE J. 1, 264-270.

Windholz, M., S. Budavari, R. F. Blumetti, and E. S. Otterbein, Eds. (1983), The Merck Index: An Encyclopedia of Chemicals, Drugs, and Biologicals, 10th Edition (Merck \& Co., Inc., Rahway, NJ). 


\section{Cellosolve Acetate}

Other names: Ethoxyethyl acetate, B-ethoxyethyl acetate, 2-ethoxyethyl acetate, ethyl cellosolve acetate, ethylene glycol ethyl ether acetate, ethylene glycol monoethyl ether acetate, glycol monoethyl ether acetate, oxytol acetate, poly-solve EE.

\section{CAS Registry Number: 111-15-9}

Cellosolve acetate is directly released into the atmosphere through its use as a solvent for surface coatings (especially the epoxy-resins based ones). It is also used as a solvent in cleaning and printing ink formulations, in coating applications for automobile, coils, machinery and equipment, and metal furniture and appliances.

Formula: $\mathrm{C}_{6} \mathrm{H}_{12} \mathrm{O}_{3}$

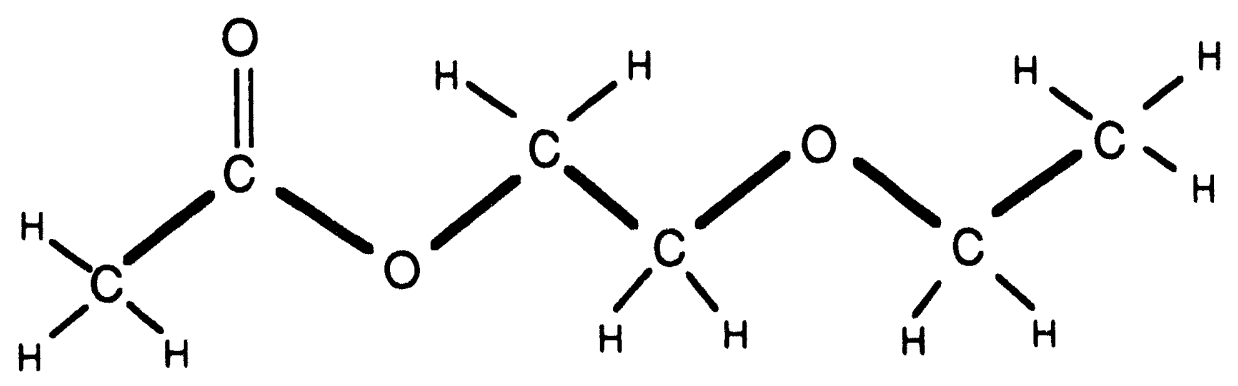

Molecular weight

132.16 (Howard et al., 1993; Windholz et al., 1983)

Recommended molecular weight for cellosolve acetate: $\quad 132.2$

\section{Melting Point}

$-61.7^{\circ} \mathrm{C}$ (Howard et al., 1993)

Octanol-water partition coefficient $\left(K_{o w}\right)$

3.16 derived from a $\log K_{o w}$ of 0.5 reported by Montgomery (1991) based on the methods of Leo et al. (1971).

4.47 derived from a $\log \mathrm{K}_{\mathrm{ow}}$ of 0.65 reported by Howard (1993) based on the value estimated using the U.S. Environmental Protection Agency computer program CLOPG with in the Graphical Exposure Modeling System (GEMS), 1986 version. 
Recommended value, based on the log-mean value of the 2 values reported above:

$\log \mathrm{K}_{\mathrm{ow}}=0.58 \pm 0.11$

Kow $=3.8 \times$ or +1.3

Vapor pressure at standard temperatures

159.9 Pa based on a VP of $1.2 \mathrm{~mm} \mathrm{Hg}$ at $20^{\circ} \mathrm{C}$ reported by Montgomery (1991) based value reported by Sax and Lewis (1987).

159.9 Pa based on a VP of $1.2 \mathrm{~mm} \mathrm{Hg}$ at $20^{\circ} \mathrm{C}$ reported in Verschueren (1983).

159.9 $\mathrm{Pa}$ based on a VP of $1.2 \mathrm{~mm} \mathrm{Hg}$ at $20^{\circ} \mathrm{C}$ reported by Rowe and Wolf (1982).

$219.9 \mathrm{~Pa}$ based on a VP of $1.65 \mathrm{~mm} \mathrm{Hg}$ at $20^{\circ} \mathrm{C}$ reported in Howard et al. (1993) and attributed to Daubert and Danner (1989).

266.6 Pa based on a VP of $2 \mathrm{~mm} \mathrm{Hg}$ at $20^{\circ} \mathrm{C}$ reported by Montgomery (1991) based a report from NIOSH (1987).

373.2 $\mathrm{Pa}$ based on a VP of $2.8 \mathrm{~mm} \mathrm{Hg}$ at $25^{\circ} \mathrm{C}$ reported by Rowe and Wolf (1982).

506.6 Pa based on a VP of $3.8 \mathrm{~mm} \mathrm{Hg}$ at $30^{\circ} \mathrm{C}$ reported by Verschueren(1983).

$101,324 \mathrm{~Pa}$ based on the boiling point of $156^{\circ} \mathrm{C}$ reported by Howard (1993).

The values reported above were fit to an Antoine equation in order to interpolate the vapor pressure of cellosolve acetate at environmental temperatures in the range -10 to $40^{\circ} \mathrm{C}$. The results of this fit are plotted below. This curve gives $\mathrm{VP}=282 \mathrm{~Pa}$ at $25^{\circ} \mathrm{C}$.

Recommended vapor pressure based on the Antoine equation interpolation from the data above:

$$
\mathrm{VP}=282 \pm 65 \mathrm{~Pa} @ 25^{\circ} \mathrm{C}
$$




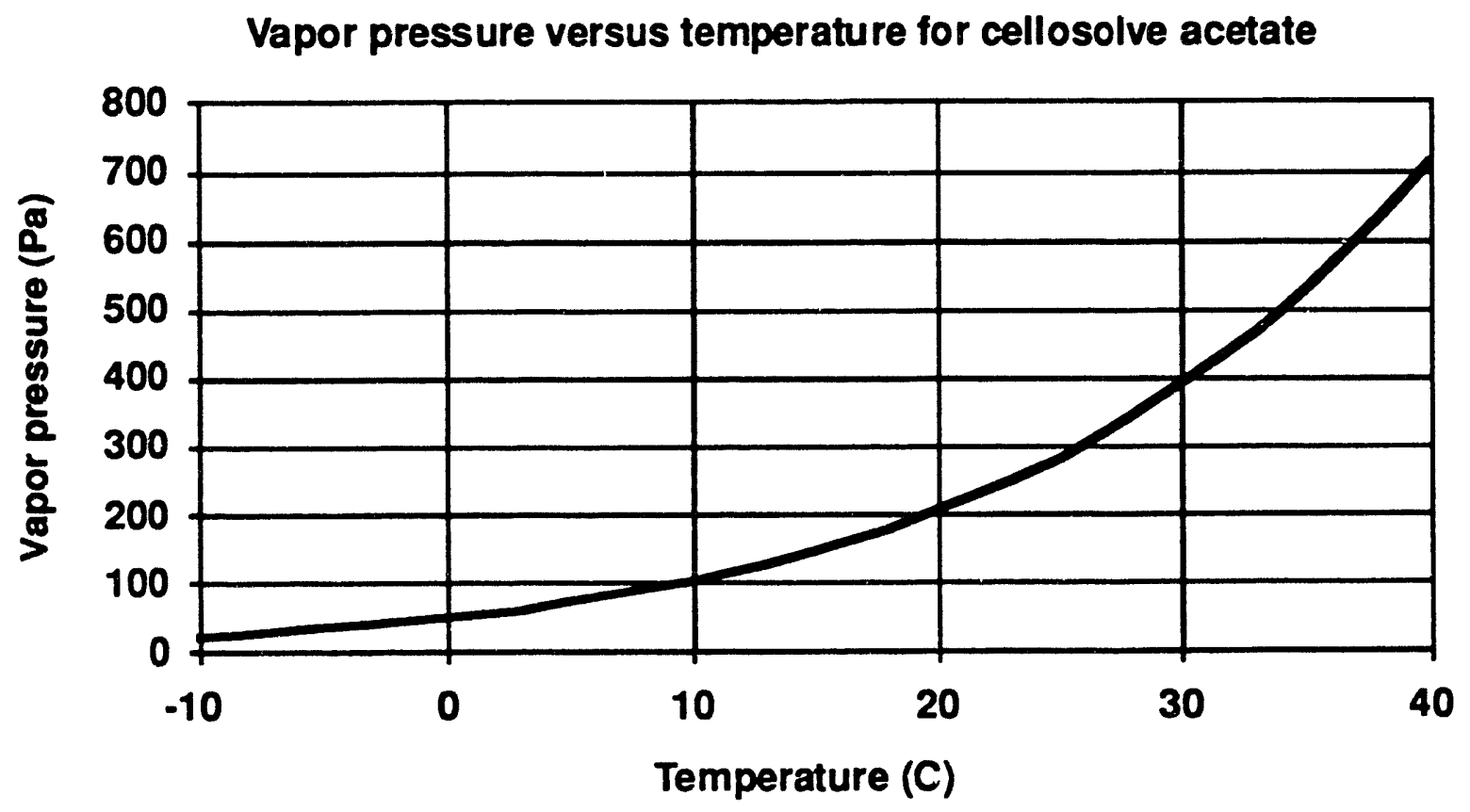

Solıbility in water

$229,000 \mathrm{mg} / \mathrm{L}$ at $20^{\circ} \mathrm{C}$ reported by Howard et al (1993), based on a value reported by Riddick et al. (1984)

$142,857 \mathrm{mg} / \mathrm{L}$ based on solubility of 1 in 6 parts of water at an unspecified temperature reported by the Merck Index (Windholz et al. 1983).

Recommended solubility based on the mean range and variance of the 2 values reported above:

$$
W S=185,000 \pm 25,000 \mathrm{mg} / \mathrm{L}
$$

Henry's law constant (dimensionless form)

$5.4 \times 10^{-5}$ based on $1.3 \times 10^{-1} \mathrm{~Pa}-\mathrm{m} 3 / \mathrm{mole}$ (or $1.25 \times 10^{-6} \mathrm{~atm}-\mathrm{m}^{3} / \mathrm{mole}$ ) at $20^{\circ} \mathrm{C}$ calculated from the ratio of vapor pressure to solubility by Howard et al. (1993).

$3.8 \times 10^{-5}$ based on $9.2 \times 10^{-2} \mathrm{~Pa}-\mathrm{m} 3 /$ mole (or $9.07 \times 10^{-7} \mathrm{~atm} \mathrm{~m} / \mathrm{mole}$ ) at $20^{\circ} \mathrm{C}$ reported by Montgomery (1991).

$8.1( \pm 2.2) \times 10^{-5}$ at $25^{\circ} \mathrm{C}$ based on the mean and standard deviation of vapor pressure and solubility recommended above and the variance propagation in the expression $\mathrm{H}=\mathrm{VP} /(\mathrm{WS} \mathrm{R} T)$. 
Recommended Henry's law value based on the $\mathrm{H}$ value calculated above at $25^{\circ} \mathrm{C}$ :

$$
\mathrm{H} /(\mathrm{RT})=8.1( \pm 2.2) \times 10^{-5} \text { at } 25^{\circ} \mathrm{C}
$$

Organic-carbon partition coefficient $\left(K_{o c}\right)$

No reported measurements of $\mathrm{K}_{\mathrm{oc}}$ or $\mathrm{K}_{\mathrm{d}}$ for cellosolve acetate in soils or sediments are available in the current literature. With $\mathrm{K}_{\mathrm{ow}}=3.8\left(\log \mathrm{K}_{\mathrm{ow}}=0.58\right)$ and $W S=185,000 \mathrm{mg} / \mathrm{L}$, estimation methods for $\mathrm{K}_{\mathrm{oc}}$ produce the following values for $\mathrm{K}_{\mathrm{oc}}$

49 as derived from the regression equation relating $\mathrm{K}_{\mathrm{oc}}$ to $\mathrm{K}_{\mathrm{ow}}$ in Kenaga and Goring (1980) and referred to in Lyman et al. (1990).

$8.1,3.7,1.7$, and 1.8 as derived from the four regression equations relating $\mathrm{K}_{\mathrm{oc}}$ to $\mathrm{K}_{\mathrm{ow}}$ in Karickhoff (1985).

7.1 as derived from the regression of $\mathrm{K}_{\mathrm{oc}}$ with water solubility proposed by Chiou et al. (1977)

5.5 as derived from the regression of $\mathrm{K}_{\mathrm{oc}}$ with water solubility proposed by Kenaga (1980)

2.4 as derived from the regression as proposed by Meylan et al (1992) of $\mathrm{K}_{\mathrm{oc}}$ with the molecular connectivity index $\left({ }^{1} \chi=4.4\right)$ and a correction factor of -2.573 for the one aliphatic-ether and one aliphatic-ester $\mathrm{C}-\mathrm{O}$ bonds .

Recommended value, based on the log-mean value of the 8 values reported above:

$$
\begin{aligned}
& \log K_{o C}=0.70 \pm 0.48 \\
& K_{o C}=5.0 \times \text { or } \div 3.0
\end{aligned}
$$

\section{Diffusion coefficient in water}

Based on the Wilke and Chang (1955) method described in Reid et al. (1987), the diffusion coefficient in $\mathrm{m}^{2} / \mathrm{d}$ in water is given by

$$
D_{\mathrm{xy}}=\frac{6.5 \times 10^{-7}\left(\phi M_{\mathrm{y}}\right)^{1 / 2} \mathrm{~T}}{\eta_{\mathrm{y}} V_{\mathrm{x}}^{0.6}} \text {. }
$$


The molecular weight $\mathrm{M}_{\mathrm{y}}$ of water is $18 \mathrm{~g} / \mathrm{mol}$. Wilke and Chang (1955) recommend an association factor, $\phi$, of 2.6 when the solvent is water. The viscosity of water, $\eta_{y}$, is $0.89 \mathrm{cP}$ at $25^{\circ} \mathrm{C}$. Molecular volume can be estimated by the LeBas incremental method as described in Lyman et al. (1990). With the molecular volume $V_{x}$ cellosolve acetate equal to $163 \mathrm{~cm}^{3} / \mathrm{mol}$, this expression gives

Recommended value:

$$
D_{\text {water }}=2.4 \times 10^{-7} \mathrm{~T} \mathrm{~m}^{2} / \mathrm{d}=7.0 \times 10^{-5} \mathrm{~m}^{2} / \mathrm{d} \text { or } 8.1 \times 10^{-10} \mathrm{~m}^{2} / \mathrm{s} @ 25^{\circ} \mathrm{C}
$$

\section{Diffusion coefficient in air}

Based on the Fuller et al. (1966) method described in Lyman et al. (1990), the diffusion coefficient in $\mathrm{m}^{2} / \mathrm{d}$ in air is given by

$$
D_{\text {air }}=8.6 \times 10^{-3} \mathrm{~T}^{1.75} \frac{\sqrt{\frac{\left(29+\mathrm{M}_{\mathrm{x}}\right)}{29 \mathrm{M}_{\mathrm{x}}}}}{\left[2.7+\left(V_{\mathrm{x}}\right)^{1 / 3}\right]^{2}}
$$

With the molecular volume, $V_{x}$, of cellosolve acetate of $163 \mathrm{~cm}^{3} / \mathrm{mol}$ and a molecular weight of $132.2 \mathrm{~g} / \mathrm{mol}$, the above expression gives (with $\mathrm{T}$ in kelvins)

Recommended value:

$$
D_{\text {air }}=2.6 \times 10^{-5} \mathrm{~T}^{1.75} \mathrm{~m}^{2} / \mathrm{d}=0.57 \mathrm{~m}^{2} / \mathrm{d} \text { or } 6.5 \times 10^{-6} \mathrm{~m}^{2} / \mathrm{s} \text { at } 25^{\circ} \mathrm{C}
$$

Bioconcentration factors for plant root concentration relative to soil concentration

No reported measurements of plant-root bioconcentration for in soils are available in the current literature. Estimation methods for this parameter are considered below.

The partition factor from surface soil to edible plant parts due to rainsplash, $\mathrm{K}_{\mathrm{ps}}^{\text {rain }}$ is equal to $0.0034 \mathrm{~kg}$ (soil) $/ \mathrm{kg}$ (plant) with a CV of 1 (Dreicer et al. 1984). This partition factor applies plant fresh mass concentration relative to soil concentration. 
Based on the Briggs et al. $(1982,1983)$ estimation equation for uptake of contaminants by roots from soil solution, we calculate the RCF (which represents the ratio of contaminant concentration in root, $\mathrm{mg} / \mathrm{kg}$ [fresh mass], to contaminant concentration in soil solution, $\mathrm{mg} / \mathrm{L}$ ) for cellosolve acetate as

$\mathrm{RCF}=0.82+0.03 \mathrm{~K}_{\mathrm{ow}}^{0.77}=0.90$

When this factor is divided by the sorption coefficient, $\mathrm{K}_{\mathrm{d}}=\mathrm{f}_{\mathrm{oc}} \times \mathrm{K}_{\mathrm{oc}}=(0.01$ to $0.02) \times \mathrm{K}_{\mathrm{oc}}$ (from above), we obtain the ratio of contaminant concentration in roots, $\mathrm{mg} / \mathrm{kg}$ (fresh mass) to contaminant concentration in soil solids, $\mathrm{mg} / \mathrm{kg}$, which we refer to as $K_{p s}$ (roots) and estimate it as being in the range

$$
\mathrm{K}_{\mathrm{ps}}\left(\text { roots) }=9.0 \text { to } 18 \times \text { or } \div 3 \text { (reflecting the error in } \mathrm{K}_{\mathrm{oc}}\right. \text { ) }
$$

Based the regression of $K_{p s}$ (roots) with $K_{o c}$ from Topp et al. (1986), and based on the range of $\mathrm{K}_{\mathrm{oc}}$ values listed above, we obtain

$$
\begin{aligned}
& \text { (recommended range for root crops) } \\
& \mathrm{K}_{\mathrm{ps}} \text { (roots) }=664 \mathrm{~K}_{\mathrm{oc}}^{-0.622}=240 \times \text { or } \div 3 \quad \text { (reflecting the error in } \mathrm{K}_{\mathrm{oc}} \text { ) }
\end{aligned}
$$

Based on the Travis and Arms (1988) correlation for plant-soil bioconcentration we obtain for total plant (not just roots) the following soil/plant partition coefficient

$$
\begin{aligned}
\mathrm{K}_{\mathrm{ps}}=7.7 \mathrm{~K}_{\mathrm{ow}}^{-0.58}=3.5 \times \text { or } \div 5.4 & \left.\begin{array}{l}
\text { (recommended value for exposed } \\
\text { produce reflecting the error in } \mathrm{K}_{\mathrm{ow}}
\end{array}\right)
\end{aligned}
$$

Bioconcentration factors for plant leaf concentration relative to air concentration

No reported measurements of plant-air bioconcentration for cellosolve acetate in air are available in the current literature. Estimation methods for this parameter are considered below.

Based on the model of Riederer (1990) for foliar uptake of gases in plant leaves, we estimate a steady-state plant-air coefficient of

$$
\mathrm{K}_{\mathrm{pa}}^{\mathrm{gs}}=\left[0.5+\left(0.4+0.01 \times \mathrm{K}_{\mathrm{ow}}\right) \times \frac{\mathrm{RT}}{\mathrm{H}}\right] \times 10^{-3} \frac{\mathrm{m}^{3}}{\mathrm{~kg}}=5.4 \text { (recommended value) }
$$


We could find no study in which the estimation error of this partition coefficient has been considered, but we assume the $\mathrm{CV}$ associated with it is on the order of 1 (or GSD=2.3).

Bioconcentration factors for fish concentration relative to water/or sediment concentrations

No information on the bioconcentration factor for cellosolve acetate could be found in the literature. However, based on its $\mathrm{K}_{\mathrm{ow}}$ value, its estimated bioconcentration factor is 0.182 based on the correlation of Mackay (1982). This value is so low as to indicate no bioconcentration. No BCF other than unity is recommended

Steady-state biotransfer factors for milk or dairy-product concentration relative to contaminant intake by cattle

No reported measurements of milk-diet biotransfer for cellosolve acetate are available in the current literature. Estimation methods for this parameter are considered below.

Based on the geometric mean regression of milk-to-diet biotransfer against $\mathrm{K}_{\mathrm{ow}}$ developed by Travis and Arms (1988) we estimate the milk biotransfer factor for cellosolve acetate as

$$
\mathrm{B}_{\mathrm{k}}=7.9 \times 10^{-9} \mathrm{~K}_{\mathrm{oW}} \times 10^{( \pm 0.84)}=3.0 \times 10^{-8} \times \text { or } \div 7 \text { (recommended value) }
$$

The estimation error in this expression corresponds to a CVs of 6.

Steady-state biotransfer factors for meat concentration relative to contaminant intake by cattle, pigs, and chickens

No reported measurements of meat-diet biotransfer for cellosolve acetate are available in the current literature. Estimation methods for this parameter are considered below.

Based on the geometric mean regression of meat-to-diet biotransfer against $\mathrm{K}_{\mathrm{ow}}$ developed by Travis and Arms (1988) we estimate the meat biotransfer factor for 1,3-butadiene as

$$
\mathrm{B}_{\mathrm{t}}=2.5 \times 10^{-8} \mathrm{~K}_{\mathrm{ow}} \times 10^{( \pm 0.952)}=9.5 \times 10^{-8} \times \text { or } \div 9 \text { (recommended value) }
$$

The estimation error in this expression corresponds to a CV of 11. 
Steady-state biotransfer factors for egg concentration relative to contaminant intake by chickens

No reported measurements of egg-diet biotransfer for cellosolve acetate are available in the current literature. An estimation method value for this parameter is considered below.

Based on the geometric mean regression of egg-to-diet biotransfer against $\mathrm{K}_{\mathrm{ow}}$ developed above, we estimate the egg biotransfer factor for cellosolve acetate as

$$
\mathrm{B}_{\mathrm{e}}=7.9 \times 10^{-6} \mathrm{~K}_{\mathrm{ow}} \times 10^{( \pm 1)}=3.0 \times 10^{-5} \times \text { or }+10 \text { (recommended value) }
$$

The estimation error in this expression corresponds to a CV of 14 .

Contaminant biodegradation factors in soil

Howard et al. (1993) report that cellosolve acetate is readily biodegradable in soils. They indicate that its half-life in soil is on the order of days. However, since there is a lack of substantive data on biodegradation, we provide here no recommended value.

Media-specific half lives for air, soil, and surface water

Air. Howard et al. (1993) estimate the half life of cellosolve acetate in lower atmosphere is on the order of about 1.2 days due primarily to photochemical reaction with hydroxyl radicals.

Soil Howard et al. (1993) report that cellosolve acetate is readily biodegradable in soils with half-life in soil is on the order of days. Since there is a lack of substantive data on biodegradation, we provide here no recommended value.

Water. Howard et al. (1993) report that cellosolve acetate is also readily biodegradable in surface waters with a half-life in water on the order of days. Volatilization from water is slow. Since there is a lack of substantive data on these removal rates, we give no recommended value.

Recommended half-lives (in days):

Air $\quad 1.2$ days

Soil no recommended value

Water no recommended value 


\section{References for Cellosolve Acetate}

Atkinson, R. (1987), "Structure-Activity Relationship for the Estimation of Rate Constants for the Gas-Phase Reactions of OH Radicals with Organic Compounds," Int. J. Chem. Kinetics 19, 799-828.

Briggs, G.G., R.H. Bromilow, and A.A. Evans (1982), “Relationships Between Lipophilicity and Root Uptake and Translocation of Non-Ionized Chemicals by Barley," Pestic. Sci. 13, 495-504.

Briggs, G.G., R.H. Bromilow, A.A. Evans, and M. Williams (1983), "Relationships Between Lipophilicity and the Distribution of Non-Ionized Chemicals in Barley Shoots Following Uptake by the Roots," Pestic. Sci. 14, 492-500.

Chiou, C. T., V. H. Freed, D.W. Schmedding, and R. L. Kohnert (1977), "Partition Coefficient and Bioaccumulation of Selected Organic Chemicals," Environ. Sci. Technol. 11(5), 475-478.

Daubert, T.E., and R.P. Danner (1989), Physical and Thermodynamic Properties of Pure Chemicals: Data Compilation, Design Institute for Physical Property Data, American Institute of Chemical Engineers, (Hemisphere Pub. Corp., New York)

Dreicer, M., T.E. Hakonson, G.C. White, and F.W. Whicker (1984), "Rainsplash as a Mechanism for Soil Contamination of Plant Surfaces," Health Phys. 46, 177-187.

Fuller, E.N., P.D. Schettler, and J.C. Giddings (1966), "A New Method for Prediction of Binary Gas-Phase Diffusion Coefficients," Ind. Eng. Chem. 58, 19-27.

Howard, P.H., G.W. Sage, W.F. Jarvis, and D.A. Gray, Eds. (1993), Handbook of Environmental Fate and Exposure Data for Organic Chemicals. Volume IV. Solvents (Lewis Publishers, Inc., Chelsea, MI).

Karickhoff, S.W. (1985), "Chapter 3. Pollutant Sorption in Environmental Systems," in Environmental Exposure From Chemicals, Volume I., W. B. Neely and G.E. Blau, Eds. (CRC Press, Inc., Boca Raton, FL), pp. 49-64.

Kenaga, E. E. (1980), "Predicted Bioconcentration Factors and Soil Sorption Coefficients of Pesticides and Other Chemicals," Ecotoxicol. Environ. Saf. 4, 26-38.

Kenaga, E. E., and C.A.I. Goring (1980), "Relationship Between Water Solubility, Soil Sorption, Octanol-Water Partitioning, and Concentration of Chemicals in Biota," in Aquatic Toxicology, ASTM STP 707, J. G. Eaton, P. R. Parrish, and A. C. Hendricks, Eds. (American Society for Testing and Materials, Philadelphia, PA) pp. 78-115.

Leo, A., C. Hansch, and D. Elkins (1971), "Partition Coefficients and their Uses," Chem. Rev. 71(6) 525-616.

Lyman, W. J., W. F. Reehl, and D. H. Rosenblatt (1990), Handbook of Chemical Property Estimation Methods: Environmental Behavior of Organic Compounds (American Chemical Society, Washington, DC). 
Mackay, D. (1982), "Correlation of Bioconcentration Factors," Environ. Sci. Technol. $16,274-278$.

Montgomery, J.H. (1991), Groundwater Chemicals Desk Reference Vol 2, (Lewis Publishers, Chelsea, Michigan).

Meylan, W., P.H. Howard, and R.S. Boethling (1992), "Molecular

Topology/Fragment Contribution Method for Predicting Soil Sorption Coefficients," Environ. Sci. Technol. 26, 1560-1567.

National Institute for Occupational Safety and Health (NIOSH) (1987), "NIOSH Pocket Guide to Chemical Hazards" US Department of Health and Human Services, US Government Printing Office.

Ridick, J.A. et al., (1984), Organic Solvents, (John Wiley and Sons Inc., New York)

Reid, R. C., J. M. Prausnitz, and B. E. Poling (1987), The Properties of Gases and Liquids (McGraw Hill, New York City, NY), 4th ed.

Reiderer, M. (1990), "Estimating Partitioning and Transport of Organic Chemicals in the Foliage/Atmosphere System: Discussion of a Fugacity-Based Model," Environ. Scil. Technol. 24, 829-837.

Rowe, V.K., and M.A. Wolf (1982), "Derivatives of Glycols," in G.D. Clayton and F.E. Clayton Eds., Patty's Industrial Hygiene Toxicology, Vol 2C, Third Revised Edition, (John Wiley and Sons, New York).

Sax, N.I., and R.J. Lewis Sr. (1989), Dangerous Properties of Industrial Materials Seventh Edition Vol II, (Van Nostrand Reinhold, New York).

Topp, E., I. Scheunert, A. Attar, and F. Korte (1986), "Factors Affecting the Uptake of 14C-Labeled Organic Chemicals by Plants From Soil," Ecotoxicol. Environ. Saf. 11, 219-228.

Travis, C. C., and A. D. Arms (1988), "Bioconcentration of Organics in Beef, Milk, and Vegetation," Environ. Sci. Technol. 22, 271-274.

Verschueren, K. (1983), Handbook of Environmental Data on Organic Chemicals, Second Edition (Van Nostrand Reinhold Company Inc., New York City, NY).

Wilke, C.R., and P. Chang (1955), "Correlation of Diffusion Coefficients in Dilute Solutions," AIChE J. 1, 264-270.

Windholz, M., S. Budavari, R. F. Blumetti, and E. S. Otterbein, Eds. (1983), The Merck Index: An Encyclopedia of Chemicals, Drugs, and Biologicals, 10th Edition (Merck \& Co., Inc., Rahway, NJ). 


\section{Chloroform}

Other names: Trichloromethane

CAS Registry Number: 67-66-3

Chloroform is released to air and water from its many uses as a solvent, bleaching agent, and intermediate chemical in manufacturing and consumer uses. Chloroform is used as a solvent for fats, oils, rubber, alkaloids, and waxes. It is used in the manufacture of fluorocarbon refrigerants and propellants and plastics. Also in manufacturing it is a primary source for chlorodifluromethane. It has been used as an anesthetic and in the manufacture of anesthetics and pharmaceuticals. Chloroform is also used as a fumigant, sweeter, and fire extinguisher. It is released to air from paper mills where it is used in the bleaching process. Chloroform is also an unavoidable by-product of the chlorination of water containing organic materials and is thus found in many water supplies throughout the U.S.

Formula: $\mathrm{C} \mathrm{Cl}_{3} \mathrm{H}$

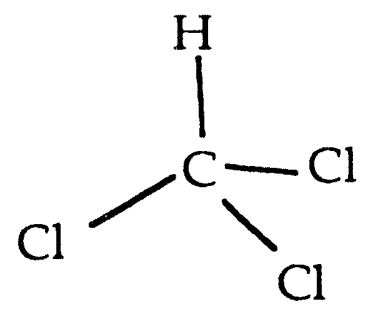

Molecular weight

119.39 (Howard et al., 1990; Windholz et al., 1983)

119.38 (Weast et al., 1986; Verschueren, 1983)

Melting Point

$-64{ }^{\circ} \mathrm{C}$ (Verschueren, 1983)

$-63.5^{\circ} \mathrm{C}$ (Howard et al., 1990; Windholz et al., 1983)

Octanol-water partition coefficient $\left(K_{o w}\right)$

93.3 corresponding to a $\log \mathrm{K}_{\mathrm{ow}}$ of 1.97 reported by Hansch and Leo (1987) and by Leo et al. (1971) based on a value published in Hansch and Anderson (1967). This value is cited in Verschueren (1983) and in Howard et al. (1990). 
87.1 corresponding to a $\log \mathrm{K}_{\mathrm{ow}}$ of 1.94 reported by Hansch and Leo (1987) based on a value published by Schauman (1938). This value was also reported by Hansch and Leo (1987) as obtained from unpublished measurements by Hansch and his colleagues.

79.4 measured by Banerjee et al. (1980) who report the standard deviation of the measurement error as $\pm 0.9 \%$ (which corresponds to an absolute error of \pm 0.7 ). This measurement is also cited by Hansch and Leo (1987) as a $\log \mathrm{K}_{\mathrm{ow}}$ of 1.90 .

Recommended value, based on the log-mean value of the 3 measured values reported above:

$$
\begin{aligned}
& \log \mathrm{K}_{\mathrm{ow}}=1.94 \pm 0.035 \\
& \mathrm{~K}_{\mathrm{ow}}=87 \times \text { or } \div 1.1
\end{aligned}
$$

\section{Vapor pressure at standard temperatures}

The Merck Index (Windholz et al., 1983) reports the boiling point of chloroform as $59^{\circ} \mathrm{C}$

Stull (1947) reports the following vapor pressures (VPs) for chloroform.

$\begin{array}{ccc}\text { Temperature }(\mathrm{C}) & \text { Vapor Pressure }(\mathrm{mm}) & \text { Vapor Pressure }(\mathrm{kPa}) \\ 0.5 & 60 & 8.0 \\ 10.4 & 100 & 13 \\ 25.9 & 200 & 26 \\ 42.7 & 400 & 53 \\ 61.3 & 760 & 101\end{array}$

Interpolating from this data gives $\mathrm{VP}$ at $25^{\circ} \mathrm{C}=25.9 \mathrm{kPa}$

Verschueren (1983) reports the following vapor pressures for chloroform.

Temperature (C) Vapor Pressure (mm) Vapor Pressure (kPa)

20 160

21

30

245

33

62

760

101

Interpolating from this data give VP at $25^{\circ} \mathrm{C}=26.5 \mathrm{kPa}$ 
The following Antoine equations have been published for estimating the vapor pressure of chloroform in $\mathrm{kPa}$

$$
\log _{10}(\mathrm{VP})=6.079-\frac{1171}{226.2+\mathrm{T}} \text { for }-10^{\circ} \mathrm{C}<\mathrm{T}<60^{\circ} \mathrm{C} \text { from Boublik et al. (1984) }
$$

which gives $\mathrm{VP}=26.1 \mathrm{kPa}$ at $25^{\circ} \mathrm{C}$, and

$$
\log _{10}(\mathrm{VP})=5.618-\frac{929.44}{196.03+\mathrm{T}} \text { for }-35^{\circ} \mathrm{C}<\mathrm{T}<61^{\circ} \mathrm{C} \text { from Dean (1985) }
$$

which gives $\mathrm{VP}=25.9 \mathrm{kPa}$ at $25^{\circ} \mathrm{C}$.

The Antoine equation above proposed by Boublik et al. (1984) for VP versus temperature is plotted below.

\section{Vapor pressure versus temperature for chloroform}

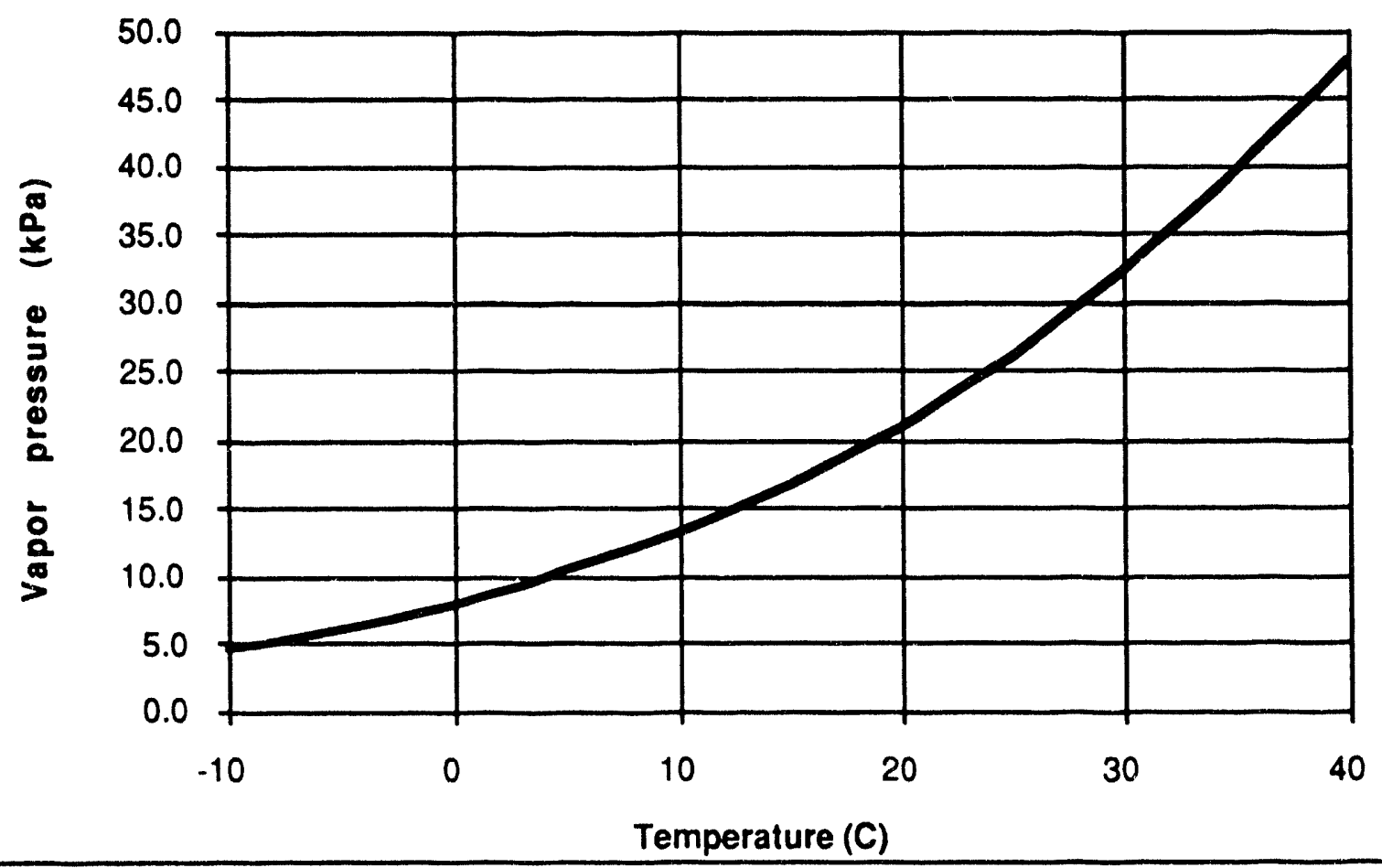


Recommended value for the temperature range -10 to $60^{\circ} \mathrm{C}$, based on the Antoine equation of Boublik et al. (1984) above:

$$
\begin{aligned}
& \mathrm{VP}(\mathrm{kPa})=10^{[6.079-1171 /(226.2+\mathrm{T})]} \pm 0.40 \text { for }-10<\mathrm{T}<60 \\
& \mathrm{VP}(\mathrm{kPa})=26 \pm 0.4 @ 25^{\circ} \mathrm{C}
\end{aligned}
$$

\section{Solubility in water}

$10,000 \mathrm{mg} / \mathrm{L}$ at $15^{\circ} \mathrm{C}$ reported by Verschueren (1983)

$8000 \mathrm{mg} / \mathrm{L}$ at $20^{\circ} \mathrm{C}$ reported by Verschueren (1983)

$9300 \mathrm{mg} / \mathrm{L}$ at $15^{\circ} \mathrm{C}$ reported by Verschueren (1983)

$7400 \mathrm{mg} / \mathrm{L}$ at $25^{\circ} \mathrm{C}$ reported by The Merck Index (Windholz et al., 1983)

$7950 \mathrm{mg} / \mathrm{L}$ at $25^{\circ} \mathrm{C}$ reported by Howard et al. (1990), who attribute this value to Mackay et al. (1980).

$15,000 \mathrm{mg} / \mathrm{L}$ at $0^{\circ} \mathrm{C}$ reported as ppm by volume by Andelman (1978). [As cited in Horvath (1982)].

$9870 \mathrm{mg} / \mathrm{L}$ at $0^{\circ} \mathrm{C}$ reported by Chancel and Parmentier (1885a,b). [As cited in Horvath (1982)].

$9800 \mathrm{mg} / \mathrm{L}$ at $0{ }^{\circ} \mathrm{C}$ reported as wt $\%$ by Reinders and de Minjer (1947). [As cited in Horvath (1982)].

$11,000 \mathrm{mg} / \mathrm{L}$ at $0^{\circ} \mathrm{C}$ reported by Rex (1906). [As cited in Horvath (1982)].

$9800 \mathrm{mg} / \mathrm{L}$ at $0^{\circ} \mathrm{C}$ reported as mole fraction by Staverman (1941). [As cited in Horvath (1982)].

$9800 \mathrm{mg} / \mathrm{L}$ at $0^{\circ} \mathrm{C}$ reported as wt \% by Washburn (1928). [As cited in Horvath (1982)].

$10,000 \mathrm{mg} / \mathrm{L}$ at $1.5^{\circ} \mathrm{C}$ reported as ppm by wt. by Dilling (1977). [As cited in Horvath (1982)].

$8900 \mathrm{mg} / \mathrm{L}$ at $3.2^{\circ} \mathrm{C}$ reported by Chancel and Parmentier (1885a,b). [As cited in Horvath (1982)].

$13,000 \mathrm{mg} / \mathrm{L}$ at $10^{\circ} \mathrm{C}$ reported as ppm by volume by Andelman (1978). [As cited in Horvath (1982)].

$8850 \mathrm{mg} / \mathrm{L}$ at $10^{\circ} \mathrm{C}$ reported as volume fraction by Larson et al. (1962) citing Ostwald (1894). [As cited in Horvath (1982)].

$8950 \mathrm{mg} / \mathrm{L}$ at $10^{\circ} \mathrm{C}$ reported by $\operatorname{Rex}$ (1906). [As cited in Horvath (1982)]. 
$8600 \mathrm{mg} / \mathrm{L}$ at $10^{\circ} \mathrm{C}$ reported as wt \% by Washburn (1928). [As cited in Horvath (1982)].

$10,000 \mathrm{mg} / \mathrm{L}$ at $15^{\circ} \mathrm{C}$ reported as wt \% by Antropov et al. (1972). [As cited in Horvath (1982)].

$8400 \mathrm{mg} / \mathrm{L}$ at $15^{\circ} \mathrm{C}$ reported as wt $\%$ by Evans (1936). [As cited in Horvath (1982)].

$8500 \mathrm{mg} / \mathrm{L}$ at $15^{\circ} \mathrm{C}$ reported by Gross and Saylor (1931). [As cited in Horvath (1982)].

$10,000 \mathrm{mg} / \mathrm{L}$ at $15^{\circ} \mathrm{C}$ reported as $w t \%$ by Gunther et al. (1968). [As cited in Horvath (1982)].

$8600 \mathrm{mg} / \mathrm{L}$ at $15^{\circ} \mathrm{C}$ reported as wt \% by Jones et al. (1957). [As cited in Horvath (1982)].

$10,000 \mathrm{mg} / \mathrm{L}$ at $15^{\circ} \mathrm{C}$ reported as $\mathrm{g} / \mathrm{cc}$ by Patty (1962). [As cited in Horvath (1982)].

$10,000 \mathrm{mg} / \mathrm{L}$ at $15^{\circ} \mathrm{C}$ reported as $\mathrm{g} / \mathrm{cc}$ by Scheflan and Jacobs (1953). [As cited in Horvath (1982)].

$8400 \mathrm{mg} / \mathrm{L}$ at $15^{\circ} \mathrm{C}$ reported as wt \% by Stephen and Stephen (1963). [As cited in Horvath (1982)].

$4820 \mathrm{mg} / \mathrm{L}$ at $15^{\circ} \mathrm{C}$ reported as $\mathrm{g} / \mathrm{g}$ at $1 \mathrm{~atm}$. pressure by Svetlanov et al. (1971). [As cited in Horvath (1982)].

$7100 \mathrm{mg} / \mathrm{L}$ at $17.4{ }^{\circ} \mathrm{C}$ reported by Chancel and Parmentier (1885a,b). [As cited in Horvath (1982)].

$12,000 \mathrm{mg} / \mathrm{L}$ at $20^{\circ} \mathrm{C}$ reported in ppm by volume by Andelman (1978). [As cited in Horvath (1982)].

$7900 \mathrm{mg} / \mathrm{L}$ at $20^{\circ} \mathrm{C}$ reported in wt \% by Antonov (1907). [As cited in Horvath (1982)].

$8200 \mathrm{mg} / \mathrm{L}$ at $20^{\circ} \mathrm{C}$ reported in wt \% by du Pont (1966). [As cited in Horvath (1982)].

$8000 \mathrm{mg} / \mathrm{L}$ at $20^{\circ} \mathrm{C}$ reported in wt \% by Evans (1936). [As cited in Horvath (1982)].

$8150 \mathrm{mg} / \mathrm{L}$ at $20^{\circ} \mathrm{C}$ reported in wt \% by Interdyne, Inc. (1976). [As cited in Horvath (1982)].

$8200 \mathrm{mg} / \mathrm{L}$ at $20^{\circ} \mathrm{C}$ reported in wt fraction by Lange (1973). [As cited in Horvath (1982)].

$8200 \mathrm{mg} / \mathrm{L}$ at $20^{\circ} \mathrm{C}$ reported in wt \% by Lax (1967). [As cited in Horvath (1982)]. 
$8000 \mathrm{mg} / \mathrm{L}$ at $20^{\circ} \mathrm{C}$ reported in wt \% by Marsden (1963). [As cited in Horvath (1982)].

$7500 \mathrm{mg} / \mathrm{L}$ at $20^{\circ} \mathrm{C}$ reported by Macintosh et al. (1963). [As cited in Horvath (1982)].

$8000 \mathrm{mg} / \mathrm{L}$ at $20^{\circ} \mathrm{C}$ reported in wt \% by Matthews (1975 and 1979). [As cited in Horvath (1982)].

$8000 \mathrm{mg} / \mathrm{L}$ at $20^{\circ} \mathrm{C}$ reported in wt \% by Mellan (1957). [As cited in Horvath (1982)].

$8000 \mathrm{mg} / \mathrm{L}$ at $20^{\circ} \mathrm{C}$ reported in wt \% by Nathan (1978). [As cited in Horvath (1982)].

$8100 \mathrm{mg} / \mathrm{L}$ at $20^{\circ} \mathrm{C}$ reported in mol/L by Pavlovskaya et al. (1977). [As cited in Horvath (1982)].

$8200 \mathrm{mg} / \mathrm{L}$ at $20^{\circ} \mathrm{C}$ reported in ppm by wt by Pearson and McConnell (1975). [As cited in Horvath (1982)].

$8200 \mathrm{mg} / \mathrm{L}$ at $20^{\circ} \mathrm{C}$ reported by Rex (1906). [As cited in Horvath (1982)].

$8200 \mathrm{mg} / \mathrm{L}$ at $20^{\circ} \mathrm{C}$ reported in wt \% by Riddick and Bunger (1970). [As cited in Horvath (1982)].

$7500 \mathrm{mg} / \mathrm{L}$ at $20^{\circ} \mathrm{C}$ reported by Salkowski (1920). [As cited in Horvath (1982)].

$8200 \mathrm{mg} / \mathrm{L}$ at $20^{\circ} \mathrm{C}$ reported by Scheflan and Jacobs (1953). [As cited in Horvath (1982)].

$6700 \mathrm{mg} / \mathrm{L}$ at $20^{\circ} \mathrm{C}$ reported in $\mathrm{g} / \mathrm{g}$ by Secher (1971). [As cited in Horvath (1982)].

$8200 \mathrm{mg} / \mathrm{L}$ at $20^{\circ} \mathrm{C}$ reported in ppm by wt by Selenka and Bauer (1978). [As cited in Horvath (1982)].

$8000 \mathrm{mg} / \mathrm{L}$ at $20^{\circ} \mathrm{C}$ reported by Smith (1932). [As cited in Horvath (1982)].

$8200 \mathrm{mg} / \mathrm{L}$ at $20^{\circ} \mathrm{C}$ reported in mole fraction by Staverman (1941). [As cited in Horvath (1982)].

$8000 \mathrm{mg} / \mathrm{L}$ at $20^{\circ} \mathrm{C}$ reported in wt \% by Stephen and Stephen (1963). [As cited in Horvath (1982)].

$8000 \mathrm{mg} / \mathrm{L}$ at $20^{\circ} \mathrm{C}$ reported in wt $\%$ by Washburn (1928). [As cited in Horvath (1982)].

$11,400 \mathrm{mg} / \mathrm{L}$ at $20^{\circ} \mathrm{C}$ reported in $\mathrm{cc} / \mathrm{cc} \mathrm{H}_{2} \mathrm{O}$ by Ostwald (1894) according to Larson et al. (1962). [As cited in Horvath (1982)].

$8100 \mathrm{mg} / \mathrm{L}$ at $20^{\circ} \mathrm{C}$ reported in $\mathrm{g} / \mathrm{g}$ by Kirk-Othmer (1964). [As cited in Horvath (1982)]. 
$7950 \mathrm{mg} / \mathrm{L}$ at $25^{\circ} \mathrm{C}$ reported by Afghan and Mackay (1980). [As cited in Horvath (1982)].

$11,500 \mathrm{mg} / \mathrm{L}$ at $25^{\circ} \mathrm{C}$ reported in ppm by volume by Andelman (1978). [As cited in Horvath (1982)].

$13,000 \mathrm{mg} / \mathrm{L}$ at $25^{\circ} \mathrm{C}$ reported by Aref'eva et al. (1979). [As cited in Horvath (1982)].

$7220 \mathrm{mg} / \mathrm{L}$ at $25^{\circ} \mathrm{C}$ reported in mol/L by Banerjee et al. (1980). [A. \& i. Horvath (1982)].

$13,000 \mathrm{mg} / \mathrm{L}$ at $25^{\circ} \mathrm{C}$ reported in $\mathrm{cc} / 100 \mathrm{cc}$ water by Booth and Everson (1948). [As cited in Horvath (1982)].

$7950 \mathrm{mg} / \mathrm{L}$ at $25^{\circ} \mathrm{C}$ reported in ppm by wt by Chiou et al. (1977). [As cited in Horvath (1982)].

$7500 \mathrm{mg} / \mathrm{L}$ at $25^{\circ} \mathrm{C}$ reported in wt \% by Conti et al. (1960). [As cited in Horvath (1982)].

$7500 \mathrm{mg} / \mathrm{L}$ at $25^{\circ} \mathrm{C}$ reported in ppm by wt by Dilling (1977). [As cited in Horvath (1982)].

$8000 \mathrm{mg} / \mathrm{L}$ at $25^{\circ} \mathrm{C}$ reported in wt \% by Gladis (1960). [As cited in Horvath (1982)].

$8300 \mathrm{mg} / \mathrm{L}$ at $25^{\circ} \mathrm{C}$ reported in cc/g water by Lax (1967). [As cited in Horvath (1982)].

$7900 \mathrm{mg} / \mathrm{L}$ at $25^{\circ} \mathrm{C}$ reported in $\mathrm{g} / \mathrm{g} \mathrm{w} \quad$ McGovern (1943). [As cited in Horvath (1982)].

$7920 \mathrm{mg} / \mathrm{L}$ at $25^{\circ} \mathrm{C}$ reported in wt \% by Miller (1969). [As cited in Horvath (1982)].

$8200 \mathrm{mg} / \mathrm{L}$ at $25^{\circ} \mathrm{C}$ reported in wt \% by Mitchell and Smith (1977). [As cited in Horvath (1982)].

$9000 \mathrm{mg} / \mathrm{L}$ at $25^{\circ} \mathrm{C}$ reported in wt \% by Reinders and de Minjer (1947). [As cited in Horvath (1982)].

$8000 \mathrm{mg} / \mathrm{L}$ at $25^{\circ} \mathrm{C}$ reported in $\mathrm{g} / 125 \mathrm{cc}$ water by Wright and Schaffer (1932). [As cited in Horvath (1982)].

$7050 \mathrm{mg} / \mathrm{L}$ at $29.4^{\circ} \mathrm{C}$ reported by Chancel and Parmentier (1885a,b). [As cited in Horvath (1982)].

$11,200 \mathrm{mg} / \mathrm{L}$ at $30^{\circ} \mathrm{C}$ reported in ppm by volume by Andelman (1978). [As cited in Horvath (1982)].

$7700 \mathrm{mg} / \mathrm{L}$ at $30^{\circ} \mathrm{C}$ reported in wt \% by Evans (1936). [As cited in Horvath (1982)]. 
$7710 \mathrm{mg} / \mathrm{L}$ at $30^{\circ} \mathrm{C}$ reported in $\mathrm{g} / \mathrm{g}$ by Gross and Saylor (1931). [As cited in Horvath (1982)].

$6200 \mathrm{mg} / \mathrm{L}$ at $30^{\circ} \mathrm{C}$ reported in cc/cc-water by Larson et al. (1962) citing Ostwald (1894). [As cited in Horvath (1982)].

$7760 \mathrm{mg} / \mathrm{L}$ at $30^{\circ} \mathrm{C}$ reported by Rex (1906). [As cited in Horvath (1982)].

$7700 \mathrm{mg} / \mathrm{L}$ at $30^{\circ} \mathrm{C}$ reported in mole fraction by Staverman (1941). [As cited in Horvath (1982)].

$7600 \mathrm{mg} / \mathrm{L}$ at $30^{\circ} \mathrm{C}$ reported in wt \% fraction by Stephen and Stephen (1963). [As cited in Horvath (1982)].

$3200 \mathrm{mg} / \mathrm{L}$ at $30^{\circ} \mathrm{C}$ reported in $\mathrm{g} / \mathrm{g}$-water at $1 \mathrm{~atm}$. pressure by Svetlanov et al. (1971). [As cited in Horvath (1982)].

$3200 \mathrm{mg} / \mathrm{L}$ at $30^{\circ} \mathrm{C}$ reported in $\mathrm{g} / \mathrm{g}$-water at $1 \mathrm{~atm}$. pressure by Svetlanov et al. (1971). [As cited in Horvath (1982)].

$8200 \mathrm{mg} / \mathrm{L}$ at $30^{\circ} \mathrm{C}$ reported by Svetlanov et al. (1971). [As cited in Horvath (1982)].

$7700 \mathrm{mg} / \mathrm{L}$ at $30^{\circ} \mathrm{C}$ reported in mol/100-g- $\mathrm{H}_{2} \mathrm{O}$ by Van Arkel (1946). [As cited in Horvath (1982)].

$7700 \mathrm{mg} / \mathrm{L}$ at $30^{\circ} \mathrm{C}$ reported in mol/100-g-water by Van Arkel and Vles (1936). [As cited in Horvath (1982)].

$7600 \mathrm{mg} / \mathrm{L}$ at $30^{\circ} \mathrm{C}$ reported in wt \% by Washburn (1928). [As cited in Horvath (1982)].

$5920 \mathrm{mg} / \mathrm{L}$ at $37^{\circ} \mathrm{C}$ reported in cc/cc-water by Allott et al. (1973), Steward et al. (1973-1974), Larson et al. (1962), and Papper and Kitz (1963), all citing Ostwald (1894). [As cited in Horvath (1982)].

$6000 \mathrm{mg} / \mathrm{L}$ at $37^{\circ} \mathrm{C}$ reported in cc/cc-water by Macintosh et al. (1963). [As cited in Horvath (1982)].

$5600 \mathrm{mg} / \mathrm{L}$ at $38^{\circ} \mathrm{C}$ reported in $\mathrm{cc} / \mathrm{cc}-$ water by Grant (1978) citing Ostwald (1894). [As cited in Horvath (1982)].

$6800 \mathrm{mg} / \mathrm{L}$ at $40^{\circ} \mathrm{C}$ reported in cc/cc-water by Larson et al. (1962) citing Ostwald (1894). [As cited in Horvath (1982)].

$7350 \mathrm{mg} / \mathrm{L}$ at $40^{\circ} \mathrm{C}$ reported in wt \% by Washburn (1928). [As cited in Horvath (1982)].

$7120 \mathrm{mg} / \mathrm{L}$ at $41.6^{\circ} \mathrm{C}$ reported by Chancel and Parmentier (1885a,b). [As cited in Horvath (1982)].

$7100 \mathrm{mg} / \mathrm{L}$ at $42^{\circ} \mathrm{C}$ reported in wt \% by Reinders and de Minjer (1947). [As cited in Horvath (1982)]. 
$2050 \mathrm{mg} / \mathrm{L}$ at $45^{\circ} \mathrm{C}$ reported in $\mathrm{g} / \mathrm{g}$-water at 1 atm. pressure by Svetlanov et al. (1971). [As cited in Horvath (1982)].

$7450 \mathrm{mg} / \mathrm{L}$ at $50{ }^{\circ} \mathrm{C}$ reported in wt \% by Washburn (1928). [As cited in Horvath (1982)].

$7750 \mathrm{mg} / \mathrm{L}$ at $54.9^{\circ} \mathrm{C}$ reported by Chancel and Parmentier (1885a,b). [As cited in Horvath (1982)].

$7700 \mathrm{mg} / \mathrm{L}$ at $55^{\circ} \mathrm{C}$ reported in wt \% by Washburn (1928). [As cited in Horvath (1982)].

$8000 \mathrm{mg} / \mathrm{L}$ at $56.1^{\circ} \mathrm{C}$ reported in wt \% by Conti et al. (1960). [As cited in Horvath (1982)].

$7500 \mathrm{mg} / \mathrm{L}$ at $60^{\circ} \mathrm{C}$ reported in wt \% by Reinders and de Minjer (1947). [As cited in Horvath (1982)].

$1300 \mathrm{mg} / \mathrm{L}$ ai $45^{\circ} \mathrm{C}$ reported in $\mathrm{g} / \mathrm{g}$-water at 1 atm. pressure by Svetlanov et al. (1971). [As cited in Horvath (1982)].

From the information above, Horvath (1982) has constructed the following polynomial fit for the dependence of chloroform solubility (in wt \%) on temperature $(\mathrm{T})$ in ${ }^{\circ} \mathrm{C}$ in the range 0 to $60^{\circ} \mathrm{C}$

$$
\text { WS }(\text { wt \% })=0.995-1.0531 \times 10^{-2} \mathrm{~T}+7.9819 \times 10^{-5} \mathrm{~T}^{2}+6.6431 \times 10^{-7} \mathrm{~T}^{3} \pm 0.001
$$

which gives

$$
\begin{aligned}
\text { WS } & =0.792 \pm 0.001\left(\text { wt \%) at } 25^{\circ} \mathrm{C}\right. \\
& =7920 \pm 10 \mathrm{mg} / \mathrm{L} \text { at } 25^{\circ} \mathrm{C} \\
& =66.3 \pm 0.1 \mathrm{~mol} / \mathrm{m}^{3} \text { at } 25^{\circ} \mathrm{C}
\end{aligned}
$$

The dependence of chloroform solubility in water on temperature as given by this formula is plotted below.

Recommended value of solubility versus temperature, $\mathrm{T}$ in ${ }^{\circ} \mathrm{C}$, based on the analysis by Horvath (1982):

$$
\begin{aligned}
\mathrm{WS}(\mathrm{mg} / \mathrm{L})= & 9950-105.31 \mathrm{~T}+0.79819 \mathrm{~T}^{2}+0.0066431 \mathrm{~T}^{3} \\
& \pm 10 \mathrm{mg} / \mathrm{L} \text { for } 0{ }^{\circ} \mathrm{C}<\mathrm{T}<60^{\circ} \mathrm{C} \\
\mathrm{WS}(\mathrm{mg} / \mathrm{L})= & 7920 \pm 10 \mathrm{mg} / \mathrm{L} @ 25^{\circ} \mathrm{C} \\
\mathrm{WS}\left(\mathrm{mol} / \mathrm{m}^{3}\right)= & 66.3 \pm 0.1 \mathrm{~mol} / \mathrm{m}^{3} @ 25^{\circ} \mathrm{C}
\end{aligned}
$$




\section{Solubility versus temperature for chloroform}

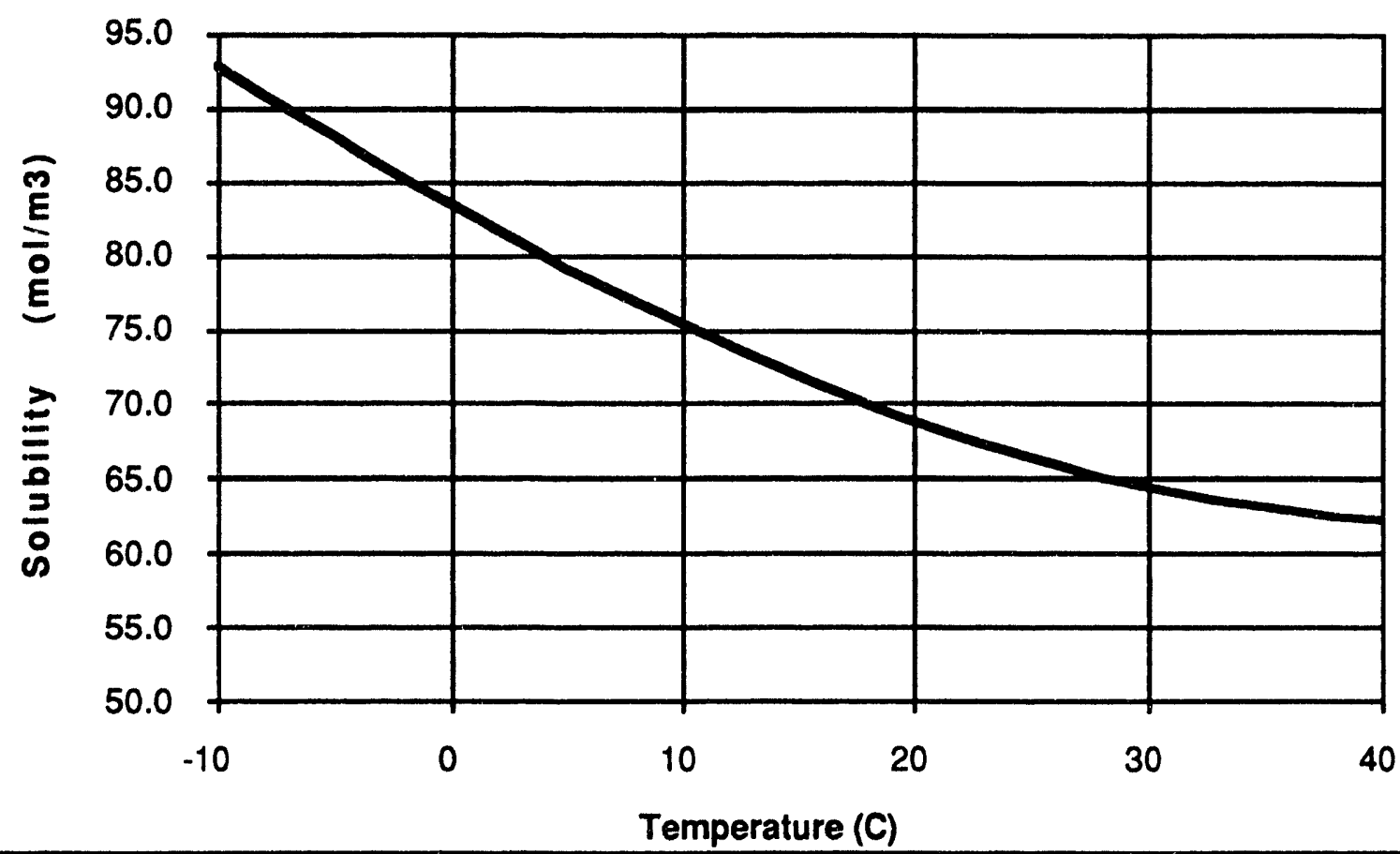

Henry's law constant (dimensionless form)

0.18 at $25^{\circ} \mathrm{C}$ reported by Howard et al. (1990), who attribute this value to Hine and Mookerjee (1975).

0.18 at $25^{\circ} \mathrm{C}$ reported as the experimental value of $\mathrm{H} / \mathrm{RT}$ by Hine and Mookerjee (1975).

0.12 at $20^{\circ} \mathrm{C}$ reported by Mackay and Shiu (1981), who attribute this value to McConnell et al. (1975).

0.13 at $25^{\circ} \mathrm{C}$ reported by Mackay and Shiu (1981), who attribute this value to Dilling (1977).

0.0645 at $9.6^{\circ} \mathrm{C}$ with a CV of 0.062 reported by Gossett (1987).

0.103 at $17.5^{\circ} \mathrm{C}$ with a CV of 0.020 reported by Gossett (1987).

0.150 at $24.8^{\circ} \mathrm{C}$ with a $\mathrm{CV}$ of 0.038 reported by Gossett (1987).

0.223 at $34.6^{\circ} \mathrm{C}$ with a $\mathrm{CV}$ of 0.020 reported by Gossett (1987).

Gossett (1987) has developed the following regression of Henry's law constant in $\mathrm{m}^{3} /(\mathrm{atm}-\mathrm{mol})$ versus temperature in $\mathrm{K}$, which applies in the temperature range 10 to $35^{\circ} \mathrm{C}$ 


$$
H=\exp (9.843-4612 / T) \pm 4 \%
$$

This can be converted to the dimensionless form to give

$\mathrm{H} / \mathrm{RT}=(1 / \mathrm{T}) \times \exp (19.25-4612 / \mathrm{T}) \pm 4 \%$

Plotted below is the dimensionless Henry's law constant H/RT versus temperature as derived from Gossett's regression above and as derived from the ratio of VP/(WS-RT) using the temperature-dependent expressions for VP and WS presented above.

\section{Dimensionless Henry's law versus temperature for chloroform}

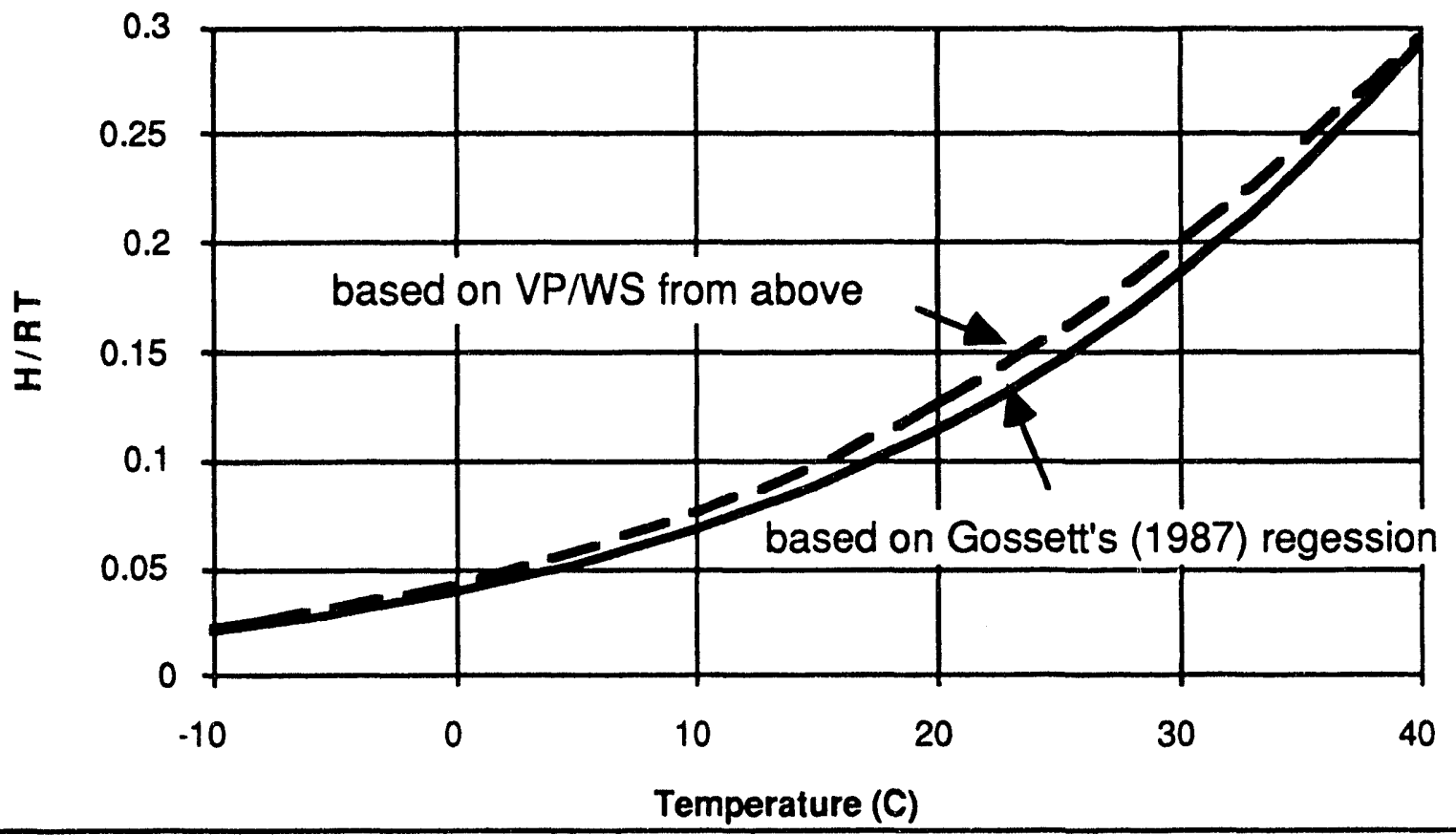

Recommended value of $\mathrm{H} / \mathrm{RT}$ versus temperature, $\mathrm{T}$ in ${ }^{\circ} \mathrm{C}$ :

$\mathrm{H} / \mathrm{RT}=(1 / \mathrm{T}) \times \exp (19.25-4612 / \mathrm{T}) \pm 4 \%$

$\mathrm{H} / \mathrm{RT}=0.15 \pm 0.006 @ 25^{\circ} \mathrm{C}$ 
Organic-carbon partition coefficient $\left(K_{o c}\right)$

Howard et al. (1990) report a $\mathrm{K}_{\mathrm{oc}}$ of 34 measured for chloroform in two soils.

Estimation methods for $\mathrm{K}_{\mathrm{oc}}$ produce the following values for $\mathrm{K}_{\mathrm{oc}}$

271 as derived from the $K_{o c}$ estimation method based on $K_{o w}$ proposed by Kenaga and Goring (1980) and referred to in Lyman et al. (1990).

$77.1,65.5,37.4$, and 42.0 as derived from the four regression equations relating $K_{o c}$ to $\mathrm{K}_{\mathrm{ow}}$ in Karickhoff (1985).

39 as derived from the regression of $\mathrm{K}_{\mathrm{oc}}$ with solubility proposed by Chiou et al. (1977)

31.3 as derived from the regression of $\mathrm{K}_{\mathrm{oc}}$ with solubility proposed by Kenaga (1980)

34.5 as derived from the regression of $\mathrm{K}_{\mathrm{oc}}$ with the molecular connectivity index $\left({ }^{1} \chi=1.73\right)$ as proposed by Meylan et al. (1992).

Recommended value base on the log mean of the measured and predicted values above:

$$
\begin{aligned}
& \log \mathrm{K}_{\mathrm{oc}}=1.7 \pm 0.3 \\
& \mathrm{~K}_{\mathrm{oc}}=53 \times \text { or } \div 2
\end{aligned}
$$

\section{Diffusion coefficient in water}

Based on the Wilke and Chang (1955) method described in Reid et al. (1987), the diffusion coefficient in $\mathrm{m}^{2} / \mathrm{d}$ in water is given by

$$
D_{\mathrm{xy}}=\frac{6.5 \times 10^{-7}\left(\phi M_{\mathrm{y}}\right)^{1 / 2} \mathrm{~T}}{\eta_{\mathrm{y}} V_{\mathrm{x}}^{0.6}} .
$$

The molecular weight, $M_{y}$, of water is $18 \mathrm{~g} / \mathrm{mol}$. Wilke and Chang (1955) recommend an association factor, $\phi$, of 2.6 when the solvent is water. The viscosity of water, $\eta_{\mathrm{y}}$, is $0.89 \mathrm{cP}$ at $25^{\circ} \mathrm{C}$. Molecular volume can be estimated by the LeBas incremental method as described in Lyman et al. (1990). With the molecular volume $V_{x}$ of chloroform equal to $81 \mathrm{~cm}^{3} / \mathrm{mol}$, this expression gives 
Recommended value:

$D_{\text {water }}=3.6 \times 10^{-7} \mathrm{~T} \mathrm{~m}^{2} / \mathrm{d}=1.1 \times 10^{-4} \mathrm{~m}^{2} / \mathrm{d}$ or $1.2 \times 10^{-9} \mathrm{~m}^{2} / \mathrm{s} @ 25^{\circ} \mathrm{C}$

Diffusion coefficient in air

Based on the Fuller et al. (1966) method described in Lyman et al. (1990), the diffusion coefficient in $\mathrm{m}^{2} / \mathrm{d}$ in air is given by

$$
D_{\text {air }}=8.6 \times 10^{-3} \mathrm{~T} \frac{\sqrt{\frac{\left(29+\mathrm{M}_{x}\right)}{29 \mathrm{M}_{\mathrm{x}}}}}{\left[2.7+\left(V_{\mathrm{x}}\right)^{1 / 3}\right]^{2}} .
$$

With the molecular volume, $\mathrm{V}_{\mathrm{x}}$, of chloroform of $81 \mathrm{~cm}^{3} / \mathrm{mol}$ and a molecular weight of $119.4 \mathrm{~g} / \mathrm{mol}$, the above expression gives (with $\mathrm{T}$ in kelvins)

Recommended value:

$$
\mathrm{D}_{\text {air }}=3.6 \times 10^{-5} \mathrm{~T}^{1.75} \mathrm{~m}^{2} / \mathrm{d}=0.77 \mathrm{~m}^{2} / \mathrm{d} \text { or } 8.9 \times 10^{-6} \mathrm{~m}^{2} / \mathrm{s} @ 25^{\circ} \mathrm{C}
$$

Steady-state bioconcentration factors for plant tissue concentration relative to soil concentration

No reported measurements of plant-root bioconcentration for chloroform in soils are available in the current literature. Estimation methods for this parameter are considered below.

The partition factor from surface soil to edible plant parts due to rainsplash, $\mathrm{K}_{\mathrm{ps}}^{\text {rain }}$ is equal to $0.0034 \mathrm{~kg}$ (soil) $/ \mathrm{kg}$ (plant) with a CV of 1 (Dreicer et al. 1984). This partition factor applies plant fresh mass concentration relative to soil concentration.

Based on the Briggs et al. $(1982,1983)$ estimation equation for uptake of contaminants by roots from soil solution, we calculate the RCF (which represents the ratio of contaminant concentration in root, $\mathrm{mg} / \mathrm{kg}$ [fresh mass], to contaminant concentration in soil solution, $\mathrm{mg} / \mathrm{L}$ ) for chloroform as

$$
\mathrm{RCF}=1.8
$$


When this factor is divided by the sorption coefficient, $K_{D}=f_{o c} \times K_{o c}=(0.01$ to $0.02) \times \mathrm{K}_{\mathrm{oc}}$ (from above), we obtain the ratio of contaminant concentration in roots, $\mathrm{mg} / \mathrm{kg}$ (fresh mass) to contaminant concentration in soil solids, $\mathrm{mg} / \mathrm{kg}$, which we refer to as $\mathrm{K}_{\mathrm{ps}}$ (roots) and estimate it as being in the range

$$
\mathrm{K}_{\mathrm{ps}}(\text { roots })=0.3 \text { to } 6
$$

Based the regression of $\mathrm{K}_{\mathrm{ps}}$ (roots) with $\mathrm{K}_{\mathrm{oc}}$ from Topp et al. (1986), and based on the range of $K_{o c}$ values listed above, we obtain

$$
K_{\mathrm{ps}} \text { (roots) }=20 \text { to } 80 \text { (recommended range for root crops) }
$$

Based on the Travis and Arms (1988) correlation for plant-soil bioconcentration we obtain for total plant (not just roots) the following soil/plant partition coefficient

$$
\mathrm{K}_{\mathrm{ps}}=2.8 \times \text { or } \div 5.3 \text { (recommended value for exposed produce) }
$$

Steady-state bioconcentration factors for plant leaf concentration relative to air concentration

No reported measurements of plant-air bioconcentration for chloroform in air are available in the current literature. Estimation methods for this parameter are considered below.

Based on the model of Riederer (1990) for foliar uptake of gases in plant leaves, we estimate a steady-state plant-air coefficient of

$$
\mathrm{K}_{\mathrm{pa}}^{\mathrm{gs}}=\left[0.5+\left(0.4+0.01 \times \mathrm{K}_{\mathrm{ow}}\right) \times \frac{\mathrm{RT}}{\mathrm{H}}\right] \times 10^{-3} \frac{\mathrm{m}^{3}}{\mathrm{~kg}}=0.009 \mathrm{~m}^{3} / \mathrm{kg}
$$

We could find no study in which the estimation error of this partition coefficient has been considered, but we assume the $\mathrm{CV}$ associated with it is on the order of 1 .

Bioconcentration factors for fish concentration relative to water/or sediment concentrations

6 reported for bluegill sunfish by Barrows et al. (1980) and cited in Howard et al. (1990).

3.34 to 10.35 reported for rainbow trout by Anderson and Lusty (1980) and cited in Howard et al. (1990). 
1.6 to 2.5 reported for bluegill by Anderson and Lusty (1980) and cited in Howard et al. (1990).

2.9 to 3.1 reported for largemouth bass by Anderson and Lusty (1980) and cited in Howard et al. (1990).

3.3 to 3.7 reported for catfish by Anderson and Lusty (1980) and cited in Howard et al. (1990).

4.2 Based the $\mathrm{K}_{\mathrm{ow}}$ value and the correlation of Mackay (1982).

Recommended value, based on the mean value of the range of measured values and the predicted value reported above:

$$
\mathrm{BCF}(\text { fish })=4 \pm 2.5
$$

Steady-state biotransfer factors for milk or dairy-product concentration relative to contaminant intake by cattle

No reported measurements of milk-diet biotransfer for chloroform are available in the current literature.

Based on the geometric mean regression of milk-to-diet biotransfer against $\mathrm{K}_{\mathrm{ow}}$ developed by Travis and Arms (1988) we estimate the milk biotransfer factor for chloroform as

$$
\mathrm{B}_{\mathrm{k}}=7 \times 10^{-7} \times \text { or } \div \text { (jecommended value) }
$$

The estimation error in this expression corresponds to a CVs of 6 .

Steady-state biotransfer factors for meat concentration relative to contaminant intake by cattle, pigs, and chickens

No reported measurements of meat-diet biotransfer for chloroform are available in the current literature.

Based on the geometric mean regression of meat-to-diet biotransfer against $\mathrm{K}_{\mathrm{ow}}$ developed by Travis and Arms (1988) we estimate the meat biotransfer factor for chloroform as

$$
B_{t}=2 \times 10^{-6} \times \text { or } \div 9 \text { (recommended value) }
$$

The estimation error in this expression corresponds to a CV of 11 . 
Steady-state biotransfer factors for egg concentration relative to contaminant intake by chickens

No reported measurements of egg-diet biotransfer for chloroform are available in the current literature.

Based on the geometric mean regression of egg-to-diet biotransfer against $\mathrm{K}_{\mathrm{ow}}$ developed above, we estimate the egg biotransfer factor for chloroform as

$$
\mathrm{B}_{\mathrm{e}}=7 \times 10^{-4} \times \text { or } \div 10 \text { (recommended value) }
$$

The estimation error in this expression corresponds to a CV of 14 .

Contaminant biodegradation factors in soil

Howard et al. (1991) have estimated the half-live of chloroform in soil due to aerobic biodegradation to be in the range of four weeks to six months.

Recommended values, based on range of the soil half lives:

aerobic soil biodegradation rate constant $=0.0143 \mathrm{~d}^{-1} \times$ or $\div 1.7$

Media-specific half lives for air, soil, and surface water

Air. Howard et al. (1991) estimate the half life of chloroform in lower atmosphere is in the range of 623 to 6230 hours (26 to 260 days ) based on photo-oxidation as a removal process.

Soil Howard et al. (1991) have estimated the half-live of chloroform in soil due to aqueous aerobic biodegradation to be in the range of 672 to 4320 hours ( 28 to 180 days).

Water Howard et al. (1991) have estimated the half-live of chloroform in surface water due to aqueous aerobic biodegradation to be in the range of $€ 72$ to 4320 hours ( 28 to 180 days).

$$
\begin{aligned}
& \begin{array}{l}
\text { Recommended half lives (in days), based on arithmetic mean of the } \\
\text { half lives and geometric range of the values: } \\
\text { Air } \quad 80 \times \text { or } \div 1.9 \\
\text { Soil } \quad 70 \times \text { or } \div 1.7 \\
\text { Water } \quad 70 \times \text { or } \div 1.7
\end{array}
\end{aligned}
$$
half lives and geometric range of the values: 


\section{References for Chloroform}

Afghan, B.K., and D. Mackay, Eds. (1980), Hydrocarbons and Halogenated Hydrocarbons in the Aquatic Environment, Environ Sci. Res. Vol. 16, Plenum, New York, NY. 602 pp.

Allott, P. R., Steward, A., Flook, V., and Mapleson, W. W. (1973), Br. J. Anaesth. 45, 294-300.

Andelman, J. B. (1978), Chlorform, Carbor Tetrachloride, and Other Halomethanes: An Environmental Assessment, National Academy of Sciences, Washington, DC. $294 \mathrm{pp}$.

Anderson, D.R., and E.B. Lusty (1980), Acute Toxicity and Bioaccumulation of Chloroform to Four Species of Fresh Water Fish, Pacific Northwest Laboratories, Richland, WA, NUREG/CR-089, pp. 8-26.

Antonov, G. N. (1907), J. Chim. Phys. 5, 372-385.

Antropov, L. I., V.E. Pogulyai, V.D. Simonov, and T.M. Shamsutdinov (1972),Russ. J. Phyhs. Chem. 46(2), 311-312 (VINITI N2. 3739-71).

Aref'eva, R.P., I.M. Korenman, and A.A. Gorokhov (1979), Determination of the Solubility of Liquid and Solid Organic Substances in Water, Using Diphenylthiocarbazone, USSR Patent 672548 (July 5). 3 pp. (CA: 91:113256k).

Banerjee, S., Yalkowsky, S. H., and Valvani, S. C. (1980), Environ. Sci. Technol. 14(10), 1227-1229.

Barrows, M.E., et al. (1980), Dyn Exposure Hazard Assess Toxic Chem Ann Arbor, MI, Ann Arbor Press, Ann Arbor, MI, pp. 379-392.

Booth, H.S., and H.E. Everson (1948), Ind. Eng. Chem. 40(8), 1491-1493.

Boublik, T., Fried, V., and Hála, E. (1984), The Vapour Pressures of Pure Substances: Selected Values of the Temperature Dependence of the Vapour Pressures of Some Pure Substances in the Normal and Low Pressure Region (Second Revised Edition), Physical sciences data; 17 (Elsevier Science Publishers, Amsterdam, The Netherlands).

Briggs, G.G., R.H. Bromilow, and A.A. Evans (1982), "Relationships Between Lipophilicity and Root Uptake and Translocation of Non-Ionized Chemicals by Barley," Pestic. Sci. 13, 495-504.

Briggs, G.G., R.H. Bromilow, A.A. Evans, and M. Williams (1983), "Relationships Between Lipophilicity and the Distribution of Non-Ionized Chemicals in Barley Shoots Following Uptake by the Roots," Pestic. Sci. 14, 492-500.

Chancel, G., and F. Parmentier, (1885a), C. R. Acad. Sci. Ser. A 100, 27-30.

Chancel, G., and F. Parmentier, (1885b), C. R. Acad. Sci. Ser. A 100, 773-776. 
Chiou, C. T., V. H. Freed, D.W. Schmedding, and R. L. Kohnert (1977), "Partition Coefficient and Bioaccumulation of Selected Organic Chemicals," Environ. Sci. Technol. 11(5), 475-478.

Conti, J.J., D.F. Othmer, and R. Gilmont (1960), J. Chem. Eng. Data 5(3), 301-307.

Dean, J.D., Ed. (1985), Lang's Handbook of Chemistry (McGraw-Hill, Inc., New York City, NY), 13th ed.

Dilling, W. L. (1977), Environ. Sci. Technol. 11(4), 405-409.

Dreicer, M., T.E. Hakonson, G.C. White, and F.W. Whicker (1984), "Rainsplash as a Mechanism for Soil Contamination of Plant Surfaces," Health Phys. 46, 177-187.

du Pont de Nemours \& Company (1966), Solvent Properties Comparison Chart, Freon Aerosol Report FA-26, Wilmington, Del. 6 pp.

Evans, T. W. (1936), Ind. Eng. Chem. Anal. Ed. 8(3), 206-208.

Fuller, E.N., P.D. Schettler, and J.C. Giddings (1966), "A New Method for Prediction of Binary Gas-Phase Diffusion Coefficients," Ind. Eng. Chem. 58, 19-27.

Gladis, G.P. (1960), Chem. Eng. Prog. 56(10), 43-51.

Gossett, J.M. (1987), "Measurement of Henry's Law Constants for $C_{1}$ and $C_{2}$ Chlorinated Hydrocarbons," Environ. Sci. Technol. 21, 202-208.

Grant, W. J. (1978), Medical Gases-Their Properties and Uses, HM + M Publ., Aylesbury. 199 pp. [cites Ostwald, 1894].

Gross, P.M., and J.H. Saylor (1931), J. Am. Chem. Soc. 53, 1744-1751.

Gunther, F.A., W.E. Westlake, and P.S. Jaglan (1968), Residue Rev. 20, 1-148.

Hansch, C., and S.M. Anderson (1967), J. Org. Chem. 32, 2583.

Hansch, C., and A. Leo (1987), "The Log P and Related Parameters Database," created and updated by the Medicinal Chemistry Project at Pomona College, Claremont, CA, under the direction of Corwin Hansch and Albert Leo - 1987 Printout.

Hine, J., and P.K. Mookerjee (1975), "The Intrinsic Hydrophilic Character of Organic Compounds. Correlations in Terms of Structural Contributions," J. Org. Chem. 40, 292-298.

Howard, P.H., R.S. Boethling, W.F. Jarvis, W.M. Meylan, and E.M. Michalenko, Eds. (1991), Handbook of Environmental Degradation Rates (Lewis Publishers, Inc, Chelsea, MI).

Howard, P.H., G.W. Sage, W.F. Jarvis, and D.A. Gray, Eds. (1990), Handbook of Environmental Fate and Exposure Data for Organic Chemicals. Volume II. Solvents (Lewis Publishers, Inc., Chelsea, MI).

Horvath, A. L. (1982), Halogenated Hydrocarbons, Solubility-Miscibility with Water (Marcel Dekker, Inc., New York City, NY). 
Interdyne, Inc. (1976), Solvent Data Sheet, SDS -104, Indianapolis, Ind., 2 pp.

Jones, D.C., R.H. Ottewill, and A.P.J. Chater (1957), Proc. 2nd Int. Congr. Surf. Activ., London, Vol. 1, pp. 188-199.

Kenaga, E. E. (1980), "Predicted Bioconcentration Factors and Soil Sorption Coefficients of Pesticides and Other Chemicals," Ecotoxicol. Environ. Saf. 4, 26-38.

Kenaga, E. E., and C.A.I. Goring (1980), "Relationship Between Water Solubility, Soil Sorption, Octanol-Water Partitioning, and Concentration of Chemicals in Biota," in Aquatic Toxicology, ASTM STP 707, J. G. Eaton, P. R. Parrish, and A. C. Hendricks, Eds. (American Society for Testing and Materials, Philadelphia, PA) pp. 78-115.

Karickhoff, S.W. (1985), "Chapter 3. Pollutant Sorption in Environmental Systems," in Environmental Exposure From Chemicals, Volume I., W. B. Neely and G.E. Blau, Eds. (CRC Press, Inc., Boca Raton, FL), pp. 49-64.

Kirk-Othmer Encyclopedia of Chemical Technology (1964), Chlorocarbons and Chlorohydrocarbons, Vol. 5 (2nd ed.), Wiley, New York, NY. pp. 100-363.

Lange, N. A., Ed. (1973), Handbook of Chem istry (11th ed.), McGraw-Hill, New York, NY. pp. 2001 (12th ed., 1979) Referenced as Lange (1967 in text).

Larson, C. P., E.I. Eger, and J.W. Severinghaus, (1962), Anesthesiology 23, 686-689, [cites Osterwald (1894)].

Lax, E., Ed. (1967), Taschenbuch für Chemiker und Physiuker (3rd ed.), Vol. 1., Springer-Verlag, Berlin, Germany.

Leo, A., C. Hansch, and D. Elkins (1971), "Partition Coefficients and their Uses," Chem. Rev. 71(6) 525-616.

Lyman, W. J., W. F. Reehl, and D. H. Rosenblatt (1990), Handbook of Chemical Property Estimation Methods: Environmental Behavior of Organic Compounds (American Chemical Society, Washington, DC).

Macintosh, R., W.W. Mushin, and H.G. Epstein (1963), Physics for the Anaesthetist, Including a Scetion on Explosion, Blackwell Science, Oxford, UK. pp. 439.

Mackay, D. (1982), "Correlation of Bioconcentration Faciors," Environ. Sci. Technol. $16,274-278$.

Mackay, D., A. Bobra, W.Y. Shiu, and S.H. Yalkowsky (1980), "Relationships Between Aqueous Solubility and Octanol-Water Partition Coefficients," Chemosphere 9, 701-711.

Mackay, D., and W.Y. Shiu (1981), "A Critical Review of Henry's Law Constants for Chemicals of Environmental Interest," J. Phys. Chem. Ref. Data 10(4), 1175-1199.

Marsden, C., Ed. (1963), Solvents Guide (2nd ed.), Cleaver-Hume, London, UK.

Matthews, P. J. (1975), Effl. Water Treat. J. 15(11), 565-567 and 626-627. 
Matthews, P. J. (1979), “Use of Vapor-Liquid Equilibrium Data for Estimating Trade Effluent Limits," Proc. Natl. Phys. Lab. Conf. on Chemical Thermodynamic Data on Fluids and Fluid Mixtures. Teddington, Sept. 11-12, 1978. IPC Science and Technology Press, Guildford, England, UK.

McConnell, G., D.M. Ferguson, and C.R. Pearson (1975), Endeavour 34, 13.

McGovern, E. W. (1943), Ind. Eng. Chem. 35(12), 1230-1239.

Mellan, I. (1957), Source Book of Industrial Solvents, Vol. 2, Reinhold, New York, NY.

Meylan, W., P.H. Howard, and R.S. Boethling (1992), "Molecular

Topology/Fragment Contribution Method for Predicting Soil Sorption Coefficients," Environ. Sci. Technol. 26, 1560-1567.

Miller, S.A., Ed. (1969), Ethylene and Its Industrial Derivatives, Ernest Benn, London, UK. $1321 \mathrm{pp}$.

Mitchell, J., and D. M. Smith (1977), Aquametry, Part 1: A Treatise on Methods for the Determination of Water (2nd ed.), Wiley, New York, NY. 632 pp.

Nathan, M. F. (1978), Chem. Eng. 85(3), 93-100.

Ostwald, W. (1894), Manual of Physico-Chemical Measurements, Macmillan, London, UK. 225 pp. [cited by Grant (1978); Larson et al. (1962); Papper and Kitz (1963); and Steward et al. (1973)].

Papper, E.M., and R.J. Kitz (1963), Uptake and Distribution of Anesthetic Agents, McGraw-Hill, New York, NY, p. 10.

Patty, F. A., Ed. (1962), Industrial Hygiene and Technology (2nd rev. ed.), Vol. 2, Interscience, New York, NY, pp. 831-2377.

Pavlovskaya, E.M., A.K. Charykov, and V.I. Tikhomirov (1977), Żh. Obshch. Khim. 47(11), 2439-2444.

Pearson, C.R., and G. McConnell (1975), Prcc. Roy. Soc. Lond. Ser. B 189, 305-332.

Reid, R. C., J. M. Prausnitz, and B. E. Poling (1987), The Properties of Gases and Liquids (McGraw Hill, New York City, NY), 4th ed.

Reiderer, M. (1990), "Estimating Partitioning and Transport of Organic Chemicals in the Foliage/Atmosphere System: Discussion of a Fugacity-Based Model," Environ. Scil. Technol. 24, 829-837.

Reinders, W., and C.H. De Minjer, (1947), Recl. TYrav. Chim. 66, 573-604.

Rex, A. (1906), Z. phys. Chem. 55, 355-370.

Riddick, J.A., and W.B. Bunger (1970), Organic Solvents. Physical Properties and Methods of Purification (3rd ed.), Vol. 2, Wiley-Interscience, New York, NY. 603 pp. Salkowski, E. (1920), Biochem. Z. 107, 191-201. 


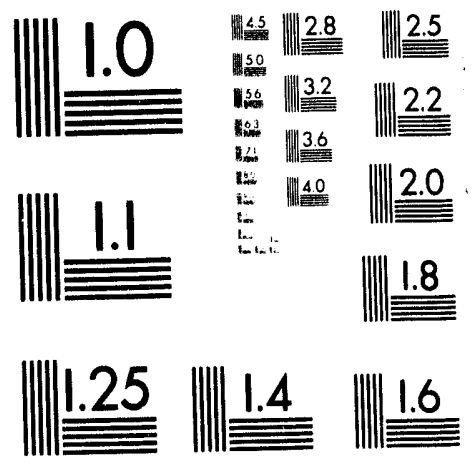



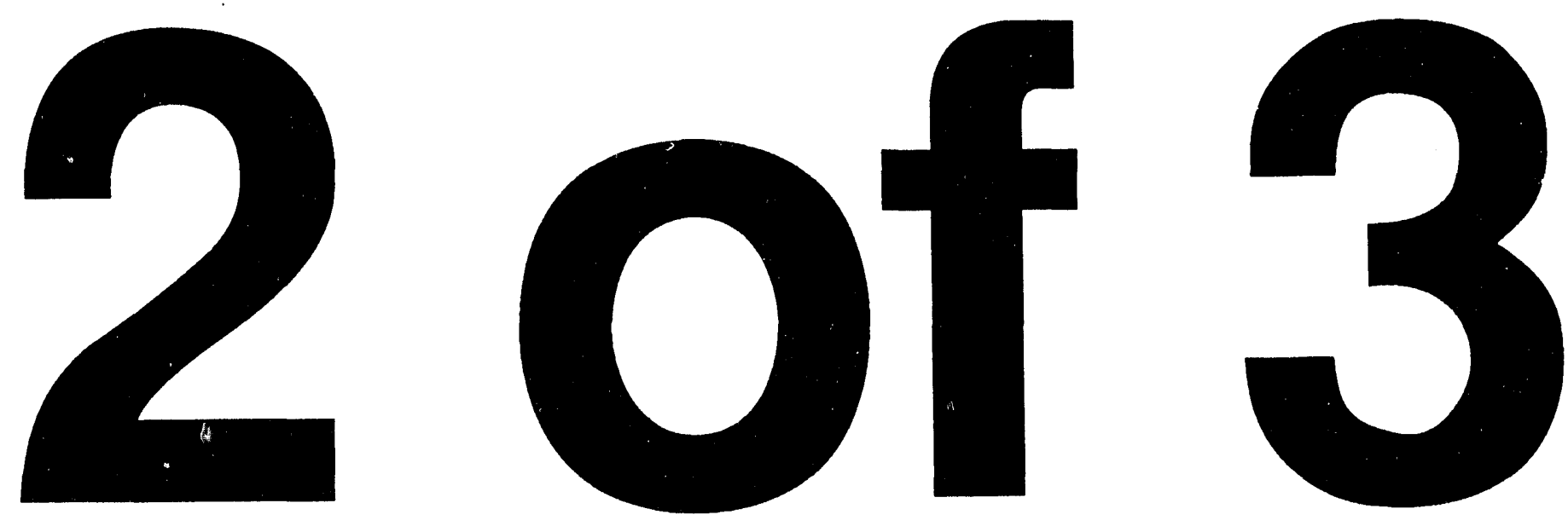
Schauman, O. (1938), Arch. Exp. Pathol. Pharm. 190, 30.

Scheflan, L., and M.B. Jacobs (1953), The Handbook of Solvents (D. Van Nostrand, New York, NY), 728 pp.

Secher, O. (1971), Physical and Chemiocal Data on Anaesthetics, Universitetsforlaget, Aarhus, Denmark. 96 pp.

Selenka, F., and U. Bauer (1978), "Detection of Readily Volatile Organochloride Compounds in Water," Org. Verunreinig. Umwelt: Erkennen, Bewerten. pp. 242-255 (CA 91:62457s).

Smith, E. L. (1932), J. Phys. Chem. 36, 1401-1418.

Staverman, A. J. (1941), Recl. Trav. Chim. 60, 836-841.

Stephen, H., and T. Stephen (1963), Solubilities of Inorganic and Organic Compounds, Vols. 1 and 2, Pergamon, Oxford, UK.

Steward, A., R.P. Allott, A.L. Cowles, and W.W. Mapleson (1973-1974), Br. J. Anaesth. 45, 282-293, and 46(4), 310.

Stull, D. R. (1947), "Vapor Pressure of Pure Substances: Organic Compounds," Ind. Eng. Chem. 39, 517-540.

Svetlanov, E.B., S.M. Velichko, M.I. Levinskii, Yu. A. Treger, and R.M. Flid (1971), Russ. J. Phys. Chem. 45(4), 488-490.

Topp, E., I. Scheunert, A. Attar, and F. Korte (1986), "Factors Affecting the Uptake of 14C-Labeled Organic Chemicals by Plants From Soil," Ecotoxicol. Environ. Saf. 11, 219-228.

Travis, C.C., and A.D. Arms (1988), "Bioconcentration of Organics in Beef, Milk, and Vegetation," Environ. Sci. Technol. 22, 271-274.

Van Arkel, A.E. (1946), Disc. Faraday Soc. 42B, 81-84.

Van Arkel, A.E., and S.E. Vles (1936), Recl. Trav. Chim. 55, 407-411.

Verschueren, K. (1983), Handbook of Environmental Data on Organic Chemicals, Second Edition (Van Nostrand Reinhold Company Inc., New York City, NY).

Washburn, E. W., Ed. (1928), International Critical Tables of Numerical Data, Physics, Chemistry, and Technology, Vol. 3, McGraw-Hill, New York, NY.

Weast, R. C., M. J. Astle, and W. H. Beyer, Eds. (1986), CRC Handbook of Chemistry and Physics: A Ready Reference Book of Chemical and Physical Data, 67th Edition (CRC Press, Inc., Boca Raton, FL).

Windholz, M., S. Budavari, R. F. Blumetti, and E. S. Otterbein, Eds. (1983), The Merck Index: An Encyclopedia of Chemicals, Drugs, and Biologicals, 10th Edition (Merck \& Co., Inc., Rahway, NJ). 
Wilke, C.R., and P. Chang (1955), "Correlation of Diffusion Coefficients in Dilute Solutions," AIChE J. 1, 264-270.

Wright, W.H., and J.M. Schaffer (1932), Am. J. Hyg. 16(2), 325-428. 


\section{Di-2-Ethylhexylphthalate (DEHP)}

Other names: di-octylphthalate (DOP), bis-(2-ethylhexyl) phthalate,

1,2-benzenedicarboxylic acid, bis(2-ethylhexyl) ester, Octoil

CAS Registry Number: 117-81-7

Di-2-ethylhexylphthalate is used in large quantities in the organic chemical industry primarily as a plasticizer for polyvinyl chloride and other polymeric materials (Howard, 1989). It is also used as organic pump fluid. DEHP is released to air and water during the production, disposal, incineration, and recycling of plastic materials in which it has been used.

Formula: $\mathrm{C}_{24} \mathrm{H}_{38} \mathrm{O}_{4}$<smiles>CCCCC(CC)COC(=O)c1ccccc1C(=O)OCC(CC)CCCC</smiles>

Molecular weight

390.54 (Howard, 1989; Windholz. et al., 1983)

Melting Point

$10^{\circ} \mathrm{C}$ (Verschueren, 1983)

$11.8^{\circ} \mathrm{C}$ (Howard, 1989)

Octanol-water partition coefficient $\left(K_{o w}\right)$

9,550 based on a $\log \mathrm{K}_{\mathrm{ow}}$ of 3.98 reported by Hansch and Leo (1987) and referenced to a value published by Scheele (1980). However, in the Scheele (1980) paper, which lists this value, no statement is made as to whether this is a measured, estimated, or cited value.

45,700 based on a $\log \mathrm{K}_{\mathrm{ow}}$ of 4.66 reported by Harnisch et al. (1983) as a measured value from the OECD/EEC laboratory comparison tests for the shake-flask method. 
87,100 based on a $\log \mathrm{K}_{\mathrm{ow}}$ of 4.94 reported by Harnisch et al. (1983) as a measured value from the OECD/EEC laboratory comparison tests for the shake-flask method.

89,100 based on a $\log \mathrm{K}_{\mathrm{ow}}$ of 4.95 reported by Harnisch et al. (1983) as a measured value from the OECD/EEC laboratory comparison tests for the shake-flask method.

151,000 based on a $\log \mathrm{K}_{\mathrm{ow}}$ of 5.18 reported by Harnisch et al. (1983) as a measured value from the OECD/EEC laboratory comparison tests for the shake-flask method.

107,000 based on a $\log \mathrm{K}_{\mathrm{ow}}$ of 5.03 reported by Hansch and Leo (1987) and referenced to the measured values published in Harnisch et al. (1983)

129,000 based on a log Kow of 5.11 as given in Howard (1989) and attributed to Howard et al (1985)

275,000 based on a $\log \mathrm{K}_{\mathrm{ow}}$ of 5.44 reported by Harnisch et al. (1983) as a measured value from the OECD/EEC laboratory comparison tests for the shake-flask method.

8.7 $\times 10^{7}$ Based on a $\log \mathrm{K}_{\mathrm{ow}}$ value of 7.94 as measured in Howard et al. (1985). However, Howard et al (1985) report that this value is suspect because the method they used may not work well with this compound. [This value is also cited in Hansch and Leo (1987).

Recommended value, based on the log-mean value of the 6 measured values reported above but excluding the suspect value reported by Howard et al. (1983):

$$
\begin{aligned}
& \log K_{o w}=5.05 \pm 0.26 \\
& K_{\text {ow }}=112,000 \times \text { or } \div 1.8
\end{aligned}
$$

\section{Vapor pressure at standard temperatures}

$0.00034 \mathrm{~Pa}$ at $25^{\circ} \mathrm{C}$ measured using the gas saturation method by Howard et al. (1985).

$0.00064 \mathrm{~Pa}$ at $25^{\circ} \mathrm{C}$ measured using the gas saturation method by Howard et al. (1985).

$0.00083 \mathrm{~Pa}$ at $25^{\circ} \mathrm{C}$ measured by Werner (1952).

$0.00086 \mathrm{~Pa}$ at $25^{\circ} \mathrm{C}$ reported by Howard (1989) based on the mean of the values measured by Howard et al. (1985). 
$0.0016 \mathrm{~Pa}$ at $25^{\circ} \mathrm{C}$ measured using the gas saturation method by Howard et al. (1985).

$670 \mathrm{~Pa}$ at $230^{\circ} \mathrm{C}$ reported by Howard (1989).

$160 \mathrm{~Pa}$ at $200^{\circ} \mathrm{C}$ reported by Verschueren (1983).

From the measured vapor pressures reported above, the following approximate Antoine equation can be developed:

$\log _{10}(\mathrm{VP}$ in $\mathrm{Pa})=11.297-\frac{4281.3}{273+\mathrm{T}}$, which gives $\mathrm{VP}=0.0085 \mathrm{~Pa}$ at $25^{\circ} \mathrm{C}$.

The Antoine equation proposed above for VP versus temperature is plotted below in the temperature range $-10^{\circ} \mathrm{C}<\mathrm{T}<40^{\circ} \mathrm{C}$.

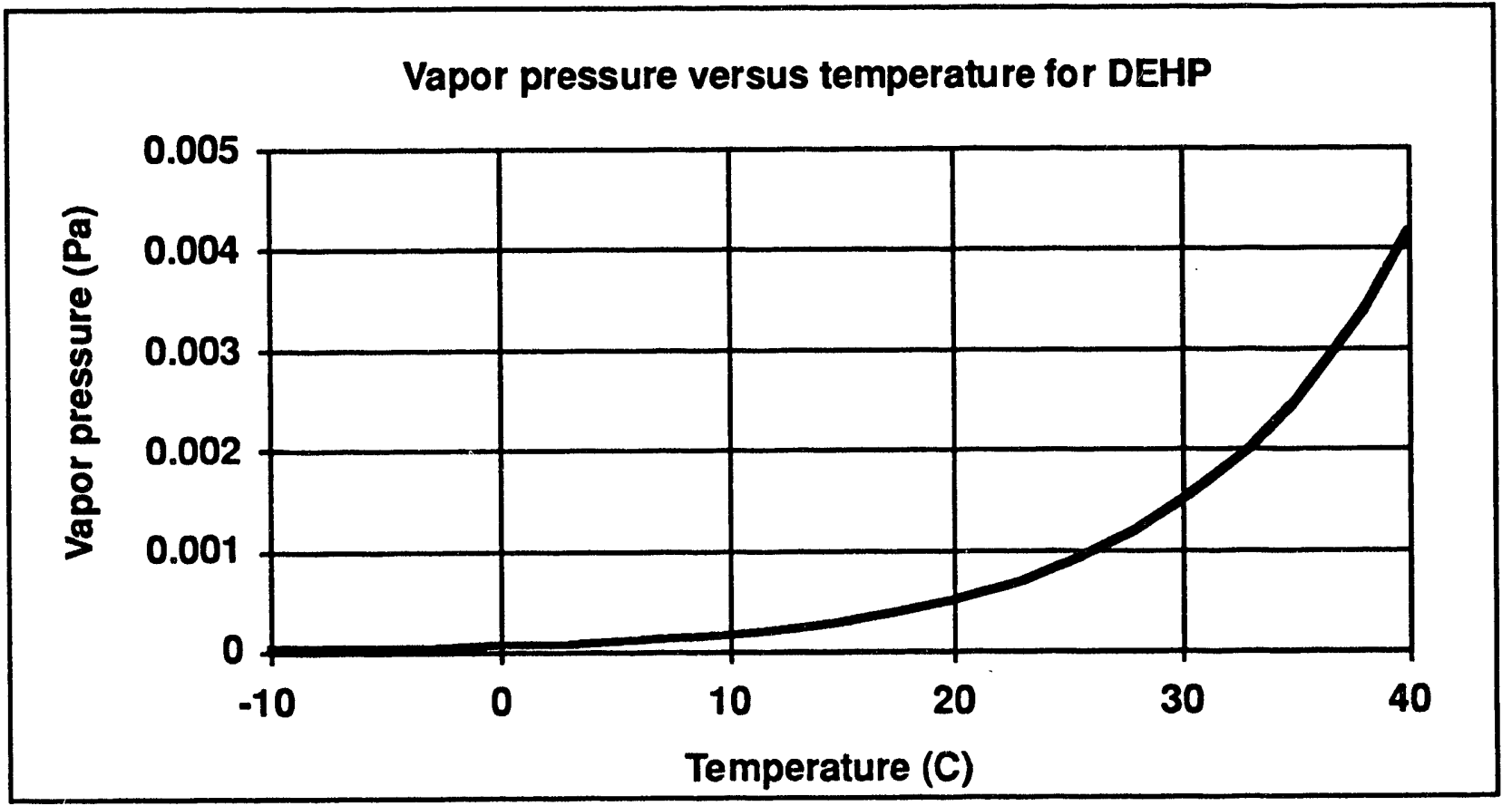

Recommended value based on the mean of the 4 measured values cited above:

$$
\mathrm{VP}(\mathrm{Pa})=0.00085 \pm 0.0005 \mathrm{~Pa} @ 25^{\circ} \mathrm{C}
$$

Solubility in water

$0.041 \mathrm{mg} / \mathrm{L}$ at $20^{\circ} \mathrm{C}$ measured by Leyder and Boulenger (1983). [This value is also cited in Howard et al. (1985)]. 
$0.285 \mathrm{mg} / \mathrm{L}$ at $24^{\circ} \mathrm{C}$ for technical grade DEHP reported by Verschueren (1983).

$0.34 \pm 0.04 \mathrm{mg} / \mathrm{L}$ at $25^{\circ} \mathrm{C}$ measured by Howard et al. (1985). [This value is also cited in Howard (1989)].

$0.40 \pm 0.05 \mathrm{mg} / \mathrm{L}$ at $25^{\circ} \mathrm{C}$ measured by Wolf et al. (1980a). [This value is also cited in Howard et al. (1985)].

Recommended water solubility (WS) based on the arithmetic mean of all the reported values above:

$$
\begin{aligned}
& W S(\mathrm{mg} / \mathrm{L})=0.27 \pm 0.16 \mathrm{mg} / \mathrm{L} @ 25^{\circ} \mathrm{C} \\
& W S\left(\mathrm{~mol} / \mathrm{m}^{3}\right)=6.9( \pm 4.1) \times 10^{-4} \mathrm{~mol} / \mathrm{m}^{3} @ 25^{\circ} \mathrm{C}
\end{aligned}
$$

Henry's law constant (dimensionless form, i.e., $H / R T$ )

$4.5 \times 10^{-4}$ at $25^{\circ} \mathrm{C}$ calculated by Howard (1989) based on the ratio of vapor pressure to solubility.

$4.9( \pm 4.1) \times 10^{-4}$ at $25^{\circ} \mathrm{C}$ derived from the mean and standard deviation of the ratio vapor pressure and solubility based on the values reported in sections above.

Recommended value, based on the values reported above:

$$
H /(R T)=4.9( \pm 4.1) \times 10^{-4} @ 25^{\circ} \mathrm{C}
$$

Organic-carbon partition coefficient $\left(K_{o c}\right)$

5,800 calculated by Kenaga (1980).

57,000 calculated by Wolfe et al. (1980b)

87,420 reported by Russell and McDuffie (1986) in a 1.59\% organic-carbon composite soil from Broome County, New York. [Also cited in Howard, 1989)]

$1400 \pm 200$ based on measurements by Sullivan et al. (1982) of DEHP desorption from ocean sediment samples containing roughly $1 \%$ organic carbon.

With $\mathrm{K}_{\mathrm{ow}}=112,000\left(\log \mathrm{K}_{\mathrm{ow}}=5.05\right)$ and WS $=0.27 \mathrm{mg} / \mathrm{L}$, estimation methods for $\mathrm{K}_{\mathrm{oc}}$ produce the following values for $\mathrm{K}_{\mathrm{oc}}$, 
13,300 as derived from the regression equation relating $K_{o c}$ to $K_{o w}$ in Kenaga and Goring (1980) and referred to in Lyman et al. (1990).

13,$400 ; 104,000 ; 44,500$; and 54,100 as derived from the four regression equations relating $\mathrm{K}_{\mathrm{oc}}$ to $\mathrm{K}_{\mathrm{ow}}$ in Karickhoff (1985).

23,000 as derived from the regression of $K_{o c}$ with water solubility proposed by Chiou et al. (1977)

8,970 as derived from the regression of $K_{o c}$ with water solubility proposed by Kenaga (1980)

166,000 calculated by Meylan et al (1992) with a regression equation relating $\mathrm{K}_{\mathrm{oc}}$ to the molecular connectivity index $\left({ }^{1} \chi=13.6\right)$.

Recommended value, based on the log-mean value of the 12 values reported above and the $68 \%$ ( $2 \mathrm{GSD}$ ) range about the log mean:

$$
\begin{aligned}
& \log \mathrm{K}_{\mathrm{OC}}=4.3 \pm 0.67 \\
& \mathrm{~K}_{\mathrm{OC}}=20,000 \times \text { or } \div 4.7
\end{aligned}
$$

\section{Diffusion coefficient in water}

Based on the Wilke and Chang (1955) method described in Reid et al. (1987), the diffusion coefficient in $\mathrm{m}^{2} / \mathrm{d}$ in water is given by

$$
D_{x y}=\frac{6.5 \times 10^{-7}\left(\phi M_{y}\right)^{1 / 2} \mathrm{~T}}{\eta_{y} V_{x}^{0.6}} .
$$

The molecular weight $M_{y}$ of water is $18 \mathrm{~g} / \mathrm{mol}$. Wilke ard Chang (1955) recommend an association factor, $\phi$, of 2.6 when the solvent is water. The viscosity of water, $\eta_{y}$, is $0.89 \mathrm{cP}$ at $25^{\circ} \mathrm{C}$. Molecular volume, $\mathrm{V}_{\mathrm{x}}$, estimated by the LeBas incremental method, described in Lyman et al. (1990) equals $459 \mathrm{~cm}^{3} / \mathrm{mol}$. With these values and with temperature $(T)$ expressed in kelvins, this expression gives,

Recommended value:

$$
D_{\text {water }}=1.3 \times 10^{-7} \mathrm{~T} \mathrm{~m}^{2} / \mathrm{d}=3.8 \times 10^{-5} \mathrm{~m}^{2} / \mathrm{d} \text { or } 4.3 \times 10^{-10} \mathrm{~m}^{2} / \mathrm{s} @ 25^{\circ} \mathrm{C}
$$


Diffusion coefficient in air

Based on the Fuller, et al. (1966) method described in Lyman et al. (1982), the diffusion coefficient in $\mathrm{m}^{2} / \mathrm{d}$ in air is given by

$$
D_{\text {air }}=8.6 \times 10^{-3} \mathrm{~T}^{1.75} \frac{\sqrt{\frac{\left(29+\mathrm{M}_{x}\right)}{29 \mathrm{M}_{\mathrm{x}}}}}{\left[2.7+\left(V_{x}\right)^{1 / 3}\right]^{2}}
$$

With the molecular volume, $\mathrm{V}_{\mathrm{x}}$, of DEHP of $459 \mathrm{~cm}^{3} / \mathrm{mol}$ and a molecular weight of $391 \mathrm{~g} / \mathrm{mol}$, and with temperature (T) expressed in kelvins, this expression gives

Recommended value:

$$
\mathrm{D}_{\text {air }}=1.5 \times 10^{-5} \mathrm{~T}^{1.75} \mathrm{~m}^{2} / \mathrm{d}=0.33 \mathrm{~m}^{2} / \mathrm{d} \text { or } 3.8 \times 10^{-6} \mathrm{~m}^{2} / \mathrm{s} @ 25^{\circ} \mathrm{C}
$$

Bioconcentration factors for plant root concentration relative to soil concentration

No reported measurements of plant-root bioconcentration for DEHP in soils are available in the current literature. Estimation methods for this parameter are considered below.

The partition factor from surface soil to edible plant parts due to rainsplash, $\mathrm{K}_{\mathrm{ps}}^{\text {rain }}$ is equal to $0.0034 \mathrm{~kg}$ (soil) $/ \mathrm{kg}$ (plant) with a CV of 1 (Dreicer et al. 1984). This partition factor relates plant fresh-mass concentration to soil concentration.

Based on the Briggs et al. $(1982,1983)$ estimation equation for uptake of contaminants by roots from soil solution, we calculate the RCF (which represents the ratio of contaminant concentration in root, $\mathrm{mg} / \mathrm{kg}$ [fresh mass], to contaminant concentration in soil solution, $\mathrm{mg} / \mathrm{L}$ ) for $\mathrm{DEHP}$ as

$\mathrm{RCF}=0.82+0.03 \mathrm{~K}_{\mathrm{ow}}^{0.77}=233$

When this factor is divided by the sorption coefficient, $\mathrm{K}_{\mathrm{D}}=\mathrm{f}_{\mathrm{OC}} \times \mathrm{K}_{\mathrm{OC}}=(0.01$ to $0.02) \times \mathrm{K}_{\mathrm{oc}}$ (from above), we obtain the ratio of contaminant concentration in roots, $\mathrm{mg} / \mathrm{kg}$ (fresh mass) to contaminant concentration in soil solids, $\mathrm{mg} / \mathrm{kg}$, which we refer to as $\mathrm{K}_{\mathrm{ps}}$ (roots) and estimate it as being in the range

$$
\mathrm{K}_{\mathrm{ps}}\left(\text { roots) }=0.46 \text { to } 0.93 \times \text { or } \div 4.4 \text { (reflecting the estimation error in } \mathrm{K}_{\mathrm{oc}}\right. \text { ) }
$$


Based the regression of $\mathrm{K}_{\mathrm{ps}}$ (roots) with $\mathrm{K}_{\mathrm{oc}}$ from Topp et al. (1986), and based on the range of $K_{o c}$ values listed above, we obtain

$$
\begin{aligned}
& \text { (recommended value for root crops) } \\
& \mathrm{K}_{\mathrm{ps}}(\text { roots })=664 \mathrm{~K}_{\mathrm{oc}}^{-0.622}=1.2 \times \text { or } \div 4.4 \quad \text { (reflecting the error in } \mathrm{K}_{\mathrm{oc}} \text { ) }
\end{aligned}
$$

Based on the Travis and Arms (1988) correlation for plant-soil bioconcentration we obtain for total plant (not just roots) the following soil/plant partition coefficient

$$
\begin{aligned}
\mathrm{K}_{\mathrm{ps}}=7.7 \mathrm{~K}_{\mathrm{ow}}^{-0.58}=0.02 \times \text { or } \div 5.4 & \begin{array}{l}
\text { (recommended value for exposed } \\
\text { produce reflecting the estimation } \\
\text { error in the regression equation) }
\end{array}
\end{aligned}
$$

Bioconcentration factors for plant leaf concentration relative to air concentration

No reported measurements of plant-air bioconcentration for DEHP in air are available in the current literature. Estimation methods for this parameter are considered below.

Based on the model of Riederer (1990) for foliar uptake of gases in plant leaves, we estimate a steady-state plant-air coefficient of

$$
\mathrm{K}_{\mathrm{pa}}^{\mathrm{gs}}=\left[0.5+\left(0.4+0.01 \times \mathrm{K}_{\mathrm{ow}}\right) \times \frac{\mathrm{RT}}{\mathrm{H}}\right] \times 10^{-3} \frac{\mathrm{m}^{3}}{\mathrm{~kg}}=2300 \text { (recommended value) }
$$

We could find no study in which the estimation error of this partition coefficient has been considered, but we assume the $\mathrm{CV}$ associated with it is on the order of 1 (or GSD = 2.3).

Bioconcentration factors for fish concentration relative to water or sediment concentrations

$209 \pm 65$ measured by Brown and Thompson (1982a) in Daphnia magna (waterfleas).

2370 to 2630 measured by Brown and Thompson (1982b) in Mytilus edulis (mussels).

13500 to 13600 measured by Sanders et al. (1973) at $25^{\circ} \mathrm{C}$ in Scud. 
260 to 270 measured by Sanders et al. (1973) at $25^{\circ} \mathrm{C}$ in Scud.

5200 measured by Sanders et al. (1973) at $25^{\circ} \mathrm{C}$ in Waterfleas.

3100 measured by Sanders et al. (1973) at $25^{\circ} \mathrm{C}$ in Midge larvae.

129 peak value measured in fish by Metcalf et al. (1973) in a study to determine uptake of $10 \mathrm{ppm}$ DEHP in water by aquatic organisms.

265 peak value measured in fish by Metcalf et al. (1973) in a study to determine uptake of $0.1 \mathrm{ppm}$ DEHP in water by aquatic organisms.

155 peak value measured in waterfleas by Metcalf et al. (1973) in a study to determine uptake of $10 \mathrm{ppm}$ DEHP in water by aquatic organisms.

183 peak value measured in waterfleas by Metcalf et al. (1973) in a study to determine uptake of $0.1 \mathrm{ppm} D E H P$ in water by aquatic organisms.

402 peak value measured in snails by Metcalf et al. (1973) in a study to determine uptake of $10 \mathrm{ppm}$ DEHP in water by aquatic organisms.

858 peak value measured in snails by Metcalf et al. (1973) in a study to determine uptake of $0.1 \mathrm{ppm}$ DEHP in water by aquatic organisms.

420 measured in waterfleas after 7 days exposure by Mayer and Sanders (1973) using a water consentration of $0.3 \mu \mathrm{g} / \mathrm{L}$.

3600 measured in scud after 14 days exposure by Mayer and Sanders (1973) using a water concentration of $0.1 \mu \mathrm{g} / \mathrm{L}$.

350 measured in midges after 7 days exposure by Mayer and Sanders (1973) using a water concentration of $0.3 \mu \mathrm{g} / \mathrm{L}$.

1380 measured in flathead minnows after 28 days exposure by Mayer and Sanders (1973) using a water concentration of $1.9 \mu \mathrm{g} / \mathrm{L}$.

247 based on measurements of DEHP concentration in rainbow trout bile relative to that in water by Statham et al. (1976).

Recommended value, based on the log-mean value of the 16 values reported above and the $68 \%$ ( 2 GSD) range about the log mean:

$\log \mathrm{BCF}=2.86 \pm 0.63$

$\mathrm{BCF}=720 \times$ or $\div 4.3$ 
Steady-state biotransfer factors for milk or dairy-product concentration relative to contaminant intake by cattle

No reported measurements of milk-diet biotransfer for DEHP are available in the current literature. An estimation method for this parameter is considered below.

Based on the geometric mean regression of milk-to-diet biotransfer against $\mathrm{K}_{\mathrm{ow}}$ developed by Travis and Arms (1988) we estimate the milk biotransfer factor for DEHP as

$$
B_{k}=7.9 \times 10^{-9} K_{o w} \times 10^{( \pm 0.84)}=8.9 \times 10^{-4} \times \text { or } \div 7 \text { (recommended value) }
$$

The estimation error in this expression corresponds to a CVs of 6.

Steady-state biotransfer factors for meat concentration relative to contaminant intake by cattle, pigs, and chickens

No reported measurements of meat-diet biotransfer for DEHP are available in the current literature. An estimation method for this parameter is considered below.

Based on the geometric mean regression of meat-to-diet biotransfer against $\mathrm{K}_{\mathrm{ow}}$ developed by Travis and Arms (1988) we estimate the meat biotransfer factor for DEHP as

$$
B_{t}=2.5 \times 10^{-8} K_{o w} \times 10^{( \pm 0.952)}=2.8 \times 10^{-3} \times \text { or } \div 9 \text { (recommended value) }
$$

The estimation error in this expression corresponds to a CV of 11.

Steady-state biotransfer factors for egg concentration rclative to contaminant intake by chickens

No reported measurements of egg-diet biotransfer for DEHP are available in the current literature. An estimation method for this parameter is considered below.

Based on the geometric mean regression of egg-to-diet biotransfer against $\mathrm{K}_{\mathrm{ow}}$ developed above, we estimate the egg biotransfer factor for DEHP as

$$
B_{e}=7.9 \times 10^{-6} K_{o w} \times 10^{( \pm 1)}=0.89 \times \text { or } \div 10 \text { (recommended value) }
$$

The estimation error in this expression corresponds to a CV of 14 . 
Contaminant biodegradation factors in soil

Based on screening biodegradation studies, DEHP degrades rapidly in the presence of water, DEHP degrades rapidly in acclimated systems, but acclirnation is very important since almost no degradation occurs in unacclimated systems (Howard et al., 1991). Based on grab-sample die-away test data from Schouten et al. (1979) and Johnson and Lulves (1975), Howard et al. (1991) have estimated the half-live of DEHP in soil due to aerobic biodegradation to be in the range of 5 to 23 days. Howard et al. (1991) have estimated the half-life of DEHP in soil due to anaerobic biodegradation to be in the range of 42 to 389 days. These estimates of soil biodegradation are based on unacclimated aqueous biodegradation.

Recommended value, based on log mean and log variance of the range of the soil half lives given above:

Soil biodegradation rate constant $=0.016 \mathrm{~d}^{-1} \times$ or $\div 3.5$

Media-specific half lives for air, soil, and surface water

Air. Based on measurements of dimethyl phthalate photolysis by Atkinson (1987), Howard et al. (1991) estimate that the half life of DEHP in the lower atmosphere is in the range of 2.9 to 29 hours ( 0.12 to 1.2 days ) as a result primarily of photo-oxidation as a removal process.

Soil Howard et al. (1991) have estimated the half-live of DEHP in soil due to aqueous aerobic biodegradation to be in the range of 5 to 23 days. Howard et al. (1991) have estimated the half-live of DEHP in soil due to aqueous anaerobic biodegradation to be in the range of 42 to 389 .

Water Howard et al. (1991) have estimated the half-live of DEHP in surface water due to aqueous aerobic biodegradation to be in the range of 5 to 23 days.

Recommended half-lives (in days), based on the log mean of the half lives and geometric range of the values:

$$
\begin{array}{ll}
\text { Air } & 0.38 \times \text { or } \div 1.9 \\
\text { Soil } & 44 \times \text { or } \div 3.5 \\
\text { Water } & 11 \times \text { or } \div 1.5
\end{array}
$$




\section{References for Di(2-ethylhexyl)phthalate (DEHP)}

Atkinson, R. (1987), "Structure-Activity Relationship for the Estimation of Rate Constants for the Gas-Phase Reactions of $\mathrm{OH}$ Radicals with Organic Compounds," Int. J. Chem. Kinetics 19, 799-828.

Briggs, G.G., R.H. Bromilow, and A.A. Evans (1982), "Relationships Between Lipophilicity and Root Uptake and Translocation of Non-Ionized Chemicals by Barley," Pestic. Sci. 13, 495-504.

Briggs, G.G., R.H. Bromilow, A.A. Evans, and M. Williams (1983), "Relationships Between Lipophilicity and the Distribution of Non-Ionized Chemicals in Barley Shoots Following Uptake by the Roots," Pestic. Sci. 14, 492-500.

Brown, D., and R.S. Thompson (1982a), "Phthalates and the Aquatic Environment: Part Is The Effect of Di-2-Ethylhexyl Phthalate (DEHP) and Di-Isodecyl Phthalate (DIDP) on the Reproduction of Daphnia magna and Observations on Their Bioconcentration," Chemosphere 11, 417-426.

Brown, D., and R.S. Thompson (1982b), "Phthalates and the Aquatic Environment: Part II. The Bioconcentration and Depuration of Di-2-Ethylhexyl Phthalate (DEHP) and Di-Isodecyl Phthalate (DIDP) in Mussels (Myutilus edulis)," Chemosphere 11, 427-435.

Chiou, C. T., V. H. Freed, D.W. Schmedding, and R. L. Kohnert (1977), "Partition Coefficient and Bioaccumulation of Selected Organic Chemicals," Environ. Sci. Technol. 11(5), 475-478.

Dreicer, M., T.E. Hakonson, G.C. White, and F.W. Whicker (1984), "Rainsplash as a Mechanism for Soil Contamination of Plant Surfaces," Health Phys. 46, 177-187.

Fuller, E.N., P.D. Schettler, and J.C. Giddings (1966), "A New Method for Prediction of Binary Gas-Phase Diffusion Coefficients," Ind. Eng. Chem. 58, 19-27.

Hansch, C., and A. Leo (1987), "The Log P and Related Parameters Database," created and updated by the Medicinal Chemistry Project at Pomona College, Claremont, CA, under the direction of Corwin Hansch and Albert Leo - 1987 Printout.

Harnisch, M., H.J. Möckel, and G. Schulze (1983), "CHROMSYMP. 160: Relationship Between Log $P_{\text {ow }}$ Shake-Flask Values and Capacity Factors Derived From Reversed-Phase High-Performance Liquid Chromatography for $n$-Alkylbenzenes and Some OECD Reference Substances," J. Chromatogr. 282, 315-332.

Howard, P.H., S. Banerjee, and K.H. Robiliard (1985), "Measurement of Water Solubilities, Octanol/Water Partition Coeficients and Vapor Pressures of Commercial Phthalate Esters," Environ. Toricol. Chem.4, 653-661. 
Howard, P.H., Ed. (1989), Handbook of Fate and Exposure Data for Organic Chemicals. Vol. I . Large Production and Priority Pollutants (Lewis Publishers, Inc., Chelsea, MI).

Howard, P. H., R. S. Boethling, W. F. Jarvis, W. M. Meylan, and E. M. Michalenko, Eds. (1991), Handbook of Environmental Degradation Rates (Lewis Publishers, Inc, Chelsea, MI).

Johnson, B.T., and W. Lulves (1975), "Biodegradation of Di-n-Butyl Phthalate and Di-2-Ethylhexyl Phthalate in Freshwater Hydrosoil," J. Fish. Res. Board

Can. 32, 333-339.

Karickhoff, S.W. (1985), "Chapter 3. Pollutant Sorption in Environmental Systems," in Environmental Exposure From Chemicals, Volume I., W. B. Neely and G.E. Blau, Eds. (CRC Press, Inc., Boca Raton, FL), pp. 49-64.

Kenaga, E. E. (1980), "Predicted Bioconcentration Factors and Soil

Sorption Coefficients of Pesticides and Other Chemicals," Ecotoxicol.

Environ. Saf. 4, 26-38.

Kenaga, E. E., and C.A.I. Goring (1980), "Relationship Between Water Solubility, Soil Sorption, Octanol-Water Partitioning, and Concentration of Chemicals in Biota," in Aquatic Toxicology, ASTM STP 707, J. G. Eaton, P. R. Parrish, and A. C. Hendricks, Eds. (American Society for Testing and Materials, Philadelphia, PA) pp. 78-115.

Leyder, F., and P. Boulenger (1983), "Ultraviolet Adsorption, Aqueous Solubility, and Octanol-Water Partition for Several Phthalates," Bull. Environ. Contam. Toxicol. 30, 152-157.

Lyman, W. J., W. F. Reehl, and D. H. Rosenblatt (1990), Handbook of Chemical Property Estimation Methods: Environmental Behavior of Organic Compounds (American Chemical Society, Washington, DC).

Mayer, F.L., Jr., and H.O. Sanders (1973), "Toxicology of Phthalic Acid Esters in Aquatic Organisms," Environ. Health Perspect. Experimental Issue Number three, 153-157 [January 1973; DHEW Publication N². (NIH) 73-218].

Metcalf, R.L., G.M. Booth, C.K. Schuth, D.J. Hansen, and P.-Y. Lu (1973), "Uptake and Fate of Di-2-ethylhexyl Phthalate in Aquatic Organisms and in a Model Ecosystem," Environ. Health Perspect. Experimental Issue Number four, 27-34 [June 1973; DHEW Publication No. (NIH) 73-218].

Meylan, W., P.H. Howard, and R.S. Boethling (1992), "Molecular Topology/Fragment Contribution Method for Predicting Soil Sorption Coefficients," Environ. Sci. Technol. 26, 1560-1567.

Reid, R. C., J. M. Prausnitz, and B. E. Poling (1987), The Properties of Gases and Liquids (McGraw Hill, New York City, NY), 4th ed. 
Reiderer, M. (1990), "Estimating Partitioning and Transport of Organic Chemicals in the Foliage/Atmosphere System: Discussion of a Fugacity-Based Model," Environ. Scil. Technol. 24, 829-837.

Russell, D.J., and B. McDuffie (1986), "Chemodynamic Properties of Phthalatc Esters: Partitioning and Soil Migration," Chemosphere 15, 1003-1021.

Sanders, H.O., F.L. Mayer, Jr., and D.F. Walsh (1973), "Toxicity, Residue Dynamics, and Reprtoductive Effects of Phthalate Esters in Aquatic Invertebrates," Environ.

Res. 6, 84-90.

Scheele, B. (1980), "Reference Chemicals as Aids in Evaluating A Research Programme - Selection Aims and Criteria," Chemosphere 9, 293-309.

Schouten, M.J., J.W.C. Peereboom, and U.A.T. Brinkman (1979), "Liquid Chromatographic Analysis of Phthalate Esters in Dutch River Water," Int. J. Analyt. Chem. 7, 13-23.

Statham, C.N., M.J. Melancon, Jr., and J.J. Lech (1976), "Bioconcentration of Xenobiotics in Trout Bile: A Proposed Monitoring Aid for Some Waterborne Chemicals," Science 193, 680-681.

Sullivan, K.F., E.L. Atlas, and C.-S. Glam (1982), "Adsorption of Phthalic Acid Esters from Seawater," Environ. Sci. Technol. 16, 428-432.

Topp, E., I. Scheunert, A. Attar, and F. Korte (1986), "Factors Affecting the Uptake of 14C-Labeled Organic Chemicals by Plants From Soil," Ecotoxicol. Environ. Saf. 11, 219-228.

Travis, C. C., and A. D. Arms (1988), "Bioconcentration of Organics in Beef, Milk, and Vegetation," Environ. Sci. Technol. 22, 271-274.

Verschueren, K. (1983), Handbook of Lnvironmental Data on Organic Chemicals, Second Edition (Van Nostrand Reinhold Company Inc., New York City, NY).

Werner, A.C. (1952), "Vapor Pressures of Phthalate Esters," Ind. Eng. Chem. 44, 2736-2740.

Wilke, C.R., and P. Chang (1955), "Correlation of Diffusion Coefficients in Dilute Solutions," AIChE J. 1, 264-270.

Windholz, M., S. Budavari, R. F. Blumetti, and E. S. Otterbein, Eds. (1983), The Merck Index: An Encyclopedia of Chemicals, Drugs, and Biologicals, 10th Edition (Merck \& Co., Inc., Rahway, NJ).

Wolfe, N.L., W.C. Steen, and L.A. Burns (1980a), "Phthalate Ester Hydrolysis: Linear Free Energy Relationships," Chemosphere 9, 403-408.

Wolfe, N.L., L.A. Burns, and W.C. Steen (1980b), "Use of Linear Free Energy

Relationships on an Evaluative Model to Assess the Fate and Transport of Phthalate Esters in the Aquatic Environment," Chemosphere 9, 393-402. 


\section{Di-2-ethylhexylphthalate}




\section{1,4-Dioxane}

Other names: glycolethylenether; 1,4-diethylenedioxide

CAS Registry Number: 123-91-1

1,4-dioxane is a widely used solvent in chemical manufacturing. It is miscible in water and relatively soluble in organic liquids. 1,4-Dioxane is produced in millions of $\mathrm{kg}$ per year (Howard, 1990). It is widely used as a solvent in such commonly used products as paints, varnishes, lacquers, cosmetics, and deodorants. It is also used as a solvent for varnish removers, for wetting and dispersing agents in textile manufacturing, for dye baths, for stain and printing compositions, for cleaning and detergent preparations, and for cements. It is used as a stabilizer for chlorinated solvents and is used in scintillation fluids. 1,4-Dioxane is also used as a solvent for cellulose acetate, ethyl cellulose, benzyl cellulose, resins, oils, waxes, oil and spirit-soluble dyes.

Formula: $\mathrm{C}_{4} \mathrm{H}_{8} \mathrm{O}_{2}$

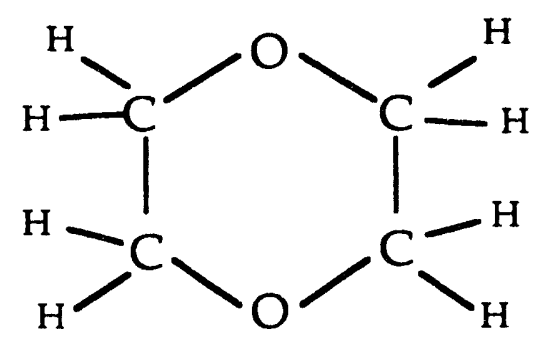

Molecular weight

88.10 (Howard, 1990; Windholz et al., 1983)

88.11 (Weast et al., 1986)

88.20 (Verschueren, 1983)

Melting Point

$10^{\circ} \mathrm{C}$ (Verschueren, 1983)

$11.8^{\circ} \mathrm{C}$ (Howard et al., 1990)

Octanol-water partition coefficient $\left(K_{o w}\right)$

0.537 based on a $\log \mathrm{K}_{\mathrm{ow}}$ of -0.27 reported by Hansch and Leo (1987) based on an unpublished analysis by $P$. Jow and C. Hansch.

0.537 based on a $\log \mathrm{K}_{\mathrm{ow}}$ of -0.27 reported by Howard et al. (1990) and referenced to a value published in Hansch and Leo (1985). 
0.380 based on a $\log \mathrm{K}_{\mathrm{ow}}$ of -0.42 reported by Verschueren (1983) and attributed to Leo and Hansch (1971).

0.380 based on a log Kow of -0.42 reported in Hansch and Leo (1987) and attributed to a measured value by Collander (1951).

Recommended value, based on the log-mean value and range of the 2 measured values reported above:

$$
\begin{aligned}
& \log K_{\text {ow }}=-0.345 \pm 0.043 \\
& K_{\text {ow }}=0.45 \times \text { or } \div 1.1
\end{aligned}
$$

\section{Vapor pressure at standard temperatures}

Stull (1947) reports the following vapor pressures for 1,4-dioxane.

$\begin{array}{ccc}\text { Temperature }\left({ }^{\circ} \mathrm{C}\right) & \text { Vapor Pressure }(\mathrm{mm}) & \text { Vapor Pressure }(\mathrm{kPa}) \\ -12.8 & 5 & 0.667 \\ -1.2 & 10 & 1.33 \\ 12.0 & 20 & 2.67 \\ 25.2 & 40 & 5.33 \\ 33.8 & 60 & 8.00 \\ 45.1 & 100 & 13.3 \\ 62.3 & 200 & 26.7 \\ 81.8 & 400 & 53.3 \\ 101.1 & 760 & 101\end{array}$

Interpolating from this data set gives $\mathrm{VP}$ at $25^{\circ} \mathrm{C}=5.32 \mathrm{kPa}$

Verschueren (1983) reports the following vapor pressures for 1,4 dioxane.

Temperature $\left({ }^{\circ} \mathrm{C}\right) \quad$ Vapor Pressure $(\mathrm{mm})$ Vapor Pressure $(\mathrm{kPa})$

20

25

30

101
30

37

50

760
4.00

4.93

6.67

101

Interpolating from this data set give VP at $25^{\circ} \mathrm{C}=5.10 \mathrm{kPa}$ 
The Merck Index (Windholz et al., 1983) reports the following vapor pressures for 1,4-dioxane, which appear to be taken from Stull (1947).

$\begin{array}{ccc}\text { Temperature }\left({ }^{\circ} \mathrm{C}\right) & \text { Vapor Pressure }(\mathrm{mm}) & \text { Vapor Pressure }(\mathrm{kPa}) \\ 12.0 & 20 & 2.67 \\ 25.2 & 40 & 5.33 \\ 33.8 & 60 & 8.00 \\ 45.1 & 100 & 13.3 \\ 62.3 & 200 & 26.7 \\ 81.8 & 400 & 53.3 \\ 101.1 & 760 & 101\end{array}$

$5.07 \mathrm{kPa}$ at $25^{\circ} \mathrm{C}$ reported by Howard (1990), who attribute this value to Boublik et al (1984).

The following Antoine equations have been published for estimating the vapor pressure of 1,4-dioxane in $\mathrm{kPa}$

$\log _{10}(\mathrm{VP})=6.56014-\frac{1556.98}{240.566+\mathrm{T}}$ for $20^{\circ} \mathrm{C}<\mathrm{T}<105^{\circ} \mathrm{C}$ from Boublik et al. (1984),

which gives $\mathrm{VP}=4.98 \mathrm{kPa}$ at $25^{\circ} \mathrm{C}$;

$\log _{10}(\mathrm{VP})=6.56891-\frac{1558.445}{240.459+\mathrm{T}}$ for $20^{\circ} \mathrm{C}<\mathrm{T}<125^{\circ} \mathrm{C}$ from Boublik et al. (1984), which gives VP $=4.99 \mathrm{kPa}$ at $25^{\circ} \mathrm{C}$; and

$\log _{10}(\mathrm{VP})=6.5565-\frac{1554.68}{240.34+\mathrm{T}}$ for $20^{\circ} \mathrm{C}<\mathrm{T}<105^{\circ} \mathrm{C}$ from Dean (1985), which gives $\mathrm{VP}=4.98 \mathrm{kPa}$ at $25^{\circ} \mathrm{C}$.

In addition, we have determined that a fit to the data of Stull (1947) can be obtained from the following Antoine equation

$\log _{10}(\mathrm{VP})=6.9948-\frac{1868.13}{273+\mathrm{T}}$ for $-13^{\circ} \mathrm{C}<\mathrm{T}<45^{\circ} \mathrm{C}$,

which gives $\mathrm{VP}=5.32 \mathrm{kPa}$ at $25^{\circ} \mathrm{C}$. 


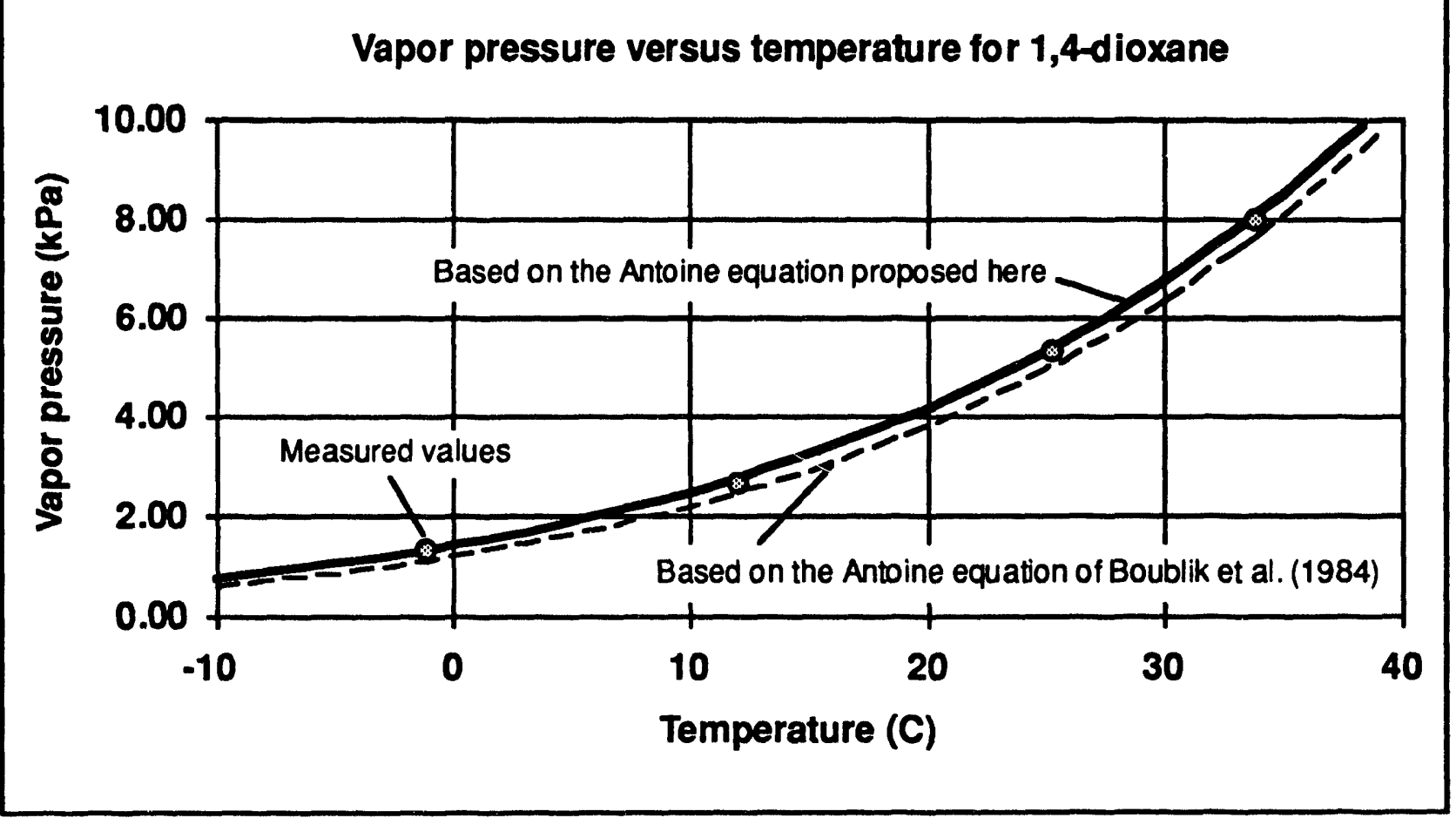

The Antoine equation above and the Antoine equation proposed by Boublik et al. (1984) based on the range $20^{\circ} \mathrm{C}<\mathrm{T}<105^{\circ} \mathrm{C}$ are both plotted in the figure above for VP versus temperature for $-10^{\circ} \mathrm{C}<\mathrm{T}<410^{\circ} \mathrm{C}$ and compared to measured values by Stull (1947).

Recommended value of vapor pressure for the temperature range -10 to $40^{\circ} \mathrm{C}$, based on the Antoine equation proposed here:

$$
\mathrm{VP}(\mathrm{kPa})=10^{[6.9948-1868.13 /(273+\mathrm{T})]} \times \text { or } \div 1.02 \text { for }-10^{\circ} \mathrm{C}<\mathrm{T}<40^{\circ} \mathrm{C}
$$

Recommended value at $25^{\circ} \mathrm{C}$, based on the range of values above:

$$
\mathrm{VP}(\mathrm{kPa})=5.12 \pm 0.15 @ 25^{\circ} \mathrm{C}
$$

\section{Solubility in water}

1,4-dioxane is miscible with water, which means that any amount of 1,4-dioxane and water will combine in solution. 
Henry's law constant (dimensionless form, i.e. $H / R T$ )

$2.0 \times 10^{-4}$ based on the measured infinite dilution activity coefficient, $\mathrm{f}_{\infty}$ of 5.6 at $25^{\circ} \mathrm{C}$ by Cabani et al. (1971) and the vapor pressure, VP, reported above, $5120 \mathrm{~Pa}$. The activity coefficient is used to find $\mathrm{C}_{\mathrm{a}} / \mathrm{C}_{\mathrm{w}}$ according to $\mathrm{C}_{\mathrm{a}} / \mathrm{C}_{\mathrm{w}}=\mathrm{f}_{\infty}(\mathrm{VP} / \mathrm{RT}) \times 10^{-6} \mathrm{~m}^{3} / \mathrm{g}$ (water) $\times 18 \mathrm{~g} / \mathrm{mol}$ (water) $]$.

$2.0 \times 10^{-4}$ at $25^{\circ} \mathrm{C}$ reported by Hine and Mookerjee (1975) who attribute this value to Cabani et al. (1971). The value is also cited in Howard (1989), who attributes it to Hine and Mookerjee (1975)].

$3.7 \times 10^{-4}$ at $25^{\circ} \mathrm{C}$ measured by Amoore and Buttery (1979).

Recommended value, based on the log-mean value and range of the 2 measured values reported above:

$$
\mathrm{H} /(\mathrm{RT})=2.8( \pm 0.50) \times 10^{-4} @ 25^{\circ} \mathrm{C}
$$

Organic-carbon partition coefficient $\left(K_{o c}\right)$

No reported measurements of $\mathrm{K}_{\mathrm{oc}}$ or $\mathrm{K}_{\mathrm{d}}$ for 1,4-dioxane in soils or sediments are available in the current literature. With $\mathrm{K}_{\mathrm{ow}}=0.45\left(\log \mathrm{K}_{\mathrm{ow}}=-0.345\right)$ estimation methods for $\mathrm{K}_{\mathrm{OC}}$ produce the following values for $\mathrm{K}_{\mathrm{oc}}$

15 as derived from the regression equation relating $\mathrm{K}_{\mathrm{oc}}$ to $\mathrm{K}_{\mathrm{ow}}$ in Kenega and Goring (1980) and referred to in Lyman et al. (1990).

$1.7,0.29,0.21$, and 0.22 as derived from the four regression equations relating $\mathrm{K}_{\mathrm{oc}}$ to $\mathrm{K}_{\mathrm{ow}}$ in Karickhoff (1985).

4.1 as derived from the regression as proposed by Meylan et al (1992) of $\mathrm{K}_{\mathrm{oc}}$ with the molecular connectivity index $\left({ }^{1} \chi=3.0\right)$ and a correction factor of -2.528 for the two aliphatic-ether $\mathrm{C}-\mathrm{O}$ bonds.

Recommended value, based on the log-mean value of the 6 values reported above and the $68 \% 2$ GSD range about the log mean:

$$
\begin{aligned}
& \log \mathrm{K}_{\mathrm{oc}}=0.56 \pm 0.73 \\
& \mathrm{~K}_{\mathrm{oc}}=3.7 \times \text { or } \div 5.4
\end{aligned}
$$


Diffusion coefficient in water

Based on the Wilke and Chang (1955) method described in Reid et al. (1987), the diffusion coefficient in $\mathrm{m}^{2} / \mathrm{d}$ in water is given by

$$
D_{\mathrm{xy}}=\frac{6.5 \times 10^{-7}\left(\phi M_{\mathrm{y}}\right)^{1 / 2} \mathrm{~T}}{\eta_{\mathrm{y}} V_{\mathrm{x}}^{0.6}}
$$

The molecular weight $\mathrm{M}_{\mathrm{y}}$ of water is $18 \mathrm{~g} / \mathrm{mol}$. Wilke and Chang (1955) recommend an association factor, $\phi$, of 2.6 when the solvent is water. The viscosity of water, $\eta_{y}$, is $0.89 \mathrm{cP}$ at $25^{\circ} \mathrm{C}$. Molecular volume can be estimated by the LeBas incremental method as described in Lyman et al. (1982). With the molecular volume $V_{x}$ 1,4-dioxane equal to $84 \mathrm{~cm}^{3} / \mathrm{mol}$, this expression gives

Recommended value:

$$
D_{\text {water }}=3.5 \times 10^{-7} \mathrm{~T} \mathrm{~m}^{2} / \mathrm{d}=1.0 \times 10^{-4} \mathrm{~m}^{2} / \mathrm{d} \text { or } 1.2 \times 10^{-9} \mathrm{~m}^{2} / \mathrm{s} @ 25^{\circ} \mathrm{C}
$$

\section{Diffusion coefficient in air}

Based on the Fuller et al. (1966) method described in Lyman et al. (1982), the diffusion coefficient in $\mathrm{m}^{2} / \mathrm{d}$ in air is given by

$$
D_{\text {air }}=8.6 \times 10^{-3} \mathrm{~T}^{1.75} \frac{\sqrt{\frac{\left(29+\mathrm{M}_{x}\right)}{29 \mathrm{M}_{\mathrm{x}}}}}{\left[2.7+\left(V_{\mathrm{x}}\right)^{1 / 3}\right]^{2}}
$$

With the molecular volume, $V_{x}$, of 1,4-dioxane equal to $84 \mathrm{~cm}^{3} / \mathrm{mol}$ and a molecular weight of $88.1 \mathrm{~g} / \mathrm{mol}$, the above expression gives (with $\mathrm{T}$ in kelvins)

Recommended value:
$\mathrm{D}_{\text {air }}=3.7 \times 10^{-5} \mathrm{~T}^{1.75} \mathrm{~m}^{2} / \mathrm{d}=0.79 \mathrm{~m}^{2} / \mathrm{d}$ or $9.1 \times 10^{-6} \mathrm{~m}^{2} / \mathrm{s} @ 25^{\circ} \mathrm{C}$ 
Bioconcentration factors for plant root concentration relative to soil concentration

No reported measurements of plant-root bioconcentration for 1,4-dioxane in soils are available in the current literature. Estimation methods for this parameter are considered below.

The partition factor from surface soil to edible plant parts due to rainsplash, $\mathrm{K}_{\mathrm{ps}}^{\text {rain }}$ is equal to $0.0034 \mathrm{~kg}$ (soil) $/ \mathrm{kg}$ (plant) with a CV of 1 (Dreicer et al. 1984). This partition factor applies plant fresh mass concentration relative to soil concentration.

Based on the Briggs et al. $(1982,1983)$ estimation equation for uptake of contaminants by roots from soil solution, we calculate the RCF (which represents the ratio of contaminant concentration in root, $\mathrm{mg} / \mathrm{kg}$ [fresh mass], to contaminant concentration in soil solution, $\mathrm{mg} / \mathrm{L}$ ) for 1,4-dioxane as

$\mathrm{RCF}=0.82+0.03 \mathrm{~K}_{\mathrm{ow}}^{0.77}=0.84$

When this factor is divided by the sorption coefficient, $\mathrm{K}_{\mathrm{d}}=\mathrm{f}_{\mathrm{oc}} \times \mathrm{K}_{\mathrm{oc}}=(0.01$ to $0.02) \times \mathrm{K}_{\mathrm{oc}}$ (from above), we obtain the ratio of contaminant concentration in roots, $\mathrm{mg} / \mathrm{kg}$ (fresh mass) to contaminant concentration in soil solids, $\mathrm{mg} / \mathrm{kg}$, which we refer to as $\mathrm{K}_{\mathrm{ps}}$ (roots) and estimate it as being in the range

$$
\mathrm{K}_{\mathrm{ps}}(\text { roots })=11 \text { to } 23 \times \text { or } \div 5.4 \text { (reflecting the estimation error in } \mathrm{K}_{\mathrm{oc}} \text { ) }
$$

Based the regression of $\mathrm{K}_{\mathrm{ps}}$ (roots) with $\mathrm{K}_{\mathrm{oc}}$ from Topp et al. (1986), and based on the range of $\mathrm{K}_{\mathrm{oc}}$ values listed above, we obtain:

Recommended value for root crops,

$$
\mathrm{K}_{\mathrm{ps}}(\text { roots })=664 \mathrm{~K}_{\mathrm{oc}}^{-0.622}=280 \times \text { or } \div 5.4 \text { (reflecting the error in } \mathrm{K}_{\mathrm{oc}} \text { ) }
$$

Based on the Travis and Arms (1988) correlation for plant-soil bioconcentration we obtain for total plant (not just roots) the following soil/plant partition coefficient:

Recommended value for exposed produce,

$$
\mathrm{K}_{\mathrm{ps}}=7.7 \mathrm{~K}_{\mathrm{ow}}^{-0.58}=12 \times \text { or } \div 5.4 \text { (reflecting the estimation error in the }
$$
regression). 
Bioconcentration factors for plant leaf concentration relative to air concentration

No reported measurements of plant-air bioconcentration for 1,4-dioxane in air are available in the current literature. Estimation methods for this parameter are considered below.

Based on the model of Riederer (1990) for foliar uptake of gases in plant leaves, we estimate a steady-state plant-air coefficient of

$$
\mathrm{K}_{\mathrm{pa}}^{\mathrm{gs}}=\left[0.5+\left(0.4+0.01 \times \mathrm{K}_{\mathrm{ow}}\right) \times \frac{\mathrm{RT}}{\mathrm{H}}\right] \times 10^{-3} \frac{\mathrm{m}^{3}}{\mathrm{~kg}}=1.4
$$

We could find no study in which the estimation error of this partition coefficient has been considered, but we assume the $\mathrm{CV}$ associated with it is on the order of 1 (or GSD = 2.3).

Bioconcentration factors for fish concentration relative to water or sediment concentrations

No information on the bioconcentration factor for 1,4-dioxane could be found in the literature. However, based on its $\mathrm{K}_{\mathrm{ow}}$ value, its estimated bioconcentration factor is 0.02 based on the correlation of Mackay (1982). However, since this is significantly less than 1 and we do not expect fish to have significantly lower levels of 1,4-dioxane than the water surrounding them, it seems reasonable to assume a BCF on the order of 1 .

Steady-state biotransfer factors for milk or dairy-product concentration relative to contaminant intake by cattle

No reported measurements of milk-diet biotransfer for 1,4-dioxane are available in the current literature. Estimation methods for this parameter are considered below.

Based on the geometric mean regression of milk-to-diet biotransfer against $\mathrm{K}_{\mathrm{ow}}$ developed by Travis and Arms (1988) we estimate the milk biotransfer factor for 1,4-dioxane as

$$
B_{k}=7.9 \times 10^{-9} K_{o w} \times 10^{( \pm 0.84)}=3.6 \times 10^{-9} \times \text { or } \div 7 \text { (recommended value) }
$$

The estimation error in this expression corresponds to a CVs of 6 . 
Steady-state biotransfer factors for meat concentration relative to contaminant intake by cattle, pigs, and chickens

No reported measurements of meat-diet biotransfer for 1,4-dioxane are available in the current literature. Estimation methods for this parameter are considered below.

Based on the geometric mean regression of meat-to-diet biotransfer against $\mathrm{K}_{\mathrm{ow}}$ developed by Travis and Arms (1988) we estimate the meat biotransfer factor for 1,4-dioxane as

$$
B_{t}=2.5 \times 10^{-8} \mathrm{~K}_{\mathrm{ow}} \times 10^{( \pm 0.952)}=1.1 \times 10^{-8} \times \text { or } \div 9 \text { (recommended value) }
$$

The estimation error in this expression corresponds to a CV of 11.

Steady-state biotransfer factors for egg concentration relative to contaminant intake by chickens

No reported measurements of egg-diet biotransfer for 1,4-dioxane are available in the current literature. An estimation method value for this parameter is considered below.

Based on the geornetric mean regression of egg-to-diet biotransfer against $\mathrm{K}_{\mathrm{ow}}$ developed in Part I, we estimate the egg biotransfer factor for 1,4-dioxane as

$$
B_{e}=7.9 \times 10^{-6} K_{o w} \times 10^{( \pm 1)}=3.6 \times 10^{-6} \times \text { or } \div 10 \text { (recommended value) }
$$

The estimation error in this expression corresponds to a CV of 14 .

Contaminant biodegradation factors in soil

Kawasaki (1980) reports that, because of the presence of oxygen in cyclic form, 1,4-dioxane is resistant to biodegradation. Howard et al. (1991) have estimated the half-live of 1,4-dioxane in soil due to aerobic biodegradation to be in the range of no less than one month to an estimated high value of 6 months. Howard et al. (1991) have estimated the half-live of 1,4-dioxane in soil due to anaerobic biodegradation to be in the range of no less than 4 months to an estimated high value of 24 months. These estimates of soil biodegradation are based on unacclimated aqueous biodegradation.

Recommended value, based on log mean and log variance of the range of the soil half lives given above:

Soil biodegradation rate constant $=0.005 \mathrm{~d}^{-1} \times$ or $\div 2.5$ 
Media-specific half lives for air, soil, and surface water

Air. 1,4-dioxane is not directly degraded by photolysis in air Howard et al. (1991). Based on measurements by Atkinson (1987), Howard et al. (1991) estimate the half life of 1,4-dioxane in lower atmosphere is in the range of 8.1 to 81 hours ( 0.34 to 3.4 days ) based on photo-oxidation as a removal process.

Soil Howard et al. (1991) have estimated the half-live of 1,4-dioxane in soil due to aqueous aerobic biodegradation to be in the range of 672 to 4320 hours (28 to 180 days). Howard et al. (1991) have estimated the half-live of 1,4dioxane in soil due to aqueous anaerobic biodegradation to be in the range of 2688 to 17280 hours (112 to 720 days).

Water Howard et al. (1991) have estimated the half-live of 1,4-dioxane in surface water due to aqueous aerobic biodegradation to be in the range of 672 to 4320 hours ( 28 to 180 days).

$\begin{aligned} & \text { Recommended half-lives (in days), based on the log mean of the half } \\ & \text { lives and geometric range of the values: } \\ & \text { Air } \quad 1.9 \times \text { or } \div 1.9 \\ & \text { Soil } \quad 142 \times \text { or } \div 2.5 \\ & \text { Water } \quad 71 \times \text { or } \div 1.7\end{aligned}$

\section{References for 1,4-Dioxane}

Amoore, J.E., and R.G. Buttery (1979), "Partition Coefficients and Comparative Olfactometry," Chem. Sens. Flavour 3, 57-71.

Atkinson, R. (1987), "Structure-Activity Relationship for the Estimation of Rate Constants for the Gas-Phase Reactions of OH Radicals with Organic Compounds," Int. J. Chem. Kinetics 19, 799-828.

Boublik, T., Fried, V., and Hála, E. (1984), The Vapour Pressures of Pure Substances: Selected Values of the Temperature Dependence of the Vapour Pressures of Some Pure Substances in the Normal and Low Pressure Region (Second Revised Edition), Physical sciences data; 17 (Elsevier Science Publishers, Amsterdam, The Netherrlands).

Briggs, G.G., R.H. Bromilow, and A.A. Evans (1982), "Relationships Between Lipophilicity and Root Uptake and Translocation of Non-Ionized Chemicals by Barley," Pestic. Sci. 13, 495-504. 
Briggs, G.G., R.H. Bromilow, A.A. Evans, and M. Williams (1983), "Relationships Between Lipophilicity and the Distribution of Non-Ionized Chemicals in Barley Shoots Following Uptake by the Roots," Pestic. Sci. 14, 492-500.

Cabani, S., G. Conti, and L. Lepori (1971), "Thermodynamic Study on Aqueous Dilute Solutions of Organic Compounds. Part 2. - Cyclic Ethers," Trans. Faraday Soc. 67, 1943-1950.

Collander, R. (1951), ACTA Chem. Scandin. 5, 774.

Dean, J.D., Ed. (1985), Lang's Handbook of Chemistry (McGraw-Hill, Inc., New York City, NY), 13th ed.

Dreicer, M., T.E. Hakonson, G.C. White, and F.W. Whicker (1984), "Rainsplash as a Mechanism for Soil Contamination of Plant Surfaces," Health Phys. 46, 177-187.

Fuller, E.N., P.D. Schettler, and J.C. Giddings (1966), "A New Method for Prediction of Binary Gas-Phase Diffusion Coefficients," Ind. Eng. Chem. 58, 19-27.

Hansch, C., and A. Leo (1985), "The Log P and Related Parameters Database, created and updated by the Medicinal Chemistry Project at Pomona College under the direction of Corwin Hansch and Albert Leo - 1985 Printout," in Medchem Project Issue $N^{2}$. 26, Pomona College, Claremont, CA.

Hansch, C., and A. Leo (1987), "The Log P and Related Parameters Database," created and updated by the Medicinal Chemistry Project at Pomona College, Claremont, CA, under the direction of Corwin Hansch and Albert Leo - 1987 Printout.

Hine, J. and P.K. Mookerjee (1975), "The Intrinsic Hydrophilic Character of Organic Compounds. Correlations in Terms of Structural Contributions," J. Org. Chem. 40, 292-298.

Howard, P.H., Ed. (1989), Handbook of Fate and Exposure Data for Organic

Chemicals. Vol. I . Large Production and Priority Pollutants (Lewis Publishers, Inc., Chelsea, MI).

Howard, P.H., G.W. Sage, W.F. Jarvis, and D.A. Gray, Eds. (1990), Handbook of Environmental Fate and Exposure Data for Organic Chemicals. Volume II. Solvents (Lewis Publishers, Inc., Chelsea, MI).

Howard, P. H., R. S. Boethling, W. F. Jarvis, W. M. Meylan, and E. M. Michalenko, Eds. (1991), Handbook of Environmental Degradation Rates (Lewis Publishers, Inc, Chelsea, MI).

Karickhoff, S.W. (1985), "Chapter 3. Pollutant Sorption in Environmental Systems," in Environmental Exposure From Chemicals, Volume I., W. B. Neely and G.E. Blau, Eds. (CRC Press, Inc., Boca Raton, FL), pp. 49-64. 
Kawasaki, M. (1980), "Experiences with the Test Scheme Under the Chemical Control Law of Japan: An Approach to Structure - Activity Correlations," Ecotoxicol. Environ. Saf. 4, 444-454.

Kenaga, E. E., and C.A.I. Goring (1980), "Relationship Between Water Solubility, Soil Sorption, Octanol-Water Partitioning, and Concentration of Chemicals in Biota," in Aquatic Toxicology, ASTM STP 707, J. G. Eaton, P. R. Parrish, and A. C. Hendricks, Eds. (American Society for Testing and Materials, Philadelphia, PA) pp. 78-115.

Leo, A., C. Hansch, and D. Elkins (1971), "Partition Coefficients and their Uses," Chem. Rev. 71(6) 525-616.

Lyman, W. J., W. F. Reehl, and D. H. Rosenblatt (1990), Handbook of Chemical Property Estimation Methods: Environmental Behavior of Organic Compounds (American Chemical Society, Washington, DC).

Mackay, D. (1982), "Correlation of Bioconcentration Factors," Environ. Sci. Technol. 16, 274-278.

Meylan, W., P.H. Howard, and R.S. Boethling (1992), "Molecular

Topology/Fragment Contribution Method for Predicting Soil Sorption Coefficients," Environ. Sci. Technol. 26, 1560-1567.

Reid, R. C., J. M. Prausnitz, and B. E. Poling (1987), The Properties of Gases and Liquids (McGraw Hill, New York City, NY), 4th ed.

Reiderer, M. (1990), "Estimating Partitioning and Transport of Organic Chemicals in the Foliage/Atmosphere System: Discussion of a Fugacity-Based Model," Environ. Scil. Technol. 24, 829-837.

Stull, D. R. (1947), "Vapor Pressure of Pure Substances: Organic Compounds," Ind. Eng. Chem. 39, 517-540.

Topp, E., I. Scheunert, A. Attar, and F. Korte (1986), "Factors Affecting the Uptake of 14C-Labeled Organic Chemicals by Plants From Soil," Ecotoxicol. Environ. Saf. 11, 219-228.

Travis, C. C., and A. D. Arms (1988), "Bioconcentration of Organics in Beef, Milk, and Vegetation," Environ. Sci. Technol. 22, 271-274.

Verschueren, K. (1983), Handbook of Environmental Data on Organic Chemicals, Second Edition (Van Nostrand Reinhold Company Inc., New York City, NY).

Weast, R. C., M. J. Astle, and W. H. Beyer, Eds. (1986), CRC Handbook of Chemistry and Physics: A Ready Reference Book of Chemical and Physical Data, 67th Edition (CRC Press, Inc., Boca Raton, FL).

Wilke, C.R., and P. Chang (1955), "Correlation of Diffusion Coefficients in Dilute Solutions," AIChE J. 1, 264-270. 
Windholz, M., S. Budavari, R. F. Blumetti, and E. S. Otterbein, Eds. (1983), The Merck Index: An Encyclopedia of Chemicals, Drugs, and Biologicals, 10th Edition (Merck \& Co., Inc., Rahway, NJ). 
1,4-Dioxane 


\section{Hexachlorobenzene}

Other names: HCB, perchlorobenzene, Anticarie, Bunt-cure, Bunt-no-more, Julin's carbon chloride

CAS Registry Number: 118-74-1

Hexachlorobenzene (HCB) is formed as a waste product in the production of several chlorinated hydrocarbons and is a contaminant in some pesticides. HCB is released to air as a fugitive emission from hydrocarbon production facilities and is also released to air in flue gases and fly ash from waste incineration. HCB is persistent in the environment due to its chemical stability and resistance to biodegradation. (Howard, 1989).

Formula: $\mathrm{C}_{6} \mathrm{Cl}_{6}$

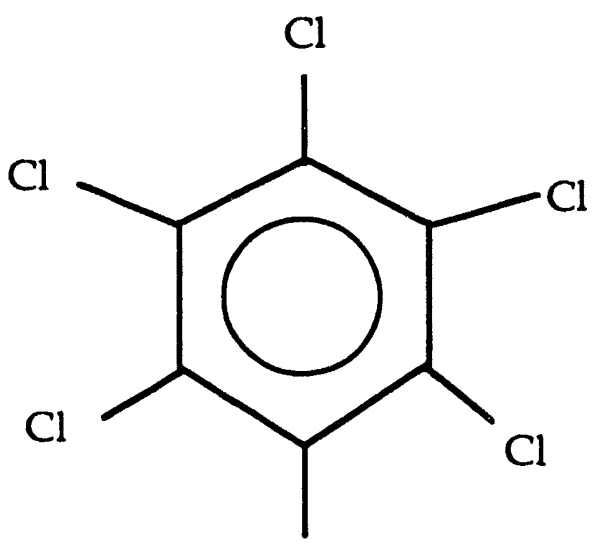

$\mathrm{Cl}$

Molecular weight

284.78 (Weast el al., 1986)

284.79 (Mackay et al., 1992)

284.8 (Howard, 1989; Verschueren, 1983; Windholz et al., 1983)

Octanol-water partition coefficient $\left(K_{o w}\right)$

$1.35 \times 10^{4}$ derived from a $\log \mathrm{K}_{\mathrm{ow}}$ of 4.13 reported by Hansch and Leo (1985) based on the value measured by Lu and Metcalf (1975). [Also cited in Mackay et al. (1992)]. 
$1.00 \times 10^{5}$ derived from a $\log K_{o w}$ of 5.00 reported by Hansch and Leo (1985) based on the value measured by Könemann et al. (1979). [Also cited in Mackay et al. (1992)].

$1.70 \times 10^{5}$ derived from a $\log \mathrm{K}_{\mathrm{ow}}$ of 5.23 reported by Mackay et al. (1992) based on the value measured by Veith et al. (1979).

$2.51 \times 10^{5}$ derived from a $\log \mathrm{K}_{\mathrm{ow}}$ of 5.40 reported by Hansch and Leo (1985) based on the value measured by Wateral et al. (1982). [Also cited in Mackay et al. (1992)].

$2.95 \times 10^{5}$ derived from a $\log \mathrm{K}_{\mathrm{ow}}$ of 5.47 reported by Mackay et al. (1992) based on the value measured by Sarna et al. (1984).

$2.95 \times 10^{5}$ derived from a $\log \mathrm{K}_{\mathrm{ow}}$ of 5.47 reported by Hansch and Leo (1985) based on the value measured by Miller et al. (1984). [Also cited in Mackay et al. (1992)].

$3.16 \times 10^{5}$ derived from a $\log \mathrm{K}_{\mathrm{ow}}$ of 5.5 reported by Mackay et al. (1992) based on the value measured by Pereira et al. (1988).

$3.16 \times 10^{5}$ derived from a $\log \mathrm{K}_{\mathrm{ow}}$ of 5.50 reported by Mackay et al. (1992) based on the value measured by Chiou et al. (1982).

$4.0 \times 10^{5}$ derived from a $\log \mathrm{K}_{\mathrm{ow}}$ of 5.6 reported by Mackay et al. (1992) based on the value measured by Brooke et al. (1986).

$4.37 \times 10^{5}$ derived from a $\log \mathrm{K}_{\mathrm{ow}}$ of 5.64 reported by Mackay et al. (1992) based on the value measured by Mailhot (1987).

$4.57 \times 10^{5}$ derived from a $\log \mathrm{K}_{\mathrm{ow}}$ of 5.66 reported by Hansch and Leo (1985) based on the value measured by Hammers et al. (1982). [Also cited in Mackay et al. (1992)].

$4.57 \times 10^{5}$ derived from a $\log \mathrm{K}_{\mathrm{ow}}$ of 5.66 reported by Mackay et al. (1992) based on the value measured using shake-flask and gas chromatography by Eadsforth and Moser (1983).

$5.37 \times 10^{5}$ derived from a $\log \mathrm{K}_{\mathrm{ow}}$ of 5.73 reported by Mackay et al. (1992) based on the value measured by De Bruijn et al. (1989).

$3.16 \times 10^{5}$ derived from a $\log \mathrm{K}_{\mathrm{ow}}$ of 5.75 reported by Mackay et al. (1992) based on the value measured by Garst and Wilson (1984).

$7.9 \times 10^{5}$ derived from a $\log \mathrm{K}_{\mathrm{ow}}$ of 5.9 reported by Mackay et al. (1992) based on the value measured by Brooke et al. (1986).

$1.66 \times 10^{6}$ derived from a $\log K_{o w}$ of 6.22 reported by Mackay et al. (1992) based on the value measured by McDuffie (1981). 
$1.66 \times 10^{6}$ derived from a $\log \mathrm{K}_{\mathrm{ow}}$ of 6.22 reported by Mackay et al. (1992) based on the value measured by Doucette and Andren (1988).

$1.86 \times 10^{6}$ derived from a $\log \mathrm{K}_{\mathrm{ow}}$ of 6.27 reported by Hansch and Leo (1985) based on the value measured by Könemann et al. (1979). [Also cited in Mackay et al. (1992)].

$2.39 \times 10^{6}$ derived from a $\log \mathrm{K}_{\mathrm{ow}}$ of 6.38 reported by Mackay et al. (1992) based on the value measured using high pressure liquid chromatography by Eadsforth and Moser (1983).

$8.32 \times 10^{6}$ derived from a $\log \mathrm{K}_{\mathrm{ow}}$ of 6.92 reported by Mackay et al. (1992) based on the value measured by De Kock and Lord (1987).

Recommended value, based on the log-mean value of the 20 measured values reported above:

$$
\begin{aligned}
& \log K_{\text {ow }}=5.68 \pm 0.58 \\
& K_{\text {ow }}=4.79 \times 10^{5} \times \text { or } \div 3.8
\end{aligned}
$$

\section{Vapor pressure in $\mathrm{Pa}$ at standard temperatures}

0.00028 reported at $25^{\circ} \mathrm{C}$ by Sears and Hopke (1949). [Also cited in Mackay et al. (1992)].

0.00145 reported at $20^{\circ} \mathrm{C}$ by Kilzer et al (1979). [Also cited in Mackay et al. (1992)].

0.0023 reported at $25^{\circ} \mathrm{C}$ by Farmer et al (1980). [Also cited in Mackay et al. (1992)].

0.000453 reported at $25^{\circ} \mathrm{C}$ by Klein et al. (1981). [Also cited in Mackay et al. (1992)].

0.000167 reported at $25^{\circ} \mathrm{C}$ by Klein et al. (1981). [Also cited in Mackay et al. (1992)].

0.00046 reported at $25^{\circ} \mathrm{C}$ by Dobbs and Cull (1982). [Also cited in Mackay et al. (1992)].

0.0006 reported at $20^{\circ} \mathrm{C}$ by Gükel at al. (1982). [Also cited in Mackay et al. (1992)].

$0.303,0.159,0.121$ values quoted and measured for subcooled liquid at $25^{\circ} \mathrm{C}$ by Bidleman (1984). [Also cited in Mackay et al. (1992)]. 
Gükel et al. (1982) have developed an Antoine equation relating vapor pressure to temperature $\left(\mathrm{T}\right.$ in ${ }^{\circ} \mathrm{C}$ ) for hexachlorobenzene in the temperature range 20 to $60^{\circ} \mathrm{C}$,

$\log \mathrm{VP}($ torr $)=12.37-5152.1 /(273+\mathrm{T})$ or

$\log \mathrm{VP}(\mathrm{Pa})=14.49-5152.1 /(273+\mathrm{T})$

This equation gives VP $=0.0016$ at $25^{\circ} \mathrm{C}$

Recommended value for the temperature range 20 to $60^{\circ} \mathrm{C}$, based on the Antoine equation above and adjusted to give the log mean value of the measured values reported above:

$$
\begin{aligned}
& \log \mathrm{VP}=14.1-5152.1 /(273+\mathrm{T}) \pm 0.40 \\
& \mathrm{VP}=0.00065 \times \text { or }+2.5 @ 25^{\circ} \mathrm{C}
\end{aligned}
$$

The adjusted Antoine equation above for VP versus temperature is plotted below.

Vapor pressure versus temperature for (HCB)

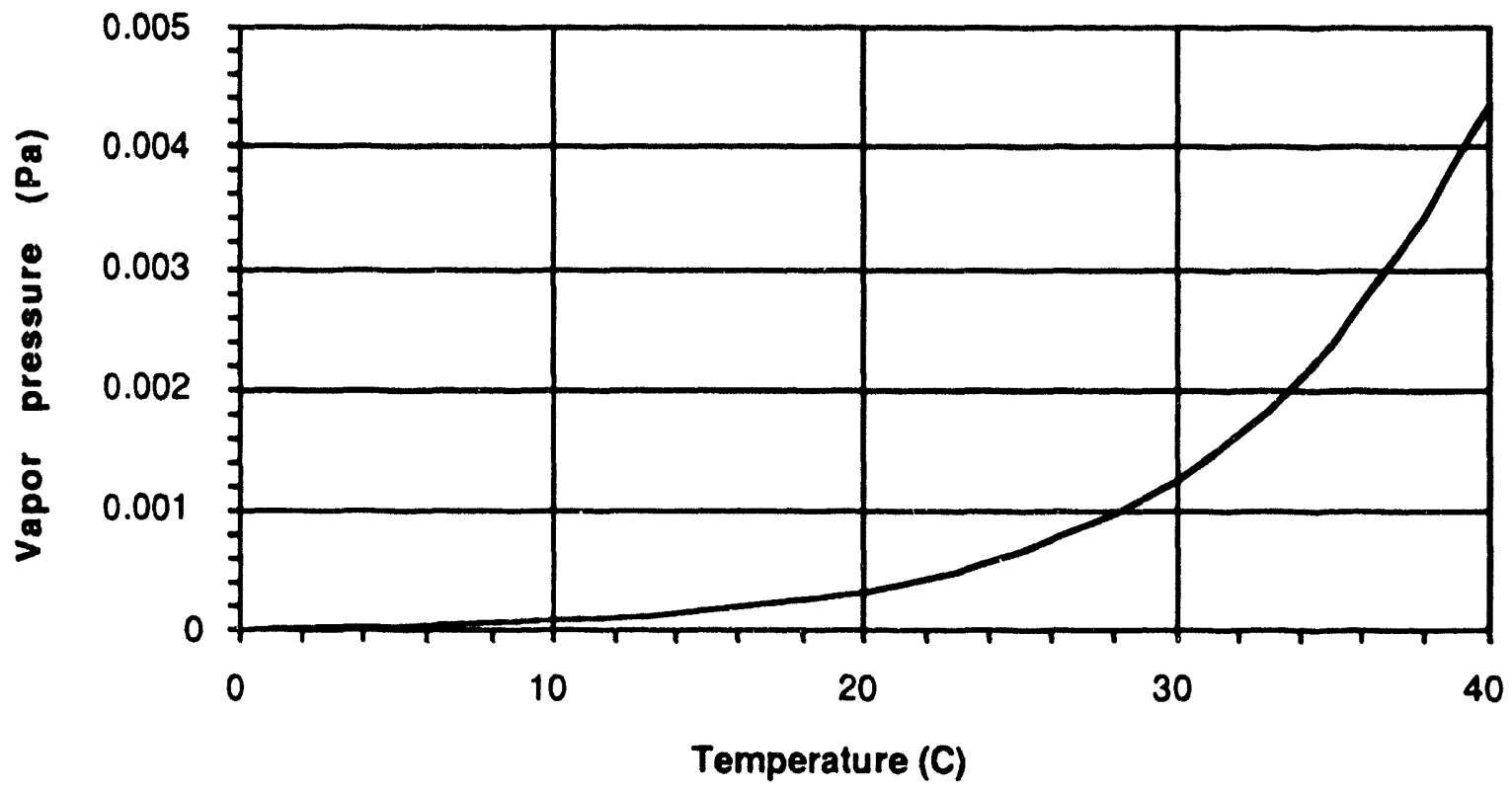


Solubility in water

$0.006 \mathrm{mg} / \mathrm{L}$ [no temperature specified] (Verschueren, 1983).

$0.004 \mathrm{mg} / \mathrm{L}$ [no temperature specified] (Verschueren, 1983).

$0.0062 \mathrm{mg} / \mathrm{L}$ at $25^{\circ} \mathrm{C}$ reported by Howard (1989), who attributes this value to Farmer et al. (1977).

$0.005 \mathrm{mg} / \mathrm{L}$ at $25^{\circ} \mathrm{C}$ reported by Weil et al. (1974). [Also cited in Horvath (1982) and Mackay et al. (1992)].

$0.006 \mathrm{mg} / \mathrm{L}$ at $25^{\circ} \mathrm{C}$ reported by $\mathrm{Lu}$ and Metcalf (1975). [Also cited in Horvath (1982) and Mackay et al. (1992)].

$0.10 \mathrm{mg} / \mathrm{L}$ at $24^{\circ} \mathrm{C}$ reported by Hollifield (1979). [Also cited in Horvath (1982) and Mackay et al. (1992)].

$0.005 \mathrm{mg} / \mathrm{L}$ at $25^{\circ} \mathrm{C}$ reported by Yalkowsy et al. (1979). [Also cited in Horvath (1982) and Mackay et al. (1992)].

$0.0039 \mathrm{mg} / \mathrm{L}$ at $25^{\circ} \mathrm{C}$ reported by Könemann (1981). [Also cited in Mackay et al. (1992)].

$0.0054 \mathrm{mg} / \mathrm{L}$ at $25^{\circ} \mathrm{C}$ reported by Hashimoto et al. (1982). [Also cited in Mackay et al. (1992)].

0.0012 to 0.014 ( 0.004 geometric mean) $\mathrm{mg} / \mathrm{L}$ at $25^{\circ} \mathrm{C}$ reported by Hashimoto et al. (1982). [Also cited in Mackay et al. (1992)].

$0.0047 \mathrm{mg} / \mathrm{L}$ at $25^{\circ} \mathrm{C}$ reported by Miller et al. (1984). [Also cited in Mackay et al. (1992)].

Recommended value based on the arithmetic mean of the measured values above excluding the value reported by Hollifield (1979):

$$
\begin{aligned}
W S= & 0.005 \pm 0.0007 \mathrm{mg} / \mathrm{L} @ 25^{\circ} \mathrm{C} \\
& 1.7 \times 10^{-5} \pm 2 \times 10^{-6} \mathrm{~mol} / \mathrm{m}^{3} @ 25^{\circ} \mathrm{C}
\end{aligned}
$$

Henry's law constant (dimensionless form, i.e. H/RT)

0.028 reported at $20^{\circ} \mathrm{C}$ by Callahan et al. (1979). [Also cited in Mackay et al. (1992)].

0.053 reported at $25^{\circ} \mathrm{C}$ by Atlas et al. (1982) based on batch stripping. [Also cited in Mackay et al. (1992)]. 
0.020 reported at $25^{\circ} \mathrm{C}$ by Oliver and Niimi (1985) based on batch stripping. [Also cited in Mackay et al. (1992)].

0.054 reported at $25^{\circ} \mathrm{C}$ by Nirmalakahandan and Speece (1988). [Also cited in Mackay et al. (1992)].

Recom tended value based on the arithmetic mean of the measured values above:

$$
\mathrm{H} / \mathrm{RT}=0.04 \pm 0.015 @ 25^{\circ} \mathrm{C}
$$

The figure below is the plot of the dimensionless Henry's law constant based on the ratio of temperature-dependent vapor pressure to solubility as recommended in sections above

\section{Dimensionless Henry's law versus temperature for HCB}

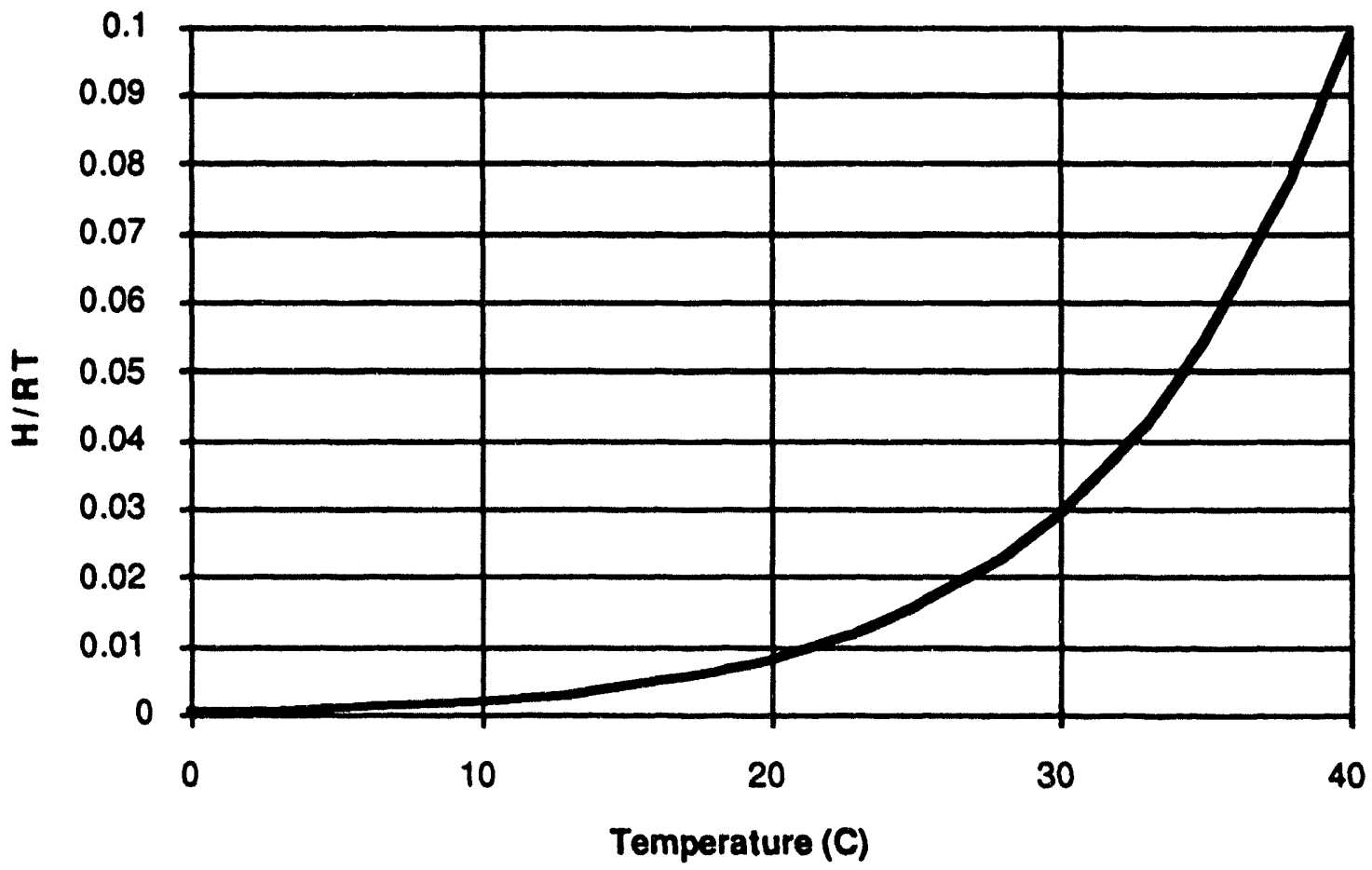


Organic-carbon partition coefficient $\left(K_{o c}\right)$

$3.63 \times 10^{2}$ derived from a $\log \mathrm{K}_{\mathrm{oc}}$ of 2.56 measured (using Speyer soil $<200 \mathrm{~mm}$ particle diameter) by Rippen et al. (1982) [Also cited in Mackay et al. (1992)].

$5.01 \times 10^{2}$ derived from a $\log \mathrm{K}_{\mathrm{oc}}$ of 2.70 measured (using Alfisol) by Rippen et al. (1982) [Also cited in Mackay et al. (1992)].

$3.89 \times 10^{3}$ derived from a $\log \mathrm{K}_{\mathrm{oc}}$ of 3.59 measured by Kenaga (1980) and also reported in Kenaga and Goring (1980) [Also cited in Mackay et al. (1992)].

$2.81 \times 10^{4}$ derived from a $\log \mathrm{K}_{\mathrm{oc}}$ of 4.45 reported by Kenaga (1980) [Also cited in Mackay et al. (1992)].

$5.89 \times 10^{4}$ derived from a $\log \mathrm{K}_{\mathrm{oc}}$ of 4.77 from the value measured by Hodson and Williams (1988) [Also cited in Mackay et al. (1992)].

$7.94 \times 10^{4}$ derived from a $\log \mathrm{K}_{\mathrm{oc}}$ of 4.90 from measured values from bottom sediment by Karickhoff and Morris (1985) [Also cited in Mackay et al. (1992)].

$7.94 \times 10^{5}$ derived from a $\log \mathrm{K}_{\mathrm{oc}}$ of 5.90 from measured field data by Oliver and Charlton (1984) [Also cited in Mackay et al. (1992)].

$7.94 \times 10^{5}$ derived from a $\log \mathrm{K}_{\mathrm{oc}}$ of 5.90 from measured field data by Oliver and Charlton (1984) [Also cited in Mackay et al. (1992)].

$1.26 \times 10^{6}$ derived from a $\log \mathrm{K}_{\mathrm{oc}}$ of 6.1 from measured suspended sediments in the Great Lakes watershed by Oliver (1987a) [Also cited in Mackay et al. (1992)].

$2.00 \times 10^{6}$ derived from a $\log \mathrm{K}_{\mathrm{oc}}$ of 6.3 from the mean of the Niagara River plume measurements by Oliver (1987b) [Also cited in Mackay et al. (1992)].

Recommended value, based on the log-mean value of the 10 measured values reported above:

$$
\begin{aligned}
& \log \mathrm{K}_{\mathrm{oC}}=4.7 \pm 1.4 \\
& \mathrm{~K}_{\mathrm{oC}}=5.0 \times 10^{4} \times \text { or } \div 25
\end{aligned}
$$


Diffusion coefficient in water

Based on the Wilke and Chang (1955) method described in Reid et al. (1987), the diffusion coefficient in $\mathrm{m}^{2} / \mathrm{d}$ in water is given by

$$
D_{x y}=\frac{6.5 \times 10^{-7}\left(\phi M_{y}\right)^{1 / 2} \mathrm{~T}}{\eta_{y} V_{x}^{0.6}}
$$

The molecular weight, $\mathrm{M}_{\mathrm{y}}$, of water is $18 \mathrm{~g} / \mathrm{mol}$. Wilke and Chang (1955) recommend an association factor, $\phi$, of 2.6 when the solvent is water. The viscosity of water, $\eta_{y}$, is $0.89 \mathrm{cP}$ at $25^{\circ} \mathrm{C}$. Molecular volume can be estimated by the LeBas incremental method as described in Lyman et al. (1982). With the molecular volume $V_{x}$ of $H C B$ equal to $221 \mathrm{~cm}^{3} / \mathrm{mol}$, this expression gives

Recommended value:

$$
D_{\text {water }}=2.0 \times 10^{-7} \mathrm{~T} \mathrm{~m}^{2} / \mathrm{d}=5.8 \times 10^{-5} \mathrm{~m}^{2} / \mathrm{d} \text { or } 6.7 \times 10^{-10} \mathrm{~m}^{2} / \mathrm{s} @ 25^{\circ} \mathrm{C}
$$

Diffusion coefficient in air

Based on the Fuller, et al. (1966) method described in Lyman et al. (1982), the diffusion coefficient in $\mathrm{m}^{2} / \mathrm{d}$ in air is given by

$$
D_{\text {air }}=8.6 \times 10^{-3} \mathrm{~T}^{1.75} \frac{\sqrt{\frac{\left(29+\mathrm{M}_{\chi}\right)}{29 \mathrm{M}_{\mathrm{x}}}}}{\left[2.7+\left(V_{\mathrm{x}}\right)^{1 / 3}\right]^{2}}
$$

With the molecular volume, $\mathrm{V}_{\mathrm{x}}$, of $\mathrm{HCB}$ of $221 \mathrm{~cm}^{3} / \mathrm{mol}$ and a molecular weight of $285 \mathrm{~g} / \mathrm{mol}$, the above expression gives (with $\mathrm{T}$ in kelvins)

Recommended value:

$D_{\text {air }}=2.2 \times 10^{-5} \mathrm{~T}^{1.75} \mathrm{~m}^{2} / \mathrm{d}=0.47 \mathrm{~m}^{2} / \mathrm{d}$ or $5.4 \times 10^{-6} \mathrm{~m}^{2} / \mathrm{s} @ 25^{\circ} \mathrm{C}$ 
Bioconcentration factors for plant tissue concentration relative to soil concentration

$0.0034 \mathrm{mg} / \mathrm{kg}$ (fresh plant) per $\mathrm{mg} / \mathrm{kg}$ (fresh soil) is the partition factor from surface soil to edible plant parts due to rainsplash, $K_{p s}^{\text {rain }}$ with a CV of 1 (Dreicer et al. 1984). This partition factor applies plant fresh mass concentration relative to soil concentration.

$0.25 \pm 0.094 \mathrm{mg} / \mathrm{kg}$ (fresh plant) per $\mathrm{mg} / \mathrm{kg}$ (fresh soil) based on a partition factor of $0.90 \pm 0.34$ as measured by Beall (1976) between grass and soil in the 0 to $2 \mathrm{~cm}$ depth on a dry-soil and dry-grass basis. We assume that the ratio of plant dry mass to fresh mass is on the order of 0.25 and that the ratio of soil dry mass to soil fresh mass is on the order of 0.9 .

$0.42 \pm 0.18 \mathrm{mg} / \mathrm{kg}$ (fresh plant) per $\mathrm{mg} / \mathrm{kg}$ (fresh soil) based on a partition factor of $1.49 \pm 0.63$ as measured by Beall (1976) between grass and soil in the 0 to $4 \mathrm{~cm}$ depth on a dry-soil and dry-grass basis. We assume that the ratio of plant dry mass to fresh mass is on the order of 0.25 and that the ratio of soil dry mass to soil fresh mass is on the order of 0.9 .

$0.55 \pm 0.41 \mathrm{mg} / \mathrm{kg}$ (fresh plant) per $\mathrm{mg} / \mathrm{kg}$ (fresh soil) as measured by Dejonckheere et al. (1975) of $\mathrm{HCB}$ residues in lettuce and in soil taken from 0 to $20 \mathrm{~cm}$ depth.

$0.13 \mathrm{mg} / \mathrm{kg}$ (fresh plant) per $\mathrm{mg} / \mathrm{kg}$ (fresh soil) based on a partition factor of $0.48 \mathrm{mg} / \mathrm{kg}$ (dry plant) per $\mathrm{mg} / \mathrm{kg}$ (dry soil) reported by Travis and Arms (1988) and attributed to Beall (1976) and Dejonckheere et al. (1975). We assume that the ratio of plant dry mass to fresh mass is on the order of 0.25 and that the ratio of soil dry mass to soil fresh mass is on the order of 0.9 .

Recommended value based on the three the measured values reported above excluding the rainsplash factor:

$$
\mathrm{K}_{\mathrm{ps}}=0.41 \pm 0.26 \mathrm{mg} / \mathrm{kg} \text { (fresh plant) per } \mathrm{mg} / \mathrm{kg} \text { (fresh soil) }
$$

Bioconcentration factors for plant leaf concentration relative to air concentration

No reported measurements of plant-air bioconcentration for HCB in air are available in the current literature. An estimation methods for this parameter is thus applied

Based on the model of Riederer (1990) for foliar uptake of gases in plant leaves, we estimate a steady-state plant-air coefficient of 


$$
\mathrm{K}_{\mathrm{pa}}^{\mathrm{gs}}=\left[0.5+\left(0.4+0.01 \times \mathrm{K}_{\mathrm{ow}}\right) \times \frac{\mathrm{RT}}{\mathrm{H}}\right] \times 10^{-3} \frac{\mathrm{m}^{3}}{\mathrm{~kg}}=190
$$

We assume the CV associated with it is on the order of 1.

Recommended value:

$$
\mathrm{K}_{\mathrm{pa}}^{\mathrm{gs}}=190 \times \text { or } \div 2.2
$$

Bioconcentration factors for fish concentration relative to water/or sediment concentrations

$1.2 \times 10^{3}$ derived from a fish/water $\log B C F$ of 3.09 reported by Körte et al. (1978) [Also cited in Mackay et al. (1992)].

$1.9 \times 10^{4}$ derived from a flathead-minnow/water log BCF of 4.27 reported by Veith et al. (1979b). [Also cited in Mackay et al. (1992)].

$5.4 \times 10^{3}$ derived from a rainbow-trout/water $\log$ BCF of 3.73 reported by Veith et al. (1979b). [Also cited in Mackay et al. (1992)].

$2.2 \times 10^{4}$ derived from a green sunfisii/water $\log$ BCF of 4.34 reported by Veith et al. (1979b). [Also cited in Mackicy et al. (1992)].

$2.9 \times 10^{5}$ derived from a guppy-lipid/water log BCF of 5.46 reported by Könemann and van Leeuwen (1980). [Also cited in Mackay et al. (1992)].

$1.9 \times 10^{4}$ derived from a fish/water log BCF of 4.27 reported by Ciam et al. (1980). [Also cited in Mackay et al. (1992)].

$8.5 \times 10^{3}$ derived from a fish/flowing-water log BCF of 3.93 reported by Kenaga and Goring (1980). [Also cited in Mackay et al. (1992)].

$2.9 \times 10^{2}$ derived from a fish/static-water log BCF of 2.46 reported by Kenaga and Goring (1980). [Also cited in Mackay et al. (1992)].

$1.5 \times 10^{4}$ derived from a rainbow-trout/water $\log B C F$ in the range 4.08 to 4.3 (mean 4.19) reported by Oliver and Niimi (1983). [Also cited in Mackay et al. (1992)]. 
$1.9 \times 10^{5}$ derived from a rainbow-trout-lipid/water $\log \mathrm{BCF}$ in the range 5.16 to 5.37 (mean 5.27) reported by Oliver and Niimi (1983). [Also cited in Mackay et al. (1992)]. (Based on values above, this implies a fish-lipid content of $8 \%$.

$2.3 \times 10^{3}$ derived from a fish/water $\log \mathrm{BCF}$ of 3.36 reported by Klein et al. (1984). [Also cited in Mackay et al. (1992)].

$2.6 \times 10^{3}$ derived from a fish/water log BCF of 3.41 reported by Freitag et al. (1984). [Also cited in Mackay et al. (1992)].

$2.2 \times 10^{4}$ derived from a flathead-minnow/water log BCF of 4.34 reported by Carlson and Kosian (1987). [Also cited in Mackay et al. (1992)].

$2.0 \times 10^{4}$ derived from a fish/water log BCF of 4.3 reported by Oliver (1987c). [Also cited in Mackay et al. (1992)].

$2.6 \times 10^{6}$ derived from a Atlantic-croaker-lipid/water log BCF of 6.42 reported by Pereira et al. (1988). [Also cited in Mackay et al. (1992)].

$5.1 \times 10^{6}$ derived from a blue-crab-lipid/water log BCF of 6.71 reported by Pereira et al. (1988). [Also cited in Mackay et al. (1992)].

$9.1 \times 10^{5}$ derived from a spotted-sea-trout-lipid/water log BCF of 5.96 reported by Pereira et al. (1988). [Also cited in Mackay et al. (1992)].

$9.5 \times 10^{5}$ derived from a blue-catfish-lipid/water $\log \mathrm{BCF}$ of 5.98 reported by Pereira et al. (1988). [Also cited in Mackay et al. (1992)].

Recommended value, based on the log-mean value of the 18 measured values reported above (lipid-based BCFs are adjusted downward by a factor of 0.08 to account for fish lipid content):

$$
\begin{aligned}
& \log B C F(\text { fish })=4.2 \pm 0.8 \\
& B C F(\text { fish })=1.6 \times 10^{4} \times \text { or } \div 6.3
\end{aligned}
$$

Steady-state biotransfer factors for milk or dairy-product concentration relative to contaminant intake by cattle

$0.016 \pm 0.0028 \mathrm{mg} / \mathrm{kg}$ (whole milk) per $\mathrm{mg} / \mathrm{d}$ based on an biotransfer factor for dairy cows of $0.39 \pm 0.070 \mathrm{~d} / \mathrm{kg}$ (milk fat) as measured by Fries and Marrow (1976) between milk fat and daily uptake. We assume that whole milk is $4 \%$ fat.

$0.00015 \pm 0.000077 \mathrm{mg} / \mathrm{kg}$ (whole milk) per $\mathrm{mg} / \mathrm{d}$ based on an milk-diet partition coefficient for dairy cows of $0.0015 \pm 0.00077$ as measured by Borzelleca 
et al (1976) between milk and diet. We assume that the cows in this study consumed $\sim 10 \mathrm{~kg}$ milking-chow per day.

$0.0085 \mathrm{mg} / \mathrm{kg}$ (whole milk) per $\mathrm{mg} / \mathrm{d}$ based on the biotransfer factor reported by Travis and Arms (1988) and attributed to Fries and Marrow (1976) and Borzelleca et al (1976).

Recommended value, based on the mean value and range of the 2 measured values reported above:

$$
B_{k}=0.0081 \times \text { or } \div 2.8 \text { or }
$$

$\log B_{k}=-2.09 \pm 0.45$

Steady-state biotransfer factors for meat concentration relative to contaminant intake by cattle, pigs, and chickens

$0.092 \pm 0.016 \mathrm{mg} / \mathrm{kg}$ (fresh meat) per $\mathrm{mg} / \mathrm{d}$ based on an biotransfer factor for body fat of cows of $0.37 \pm 0.065 \mathrm{~d} / \mathrm{kg}$ (body fat) as measured by Fries and Marrow (1976) between milk fat and daily uptake. We assume that fresh meat is $25 \%$ fat.

$0.0024 \pm 0.00084 \mathrm{mg} / \mathrm{kg}$ (fresh meat) per $\mathrm{mg} / \mathrm{d}$ based on an fat-diet bioconcentration factor [mg $/ \mathrm{kg}$ (fat) per $\mathrm{mg} / \mathrm{kg}$ (diet)] for cows of $0.076 \pm 0.027$ as measured by Borzelleca et al (1976). We assume that the cows in this study consumed $\sim 8 \mathrm{~kg}$ of dry feed per day and that fresh meat is $25 \%$ fat.

$0.045 \mathrm{mg} / \mathrm{kg}$ (fresh meat) per $\mathrm{mg} / \mathrm{d}$ based on the biotransfer factor reported by Travis and Arms (1988) and attributed to Fries and Marrow (1976) and Borzelleca et al (1976).

Recommended value, based on the mean value and range of the 2 measured values reported above:

$$
B_{t}=0.047 \times \text { or } \div 2.8 \text { or }
$$

$\log B_{t}=-1.33 \pm 0.45$ 
Steady-state biotransfer factors for egg concentration relative to contaminant intake by chickens

No reported measurements of egg-diet biotransfer for HCB are available in the current literature. An estimation method value for this parameter is considered below.

If we assume that the fat-diet partition factor in chickens is similar to that in cattle, then the fat-to-diet biotransfer values reported above can be used to estimate $\mathrm{K}_{\mathrm{fd}}$ as $1.7 \pm 2.0 \mathrm{mg} / \mathrm{kg}$ (fat) per $\mathrm{mg} / \mathrm{kg}$ (diet). Then based on a fat content of eggs of $0.08 \mathrm{~kg}(\mathrm{fat}) / \mathrm{kg}$ (contents) and a feed intake of $0.12 \mathrm{~kg}$ (fresh mass) $/ \mathrm{d}$ by chickens, we obtain the following estimate of a biotransfer factor, $B_{e}$, from chicken diet to eggs with units $\mathrm{d} / \mathrm{kg}$ (eggs)

$$
\begin{aligned}
& \mathrm{Be}=1.1 \times \text { or } \div 8.6 \\
& \log B_{e}=0.041 \pm 0.9
\end{aligned}
$$

The coefficient of variation attributable to the extrapolation of fat-diet bioconcentration factors from cows to chickens is assumed to be a factor of 10 .

\section{Contaminant biodegradation factors in soil}

Beck and Hansen (1974) have reported the aqueous, aerobic biodegradation halflife of HCB in unacclimated soil grab samples in the range 23,256 to 50,136 hours (2.7 to 5.7 years). [This study is also cited in Howard et al. (1991) and Mackay et al. (1992)]. This range of soil half-lives corresponds to a soil biodegradation rate constant of 0.12 to $0.26 \mathrm{yr}^{-1}$.

Beck and Hansen (1974) have reported the aqueous, anaerobic biodegradation half-life of HCB in unacclimated soil grab samples in the range 93,024 to 200,544 hours (11 to 22 years). This range of soil half-lives corresponds to a soil biodegradation rate constant of 0.032 to $0.063 \mathrm{yr}^{-1}$.

Recommended values, based on arithmetic mean of the soil half lives:

aerobic soil biodegradation rate constant $=0.18 \mathrm{y}^{-1} \times$ or $\div 1.3$

anaerobic soil biodegradation rate constant $=0.044 \mathrm{y}^{-1} \times$ or $\div 1.2$ 
Hexachlorbenzene

Media-specific half lives for air, soil, and surfuce water

Air. Howard et al. (1991) estimate the half life of HCB in lower atmosphere is in the range of 3750 to 37500 hours ( 0.43 to 4.2 years) based on photo oxidation as a removal process.

Soil Howard et al. (1991) have estimated the half-live of HCB in soil due to aerobic biodegradation to be in the range of 2.7 to 5.7 years.

Water Howard et al. (1991) have estimated the half-live of HCB in surface water due to aerobic biodegradation to be in the range of 2.7 to 5.7 years.

Recommended values, based on arithmetic mean of the half lives and
geometric range of the values:
Air $\quad 2.3 \times$ or $\div 3$ years
Soil $\quad 4.2 \times$ or $\div 1.5$ years
Water $\quad 4.2 \times$ or $\div 1.5$ years

\section{References for Hexachlorobenzene}

Atlas, E., R. Foster, and C. S. Giam (1982), "Air-Sea Exchange of High Molecular Weight Organic Pollutants: Laboratory Studies," Environ. Sci. Technol. 16, 283-286.

Beck, J., and K. E. Hansen (1974), "The Degradation of Quintozene, Pentachlorobenzene, Hexachlorobenzene, and Pentachloroaniline in Soil," Pestic. Sci. 5, 41-48.

Beall, M.L., Jr. (1976), 'Persistence of Aerially Applied Hexachlorobenzene on Grass and Soil," J. Environ. Qual. 4, 367-369.

Bidleman, T. F. (1984), "Estimation of Vapor Pressures for Nonpolar Organic Compounds by Capillary Gas Chromatography," Anal. Chem.. 56, 2490-2496.

Borzelleca, J.F., P.S. Larson, E.M. Crawford, G.R. Hennigar Jr., E.J. Kuchar, and H.H. Klein (1971), Toxicologic and Metabolic Studies on Pentachloronitrobenzene," Toxicol. and Appl. Pharacol. 18, 522-534.

Brooke, D. N., A. J. Dobbs, and N. Williams (1986), "Octanol/Water Partition Coefficients $(P)$ : Measurement, Estimation, and Interpretation, Particularly for Chemicals with P > 105," Ecotoxicol. Environ. Safety 11, 251-260. 
Callahan, M. A., M. W. Slimak, N. W. Gabel, I. P. May, C. F. Fowler, J. R. Freed, P. Jennings, R. L. Durfee, F. C. Whitmore, B. Maestri, W. R. Mabey, B. R. Holt, and C. Gould (1979), Water Related Environmental Fate of 129 Priority Pollutants, (Versar, Inc., Springfield, VA), U.S. Environmental Protection Agency EPA-440-4-79-029a,b

Carlson, A. R., and P. A. Kosian (1987), "Toxicity of Chlorinated Benzenes to Fathead Minnows (Pimephales promelas)," Arch. Environ. Contam. Toxicol. 16, 129-135.

Chiou, C. T., D. W. Schmedding, and M. Manes (1982), "Partitioning of Organic Compounds in Octanol-Water System," Environ. Sci. Technol. 16, 4-10.

Ciam, C. S., H. E. Murray, L. E. Ray, and S. Kira (1980), "Bioaccumulation of Hexachlorobenzene in Killifish," Bull. Environ. Contam.Toxic. 25, 891-897.

De Bruijn, J., F. Busser, W. Seinen, and J. Hermens (1989), "Determination of Octanol/Water Partition Coefficients for Hydrophobic Organic Chemicals with the 'Slow-Stirring' Method," Environ. Toxicol. Chem. 8, 499-512.

Dejonckheere, W., W. Seurbaut, and R.H. Kips (1975), "Residues of Quintozene, Hexachlorobenzene, Dichloran and Pentachloroaniline in Soil and Lettuce," Bull. Environ. Contam. and Toxicol. 13, 720-729.

De Kock, A. C., and D. A. Lord (1987), "A Simple Procedure for Determining Octanol-Water Partition Coefficients Using Reversed Phase High Performance Liquid Chromatography (RPHPLC),"Chemosphere 16(1), 133-142.

Dobbs, A. J., and M. R. Cull (1982), "Volatilization of Chemicals - Relative Loss Rates and the Estimation of Vapor Pressures," Environ. Pollut. (Series B) 3, 289-298.

Doucette, W. J., and A. W. Andren (1988), "Estimation of Octanol/Water Partition Coefficients: Evaluation of Six Methods for Highly Hydrophobic Aromatic Hydrocarbons," Chemosphere 17, 345-359.

Dreicer, M., T.E. Hakonson, G.C. White, and F.W. Whicker (1984), "Rainsplash as a Mechanism for Soil Contamination of Plant Surfaces," Health Phys. 46, 177-187.

Eadsforth, C. V., and P. Moser (1983), "Assessment of Reversed Phase Chromatographic Methods for Determining Partition Coefficients," Chemosphere 12, 1459-1475.

Farmer, W. J., M. Yang, J. Letey, and W. F. Spencer (1977), 'Land Disposal of Organic Hazardous Wastes Containing HCB," in Disposal of Residues on Land. Proceedings of the Natinonal Conference on Disposal of Residues on Land, September 13-15, St. Louis, MO, U.S. Environmental Protection Agency, Cincinnati, $\mathrm{OH}$ (Information Transfer Inc., Rockville, MD), Library of Congress Catalog N. 7778970, pp. 83-86. 
Farmer, W. J., M.S. Yang, and W. F. Spencer (1980), “Hexachlorobenzene: Its Vapor Pressure and Vapor Phase Diffusion in Soil," Soil Sci. Soc. Am. J. 44, 676-680.

Freitag, D., J. P. Lay, and F. Korte (1984), "Envireonmental Hazard Profile-Test Results as Related to Structures and Translation Into the Environment," in QSAR in Environmental Toxicology - II, K. L. E. Kaiser, Ed. (D. Reidel Publishing Co., Dordrecht, The Netherlands).

Fries, G.F. and G.S. Marrow (1976), "Hexachlorbenzene Retention and Excretion by Dairy Cows," J. Dairy Sci. 59, 475-480.

Fuller, E.N., P.D. Schettler, and J.C. Giddings (1966), "A New Method for Prediction of Binary Gas-Phase Diffusion Coefficients," Ind. Eng. Chem. 58, 19-27.

Garst, J. E., and W. C. Wilson (1984), "Accurate, Wide-Range, Automated, High-Performance Chromatographic Method for the Estimation of Octanol/Water Partition Coefficients. I: Effect of Chromatographic Conditions and Procedure Variables on Accuracy and Reproducibility of the Method," J. Pharm. Sci. 7, 16161622.

Gückel, W., R. Kstel, J. Lewerenz, and G. Synnatschke (1982), "A Method for Determining the Volatility of Active Ingredients Used in Plant Protection. Part III: The Temperature Relationship Between Vapor Pressure and Evaporation Rate," Pest. Sci. 13, 161-168.

Hammers, W. E., G. J. Meurs, and C. L. De Ligny (1982), “Correlations Between Liquid Chromatographic Capacity Ratio Data on Lichrosorb RP-18 and Partition Coefficients in the Octanol-Water System," J. Chromatogr. 247, 1-13.

Hansch, C., and A. Leo (1985), "The Log P and Related Parameters Database, created and updated by the Medicinal Chemistry Project at Pomona College under the direction of Corwin Hansch and Albert Leo - 1985 Printout," in Medchem Project Issue $N^{\circ}$. 26, Pomona College, Claremont, CA.

Hashimoto, Y., K. Tokura, K. Ozaki, and W.M.J. Strachan (1982), "A Comparison of Water Solubility by the Flask and Micro-Column Methods," Chemosphere 11(10), 991-1001.

Hodson, J., and N. A. Williams (1988), "The Estimation of the Adsorption Coefficient $\left(\mathrm{K}_{\mathrm{oc}}\right)$ for Soils by High Performance Liquid Chromatography," Chemosphere 17, 67-77.

Hollifield, H. C. (1979), "Rapid Nephelometric Estimate of Water Solubility of Highly Insoluble Organic Chemicals of Environmental Interests,"Bull. Environ. Contam. Toxicol. 23, 579-586.

Horvath, A. L. (1982), Halogenated Hydrocarbons, Solubility-Miscibility with Water , (Marcel Dekker, Inc., New York City, NY). 
Howard, P. H., Ed. (1989), Handbook of Fate and Exposure Data for Organic Chemicals. Vol. I . Large Production and Priority Pollutants (Lewis Publishers, Chelsea, MI).

Howard, P. H., R. S. Boethling, W. F. Jarvis, W. M. Meylan, and E. M. Michalenko, Eds. (1991), Handboc': of Environmental Degradation Rates (Lewis Publishers, Inc, Chelsea, MI).

Karickhoff, S. W., and K. R. Morris (1985), "Impact of Tubificid Oligochaetes on Pollutant Transport in Bottom Sediments," Environ. Sci. Technol. 19, 51-56.

Kenaga, E. E. (1980), "Predicted Bioconcentration Factors and Soil Sorption Coefficients of Pesticides and Other Chemicals," Ecotoxicol. Environ. Safety 4, 26-38.

Kenaga, E. E., and C. A. I. Goring (1980), "Relationship Between Water Solubility, Soil Sorption, Octanol-Water Partitioning, and Concentration of Chemicals in Biota," in Aquatic Toxicology, ASTM STP 707, J. G. Eaton, P. R. Parrish, and A. C. Hendricks, Eds. (American Society for Testing and Materials, Philadelphia, PA) pp. 78-115.

Kilzer, L., I. Scheunert, H. Geyer, W. Klein, and F. Korte (1979), "Laboratory Screening of the Volatilization Rates of Organic Chemicals from Water and Soil," Chemosphere 8(10), 751-761.

Klein, W., H. Geyer, D. Freitag, and H. Rohleder (1984), "Sensitivity of Schemes for Ecotoxicological Hazard Banking of Chemicals," Chemosphere 13(1), 203-211.

Klein, A. W., M. Harnish, H. J. Porenski, and F. Schmidt-Bleek (1981), “OECD Chemicals Testing Programme Physico-Chemical Tests," Chemosphere 10, 153-207.

Könemann, H. (1981), "Quantitative Structure-Activity Relationships in Fish Toxicity Stuidies. Part 1: Relationship for 50 Industrial Pollutants," Toxicology 19, 209-221.

Könemann, H., and K. van Leeuwen (1980), "Toxicokinetics in Fish: Accumulation and Elimination of Six Chlorobenzenes by Guppies,"

Chemosphere 9, 3-19.

Könemann, W. H. (1979), Quantitative Structure Activity Relationship for Kinetics and Toxicity of Aquatic Pollutants and Their Mixtures in Fish, Ph.D. Thesis, University of Utrecht, Utrecht, The Netherlands.

Körte, F., D. Freitag, H. Geyer, W. Klein, A. G. Kraus, and E. Lahaniatis (1978), "Ecotoxicologic Profile Analysis - A Concept for Establishing Ecotoxicologic Priority Lists for Chemicals," Chemosphere 7(1), 79-102.

Lu, P. Y., and R. Metcalf (1975), "Environmental Fate and Biodegradability of Benzenes Derivatives as Studied in a Model Aquatic Ecosystem," Environ. Health Perspec. 10, 269-284. 
Lyman, W. J., W. F. Reehl, and D. H. Rosenblatt (1982), Handbook on Chemical Property Estimation Methods, Environmental Behavior of Organic Compounds (McGraw Hill, New York City, NY).

Mackay, D., W.-Y. Shiu, and K.-C. Ma (1992), Illustrated Handbook of Physical-Chemical Properties and Environmental Fate for Organic Chemicals. Volume 1. Monoaromatic Hydrocarbons, Chlorobenzenes, and PCBs (Lewis Publishers, Inc., Chelsea, MI), pp. 195-323.

Mailhot, H. (1987), "Prediction of Algae Bioaccumulation and Uptake Rate of Nine Organic Compounds by Ten Physicochemical Properties," Environ. Sci. Technol. 21, 1009-1013.

McDuffie, D. (1981), "Estimation of Octanol/Water Partition Coefficients for Organic Pollutants Using Reversed-Phase HPLC," Chemosphere 10, 73-83.

Miller, M. M., S. Ghodbane, S. P. Wasik, Y. B. Tewari, and D. E. Martire (1984), "Aqueous Solubilities, Octanol/Water Partition Coefficients and Entropies of Melting of Chlorinated Benzenes and Biphenyls," J. Chem. Eng. Data 29, 184-190.

Nirmalakhandan, N. N., and R. E. Speece (1988), "QSAR Model for Predicting Henry's Law Constant," Environ. Sci. Technol. 22, 1349-1357.

Oliver, B. G. (1987a), "Fate of Some Chlorobenzenes from the Niagara River in Lake Ontario," in Advances in Chemistry Series 216: Sources and Fates of Aquatic Pollutants, R. A. Hite, and S. J. Eisenreich, Eds. (American Chemical Society, Washington, DC), pp. 471-489.

Oliver, B. G. (1987b), "Partitioning Relationships for Chlorinated

Organics Between Water and Particulates in the St. Clair, Detroit and

Niagara Rivers," in QSAR in Environmental Toxicology - II, K. L. E. Kaiser, Ed.

(D. Reidel Publishing Co., Dordrecht, The Netherlands), pp. 251-260.

Oliver, B. G. (1987c), "Biouptake of Chlorinated Hydrocarbons From Laboratory-Spiked and Field Sediments by Oligochaete Worms," Environ. Sci. Technol. 21, 785-790.

Oliver, B. G., and M. N. Charlton (1984), "Chlorinated Organic Contaminants on Settling Particulates in the Niagara River Vicinity of Lake Ontario," Environ. Sci. Technol. 18, 903-908.

Oliver, B. G., and A. J. Niimi (1985), “Bioconcentration Factors of Some Halogenated Organics for Rainbow Trout: Limitations in Their Use for Prediction of Environmental Residues," Environ. Sci. Technol. 19, 842-849.

Oliver, B. G., and A. J. Niimi (1983), "Bioconcentration of Chlorobenzenes from Water by Rainbow Trout: Correlations with Partition Coefficients and Environmental Residues," Environ. Sci. Technol. 17, 287-291. 
Pereira, W. E., C. E. Rostad, C. T. Chiou, T. I. Brinton, L. B. Barber, II, D. K. Demcheck, and C. R. Demas (1988), "Contamination of Estuarine Water, Biota and Sediment By Halogenated Organic Compounds: A Field Study," Environ. Sci. Technol. 22, 772-778.

Reid, R. C., J. M. Prausnitz, and B. E. Poling (1987), The Properties of Gases and Liquids (McGraw Hill, New York City, NY), 4th ed.

Rippen, G., M. Ilgenstein, W. Klöpffer, and H. J. Poreniski (1982), "Screening of the Adsorption Behavior of New Chemicals: Natural Soils and Model Adsorbents," Ecotoxicol. Environ. Safety 6, 236-245.

Sarna, L. P., P. E. Hodge, and G.R.B. Webster (1984), “Octanol-Water Partition Coefficients of Chlorinated Dioxins and Dibenzofurans by Reversed-Phase HPLC Using Several $C_{18}$ Columns," Chemosphere 13, 975-983.

Sears, G. W., and E. R. Hopke (1949), "Vapor Pressures of Napththalene, Anthracene, and Hexachlorobenzene in a Low Pressure Region," J. Am. Chem. Soc. 71, 1632-1634.

Travis, C. C., and A. D. Arms (1988), "Bioconcentration of Organics in Beef, Milk, and Vegetation," Environ. Sci. Technol. 22, 271-274.

Veith, G. D., N. M. Austin, and R. T. Morris (1979a), "A Rapid Method for Estimating Log P for Organic Chemicals," Water Res. 13, 43-47.

Veith, G. D., D. L. Defor, and B. V. Bergstedt (1979b), "Measuring and Estimating the Bioconcentration Factor of Chemicals in Fish," J. Fish Res. Board Can. 26, 1040-1048.

Verschueren, K. (1983), Handbook of Environmental Data on Organic Chemicals, Second Edition (Van Nostrand Reinhold Company Inc., New York City, NY).

Wateral, H., M. Tanaka, and N. Suzuki (1982), "Determination of Partition Coefficients of Halobenzenes in Heptane/Water and 1-Octanol/Water Systems and Comparison with the Scaled Particle Calculation," Anal. Chem. 54, 702-705.

Weast, R. C., M. J. Astle, and W. H. Beyer, Eds. (1986), CRC Handbook of Chemistry and Physics: A Ready Reference Book of Chemical and Physical Data, 67th Edition (CRC Press, Inc., Boca Raton, FL).

Weil, L., G. Dure, and K. L. Quentin (1974), "Solubility in Water of Insecticide Chlorinated Hydrocarbons and Polychlorinated Biphenyls in View of Water Pollution,"Z. Wasser Abwasser Forsch. 7, 169-175.

Wilke, C.R., and P. Chang (1955), "Correlation of Diffusion Coefficients in Dilute Solutions," AIChE J. 1, 264-270.

Windholz, M., S. Budavari, R. F. Blumetti, and E. S. Otterbein, Eds. (1983), The Merck Index: An Encyclopedia of Chemicals, Drugs, and Biologicals, 10th Edition (Merck \& Co., Inc., Rahway, NJ). 
Yalkowsky, S. H., R. J. Orr, S. C. Valvani (1979), "Solubility and Partitioning. 3. The Solubility of Halobenzenes in Water," Ind. Eng. Chem. Fundam. 18, 351-353. 


\section{Inorganic Arsenic (As)}

Over 100 minerals and ores contain arsenic (Bodek et al., 1988). In nature, arsenic is usually associated with sulfide ores. Arsenic has valance states of $-3,0$, +3 or +5 . The principal arsenic-bearing minerals include arsenopyrite (FeAsS), niccolite (NiAsS), cobaltite (CoAsS), tennantite $\left(\mathrm{Cu}_{12} \mathrm{As}_{4} \mathrm{~S}_{13}\right)$, enargite $\left(\mathrm{Cu}_{3} \mathrm{AsS}_{4}\right)$, and native arsenic. The principal arsenic compounds produced for industrial use are arsenic trioxide $\left(\mathrm{As}_{2} \mathrm{O}_{3}\right)$ and arsenic metal. From these other arsenic compounds are made. About $70 \%$ of all arsenic consumed by industry is used in pesticides. Other uses of arsenic and arsenic compounds are in wood preservatives, glass manufacturing, alloys, electronics, catalysts, feed additives, and veterinary chemicals (Bodek et al., 1988). The forms of inorganic arsenic found in waters and soils include arsenious acids such as $\mathrm{H}_{3} \mathrm{AsO}_{3}, \mathrm{H}_{2} \mathrm{AsO}_{3}{ }^{-1}$, and $\mathrm{HAsO}_{3}{ }^{-2}$, and arsenic acids such as $\mathrm{H}_{3} \mathrm{AsO}_{4}, \mathrm{H}_{2} \mathrm{AsO}_{4}{ }^{-1}$, and $\mathrm{HAsO}_{4}^{-2}$, as well as arsenite $\left(\mathrm{H}_{2} \mathrm{AsO}_{3}{ }^{-1}\right)$ compounds, arsenate $\left(\mathrm{H}_{2} \mathrm{AsO}_{4}{ }^{-1}\right)$ compounds, and arsine gas $\left(\mathrm{AsH}_{3}\right)$. Arsine is only produced in extremely anoxic environments and appears to be rapidly oxidized under aerobic conditions or in the atmosphere.

Molecular and atomic weights

$74.92 \mathrm{~g} / \mathrm{mol}$, atomic weight of As (Bowen, 1979; Weast et al., 1986).

$77.93 \mathrm{~g} / \mathrm{mol}$, molecular weight of arsine gas, $\mathrm{AsH}_{3}$ (Windholz et al., 1983).

$141.93 \mathrm{~g} / \mathrm{mol}$, molecular weight of arsenic acid, $\mathrm{H}_{3} \mathrm{AsO}_{4}$ (Windholz et al., 1983).

$197.84 \mathrm{~g} / \mathrm{mol}$, molecular weight of arsenic trioxide, $\mathrm{As}_{2} \mathrm{O}_{3}$ (Weast et al., 1986).

$386.72 \mathrm{~g} / \mathrm{mol}$, molecular weight of arsenic pentoxide, $\mathrm{As}_{2} \mathrm{O}_{5}$ (Weast et al., 1986).

Melting points

$814{ }^{\circ} \mathrm{C}$ for arsenic metal, As [but only at high pressure $\sim 28$ atm., at atmospheric pressure it boils before melting (Stull, 1947).

$312.8{ }^{\circ} \mathrm{C}$ for arsenic trioxide, $\mathrm{As}_{2} \mathrm{O}_{3}$ (Stull, 1947).

$35.5{ }^{\circ} \mathrm{C}$ for arsenic acid, $\mathrm{H}_{3} \mathrm{AsO}_{4}$ (Weast et al., 1986).

$-116.3{ }^{\circ} \mathrm{C}$ for arsine gas, $\mathrm{AsH}_{3}$ (Stull, 1947).

Vapor pressure

$610^{\circ} \mathrm{C}$ is the boiling point of arsenic, As (Stull, 1947).

$160{ }^{\circ} \mathrm{C}$ is the boiling point of arsenic acid, $\mathrm{H}_{3} \mathrm{AsO}_{4}$ (Weast et al., 1986).

$457.2{ }^{\circ} \mathrm{C}$ is the boiling point of arsenic trioxide, $\mathrm{As}_{2} \mathrm{O}_{3}$ (Stull, 1947). 
Stull (1947) reports the following vapor pressures for arsenic trioxide $\left(\mathrm{As}_{2} \mathrm{O}_{3}\right)$.

Temperature $\left({ }^{\circ} \mathrm{C}\right) \quad$ Vapor Pressure $(\mathrm{mm}) \quad$ Vapor Pressure $(\mathrm{kPa})$

$\begin{array}{rrc}212.5 & 1 & 0.133 \\ 242.6 & 5 & 0.667 \\ 259.7 & 10 & 1.33 \\ 279.2 & 20 & 2.67 \\ 299.2 & 40 & 5.33 \\ 310.3 & 60 & 8.00 \\ 332.5 & 100 & 13.3 \\ 370.0 & 200 & 26.7 \\ 412.2 & 400 & 53.3 \\ 457.2 & 760 & 101\end{array}$

Interpolating from this data gives VP at $25^{\circ} \mathrm{C}=10^{-3} \mathrm{~Pa}$

Stull (1947) reports the following vapor pressures for arsine gas $\left(\mathrm{AsH}_{3}\right)$.

$\begin{array}{ccc}\text { Temperature }\left({ }^{\circ} \mathrm{C}\right) & \text { Vapor Pressure }(\mathrm{mm}) & \text { Vapor Pressure }(\mathrm{kPa}) \\ -142.6 & 1 & 0.133 \\ -130.8 & 5 & 0.667 \\ -124.7 & 10 & 1.33 \\ -117.7 & 20 & 2.67 \\ -110.2 & 40 & 5.33 \\ -104.8 & 60 & 8.00 \\ -98.0 & 100 & 13.3 \\ -87.2 & 200 & 26.7 \\ -75.2 & 400 & 53.3 \\ -62.1 & 760 & 101\end{array}$

Interpolating from this data gives $\mathrm{VP}$ at $25^{\circ} \mathrm{C}=7 \mathrm{kPa}$

Recommended value:

No recommended vapor pressure for inorganic arsenic since it is there is no significant VP for any arsenic compound other than arsine gas, which is quickly transformed in the environment. 
Solubility in water

In aqueous systems, arsenic forms anions in solution, and thus it does not form complexes with simple anions such as $\mathrm{Cl}^{-}$or $\mathrm{SO}_{4}^{-}$(Bodek et al., 1988). Anionic arsenic complexes behave like ligands in water. In aerobic aqueous systems, the arsenic acids $\mathrm{H}_{2} \mathrm{AsO}_{4}{ }^{-1}$ and $\mathrm{HAsO}_{4}{ }^{-2}$ are the dominant species in the $\mathrm{pH}$ range 2 to 11. Below pH 2, the arsenious acid, $\mathrm{H}_{2} \mathrm{AsO}_{3}{ }^{-1}$ can be the dominant species in reducing conditions and above $\mathrm{pH} 12$, the arsenious acid, $\mathrm{HAsO}_{3}{ }^{-2}$ appears.

metal arsenic, As, is insoluble in water (Weast et al., 1986).

$0.2 \mathrm{~L} / \mathrm{L}\left(8.0 \mathrm{~mol} / \mathrm{m}^{3}\right.$ at $25^{\circ} \mathrm{C}$ and $1 \mathrm{~atm}$. assuming an ideal gas) of arsine gas, $\left(\mathrm{AsH}_{3}\right)$ (Weast et al., 1986).

$12,000 \mathrm{mg} / \mathrm{L}\left(60.65 \mathrm{~mol} / \mathrm{m}^{3}\right)$ of arsenic trioxide $\left(\mathrm{As}_{2} \mathrm{O}_{3}\right)$, at $5^{\circ} \mathrm{C}$ (Weast et al., 1986).

$115,000 \mathrm{mg} / \mathrm{L}\left(580 \mathrm{~mol} / \mathrm{m}^{3}\right)$ of arsenic trioxide $\left(\mathrm{As}_{2} \mathrm{O}_{3}\right)$, at $100^{\circ} \mathrm{C}$ (Weast et al., 1986).

$767,000 \mathrm{mg} / \mathrm{L}\left(1980 \mathrm{~mol} / \mathrm{m}^{3}\right)$ of arsenic pentoxide $\left(\mathrm{As}_{2} \mathrm{O}_{5}\right)$, at $100^{\circ} \mathrm{C}$ (Weast et al., 1986).

$470,000 \mathrm{mg} / \mathrm{L}\left(3311 \mathrm{~mol} / \mathrm{m}^{3}\right)$ of arsenic acid $\left(\mathrm{H}_{3} \mathrm{AsO}_{4}\right)$ in "hot" water (Weast et al., 1986).

$1,500,000 \mathrm{mg} / \mathrm{L}\left(3880 \mathrm{~mol} / \mathrm{m}^{3}\right)$ of arsenic pentoxide $\left(\mathrm{As}_{2} \mathrm{O}_{5}\right)$, at $16^{\circ} \mathrm{C}$ (Weast et al., 1986).

$2,840,000 \mathrm{mg} / \mathrm{L}\left(20,000 \mathrm{~mol} / \mathrm{m}^{3}\right)$ of arsenic acid $\left(\mathrm{H}_{3} \mathrm{AsO}_{4}\right)$ at $12.5^{\circ} \mathrm{C}$ (Weast et al., 1986).

Recommended values for water solubility (WS):
$\begin{aligned} & \text { WS(As metal) }=\sim 0 \\ & W S\left(\text { Arsine gas) }=\sim 8 \mathrm{~mol} / \mathrm{m}^{3} @ 25^{\circ} \mathrm{C}\right. \\ & W S\left(A s^{+3}\right)=8 \text { to } 200 \mathrm{~mol} / \mathrm{m}^{3} \text { in at ambient temperatures } \\ & W S\left(\mathrm{As}^{+5}\right)=4,000 \text { to } 12,000 \mathrm{~mol} / \mathrm{m}^{3} \text { in aerobic environments at } \\ & \text { ambient temperatures }\end{aligned}$




\section{Henry's law constant}

0.35 estimated dimensionless Henry's law constant (H/RT) for Arsine $\left(\mathrm{AsH}_{3}\right)$ based on the vapor pressure and solubility information provided above.

Because of their almost complete speciation in water and extremely low vapor pressures, most arsenic compounds do not have measurable or predicted Henry's law constants. However, at low concentrations, the ratio of air to water concentration in air and water environments that are in contact can be estimated as

$$
\mathrm{C}_{\mathrm{w}} / \mathrm{C}_{\mathrm{a}}=\mathrm{A} \times \mathrm{v}_{\mathrm{d}} /\left(\mathrm{V}_{\mathrm{w}} \times \mathrm{R}_{\mathrm{w}}\right)
$$

where $C_{w}$ is the arsenic concentration in a given water body, $\mathrm{mol} / \mathrm{m}^{3} ; \mathrm{C}_{\mathrm{a}}$ is the arsenic concentration in air above the water body, $\mathrm{mol} / \mathrm{m}^{3} ; \mathrm{v}_{\mathrm{d}}$ is the deposition velocity that represents the rate of arsenic transfer from air to water, $m / d ; A$ is the contact area between the air and water, $\mathrm{m}^{2} ; \mathrm{V}_{\mathrm{w}}$ is the volume of the water body, $\mathrm{m}^{3}$; and $\mathrm{R}_{\mathrm{w}}$ is the first-order rate constant that accounts for all arsenic removals from water (i.e. precipitation and deposition), day-1.

Partition coefficients in soils and sediments

62 to $170 \mathrm{~L} / \mathrm{kg}$ reported by Wauchope and McDowell (1984) in lake sediments for As (V) when the As concentration in water is $0.37 \mu \mathrm{mol} / \mathrm{L}$. [As cited in Bodek et al. (1988).]

88 to $179 \mathrm{~L} / \mathrm{kg}$ reported by Wauchope and McDowell (1984) in lake sediments for As (V) when the As concentration in water is $3.97 \mu \mathrm{mol} / \mathrm{L}$. [As cited in Bodek et al. (1988).]

243 (2.3) $\mathrm{L} / \mathrm{kg}$ are the mean and geometric standard deviation (in parentheses) of the distribution coefficient $\left(K_{d}\right)$ reported by Sakata (1987) for As (III) in 15 different soils.

512 to $5500 \mathrm{~L} / \mathrm{kg}$ reported by Arthur D. Little (1984) in alluvial material for total arsenic. [As cited in Bodek et al. (1988).]

128 to $5500 \mathrm{~L} / \mathrm{kg}$ reported by Arthur D. Little (1984) in residual soil from a landfill for 'total arsenic. [As cited in Bodek et al. (1988).]

521 to $2500 \mathrm{~L} / \mathrm{kg}$ reported by Arthur D. Little (1984) in silty fine sand with little clay for total arsenic. [As cited in Bodek et al. (1988).]

71 to $254 \mathrm{~L} / \mathrm{kg}$ reported by Arthur D. Little (1984) in gravelly, well-graded silty sand for total arsenic. [As cited in Bodek et al. (1988).]

162 to $455 \mathrm{~L} / \mathrm{kg}$ reported by Arthur D. Little (1984) in brown, clayey sand for total arsenic. [As cited in Bodek et al. (1988).] 
15 to $110 \mathrm{~L} / \mathrm{kg}$ reported by Arthur D. Little (1984) in fine sand for total arsenic. [As cited in Bodek et al. (1988).]

Bodek et al. (1988) list Langmuir constants for arsenic (V). These equations give the following estimates of the distribution coefficient $K_{d}$ in soils.

$$
K_{d}=S / C=A_{m} K_{L} /\left(1+K_{L} C\right)[L / k g]
$$

where

$\mathrm{S}$ is the arsenic sorbed to soil, $\mathrm{mol} / \mathrm{kg}$;

$C$ is the arsenic concentration in soil water, $\mathrm{mol} / \mathrm{L}$;

$A_{m}$ is the maximum amount of arsenic that can be absorbed by soil and ranges from 0.0072 to $0.0099 \mathrm{~mol} / \mathrm{kg}$; and

$\mathrm{K}_{\mathrm{L}}$ is the measure of bond strength holding the sorbed arsenic to the soil surface and ranges from 3500 to $3700 \mathrm{~L} / \mathrm{mol}$.

The two solid lines in the figure below represent this range of distribution coefficients associated with the range of Langmuir constants quoted above.

Elkhatib et al. (1984) have reported values for As (III) sorption by various soils in West Virginia and fit Freundlich isotherms to model sorption for five of these soils. The following Freundlich-isotherm derived distribution coefficients, $K_{d}$, bracket the range of isotherms developed by Elkhatib et al. (1984),

$$
\begin{aligned}
& K_{d}=S / C=19.2 C^{0.958} / C[L / k g] \\
& K_{d}=S / C=28.3 C^{0.399} / C[L / k g]
\end{aligned}
$$

where $S$ is the sorbed arsenic (III) concentration, $\mathrm{mg} / \mathrm{kg}$, and $\mathrm{C}$ is arsenic (III) concentration in water, $\mathrm{mg} / \mathrm{L}$. The dashed lines in the figure below illustrate the dependence of the distribution coefficient for arsenic on arsenic concentration in the water phase based on these Freundlich isotherms.

Recommended value of $\mathrm{K}_{\mathrm{d}}$ for arsenic in soils and in sediments based on the geometric mean and geometric standard deviation of values considered above:

$$
\begin{aligned}
& 15 \leq K_{d} \leq 5500 \\
& \log K_{d}=2.44 \pm 0.67 \\
& K_{d}=274 \times \text { or } \div 4.7
\end{aligned}
$$




\section{Distribution coefficient $\left(K_{d}\right)$ for arsenic in soils}

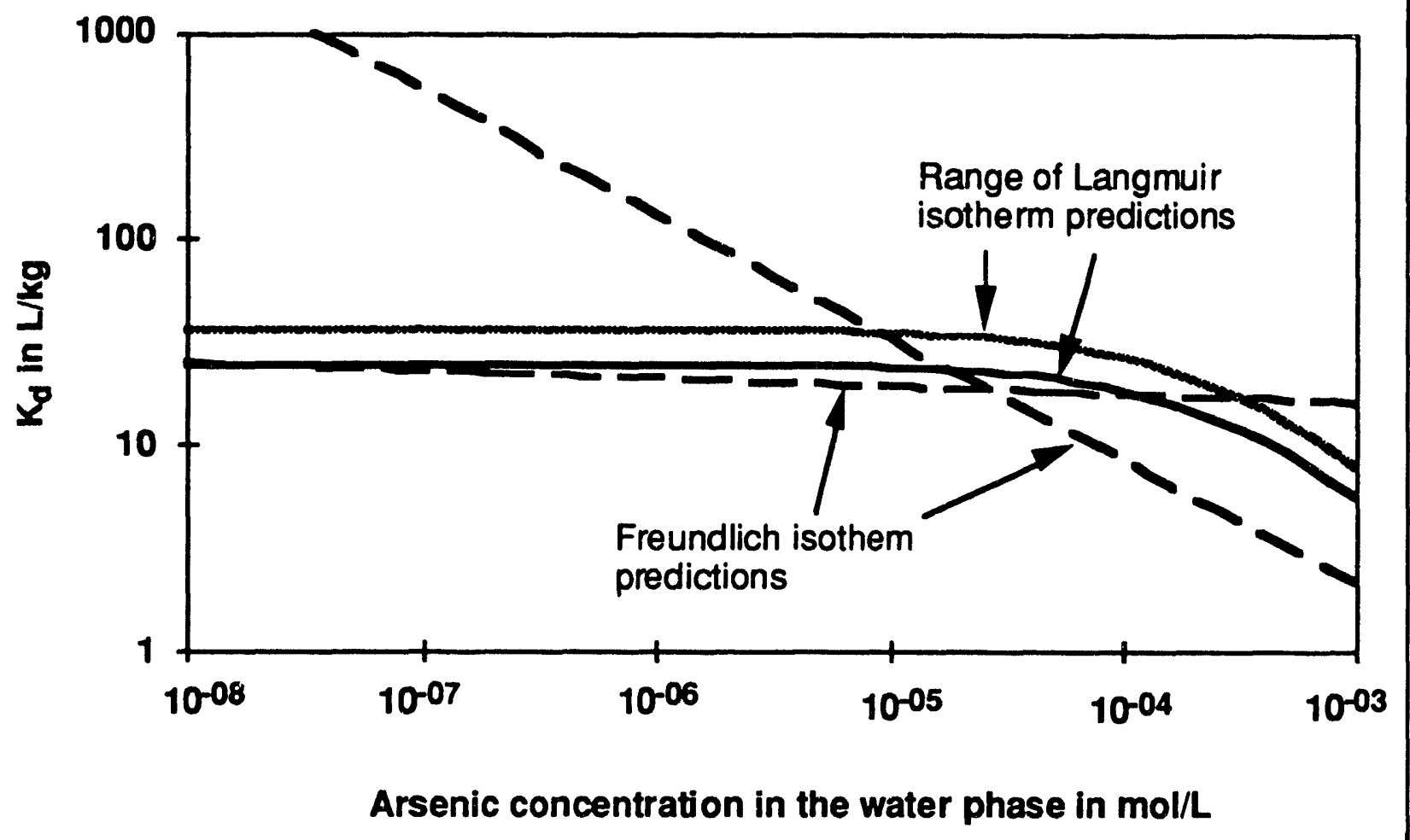

Diffusion coefficient in water

In dilute solutions of ionized species, such as arsenic compounds, in which there are no rapid chemical reactions and the solution is isothermal, Bodek et al. (1988) have shown that diffusion coefficients for the anions and cations in solution do not vary greatly and are on the order of $1.5 \times 10^{-9} \mathrm{~m}^{2} / \mathrm{s}$. The diffusion coefficients of many simple salts generally do not vary by more than a factor of 2 over a range of concentrations and temperatures even though there conductivities can vary greatly (Bodek et al., 1988).

Recommended value:

$D_{\text {water }}=1.3 \times 10^{-4} \mathrm{~m}^{2} / \mathrm{d}$ or $1.5 \times 10^{-9} \mathrm{~m}^{2} / \mathrm{s} \times$ or $\div 2$ for $0^{\circ} \mathrm{C} \leq \mathrm{T} \leq 40^{\circ} \mathrm{C}$ 
Diffusion coefficient in air

Because of the extremely low vapor pressure of arsenic and inorganic arsenic compounds, these chemical species are not likely to be found in the gas phase of the environment. There is no need for a diffusion coefficient in air and, thus no value is recommended.

Bioconcentration factors for plant tissue concentration relative to soil concentration $\mathrm{kg}\left(\right.$ soil)/ $\mathrm{kg}$ (plant fresh mass), $K_{\text {ps }}$

Arsenic is considered an essential trace element for plants and animals (Mertz, 1981). As a likely result of uptake in water, arsenic is absorbed by roots and readily translocated to other plant parts (Bodek et al. (1988).

0.004 to 0.012 based on a soil-to-plant-dry-mass coefficient of 0.040 used by Baes et al. (1984) for the vegetative portion of food crops and our assumed plant dry mass fraction in the range 0.1 to 0.3 .

0.0006 to 0.0018 based on soil-to-plant-dry-mass coefficient of 0.006 used by Baes et al. (1984) for the non-vegetative (reproductive) portion of food crops and our assumed plant dry mass fraction in the range 0.1 to 0.3 .

0.0013 to 1.4 based on a $1.5 \mathrm{mg} / \mathrm{kg}$ as geosphere average of soil arsenic concentration and 0.02 to $7 \mathrm{mg} / \mathrm{kg}$ (dry mass) as a geosphere average of land-plant arsenic concentration reported by Bowen (1979) and our assumed plant dry mass fraction in the range 0.1 to 0.3 .

$0.01 \times$ or $\div 34$ based on a 2 to $200 \mathrm{mg} / \mathrm{kg}$ as the range of background soil arsenic levels and 0.1 to $10 \mathrm{mg} / \mathrm{kg}$ (dry mass) as the range of background soil plant levels reported by Bodek et al. (1988) and our assumed plant dry mass fraction in the range 0.1 to 0.3 .

$0.0034 \times$ or $\div 2.2$ is the partition factor from surface soil to edible plant parts due to rainsplash, $K_{\mathrm{ps}}^{\text {rain }}$ (Dreicer et al. 1984).

Recommended value of $\mathrm{K}_{\mathrm{ps}}$ based on the log mean of the ranges of values considered above (excluding rainsplash),

$\log \mathrm{K}_{\mathrm{ps}}=-2.1 \pm 1.3$

$\mathrm{K}_{\mathrm{ps}}=0.008 \times$ or $\div 20 \mathrm{~kg}($ soil $) / \mathrm{kg}$ (plant fresh mass) 
Steady-state bioconcentration factors for plant leaf concentration relative to air concentration

According to Bodek et al. (1988), airborne deposition is believed to contribute to concentrations of arsenic found in plant leaves. At low concentrations, the ratio of plant leaf concentration to air concentration when air and plant environments are in contact, can be estimated as

$$
C_{p} / C_{a}=A \times v_{d} /\left(V_{p} \times R_{p}\right)
$$

where $C_{p}$ is arsenic concentration in the plants in contact with contaminated air, $\mathrm{mol} / \mathrm{m}^{3} ; \mathrm{C}_{\mathrm{a}}$ is the arsenic concentration in air above the plants, $\mathrm{mol} / \mathrm{m}^{3} ; \mathrm{v}_{\mathrm{d}}$ is the deposition velocity that represents the rate of arsenic transfer from air to plant surfaces, $\mathrm{m} / \mathrm{d} ; A$ is the contact area between the air and plants, $\mathrm{m}^{2} ; \mathrm{V}_{\mathrm{p}}$ is the volume of the plants compartment, $\mathrm{m}^{3}$; and $R_{\mathrm{p}}$ is the first-order rate constant that accounts for all arsenic removals from plants (i.e. wash-off, biodegradation, etc.), day-1.

Bioconcentration factors for fish relative to water or sediment concentrations

333 reported by Bodek et al. (1988) as a typical concentration ratio in freshwater fish, freshwater invertebrates, marine invertebrates, and marine fish relative to water concentration.

11 to 540 based on $0.0037 \mathrm{mg} / \mathrm{L}$ as a geosphere average of ocean-water arsenic concentration and 0.2 to $10 \mathrm{mg} / \mathrm{kg}$ (dry mass) as an average of marinefish arsenic concentration reported by Bowen (1979) and our assumed fish dry mass fraction in the range 0.2 .

Recommended $\mathrm{BCF}$ value, based on the geometric mean and geometric standard deviation reflecting the range of $B C F$ values described above:

$\log B C F($ fish $)=2.3 \pm 0.63$

$$
\mathrm{BCF}(\text { fish })=200 \times \text { or } \div 4.3
$$

Steady-state biotransfer factors for milk or dairy-products concentration relative to contaminant intake by cattle, $B_{k}$

Stevens (1991) evaluated several studies investigating the concentration of soluble forms of arsenic (As) in milk relative to the As intake in feed.

$6.2 \times 10^{-5} \mathrm{~d} / \mathrm{L}$ is uptake to milk from feed based on radioisotope studies reported by $\mathrm{Ng}$ (1982). 
0 to $3 \times 10^{-4} \mathrm{~d} / \mathrm{L}$ is the range of values Stevens (1991) identified in studies investigating the concentration of soluble forms of arsenic (As) in milk, relative to the As intake in feed.

$3 \times 10^{-5} \mathrm{~d} / \mathrm{L}$ was derived from a study by Vreman et al. (1986) by Stevens (1991) who recommended this estimate of this biotransfer factor.

Recommended biotransfer factor, $\mathrm{B}_{\mathrm{k}}$, for milk based on the geometric mean and geometric standard deviation reflecting the range of values above:

$$
\begin{aligned}
& \log B_{k}=-4.4 \pm 0.83 \\
& B_{k}=4 \times 10^{-4} \times \text { or } \div 6.8
\end{aligned}
$$

Steady-state biotransfer factors for meat relative to contaminant intake by cattle, pigs, and chickens

Stevens (1992) evaluated several studies investigating the concentration of soluble forms of arsenic (As) in meat from cattle, relative to the As intake in feed by these cattle.

$5 \times 10^{-4}$ to $2.4 \times 10^{-3} \mathrm{~d} / \mathrm{kg}$ is the range of values Stevens (1992) identified in studies investigating the concentration of arsenic (As) in bovine muscle relative to the As intake in feed.

$1.0 \times 10^{-3}$ to $3.6 \times 10^{-3} \mathrm{~d} / \mathrm{kg}$ is the range of values Stevens (1992) identified in studies investigating the concentration of arsenic (As) in bovine kidney relative to the As intake in feed.

$1.8 \times 10^{-3}$ to $3.0 \times 10^{-3} \mathrm{~d} / \mathrm{kg}$ is the range of values Stevens (1992) identified in studies investigating the concentration of arsenic (As) in bovine liver relative to the As intake in feed.

$1.3 \times 10^{-3} \mathrm{~d} / \mathrm{kg}$ is the value considered by Stevens (1992) to be the most reasonable estimate of a steady-state biotransfer factor for arsenic to bovine muscle.

$2.5 \times 10^{-3} \mathrm{~d} / \mathrm{kg}$ is the value considered by Stevens (1992) to be the most reasonable estimate of a steady-state biotransfer factor for arsenic to bovine liver.

$2.1 \times 10^{-3} \mathrm{~d} / \mathrm{kg}$ is the value considered by Stevens (1992) to be the most reasonable estimate of a steady-state biotransfer factor for arsenic to bovine kidney. 
Recommended biotransfer factor, $\mathrm{B}_{\mathrm{t}}$, for meat based on the geometric mean and geometric standard deviation reflecting the range of values above:

$$
\begin{aligned}
& \log B_{t}=-2.75 \pm 0.27 \\
& B_{t}=0.0018 \times \text { or } \div 1.9
\end{aligned}
$$

Steady-state biotransfer factors for egg concentration relative to contaminant intake by chickens

No reported measurements of egg-diet biotransfer for arsenic are available in the current literature.

$\mathrm{Ng}$ (1982) has shown that for the seven elements strontium, rubidium, iodine, cesium, cerium, plutonium, and americium, the ratio of egg contents biotransfer to beef biotransfer is $60 \times$ or $\div 13$. Based on this observation, the meat biotransfer above can be used to make an estimate of egg contents biotransfer of $0.11 \times$ or $\div 13$.

$$
\begin{aligned}
& \text { Recommended biotransfer factor, } \mathrm{B}_{\mathrm{e}} \text {, for eggs: } \\
& \log \mathrm{B}_{\mathrm{e}}=-0.97 \pm 1.1 \\
& \mathrm{~B}_{\mathrm{e}}=0.11 \times \text { or } \div 13
\end{aligned}
$$

Contaminant biodegradation factors in soil

Although laboratory experiments have demonstrated arsenic methylation in lake sediments, there is no evidence of biodegradation of inorganic arsenic in soils (Bodek et al. 1988). Thus there is no recommended biodegradation factor for inorganic arsenic compounds in soils.

Media-specific half lives for air, soil, and surface water

There is no evidence that inorganic arsenic compounds react in air, soil, or water in such a way as to increase an existing physical removal of arsenic from these compartments. Thus the half lives of arsenic species in these compartments will depend entirely upon the removal rate due to natural physical processes such as deposition and erosion. 


\begin{tabular}{|cl|}
\hline Recommended half-lives: \\
Air & deposition half life \\
Soil & erosion half life \\
Water & suspended particle half life \\
\hline
\end{tabular}

\section{References for Arsenic}

Arthur D. Little, Inc. (1984), Full-Scale Field Evaluation of Waste Disposal from Coal-Fired Electric Generating Plants. Appendix F (Part 4), U.S. Environmental Protection Agency (EPA) Contract N2. 68-02-3167, Final Report to U.S. EPA Office of Research and Development, Washington, DC.

Baes, III, C.F., R.D. Sharp, A.L. Sjoreen, and R.W. Shor (1984), A Review and Analysis of Parameters for Assessing Transport of Environmentally Released Radionuclides Through Agriculture, Oak Ridge National Laboratory, Oak Ridge, TN, ORNL-5786/NTIS DE85-000287.

Bodek, I., W.J. Lyman, W.F. Reehl, and D.H. Rosenblatt, Eds. (1988), Environmental Inorganic Chemistry: Properties, Processes, and Estimation Methods (Pergamon Press, New York City, NY.)

Bowen, H.J.M. (1979), Environmental Chemistry of the Elements (Academic Press, New York City, NY).

Dreicer, M., T.E. Hakonson, G.C. White, and F.W. Whicker (1984), "Rainsplash as a Mechanism for Soil Contamination of Plant Surfaces," Health Phys. 46, 177-187.

Elkhatib, E.A., O.L. Bennett, and R.J. Wright (1984), "Arsenite Sorption and Desorption in Soils," Soil Sci. Soc. Am. J. 48, 1025-1030.

Mertz, W. (1981), "The Essential Trace Elements," Science 213, 1332-1338.

$\mathrm{Ng}$, Y.C. (1982), "A Review of Transfer Factors for Assessing the Dose from Radionuclides in Agricultural Products," Nucl. Saf. 23, 57-71.

Sakata, M. (1987), "Relationship Between Adsorption of Arsenic(III) and Boron by Soil and Soil Properties," Environ. Sci. Technol. 21, 1126-1130.

Stevens, J.B. (1991), "Disposition of Toxic Metals in the Agricultural Food Chain. 1. Steady-State Bovine Milk Biotransfer Factors," Environ. Sci. Technol. 25, 12891294.

Stevens, J.B. (1992), "Disposition of Toxic Metals in the Agricultural Food Chain. 2. Steady-State Bovine Tissue Biotransfer Factors," Environ. Sci. Technol. 26, 19151921. 
Stull, D.R. (1947), "Vapor Pressure of Pure Substances: Inorganic Compounds," Ind. Eng. Chem. 39, 540-550.

Vreman, K., N.G. van der Veen, E.J. van der Molen, W.G. de Ruig (1986), Neth. J. Agric. Sci. 34, 129.

Wauchope, R.D., and L.L. McDowell (1984), "Adsorption of Phosphate, Arsenate, Methanearsonate, and Cacodylate by Lake and Stream Sediments: Comparisons with Soils," J. Environ. Qual. 13, 499-504.

Weast, R.C., M.J. Astle, and W.H. Beyer, Eds. (1986), CRC Handbook of Chemistry and Physics: A Ready Reference Book of Chemical and Physical Data, 67th Edition (CRC Press, Inc., Boca Raton, FL).

Windholz, M., S. Budavari, R. F. Blumetti, and E. S. Otterbein, Eds. (1983), The Merck Index: An Encyclopedia of Chemicals, Drugs, and Biologicals, 10th Edition (Merck \& Co., Inc., Rahway, NJ). 


\section{Inorganic Lead $(\mathrm{Pb})$}

Lead $(\mathrm{Pb})$ is the most abundant naturally occurring heavy element, appearing primarily in the form of galena (PbS), an ore that is relatively insoluble. Lead has a valance of 2 or 4 . Other forms of lead found in the environment are plattnerite $\left(\mathrm{PbO}_{2}\right)$, cerussite or lead carbonate $\left(\mathrm{PbCO}_{3}\right)$ and anglesite $\left(\mathrm{PbSO}_{4}\right)$ Bodek et al. (1988). Large quantities of lead (both as metal and as oxide are used in storage batteries. lead compounds have been used extensively in paints. Lead oxide (PbO) is used in producing fine "crystal glass" and "flint glass."

Molecular and atomic weights

2.07.2 $\mathrm{g} / \mathrm{mol}$ is the crustal average atomic weight of $\mathrm{Pb}$ (Weast et al., 1986).

Atomic weight on earth is slightly variable due to variations in stable isotope abundance. Stable isotopes and their fractional abundances (in parentheses) are: ${ }^{204} \mathrm{~Pb}(0.0148),{ }^{206 \mathrm{~Pb}}(0.236),{ }^{207} \mathrm{~Pb}(0.226)$, and ${ }^{208} \mathrm{~Pb}(0.523)$ (Bowen, 1979). Natural isotopes of lead include $210 \mathrm{~Pb}$ (21 y half life) ${ }^{214} \mathrm{~Pb}$ ( $26.8 \mathrm{~m}$ half life), which are part of the uranium decay series; $212 \mathrm{~Pb}(10.6 \mathrm{~h}$ half life), which is part in the thorium decay series; and $211 \mathrm{~Pb}(36 \mathrm{~m}$ half life), which is part of the uranium decay series.

$267.21 \mathrm{~g} / \mathrm{mol}$, molecular weight of lead carbonate, $\mathrm{PbCO}_{3}$ (Weast et al., 1986).

$223.20 \mathrm{~g} / \mathrm{mol}$, molecular weight of lead oxide, $\mathrm{PbO}$ (Weast et al., 1986).

$239.20 \mathrm{~g} / \mathrm{mol}$, molecular weight of lead dioxide, $\mathrm{PbO}_{2}$ (Weast et al., 1986).

$303.26 \mathrm{~g} / \mathrm{mol}$, molecular weight of lead sulfate, $\mathrm{PbSO}_{4}$ (Weast et al., 1986).

$239.26 \mathrm{~g} / \mathrm{mol}$, molecular weight of lead sulfide, $\mathrm{PbS}$ (Weast et al., 1986).

\section{Melting points}

$327.5{ }^{\circ} \mathrm{C}$ for lead metal, $\mathrm{Pb}$ (Stull, 1947).

$1114{ }^{\circ} \mathrm{C}$ for lead sulfide, PbS (Stull, 1947).

$890{ }^{\circ} \mathrm{C}$ for lead oxide, $\mathrm{PbO}$ (Stull, 1947). 
Vapor pressure

Stull (1947) reports the following vapor pressures for lead sulfide (PbS).

$\begin{array}{ccc}\text { Temperature }\left({ }^{\circ} \mathrm{C}\right) & \text { Vapor Pressure }(\mathrm{mm}) & \text { Vapor Pressure }(\mathrm{kPa}) \\ 852 & 1 & 0.133 \\ 928 & 5 & 0.667 \\ 975 & 10 & 1.33 \\ 1005 & 20 & 2.67 \\ 1048 & 40 & 5.33 \\ 1074 & 60 & 8.00 \\ 1108 & 100 & 13.3 \\ 1160 & 200 & 26.7 \\ 1221 & 400 & 53.3 \\ 1281 & 760 & 101\end{array}$

Interpolating from this data with an Antoine-type equation gives VP at $25^{\circ} \mathrm{C}=10^{-27} \mathrm{~Pa}$

Recommended value:

No recommended vapor pressure because it is virtually impossible to measure for $\mathrm{Pb}$ at environmental temperatures.

Solubility in water

The free hydrated $\mathrm{Pb}^{+2}$ is predominant in freshwater systems in the $\mathrm{pH}$ range typical of natural environments (Bodek et al. 1988). However, $\mathrm{PbHCO}_{3}{ }^{+1}$, $\mathrm{PbCO}_{3}$, and $\mathrm{PbOH}^{+1}$ can also be present in freshwater. $\mathrm{PbCl}^{+1}$ is the dominant species in seawater for normal $\mathrm{pH}$ ranges, but $\mathrm{Pb}^{+2}, \mathrm{PbCl}_{2}$, and $\mathrm{PbCl}_{3}^{-1}$ are also found in seawater in the normal $\mathrm{pH}$ range (Bodek et al. 1988).

metal lead, $\mathrm{Pb}$, is only soluble in strong acids (Weast et al., 1986).

lead dioxide, $\mathrm{PbO}_{2}$, is insoluble in water at ambient temperatures and $\mathrm{pH}$, (Weast et al., 1986).

$\mathrm{Pb}^{+2}$ solubility increases with decreasing $\mathrm{pH}$.

$1.1 \mathrm{mg} / \mathrm{L}\left(0.0041 \mathrm{~mol} / \mathrm{m}^{3}\right)$ of lead carbonate, $\mathrm{PbCO}_{3}$, at $20^{\circ} \mathrm{C}(\mathrm{CRC}, 1986)$. 
$17 \mathrm{mg} / \mathrm{L}\left(0.076 \mathrm{~mol} / \mathrm{m}^{3}\right)$ of lead oxide, $\mathrm{PbO}$, at $20^{\circ} \mathrm{C}$ (Weast et al., 1986).

$42.5 \mathrm{mg} / \mathrm{L}\left(0.14 \mathrm{~mol} / \mathrm{m}^{3}\right)$ of lead sulfate, $\mathrm{PbSO}_{4}$, at $25^{\circ} \mathrm{C}$ ((Weast et al., 1986).

$56 \mathrm{mg} / \mathrm{L}\left(0.18 \mathrm{~mol} / \mathrm{m}^{3}\right)$ of lead sulfate, $\mathrm{PbSO}_{4}$, at $40^{\circ} \mathrm{C}$ (Weast et al., 1986).

$0.86 \mathrm{mg} / \mathrm{L}\left(0.0036 \mathrm{~mol} / \mathrm{m}^{3}\right)$ of lead sulfide, $\mathrm{PbS}$, at $13^{\circ} \mathrm{C}$ (Weast et al., 1986).

Recommended value:
$\mathrm{WS}(\mathrm{Pb})=\sim 0$
Depending on the availability of $\mathrm{S}, \mathrm{SO}_{4}$, and $\mathrm{CO}_{3}$ anions, the $\mathrm{pH}$
and temperature in the water phase, the solubility of the $\mathrm{Pb}^{+2}$
ion can vary significantly. However, for soils and surface waters
with a relatively high oxygen and $\mathrm{CO}_{3}$ anion and other ligands
levels,
$\mathrm{WS}\left(\mathrm{Pb}^{+2}\right)=0.01$ to $0.1 \mathrm{~mol} / \mathrm{m}^{3}$

\section{Henry's law constant}

Because of their almost complete speciation in water and extremely low vapor pressures, lead compounds do not have measurable or predicted Henry's law constants. However, at low concentrations, the ratio of air to water concentration in air and water environments that are in contact can be estimated as

$$
\mathrm{C}_{\mathrm{w}} / \mathrm{C}_{\mathrm{a}}=\mathrm{A} \times \mathrm{v}_{\mathrm{d}} /\left(\mathrm{V}_{\mathrm{w}} \times \mathrm{R}_{\mathrm{w}}\right)
$$

where $C_{w}$ is the total lead concentration in a given water body, $\mathrm{mol} / \mathrm{m}^{3} ; \mathrm{C}_{\mathrm{a}}$ is the lead concentration in air above the water body, $\mathrm{mol} / \mathrm{m}^{3} ; \mathrm{v}_{\mathrm{d}}$ is the deposition velocity that represents the rate of $\mathrm{Pb}$ transfer from air to water, $\mathrm{m} / \mathrm{d} ; \mathrm{A}$ is the contact area between the air and water, $\mathrm{m}^{2} ; \mathrm{V}_{\mathrm{w}}$ is the volume of the water body, $\mathrm{m}^{3}$; and $\mathrm{R}_{\mathrm{w}}$ is the first-order rate constant that accounts for all $\mathrm{Pb}$ removals from water (i.e. precipitation and deposition), day ${ }^{-1}$.

\section{Partition coefficients in soils and sediments}

Bodek et al. (1988) list Langmuir constants for lead in various soils at pH 7.0. The resulting Langmuir equations give estimates of the distribution coefficient $\mathrm{K}_{\mathrm{d}}$ in soils and sediments according to the following, 


$$
K_{d}=S / C=A_{m} K_{L} /\left(1+K_{L} C\right)[L / k g]
$$

where

$S$ is the lead sorbed to soil, $\mathrm{mol} / \mathrm{kg}$;

$C$ is the lead concentration in soil water, $\mathrm{mol} / \mathrm{L}$;

$A_{m}$ is the maximum amount of lead that can be absorbed by soil and ranges from 0.007 to $0.031 \mathrm{~mol} / \mathrm{kg}$; and

$\mathrm{K}_{\mathrm{L}}$ is the measure of bond strength holding the sorbed lead to the soil surface and ranges from 5000 to $79,000 \mathrm{~L} / \mathrm{mol}$.

The higher of these ranges is described by Bodek et al (1988) as being more typical of sediments.

The two solid lines in the figure below represent the range of distribution coefficients associated with the range of Langmuir constants quoted above.

Bodek et al. (1988) recommend the following Freundlich-isotherm derived distribution coefficients, $K_{d}$,

$$
\begin{aligned}
& K_{d}=S / C=2200 C 0.926 / C \quad[L / k g] \text { for sediments } \\
& K_{d}=S / C=15000 C 0.2 / C \quad[L / k g] \text { for sediments }
\end{aligned}
$$

where $S$ is the sorbed lead concentration, $\mu \mathrm{mol} / \mathrm{kg}$, and $\mathrm{C}$ is lead concentration in water, $\mu \mathrm{mol} / \mathrm{L}$. The dashed lines in the figure below illustrate the dependence of the distribution coefficient for lead on lead concentration in the water phase based on these Freundlich isotherms.

Recommended value of $\mathrm{K}_{\mathrm{d}}$ for lead in soils and in sediments based on the range of values considered above:

$$
\begin{aligned}
& 20 \leq K_{d} \leq 5000 \\
& \log K_{d}=2.5 \pm 0.69 \\
& K_{d}=320 \times \text { or } \div 5
\end{aligned}
$$




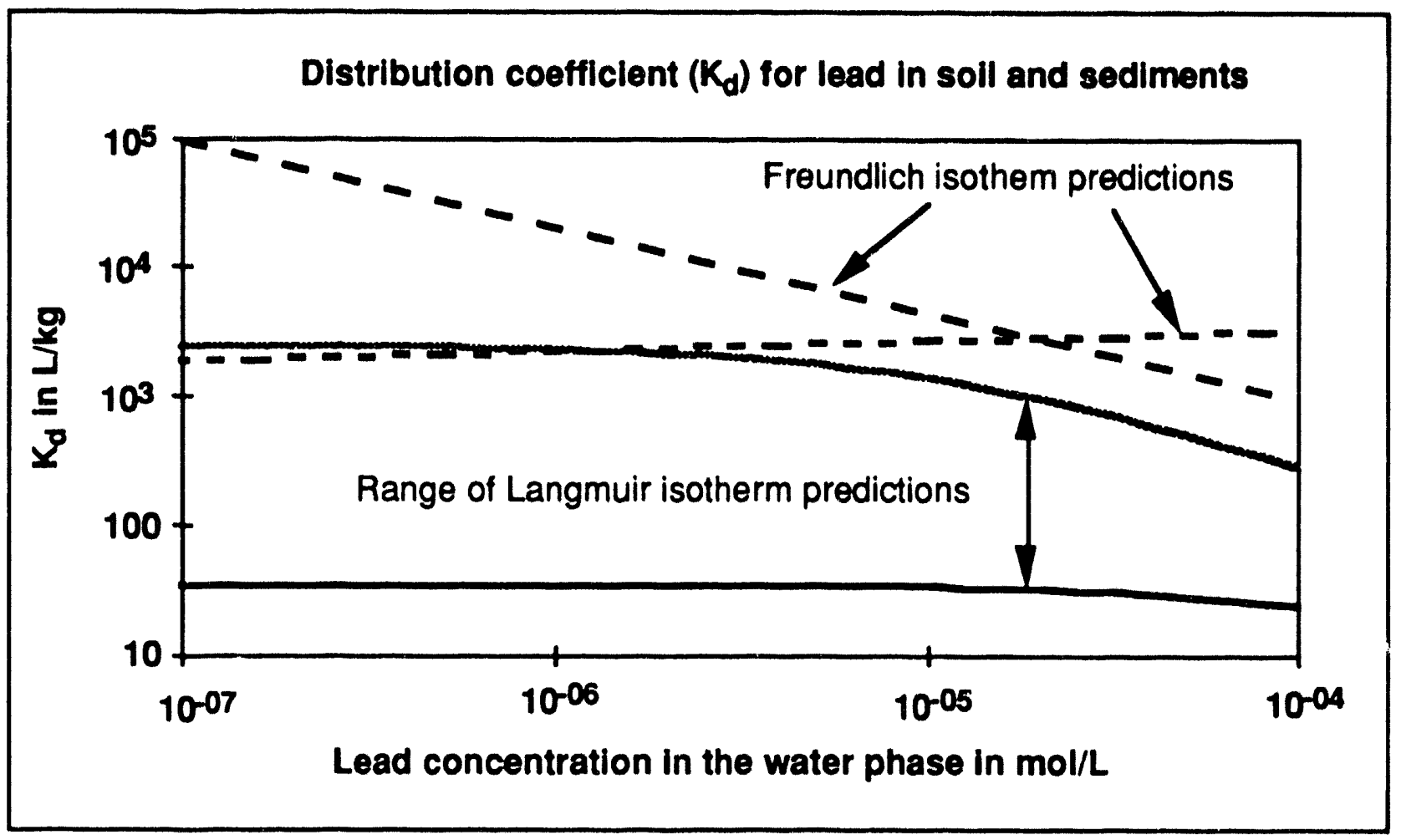

Diffusion coefficient in water

In dilute solutions of ionized species, such as lead compounds, in which there are no rapid chemical reactions and the solution is isothermal, Bodek et al. (1988) have shown that diffusion coefficients for the anions and cations in solution do not vary greatly and are on the order of $1.5 \times 10^{-9} \mathrm{~m}^{2} / \mathrm{s}$. The diffusion coefficients of many simple salts generally do not vary by more than a factor of 2 over a range of concentrations and temperatures even though their conductivities can vary greatly (Bodek et al., 1988).

Recommended value:

$$
D_{\text {water }}=1.3 \times 10^{-4} \mathrm{~m}^{2} / \mathrm{d} \text { or } 1.5 \times 10^{-9} \mathrm{~m}^{2} / \mathrm{s} \times \text { or }+2 \text { for } 0^{\circ} \mathrm{C} \leq \mathrm{T} \leq 40^{\circ} \mathrm{C}
$$

Diffusion coefficient in air

Because of the extremely low vapor pressure of lead and inorganic lead compounds, these chemical species are not likely to be found in the gas phase of the environment. There is no need fro a diffusion coefficient in air and, thus no value is recommended. 
Bioconcentration factors for plant tissue concentration relative to soil concentration $\mathrm{kg}\left(\right.$ soil)/ $\mathrm{kg}\left(\right.$ plant fresh mass), $K_{\text {ps }}$

Lead is considered a non-essential element for plants. As a likely result of passive uptake in water, lead is absorbed by roots and concentrated there with little translocation to other plant parts (Bodek et al. (1988).

0.0045 to 0.0135 based on a soil-to-plant-dry-mass coefficient of 0.045 used by Baes et al. (1984) for the vegetative portion of food crops and our assumed plant dry mass fraction in the range 0.1 to 0.3 .

0.0009 to 0.003 based on a soil-to-plant-dry-mass coefficient of 0.009 used by Baes et al. (1984) for the non-vegetative (reproductive) portion of food crops and our assumed plant dry mass fraction in the range 0.1 to 0.3 .

0.003 to 0.1 based on a $35 \mathrm{mg} / \mathrm{kg}$ as geosphere average of soil lead concentration and 1 to $13 \mathrm{mg} / \mathrm{kg}$ (dry mass) as a geosphere average of land-plant lead concentration reported by Bowen (1979) and our assumed plant dry mass fraction in the range 0.1 to 0.3 .

0.0006 to 0.2 based on a $35 \mathrm{mg} / \mathrm{kg}$ as geosphere average of soil lead concentration and 0.2 to $20 \mathrm{mg} / \mathrm{kg}$ (dry mass) as a geosphere average of ediblevegetable lead concentration reported by Bowen (1979) and our assumed plant dry mass fraction in the range 0.1 to 0.3 .

$0.009 \times$ or $\div 16$ based on a 2 to $200 \mathrm{mg} / \mathrm{kg}$ as the range of background soil lead levels and 0.1 to $10 \mathrm{mg} / \mathrm{kg}$ (dry mass) as the range of background soil plant levels reported by Bodek et al. (1988) and our assumed plant dry mass fraction in the range 0.1 to 0.3 .

0.0003 to 0.073 is the range of lead plant-to-soil concentration factors (on a plant fresh-mass basis reported by $\mathrm{Ng}$ (1982).

$0.0034 \times$ or $\div 2.3$ is the partition factor from surface soil to edible plant parts due to rainsplash, $K_{\mathrm{ps}}^{\text {rain }}$ (Dreicer et al., 1984).

Recommended value of $\mathrm{K}_{\mathrm{ps}}$ based on the log mean of the ranges of values considered above (excluding rainsplash),

$$
\begin{aligned}
& \log \mathrm{K}_{\mathrm{ps}}=-2.2 \pm 0.98 \\
& \mathrm{~K}_{\mathrm{ps}}=0.006 \times \text { or } \div 9.5 \mathrm{~kg} \text { (soil) } / \mathrm{kg} \text { (plant fresh mass) }
\end{aligned}
$$


Steady-state bioconcentration factors for plant leaf concentration relative to air concentration

According to Bodek et al. (1988), airborne deposition is believed to contribute to concentrations of lead found in plant leaves. At low concentrations, the ratio of plant leaf concentration to air concentration when air and plant environments are in contact, can be estimated as

$$
\mathrm{C}_{\mathrm{p}} / \mathrm{C}_{\mathrm{a}}=\mathrm{A} \times \mathrm{v}_{\mathrm{d}} /\left(\mathrm{V}_{\mathrm{p}} \times \mathrm{R}_{\mathrm{p}}\right)
$$

where $C_{p}$ is lead concentration in the plants in contact with contaminated air, $\mathrm{mol} / \mathrm{m}^{3} ; \mathrm{C}_{\mathrm{a}}$ is the lead concentration in air above the plants, $\mathrm{mol} / \mathrm{m}^{3} ; \mathrm{v}_{\mathrm{d}}$ is the deposition velocity that represents the rate of lead transfer from air to plant surfaces, $\mathrm{m} / \mathrm{d} ; \mathrm{A}$ is the contact area between the air and plants, $\mathrm{m}^{2} ; \mathrm{V}_{\mathrm{p}}$ is the volume of the plants compartment, $\mathrm{m}^{3}$; and $R_{\mathrm{p}}$ is the first-order rate constant that accounts for all lead removals from plants (i.e. wash-off, biodegradation, etc.), day ${ }^{-1}$.

Bioconcentration factors for fish concentration relative to water/or sediment concentrations

Although lead is a nonessential element, marine fish have been shown to accumulate lead at concentration in tissue that exceed those in water. Lead accumulation in marine fish tends to be in bone so that whole fish levels are often higher than those in muscle or viscera (Bodek et al., 1988). Both invertebrate and vertebrate freshwater organisms indicate bioconcentration of lead. In freshwater invertebrates, highest concentrations are in viscera and in freshwater vertebrates highest concentrations are in mucus.

1000 reported by Bodek et al. (1988) as a typical concentration ratio in marine invertebrates relative to water concentration.

300 reported by Bodek et al. (1988) as a typical concentration ratio in marine fish relative to water concentration.

100,000 reported by Bodek et al. (1988) as a typical concentration ratio in freshwater invertebrates relative to water concentration.

300 reported by Bodek et al. (1988) as a typical concentration ratio in freshwater fish relative to water concentration.

7 to 100,000 based on $0.00003 \mathrm{mg} / \mathrm{L}$ as a geosphere average of ocean-water lead concentration and 0.001 to $15 \mathrm{mg} / \mathrm{kg}$ (dry mass) as an average of marine-fish lead concentration reported by Bowen (1979) and our assumed fish dry mass fraction in the range 0.2 . 
Recommended $\mathrm{BCF}$ value, based on the geometric mean and geometric standard deviation reflecting the range of $B C F$ values described above:

$\log B C F($ fish $)=2.7 \pm 1.7$

$\mathrm{BCF}($ fish $)=500 \times$ or +50

Steady-state biotransfer factors for milk or dairy-product concentration relative to contaminant intake by cattle, $B_{k}$

$\mathrm{Ng}$ (1982) and Stevens (1991) have evaluated several studies investigating the concentration of soluble forms of lead $(\mathrm{Pb})$ in milk relative to the $\mathrm{Pb}$ intake in feed.

$2.1 \times 10^{-5}$ to $6.5 \times 10^{-5} \mathrm{~d} / \mathrm{L}$ is the range of values $\mathrm{Ng}$ (1982) reported in studies for uptake to milk from feed based on radioisotope studies.

$1.4 \times 10^{-4}$ to $4.5 \times 10^{-4} \mathrm{~d} / \mathrm{L}$ is the range of values $\mathrm{Ng}$ (1982) reported in studies for uptake to milk from feed based on the naturally occurring stable isotopes of lead.

$1.2 \times 10^{-5}$ to $1.4 \times 10^{-3} \mathrm{~d} / \mathrm{L}$ is the range of values Stevens (1991) identified in studies investigating the concentration of soluble forms of lead $(\mathrm{Pb})$ in milk, relative to the $\mathrm{Pb}$ intake in feed.

$4.9 \times 10^{-5} \mathrm{~d} / \mathrm{L}$ was derived from a study by Vreman et al. (1986) by Stevens (1991) who considered this to be the most reliable estimate of this biotransfer factor.

Recommended biotransfer factor, $\mathrm{B}_{\mathrm{k}}$, for milk based on the geometric mean and geometric standard deviation reflecting the range of values above:

$\log B_{k}=-4.0 \pm 0.73$

$B_{k}=0.0001 \times$ or $\div 5.4$

Steady-state biotransfer factors for meat concentration relative to contaminant intake by cattle, pigs, and chickens

$\mathrm{Ng}$ (1982) and Stevens (1992) have evaluated several studies investigating the concentration of soluble forms of lead $(\mathrm{Pb})$ in meat from cattle, relative to the $\mathrm{Pb}$ intake in feed by these cattle. 
$2 \times 10^{-4}$ to $2 \times 10^{-3} \mathrm{~d} / \mathrm{kg}$ is the range of values $\mathrm{Ng}$ (1982) reported in studies for uptake to beef from feed.

$6 \times 10^{-5}$ to $1.2 \times 10^{-3} \mathrm{~d} / \mathrm{kg}$ is the range of values Stevens (1992) identified in studies investigating the concentration of lead $(\mathrm{Pb})$ in bovine muscle relative to the $\mathrm{Pb}$ intake in feed.

$2.4 \times 10^{-3}$ to $7.3 \times 10^{-1} \mathrm{~d} / \mathrm{kg}$ is the range of values Stevens (1992) identified in studies investigating the concentration of lead $(\mathrm{Pb})$ in bovine kidney relative to the $\mathrm{Pb}$ intake in feed.

$4.1 \times 10^{-3}$ to $4.9 \times 10^{-1} \mathrm{~d} / \mathrm{kg}$ is the range of values Stevens (1992) identified in studies investigating the concentration of lead $(\mathrm{Pb})$ in bovine liver relative to the $\mathrm{Pb}$ intake in feed.

$1.25 \times 10^{-2} \mathrm{~d} / \mathrm{kg}$ is the value considered by Stevens (1992) to be the most reasonable estimate of a steady-state biotransfer factor for lead to beef.

Recommended biotransfer factor, $\mathrm{B}_{\mathrm{t}}$, for meat based on the geometric mean and geometric standard deviation reflecting the range of values above:

$$
\begin{aligned}
& \log B_{t}=-2.3 \pm 1.4 \\
& B_{t}=0.0048 \times \text { or } \div 24
\end{aligned}
$$

Steady-state biotransfer factors for egg concentration relative to contaminant intake by chickens

No reported measurements of egg-diet biotransfer for lead are available in the current literature.

$\mathrm{Ng}$ (1982) has shown that for the seven elements strontium, rubidium, iodine, cesium, cerium, plutonium, and americium, the $68 \%$ confidence interval range of the ratio of egg contents biotransfer to beef biotransfer is $60 \times$ or $\div 13$. Based this observation, the meat biotransfer above can be used to make an estimate of egg contents biotransfer of $0.3 \times$ or $\div 13$.

Recommended biotransfer factor, $\mathrm{B}_{\mathrm{e}}$, for eggs:

$$
\begin{aligned}
& \log B_{e}=-0.52 \pm 1.1 \\
& B_{e}=0.3 \times \text { or } \div 13
\end{aligned}
$$


Contaminant biodegradation factors in soil

Although laboratory experiments have demonstrated lead methylation in lake sediments, there is no evidence of biodegradation of inorganic lead in soils (Bodek et al. 1988). Thus there is no recommended biodegradation factor for inorganic lead compounds in soils.

Media-specific half lives for air, soil, and surface water

There is no evidence that lead and its inorganic compounds react in air, soil, or water in such a way as to increase an existing physical removal of lead from these compartments. Thus the half lives of lead species in these compartments will depend entirely upon the removal rate due to natural physical processes such as deposition and erosion.

Recommended half-lives:

Air deposition half time

Soil erosion half time

Water suspended particle half time

\section{References for Inorganic Lead}

Baes, C. F., III, R. D. Sharp, A. L. Sjoreen, and R. W. Shor (1984), A Review and Analysis of Parameters for Assessing Transport of Environmentally Released Radionuclides Through Agriculture, Oak Ridge National Laboratory, Oak Ridge, TN, Report N². ORNL-5786; NTIS: DE85-000287.

Bodek, I., W. J. Lyman, W. F. Reehl, and D. H. Rosenblatt, Eds. (1988), Environmental Inorganic Chemistry: Properties, Processes, and Estimation Methods (Pergamon Press, New York City, NY.)

Bowen, H. J. M. (1979), Environmental Chemistry of the Elements (Academic Press, New York City, NY).

Dreicer, M., T. E. Hakonson, G. C. White, and F. W. Whicker (1984), "Rainsplash as a Mechanism for Soil Contamination of Plant Surfaces," Health Phys. 46, 177-187.

Stevens, J. B. (1991), "Disposition of Toxic Metals in the Agricultural Food Chain. 1. Steady-State Bovine Milk Biotransfer Factors," Environ. Sci. Technol. 25, 1289-1294. 
Stevens, J. B. (1992), "Disposition of Toxic Metals in the Agricultural Food Chain. 2. Steady-State Bovine Tissue Biotransfer Factors," Environ. Sci. Technol. 26, 19151921.

$\mathrm{Ng}$, Y. C. (1982), "A Review of Transfer Factors for Assessing the Dose From Radionuclides in Agricultural Products," Nucl. Saf. 23(1), 57-71.

Stull, D. R. (1947), "Vapor Pressure of Pure Substances: Inorganic Compounds," Ind. Eng. Chem. 39, 540-550.

Weast, R. C., M. J. Astle, and W. H. Beyer, Eds. (1986), CRC Handbook of Chemistry and Physics: A Ready Reference Book of Chemical and Physical Data, 67th Edition (CRC Press, Inc., Boca Raton, FL).

Vreman, K., N. G. van der Veen, E. J. van der Molen, W. G. de Ruig (1986), Neth. J. Agric. Sci. 34, 129. (cited by Stevens, 1991, 1992). 


\section{Nickel (Ni)}

Nickel is one of many trace elements that are pervasive in the environment as a result of releases from both human and natural sources. Nickel ores occur primarily in the form of the oxides, silicates, and sulfides and are usually associated with other sulfide, silicate, or arsenide minerals (Bodek et al., 1988). Nickel is obtained commercially from pentlandite and pyrrhotite ores. Pentlandite also contains copper and iron. Nickel belongs to the iron-cobalt group of metals and is chiefly valuable for the alloys it forms. It is extensively used for making stainless steel and other corrosion-resistant alloys. It is also used extensively for making coins. Nickel metal, nickel sulfate, nickel chloride, and nickel cyanide are used in electroplating (Bodek et al., 1988). Other uses of nickel are in batteries and catalysts (Weast et al., 1986). Although nickel can have a valance of $+1,+2,+3$, or +4 , the only oxidation state of importance under environmental conditions is the +2 state (Bodek et al., 1988). Nickel forms a number of salts, including nickel carbonate $\left(\mathrm{NiCO}_{3}\right)$, nickel chloride $\left(\mathrm{NiCl}_{2}\right)$, nickel hydroxide $\left[\mathrm{Ni}(\mathrm{OH})_{2}\right]$, nickel sulfate $\left(\mathrm{NiSO}_{4}\right)$, and nickel sulfide (NiS). The environmentally important nickel compounds are the sulfide, hydroxide, and carbonate compounds.

\section{Molecular and atomic weights}

$58.69 \mathrm{~g} / \mathrm{mol}$, atomic weight of elemental $\mathrm{Ni}$ (Weast et al., 1986).

$58.71 \mathrm{~g} / \mathrm{mol}$, atomic weight of $\mathrm{Ni}$ (Bowen, 1979).

$118.70 \mathrm{~g} / \mathrm{mol}$, molecular weight of nickel carbonate, $\mathrm{NiCO}_{3}$ (Weast et al., 1986).

$129.60 \mathrm{~g} / \mathrm{mol}$, molecular weight of nickel chloride, $\mathrm{NiCl}_{2}$ (Weast et al., 1986).

$92.70 \mathrm{~g} / \mathrm{mol}$, molecular weight of nickel hydroxide, $\mathrm{Ni}(\mathrm{OH})_{2}$ (Weast et al., 1986).

$154.75 \mathrm{~g} / \mathrm{mol}$, molecular weight of nickcl sulfate, $\mathrm{NiSO}_{4}$ (Weast et al., 1986).

$90.75 \mathrm{~g} / \mathrm{mol}$, molecular weight of nickel sulfide, NiS (Weast et al., 1986).

\section{Melting points}

$1452{ }^{\circ} \mathrm{C}$ for nickel metal, Ni (Stull, 1947).

$1455{ }^{\circ} \mathrm{C}$ for nickel metal, $\mathrm{Ni}$ (Weast et al., 1986).

nickel carbonate, $\mathrm{NiCO}_{3}$, decomposes before melting, (Weast et al., 1986)

$1001{ }^{\circ} \mathrm{C}$ for nickel chloride, $\mathrm{NiCl}_{2}$ (Stull, 1947). 
$848{ }^{\circ} \mathrm{C}$ nickel sulfate, $\mathrm{NiSO}_{4}$, decomposes before melting (Weast et al., 1986).

$797{ }^{\circ} \mathrm{C}$ for nickel sulfide, NiS (Weast et al., 1986).

\section{Vapor pressures}

$2732{ }^{\circ} \mathrm{C}$ is the boiling point of nickel metal, $\mathrm{Ni}$ (Stull, 1947). nickel chloride, $\mathrm{NiCl}_{4}$, sublimates at $973{ }^{\circ} \mathrm{C}$ (Weast et al., 1986).

Stull (1947) reports the following vapor pressures for nickel metal (Ni).

$\begin{array}{ccc}\text { Temperature }\left({ }^{\circ} \mathrm{C}\right) & \text { Vapor Pressure }(\mathrm{mm}) & \text { Vapor Pressure }(\mathrm{kPa}) \\ 1810 & 1 & 0.133 \\ 1979 & 5 & 0.667 \\ 2087 & 10 & 1.33 \\ 2143 & 20 & 2.67 \\ 2234 & 40 & 5.33 \\ 2289 & 60 & 8.00 \\ 2364 & 100 & 13.3 \\ 2473 & 200 & 26.7 \\ 2603 & 400 & 53.3 \\ 2732 & 760 & 101\end{array}$

Recommended value:

No recommended vapor pressure for inorganic Nickel, because of the extremely low vapor pressures of $\mathrm{Ni}$ and its compounds, a VP of 0 is appropriate.

\section{Solubility in water}

The nickel compounds that are environmentally important are the relatively insoluble sulfide, hydroxide, and carbonate compound (Bodek et al., 1988). The only oxidation state of importance for nickel under environmental conditions is +2 . Because nickel tends to form complexes with both organic and inorganic ligands in aquatic systems, its apparent solubility in surface water systems and in soil solutions can increase significantly over the values reported below for 
solubility in pure water. In an organic-free aquatic system, the predominant $\mathrm{Ni}$ species over the $\mathrm{pH}$ range 2 to 9 are $\mathrm{Ni}^{+2}$ and $\mathrm{NiSO}_{4}$.

metal nickel, $\mathrm{Ni}$, is insoluble in water (Weast et al., 1986).

$93 \mathrm{mg} / \mathrm{L}\left(0.78 \mathrm{~mol} / \mathrm{m}^{3}\right)$ of nickel carbonate $\left(\mathrm{NiCO}_{3}\right)$, at $25^{\circ} \mathrm{C}$ (Weast et al., 1986).

$130 \mathrm{mg} / \mathrm{L}\left(1.4 \mathrm{~mol} / \mathrm{m}^{3}\right)$ of nickel hydroxide $\left(\mathrm{Ni}[\mathrm{OH}]_{2}\right)$, at $20^{\circ} \mathrm{C}$ (Weast et al., 1986).

$293,000 \mathrm{mg} / \mathrm{L}\left(1890 \mathrm{~mol} / \mathrm{m}^{3}\right)$ of nickel sulfate $\left(\mathrm{NiSO}_{4}\right)$, at $20^{\circ} \mathrm{C}$ (Weast et al., 1986).

$873,000 \mathrm{~g} / \mathrm{L}\left(5640 \mathrm{~mol} / \mathrm{m}^{3}\right)$ of nickel sulfate $\left(\mathrm{NiSO}_{4}\right)$, at $100{ }^{\circ} \mathrm{C}$ (Weast et al., 1986).

$3.6 \mathrm{mg} / \mathrm{L}\left(0.039 \mathrm{~mol} / \mathrm{m}^{3}\right)$ of nickel sulfide $(\mathrm{NiS})$, at $18{ }^{\circ} \mathrm{C}$ (Weast et al., 1986).

Recommended values:
$\begin{aligned} & \mathrm{WS}(\mathrm{Ni} \text { metal })=\sim 0 \\ & \mathrm{WS}(\mathrm{Ni}+2)= 0.039 \text { to } 5640 \mathrm{~mol} / \mathrm{m}^{3} \text { depending on the presence of } \\ & \text { inorganic species in the water system. }\end{aligned}$

Henry's law constant

Because of their almost complete speciation in water and extremely low vapor pressures, most nickel compounds do not have measurable or predicted Henry's law constants. However, at low concentrations, the ratio of air to water concentration in air and water environments that are in contact can be estimated as

$$
\mathrm{C}_{\mathrm{w}} / \mathrm{C}_{\mathrm{a}}=\mathrm{A} \times \mathrm{v}_{\mathrm{d}} /\left(\mathrm{V}_{\mathrm{w}} \times \mathrm{R}_{\mathrm{w}}\right)
$$

where $C_{w}$ is the nickel concentration in a given water body, $\mathrm{mol} / \mathrm{m}^{3} ; \mathrm{C}_{\mathrm{a}}$ is the nickel concentration in air above the water body, $\mathrm{mol} / \mathrm{m}^{3} ; \mathrm{v}_{\mathrm{d}}$ is the deposition velocity that represents the rate of nickel transfer from air to water, $\mathrm{m} / \mathrm{d} ; \mathrm{A}$ is the contact area between the air and water, $\mathrm{m}^{2} ; \mathrm{V}_{\mathrm{w}}$ is the volume of the water body, $\mathrm{m}^{3}$; and $\mathrm{R}_{\mathrm{w}}$ is the first-order rate constant that accounts for all nickel removals from water (i.e. precipitation and deposition), day ${ }^{-1}$. 
Partition coefficients in soils and sediments

$200 \mathrm{~L} / \mathrm{kg}$ reported by Bodek et al. (1988) as a $\mathrm{K}_{\mathrm{d}}$ value observed for $\mathrm{Ni}$ in clay soils.

Bodek et al. (1988) list ranges of Freundlich isotherm parameters for modeling sorption of nickel in six different soil types, silt loam, sandy loam, loamy sand, sand, clay, and clay loam. The following Freundlich-isotherm derived distribution coefficients, $K_{d}$, bracket the range of isotherms developed by Bodek et al. (1988),

$$
\begin{aligned}
& K_{d}=S / C=5.0 C 0.81 / C[L / k g] \\
& K_{d}=S / C=10 C^{0.99} / C[L / k g] \\
& K_{d}=S / C=57 C^{0.57 / C[L / k g]} \text { for loamy-sand soil } \\
& K_{d}=S / C=444 C^{0.96 / C[L / k g]} \quad \text { for silt-loam soil } \\
& K_{d}=S / C=600 C^{0.95 / C[L / k g]} \quad \text { for clay soil } \\
& K_{d}=S / C=730 C^{1.03 / C[L / k g]} \quad
\end{aligned}
$$

where $S$ is the sorbed nickel concentration, $\mathrm{mg} / \mathrm{kg}$, and $\mathrm{C}$ is nickel concentration in water, $\mathrm{mg} / \mathrm{L}$. The figure below illustrate the dependence of the distribution coefficient for nickel on nickel concentration in the water phase based on these Freundlich isotherms.

Recommended value of $\mathrm{K}_{\mathrm{d}}$ for nickel in soils and in sediments based on the geometric mean and geometric standard deviation of values considered above:

$5 \leq K_{d} \leq 1500$ in soils and sediments

$\log K_{d}=1.9 \pm 0.715$ in soils

$K_{d}=80 \times$ or $\div 5.2$ in soils 


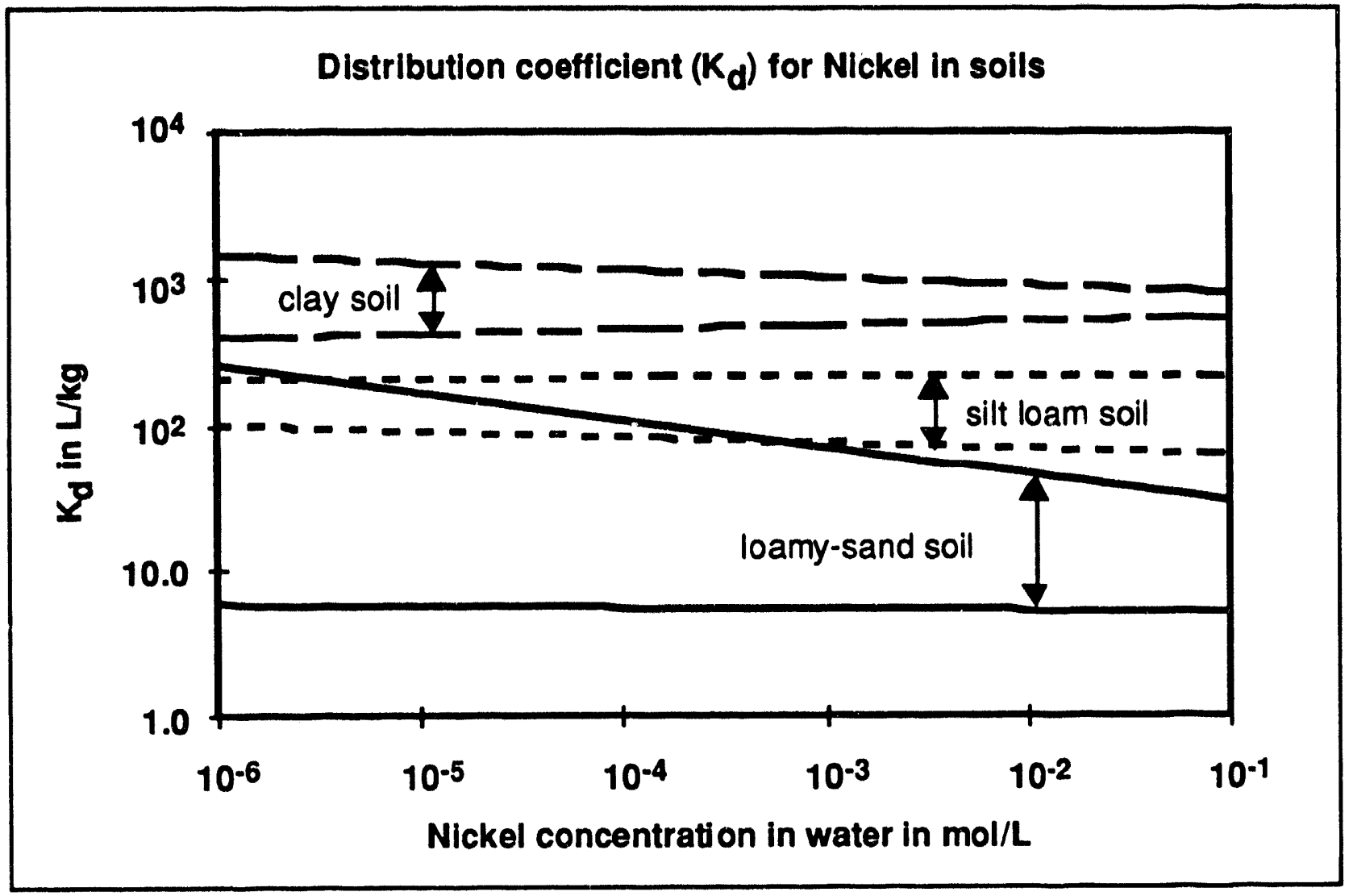

Diffusion coefficient in water

In dilute solutions of ionized species, such as nickel compounds, in which there are no rapid chemical reactions and the solution is isothermal, Bodek et al. (1988) have shown that diffusion coefficients for the anions and cations in solution do not vary greatly and are on the order of $1.5 \times 10^{-9} \mathrm{~m}^{2} / \mathrm{s}$. The diffusion coefficients of many simple salts generally do not vary by more than a factor of 2 over a range of concentrations and temperatures even though the conductivities can vary greatly (Bodek et al., 1988).

Recommended value:

$\mathrm{D}_{\text {water }}=1.3 \times 10^{-4} \mathrm{~m}^{2} / \mathrm{d}$ or $1.5 \times 10^{-9} \mathrm{~m}^{2} / \mathrm{s} \times$ or +2 for $0^{\circ} \mathrm{C} \leq \mathrm{T} \leq 40^{\circ} \mathrm{C}$

Diffusion coefficient in air

Because of the extremely low vapor pressure of nickel and inorganic nickel compounds, these chemical species are not likely to be found in the gas phase of the environment. There is no need for a diffusion coefficient in air and, thus no value is recommended. 
Bioconcentration factors for plant tissue relative to soil concentration $\mathrm{kg}($ soil)/ $\mathrm{kg}$ (plant fresh mass), $K_{p s}$

Nickel is an essential trace element for plants and animals (Mertz, 1981). Root uptake of nickel as $\mathrm{Ni}^{+2}$ occurs though water uptake by roots (Bodek et al. (1988).

0.019 based on a vegetation-fresh-mass-to-soil coefficient described by $\mathrm{Ng}$ (1982).

0.006 to 0.018 based on a soil-to-plant-dry-mass coefficient of 0.06 used by Baes et al. (1984) for the vegetative and non-vegetative portions of food crops and our assumed plant dry-mass fraction in the range 0.1 to 0.3 .

0.0017 to 0.0051 based on a soil-to-plant-dry-mass coefficient of 0.017 used by Bennett (1982) for land plants and foods and our assumed plant dry-mass fraction in the range 0.1 to 0.3 .

0.002 to 0.03 based on $50 \mathrm{mg} / \mathrm{kg}$ as the geosphere average of soil nickel concentration and 1 to $5 \mathrm{mg} / \mathrm{kg}$ (dry mass) as a geosphere average of land-plant nickel concentration reported by Bowen (1979) and our assumed plant dry-mass fraction in the range 0.1 to 0.3 .

0.00004 to 0.024 based on $50 \mathrm{mg} / \mathrm{kg}$ as the geosphere average of soil nickel concentration and 0.02 to $4 \mathrm{mg} / \mathrm{kg}$ (dry mass) as a geosphere average of edible-plant nickel concentration reported by Bowen (1979) and our assumed plant dry-mass fraction in the range 0.1 to 0.3 .

$0.0008 \times$ or +29 based on 5 to $5000 \mathrm{mg} / \mathrm{kg}$ as the range of background soil nickel levels and 0.1 to $5 \mathrm{mg} / \mathrm{kg}$ (dry mass) as the range of background plant levels reported by Bodek et al. (1988) and our assumed plant dry-mass fraction in the range 0.1 to 0.3 .

$0.0008 \times$ or $\div 20$ based on a 4 to $230 \mathrm{mg} / \mathrm{kg}$ as the range of background soil nickel levels and 0.01 to $3 \mathrm{mg} / \mathrm{kg}$ (dry mass) as the range of plant levels reported by Bennett (1982) and our assumed plant dry-mass fraction in the range 0.1 to 0.3 .

$0.0034 \times$ or $\div 2.2$ is the partition factor from surface soil to edible plant parts due to rainsplash, $K_{p s}^{\text {rain }}$ (Dreicer et al. 1984).

Recommended value of $\mathrm{K}_{\mathrm{ps}}$ based on the log mean of the ranges of values considered above,

$$
\begin{aligned}
& \log \mathrm{K}_{\mathrm{ps}}=-2.6 \pm 1.1 \\
& \mathrm{~K}_{\mathrm{ps}}=0.0024(\times \text { or }+12) \mathrm{kg}(\text { soil }) / \mathrm{kg} \text { (plant fresh mass) }
\end{aligned}
$$


Steady-state bioconcentration factors for plant leaf relative to air concentration

According to Bodek et al. (1988), airborne deposition is believed to contribute to concentrations of nickel found in plant leaves. At low concentrations, the ratio of plant leaf concentration to air concentration when air and plant environments are in contact, can be estimated as

$$
C_{p} / C_{a}=A \times v_{d} /\left(V_{p} \times R_{p}\right)
$$

where $C_{p}$ is nickel concentration in the plants in contact with contaminated air, $\mathrm{mol} / \mathrm{m}^{3} ; \mathrm{C}_{\mathrm{a}}$ is the nickel concentration in air above the plants, $\mathrm{mol} / \mathrm{m}^{3} ; \mathrm{v}_{\mathrm{d}}$ is the deposition velocity that represents the rate of nickel transfer from air to plant surfaces, $m / d ; A$ is the contact area between the air and plants, $m^{2} ; V_{p}$ is the volume of the plants compartment, $\mathrm{m}^{3}$; and $R_{\mathrm{p}}$ is the first-order rate constant that accounts for all nickel removals from plants (i.e. wash-off, biodegradation, etc.), day-1.

Bioconcentration factors for fish relative to water/or sediment concentrations

250 reported by Bodek et al. (1988) as a typical concentration ratio in marine invertebrates relative to water concentration.

100 reported by Bodek et al. (1988) as a typical concentration ratio in marine fish relative to water concentration.

100 reported by Bodek et al. (1988) as a typical concentration ratio in freshwater invertebrates relative to water concentration.

100 reported by Bodek et al. (1988) as a typical concentration ratio in freshwater fish relative to water concentration.

34 to 1400 based on $0.00058 \mathrm{mg} / \mathrm{L}$ as a geosphere average of ocean-water nickel concentration and 0.1 to $4 \mathrm{mg} / \mathrm{kg}$ (dry mass) as an average of marinefish nickel concentration reported by Bowen (1979) and our assumed fish dry-mass fraction of 0.2 .

Recommended $\mathrm{BCF}$ value, based on the geometric mean and geometric standard deviation reflecting the range of $B C F$ values described above:

$\log B C F($ fish $)=2.2 \pm 0.55$

$\mathrm{BCF}($ fish $)=160 \times$ or $\div 3.5$ 
Steady-state biotransfer factors for milk or dairy-product concentration relative to contaminant intake by cattle, $B_{k}$

0.001 to $0.0067 \mathrm{~d} / \mathrm{L}$ is the range of values of uptake to milk from feed based on radioisotope studies reported by $\mathrm{Ng}$ (1982).

Stevens (1991) evaluated several studies investigating the concentration of soluble forms of $\mathrm{Ni}$ in milk relative to the $\mathrm{Ni}$ intake in feed and found insufficient information available to calculate an accurate biotransfer factor for nickel.

Recommended biotransfer factor, $\mathrm{B}_{\mathrm{k}}$, for milk based on the geometric mean and geometric standard deviation reflecting the value range above:

$$
\begin{aligned}
& \log B_{k}=-2.6 \pm 0.24 \\
& B_{k}=0.0025(\times \text { or } \div 1.7) d / L
\end{aligned}
$$

Steady-state biotransfer factors for meat concentration relative to contaminant intake by cattle, pigs, and chickens

$0.002(x$ or $\div 1.7) \mathrm{d} / \mathrm{kg}$ are the geometric mean and geometri standard deviation of the meat-diet biotransfer factor reported by

$0.006 \mathrm{~d} / \mathrm{kg}$ is the value considered by Stevens (19\%. Je the most reasonable estimate of a steady-state biotransfer factor for nickel to bovine muscle.

Recommended biotransfer factor, $\mathrm{B}_{\mathrm{t}}$, for meat based on the geometric mean and geometric standard deviation reflecting the range of values above:

$$
\begin{aligned}
& \log B_{t}=-2.6 \pm 0.23 \\
& B_{t}=0.003 \times \text { or } \div 1.7
\end{aligned}
$$

Steady-state biotransfer factors for egg concentration relative to contaminant intake by chickens

No reported measurements of egg-diet biutransfer for nickel are available in the current literature. 
$\mathrm{Ng}$ (1982) has shown that for the seven elements strontium, rubidium, iodine, cesium, cerium, plutonium, and americium, the ratio of egg contents biotransfer to beef biotransfer is $60 \times$ or $\div 13$. Based this observation, the meat biotransfer above can be used to make an estimate of egg contents biotransfer of $0.18 \times$ or $\div 13$.

Recommended biotransfer factor, $\mathrm{B}_{\mathrm{e}}$, for eggs:

$\log B_{e}=-0.74 \pm 1.1$

$B_{e}=0.18 \times$ or $\div 13$

Contaminant biodegradation factors in soil

There is no evidence of biodegradation of inorganic nickel in soils and sediments (Bodek et al. 1988). Thus, there is no recommended biodegradation factor for inorganic nickel compounds in soils.

Media-specific half lives for air, soil, and surface water

There is no evidence that inorganic nickel compounds react in air, soil, or water in such a way as to increase an existing physical removal of nickel from these compartments. Thus the half lives of nickel species in these compartments will depend entirely upon the removal rate due to natural physical processes such as deposition and erosion.

Recommended half-lives:

Air deposition half life

Soil erosion half life

Water suspended particle half life 


\section{References for Nickel}

Baes, III, C.F., R.D. Sharp, A.L. Sjoreen, and R.W. Shor (1984), A Review and Analysis of Parameters for Assessing Transport of Environmentally Released Radionuclides Through Agriculture, Oak Ridge National Laboratory, Oak Ridge, TN, ORNL-5786/NTIS DE85-000287.

Bennett, B.G. (1982), "Exposure of Man to Envireonmental Nickel - An Exposure Commitment Assessment," Sci. Total Environ. 22, 203-212.

Bodek, I., W.J. Lyman, W.F. Reehl, and D.H. Rosenblatt, Eds. (1988), Environmental Inorganic Chemistry: Properties, Processes, and Estimation Methods (Pergamon Press, New York City, NY.)

Bowen, H.J.M. (1979), Environmental Chemistry of the Elements (Academic Press, New York City, NY).

Dreicer, M., T.E. Hakonson, G.C. White, and F.W. Whicker (1984), "Rainsplash as a Mechanism for Soil Contamination of Plant Surfaces," Health Phys. 46, 177-187.

Mertz, W. (1981), "The Essential Trace Elements," Science 213, 1332-1338.

$\mathrm{Ng}$, Y.C. (1982), "A Review of Transfer Factors for Assessing the Dose from Radionuclides in Agricultural Products," Nucl. Saf. 23, 57-71.

Stevens, J.B. (1991), "Disposition of Toxic Metals in the Agricultural Food Chain. 1. Steady-State Bovine Milk Biotransfer Factors," Environ. Sci. Technol. 25, 12891294.

Stevens, J.B. (1992), "Disposition of Toxic Metals in the Agricultural Food Chain. 2. Steady-State Bovine Tissue Biotransfer Factors," Environ. Sci. Technol. 26, 19151921.

Strill, D.R. (1947), "Vapor Pressure of Pure Substances: Inorganic Compounds," Ind. Eng. Chem. 39, 540-550.

Weast, R.C., M.J. Astle, and W.H. Beyer, Eds. (1986), CRC Handbook of Chemistry and Physics: A Ready Reference Book of Chemical and Physical Data, 67th Edition (CRC Press, Inc., Boca Raton, FL). 


\section{Tetrachloroethylene (PCE)}

Other names: Perchloroethylene, ethylene tetrachloride, tetrachloroethene.

CAS Registry Number: 127-18-4

Tetrachloroethylene (PCE) is released to air and water from its uses as a solvent, dry cleaning agent, and degreasing agent. PCE is used as a solvent for fats, greases, waxes, rubber, and decaffeinating coffee. It is used to remove soot from industrial boilers. PCE is used as a heat-transfer medium and also used in the manufacture of fluorocarbon refrigerants, paint removers, and printing inks. Additionally, in manufacturing, PCE is a primary source for the preparation of trichloroacetic acid. PCE typically enters the atmosphere as a fugitive emission from these industrial uses.

Formula: $\mathrm{C}_{2} \mathrm{Cl}_{4}$

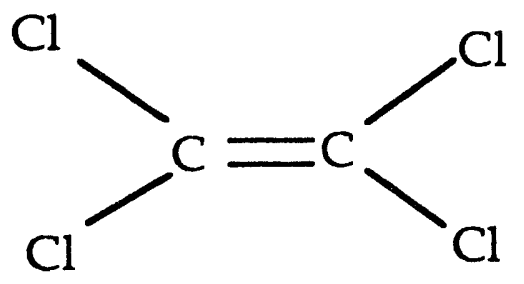

Molecular weight

165.82 (Howard et al., 1990)

165.83 (Verschueren, 1983: Weast et al., 1986; Weast and Grasselli, 1989)

165.85 (Windholz et al., 1983)

Melting Point

$-19{ }^{\circ} \mathrm{C}$ (Howard et al., 1990; Weast and Grasselli, 1989)

$-22.7^{\circ} \mathrm{C}$ (Verschueren, 1983)

$-22^{\circ} \mathrm{C}$ (Windholz et al., 1983)

Octanol-water partition coefficient $\left(K_{o w}\right)$

339 based on a $\log \mathrm{K}_{\mathrm{ow}}$ of 2.53 reported by Hansch and Leo (1987) from a value measured by and reported in Chiou et. al. (1977)

398 based on a $\log \mathrm{K}_{\mathrm{ow}}$ of 2.60 reported by Hansch and Leo (1987) from an unpublished value measured by G. Gould and C. Hansch. This value is also cited by Verschueren (1983). 
759 based on a $\log \mathrm{K}_{\mathrm{ow}}$ of 2.88 reported by Hansch and Leo (1987) based on a value measured by and reported in Banerjee et. al. (1980)

759 based on a $\log \mathrm{K}_{\mathrm{ow}}$ of 2.88 reported by Hansch and Leo (1987) based on a value measured by and reported in Banerjee et. al. (1980)

2510 based on a $\log \mathrm{K}_{\mathrm{ow}}$ of 3.40 reported by Hansch and Leo (1987) from an unpublished value measured by $G$. Gould and $C$. Hansch. This value is also cited by Howard et al. (1990), who attribute the value to Hansch and Leo (1985).

6030 based on a $\log \mathrm{K}_{\mathrm{ow}}$ of 3.78 reported by Hansch and Leo (1987) based on a value measured by and reported in Kenaga and Goring (1980).

Recommended value, based on the log-mean value of the 6 measured values reported above:

$$
\begin{aligned}
& \log \mathrm{K}_{\mathrm{ow}}=3.0 \pm 0.5 \\
& \mathrm{~K}_{\mathrm{ow}}=1000 \times \text { or } \div 3
\end{aligned}
$$

\section{Vapor pressure at standard temperatures}

$2.47 \mathrm{kPa}$ at $25^{\circ} \mathrm{C}$ reported by Howard et al. (1990), who attribute this value to Daubert and Danner (1985).

The Merck Index (Windholz et al., 1983) reports the boiling point of PCE as $121^{\circ} \mathrm{C}$

Stull (1947) reports the following vapor pressures (VPs) for PCE.

$\begin{array}{ccc}\text { Temperature }\left({ }^{\circ} \mathrm{C}\right) & \text { Vapor Pressure }(\mathrm{mm}) & \text { Vapor Pressure }(\mathrm{kPa}) \\ 2.4 & 5 & 0.667 \\ 13.8 & 10 & 1.33 \\ 26.3 & 20 & 2.67 \\ 40.1 & 40 & 5.33 \\ 49.2 & 60 & 8.00 \\ 61.3 & 100 & 13.3 \\ 79.8 & 200 & 26.7 \\ 100 & 400 & 53.3 \\ 121 & 760 & 101\end{array}$


Interpolating from this data gives $\mathrm{VP}$ at $25^{\circ} \mathrm{C}=2.46 \mathrm{kPa}$

Verschueren (1983) reports the following vapor pressures for PCE.

$\begin{array}{ccc}\text { Temperature }\left({ }^{\circ} \mathrm{C}\right) & \text { Vapor Pressure }(\mathrm{mm}) & \text { Vapor Pressure }(\mathrm{kPa}) \\ 20 & 14 & 1.87 \\ 30 & 24 & 3.20 \\ 40 & 45 & 6.00 \\ 121.4 & 760 & 101\end{array}$

Interpolating from this data give VP at $25^{\circ} \mathrm{C}=2.57 \mathrm{kPa}$

The following Antoine equations have been published for estimating the vapor pressure of $\mathrm{PCE}$ in $\mathrm{kPa}$

$$
\log _{10}(\mathrm{VP})=6.195-\frac{1446}{224.1+\mathrm{T}} \text { for } 28^{\circ} \mathrm{C}<\mathrm{T}<108^{\circ} \mathrm{C} \text { from Boublik et al (1984), }
$$

which gives $\mathrm{VP}=2.45 \mathrm{kPa}$ at $25^{\circ} \mathrm{C}$;

$$
\log _{10}(\mathrm{VP})=6.103-\frac{1388}{217.6+\mathrm{T}} \text { for } 37^{\circ} \mathrm{C}<\mathrm{T}<120^{\circ} \mathrm{C} \text { from Boublik et al (1984), }
$$

which gives $\mathrm{VP}=2.41 \mathrm{kPa}$ at $25^{\circ} \mathrm{C}$; and

$$
\log _{10}(\mathrm{VP})=6.102-\frac{1387}{217.5+\mathrm{T}} \text { for } 37^{\circ} \mathrm{C}<\mathrm{T}<120^{\circ} \mathrm{C} \text { from Dean (1985), }
$$

which also gives $\mathrm{VP}=2.41 \mathrm{kPa}$ at $25^{\circ} \mathrm{C}$.

The Antoine equation above in the temperature range $28^{\circ} \mathrm{C}<\mathrm{T}<108^{\circ} \mathrm{C}$ proposed by Boublik et al. (1984) for VP versus temperature is plotted below.

Recommended value for the temperature range -10 to $40^{\circ} \mathrm{C}$, based on the Antoine equation of Boublik et al. (1984) above:

$$
\begin{aligned}
& \mathrm{VP}(\mathrm{kPa})=10^{[6.195-1446 /(224.1+\mathrm{T})]} \pm 0.07 \text { for }-10^{\circ} \mathrm{C}<\mathrm{T}<40^{\circ} \mathrm{C} \\
& \mathrm{VP}(\mathrm{kPa})=2.45 \pm 0.07 @ 25^{\circ} \mathrm{C}
\end{aligned}
$$




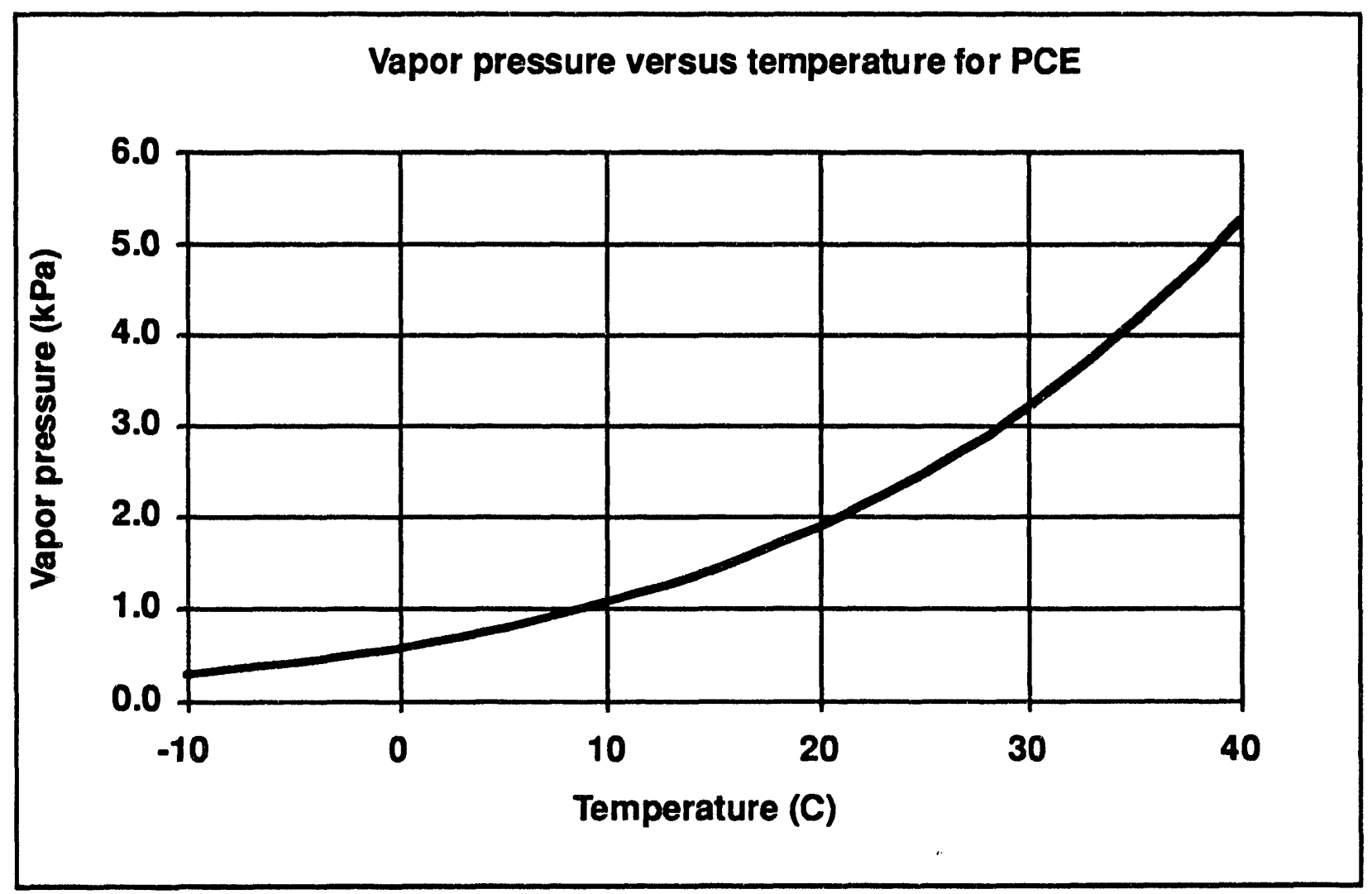

Solubility in water

$150 \mathrm{mg} / \mathrm{L}$ at $25^{\circ} \mathrm{C}$ reported by Verschueren (1983).

$162 \mathrm{mg} / \mathrm{L}$ approximate solubility reported by The Merck Index (Windholz et al., 1983).

$150.3 \mathrm{mg} / \mathrm{L}$ at $25^{\circ} \mathrm{C}$ reported by Howard et al. (1990), who attribute this value to Horvath (1982).

$130 \mathrm{mg} / \mathrm{L}$ at $1.5^{\circ} \mathrm{C}$ reported as ppm by wt by Dilling (1977). [As cited in Horvath (1982)].

$75 \mathrm{mg} / \mathrm{L}$ at $15^{\circ} \mathrm{C}$ reported as wt $\%$ by Antropov et al. (1972). [As cited in Horvath (1982)].

$87 \mathrm{mg} / \mathrm{L}$ at $20^{\circ} \mathrm{C}$ reported as wt \% by Antropov et al. (1972). [As cited in Horvath (1982)].

$120 \mathrm{mg} / \mathrm{L}$ at $20^{\circ} \mathrm{C}$ reported as ppm by wt by Dilling (1977). [As cited in Horvath (1982)].

$200 \mathrm{mg} / \mathrm{L}$ at $20^{\circ} \mathrm{C}$ reported as wt \% by du Pont (1966). [As cited in Horvath (1982)]. 
$200 \mathrm{mg} / \mathrm{L}$ at $20^{\circ} \mathrm{C}$ reported as wt $\%$ by Marsden (1963). [As cited in Horvath (1982)].

$210 \mathrm{mg} / \mathrm{L}$ at $20^{\circ} \mathrm{C}$ reported by Moiseeva et al. (1977). [As cited in Horvath (1982)].

$150 \mathrm{mg} / \mathrm{L}$ at $20^{\circ} \mathrm{C}$ reported as ppm by wt by Pearson and McConnell (1975). [As cited in Horvath (1982)].

$150 \mathrm{mg} / \mathrm{L}$ at $20^{\circ} \mathrm{C}$ reported as ppm by wt by Selenka and Bauer (1978). [As cited in Horvath (1982)].

$100 \mathrm{mg} / \mathrm{L}$ at $25^{\circ} \mathrm{C}$ reported as $\mathrm{g} / \mathrm{g}$-water by Valluad et al. (1957). [As cited in Horvath (1982)].

$140 \mathrm{mg} / \mathrm{L}$ at $25^{\circ} \mathrm{C}$ reported as ppm by wt by Dilling (1977). [As cited in Horvath (1982)].

$150 \mathrm{mg} / \mathrm{L}$ at $25^{\circ} \mathrm{C}$ reported as g/g-water by Archer and Stevens (1977). [As cited in Horvath (1982)].

$150 \mathrm{mg} / \mathrm{L}$ at $25^{\circ} \mathrm{C}$ reported as wt \% by Gladis (1960). [As cited in Horvath (1982)].

$150 \mathrm{mg} / \mathrm{L}$ at $25^{\circ} \mathrm{C}$ reported as g/g-water by Hancock (1973). [As cited in Horvath (1982)].

$150 \mathrm{mg} / \mathrm{L}$ at $25^{\circ} \mathrm{C}$ reported as g/g-water by Hooker Chemical Corp. (1966). [As cited in Horvath (1982)].

$150 \mathrm{mg} / \mathrm{L}$ at $25^{\circ} \mathrm{C}$ reported by Imperial Chemical Industries (1972). [As cited in Horvath (1982)].

$150 \mathrm{mg} / \mathrm{L}$ at $25^{\circ} \mathrm{C}$ reported by as wt $\%$ by Interdyne, Inc. (1976). [As cited in Horvath (1982)].

$150 \mathrm{mg} / \mathrm{L}$ at $25^{\circ} \mathrm{C}$ reported as g/g-water by Kirk-Othmer (1964). [As cited in Horvath (1982)].

$150 \mathrm{mg} / \mathrm{L}$ at $25^{\circ} \mathrm{C}$ reported as $\mathrm{g} / \mathrm{g}$-water by McGovern (1943). [As cited in Horvath (1982)].

$150 \mathrm{mg} / \mathrm{L}$ at $25^{\circ} \mathrm{C}$ reported as wt \% by Miller (1969). [As cited in Horvath (1982)].

$150 \mathrm{mg} / \mathrm{L}$ at $25^{\circ} \mathrm{C}$ reported as wt \% by Mitchell and Smith (1977). [As cited in Horvath (1982)].

$150 \mathrm{mg} / \mathrm{L}$ at $25^{\circ} \mathrm{C}$ reported as wt \% by Nathan (1978). [As cited in Horvath (1982)].

$150 \mathrm{mg} / \mathrm{L}$ at $25^{\circ} \mathrm{C}$ reported as $\mathrm{g} / \mathrm{g}$-water by $\mathrm{O}^{\prime}$ Connel (1963). [As cited in Horvath (1982)]. 
$150 \mathrm{mg} / \mathrm{L}$ at $25^{\circ} \mathrm{C}$ reported as g/g-water by Pittsburgh Plate Glase Ind. (1971). [As cited in Horvath (1982)].

$150 \mathrm{mg} / \mathrm{L}$ at $25^{\circ} \mathrm{C}$ reported as wt \% by Riddick and Bunger (1970). [As cited in Horvath (1982)].

$150 \mathrm{mg} / \mathrm{L}$ at $25^{\circ} \mathrm{C}$ reported by Schwarzenbach et al. (1979). [As cited in Horvath (1982)].

$150 \mathrm{mg} / \mathrm{L}$ at $25^{\circ} \mathrm{C}$ reported as $\mathrm{g} / \mathrm{g}$-water by Sconce (1962). [As cited in Horvath (1982)].

$189 \mathrm{mg} / \mathrm{L}$ at $25^{\circ} \mathrm{C}$ reported by Wright and Schaffer (1932). [As cited in Horvath (1982)].

$200 \mathrm{mg} / \mathrm{L}$ at $25^{\circ} \mathrm{C}$ reported as wt \% by Coca and Diaz (1980). [As cited in Horvath (1982)].

$200 \mathrm{mg} / \mathrm{L}$ at $25^{\circ} \mathrm{C}$ reported as wt \% by Gunther et al. (1968). [As cited in Horvath (1982)].

$400 \mathrm{mg} / \mathrm{L}$ at $25^{\circ} \mathrm{C}$ reported as ppm by wt by Chiou et al. (1977). [As cited in Horvath (1982)].

$400 \mathrm{mg} / \mathrm{L}$ at $25^{\circ} \mathrm{C}$ reported as wt $\%$ by Matthews $(1975,1979)$. [As cited in Horvath (1982)].

$480 \mathrm{mg} / \mathrm{L}$ at $25^{\circ} \mathrm{C}$ reported as mo / L-solution by Banerjee et al. (1980). [As cited in Horvath (1982)].

$1000 \mathrm{mg} / \mathrm{L}$ at $25^{\circ} \mathrm{C}$ reported as wt $\sigma_{o}$ by Ethyl Corp. (1958). [As cited in Horvath (1982)].

$151 \mathrm{mg} / \mathrm{L}$ at $26^{\circ} \mathrm{C}$ reported $2 s$ wt \% by Antropov et al. (1972). [As cited in Horvath (1982)].

$166 \mathrm{mg} / \mathrm{L}$ at $40^{\circ} \mathrm{C}$ reported as wt \% by Simonov et al. (1974). [As cited in Horvath (1982)].

From the information above, Horvath (1982) has constructed the following polynomial fit for the dependence of PCE solubility (in wt \%) on temperature (T) in ${ }^{\circ} \mathrm{C}$ in the range 0 to $80^{\circ} \mathrm{C}$

$$
\begin{aligned}
\mathrm{WS}(\mathrm{wt} \%)= & 1.497 \times 10^{-2}-7.801 \times 10^{-6} \mathrm{~T}-5.1403 \times 10^{-7} \mathrm{~T}^{2}+3.694 \times 10^{-8} \mathrm{~T}^{3} \\
& \pm 0.001 \text { (standard error of the estimate) }
\end{aligned}
$$

which gives

$$
\begin{aligned}
\text { WS } & =0.015 \pm 0.0076(\mathrm{wt} \%) \text { at } 25^{\circ} \mathrm{C} \\
& =150 \pm 76 \mathrm{mg} / \mathrm{L} \text { at } 25^{\circ} \mathrm{C} \\
& =0.91 \pm 0.46 \mathrm{~mol} / \mathrm{m}^{3} \text { at } 25^{\circ} \mathrm{C}
\end{aligned}
$$


The dependence of PCE solubility in water on temperature as given by this formula is plotted below.

The standard deviation in the water solubility at $25^{\circ} \mathrm{C}$ is based on the coefficient of variation in the average solubility of $\mathrm{PCE}$ at $25^{\circ} \mathrm{C}$ as derived from the values listed above instead of the standard error of the estimate as reported by Horvath (1982) in the correlation of water solubility above. (The standard error of the estimate is based on the estimation of the average solubility as a function of temperature and does not reflect the variation of solubility with temperature at any given temperature value. As reflected by the range of measured solubilities listed above, the coefficient of variation of solubility for PCE is 0.508 at $25^{\circ} \mathrm{C}$ and 0.3 at $20^{\circ} \mathrm{C}$.

$$
\begin{aligned}
& \text { Recommended values of solubility versus temperature, } \mathrm{T} \text { in }{ }^{\circ} \mathrm{C} \text {, based on } \\
& \text { Horvath's (1982) analysis: } \\
& \begin{aligned}
\mathrm{WS}(\mathrm{mg} / \mathrm{L})= & 149.7-0.07801 \mathrm{~T}-5.1403 \times 10^{-3} \mathrm{~T}^{2}+3.694 \times 10^{-4} \mathrm{~T}^{3} \\
& \pm 10 \mathrm{mg} / \mathrm{L} \text { for } 0{ }^{\circ} \mathrm{C}<\mathrm{T}<60^{\circ} \mathrm{C} \\
\mathrm{WS}\left(\mathrm{mol} / \mathrm{m}^{3}\right)= & 0.9029-4.7051 \times 10^{-4} \mathrm{~T}-3.100 \times 10^{-5} \mathrm{~T}^{2}+2.228 \times 10^{-6} \mathrm{~T}^{3} \\
& \pm 0.060 \mathrm{~mol} / \mathrm{m}^{3} \text { for } 0^{\circ} \mathrm{C}<\mathrm{T}<60^{\circ} \mathrm{C} \\
\mathrm{WS}(\mathrm{mg} / \mathrm{L})= & 150 \pm 76 \mathrm{mg} / \mathrm{L} @ 25^{\circ} \mathrm{C} \\
\mathrm{WS}\left(\mathrm{mol} / \mathrm{m}^{3}\right)= & 0.91 \pm 0.46 \mathrm{~mol} / \mathrm{m}^{3} @ 25^{\circ} \mathrm{C}
\end{aligned}
\end{aligned}
$$




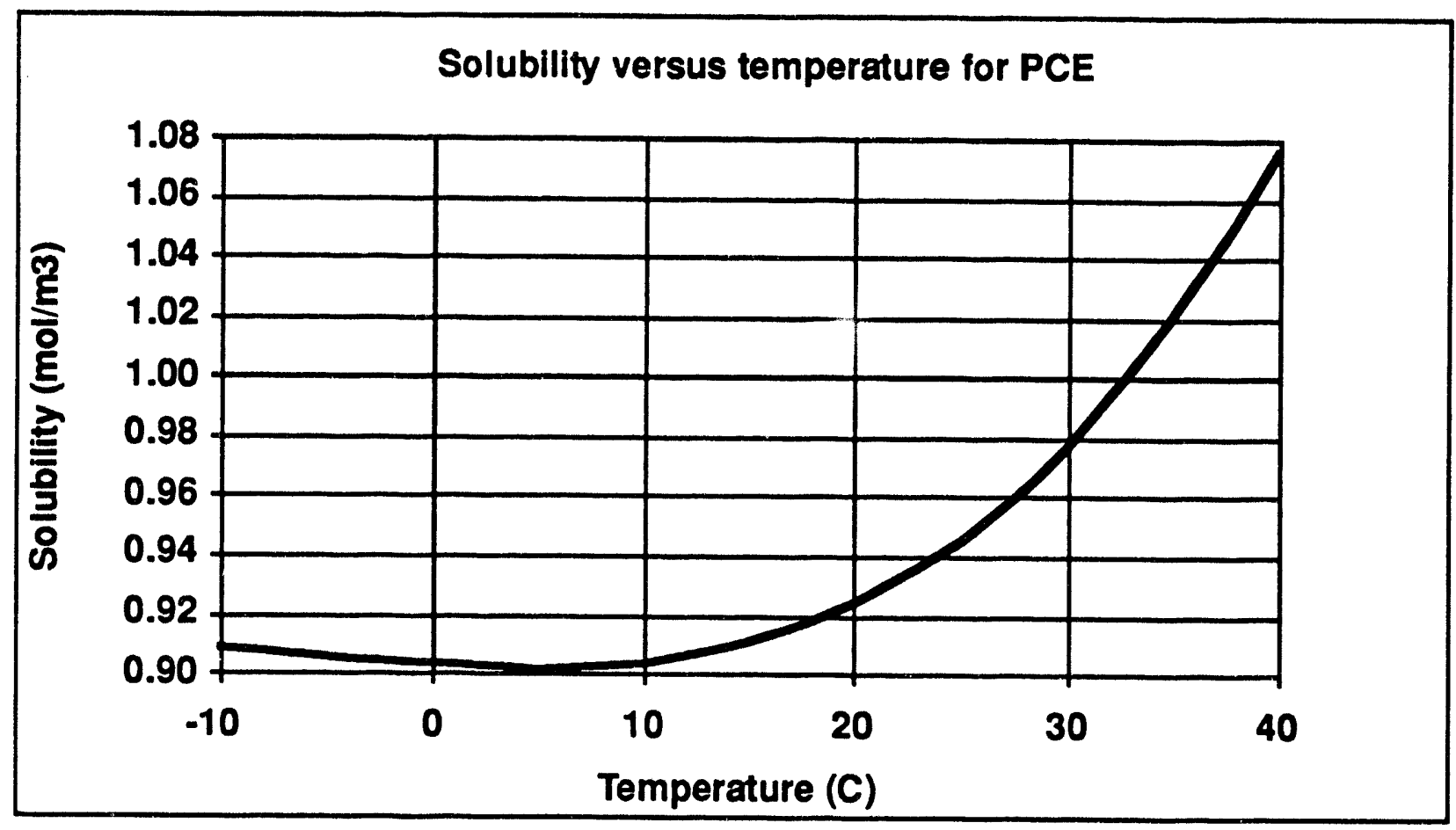

Henry's law constant (dimensionless form, i.e. $H / R T$ )

0.48 reported at $20^{\circ} \mathrm{C}$ by Lincoff and Gossett (1984) based on batch stripping. [Also cited in Mackay et al. (1993)].

0.54 reported at $20^{\circ} \mathrm{C}$ by Lincoff and Gossett (1984) based on EPICS. [Also cited in Mackay et al. (1993)].

0.54 reported at $20^{\circ} \mathrm{C}$ by Yurteri et al. (1987) based on EPICS. [Also cited in Mackay et al. (1993)].

0.55 reported at $20^{\circ} \mathrm{C}$ by Gossett (1987) based on EPICS. [Also cited in Mackay et al. (1993)].

0.59 reported at $20^{\circ} \mathrm{C}$ by Munz and Roberts (1987) based on multiple equilibrium. [Also cited in Mackay et al. (1993)].

0.63 reported at $20^{\circ} \mathrm{C}$ by Munz and Roberts (1982) based on batch stripping. [Also cited in Mackay et al. (1993)].

0.67 reported at $20^{\circ} \mathrm{C}$ by Mackay et al. (1979) based on batch stripping. [Also cited in Mackay et al. (1993)].

0.70 reported at $20^{\circ} \mathrm{C}$ by Ashworth et al. (1986) based on EPICS. [Also cited in Mackay et al. (1993)].

0.82 reported at $20^{\circ} \mathrm{C}$ by McConnell et al. (1975). [Also cited in Mackay et al. (1993)]. 
$0.85 \pm 0.43$ obtained by taking the ratio of VP/WS divided by RT at $20^{\circ} \mathrm{C}$, where VP and WS are the values recommended above.

0.66 reported at $25^{\circ} \mathrm{C}$ by Leighton and Calo (1981) based on concentration-ratio gas chromatography. [Also cited in Mackay et al. (1993)].

1.17 reported at $25^{\circ} \mathrm{C}$ by Urano and Murata (1985) based on the adsorption-isotherm method. [Also cited in Mackay et al. (1993)].

0.75 reported at $25^{\circ} \mathrm{C}$ by Gossett (1987) based on EPICS. [Also cited in Mackay et al. (1993)].

0.71 reported at $25^{\circ} \mathrm{C}$ by Munz and Roberts (1987). [Also cited in Mackay et al. (1993)].

0.55 reported at $25^{\circ} \mathrm{C}$ by Tancréde and Yanagisawa (1990) based on purge and trap gas chromatography. [Also cited in Mackay et al. (1993)].

$0.90 \pm 0.46$ obtained by taking the ratio of VP/WS divided by RT at $25^{\circ} \mathrm{C}$, where VP and WS are the values recommended above.

Recommended value at $20^{\circ} \mathrm{C}$ based on the arithmetic mean of the nine measured values above:

$$
\mathrm{H} / \mathrm{RT}=0.61 \pm 0.10 @ 20^{\circ} \mathrm{C}
$$

Recommended value at $25^{\circ} \mathrm{C}$ based on the arithmetic mean of the five measured values above:

$$
\mathrm{H} / \mathrm{RT}=0.77 \pm 0.24 @ 20^{\circ} \mathrm{C}
$$

Plotted below is the dimensionless Henry's law constant H/RT versus temperature as derived from the ratio of VP/WS/RT using the temperaturedependent expressions for VP and WS presented above. 


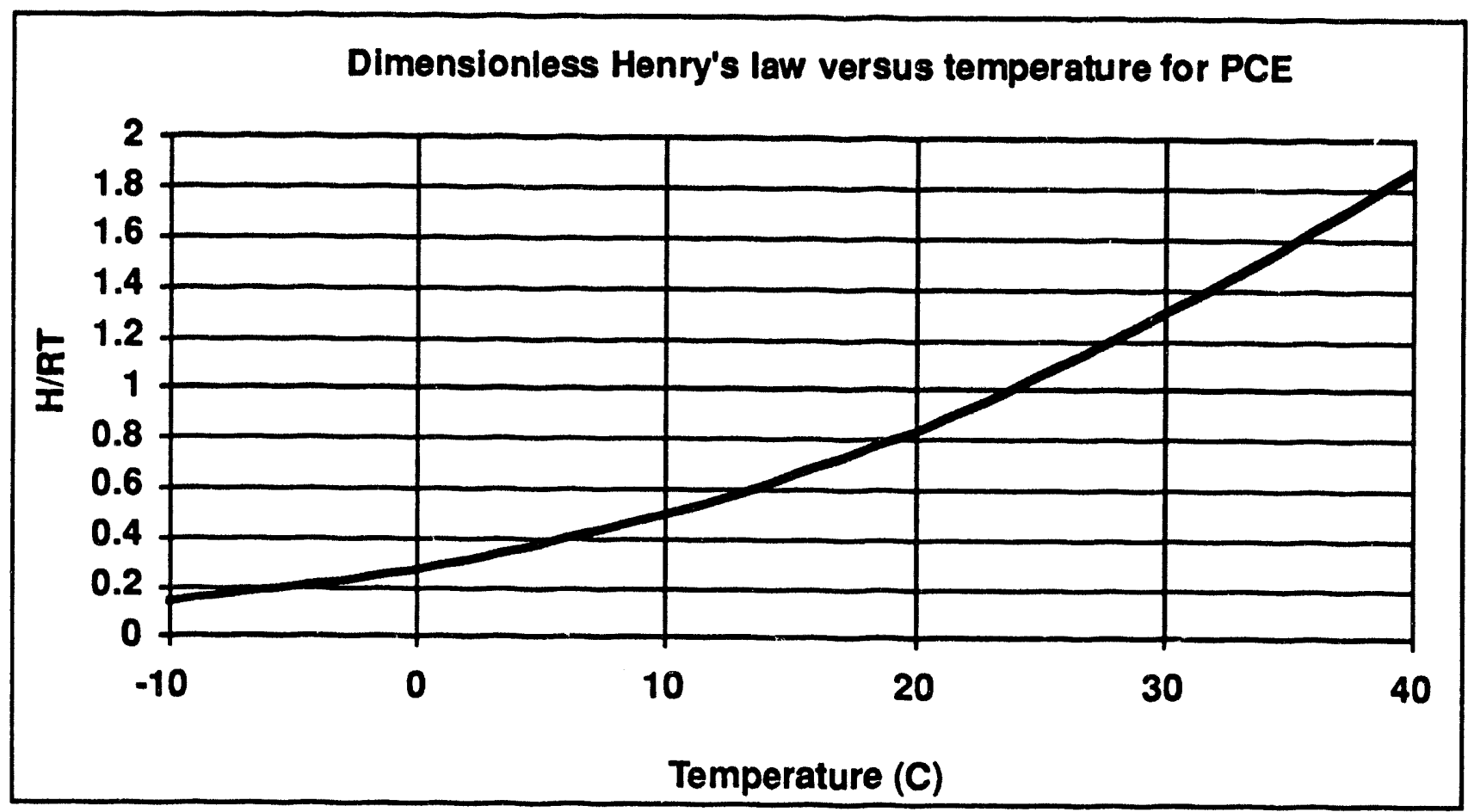

Organic-carbon partition coefficient $\left(K_{o c}\right)$

75 derived from a $\log \mathrm{K}_{\mathrm{om}}$ of 1.64 for untreated $\mathrm{B}_{\mathrm{t}}$-horizon Marlette soil reported at $25^{\circ} \mathrm{C}$ by Lee et al. (1989) and the assumption that $\mathrm{K}_{\mathrm{oc}}=\mathrm{K}_{\mathrm{om}} \times 1.724$ (Lyman et al., 1990). [ $\mathrm{K}_{\mathrm{om}}$ value cited in Mackay et al. (1993)].

86 derived from a $\log \mathrm{K}_{\mathrm{om}}$ of 1.70 for untreated A-horizon Marlette soil reported at $25^{\circ} \mathrm{C}$ by Lee et al. (1989) and the assumption that $\mathrm{K}_{\mathrm{oc}}=\mathrm{K}_{\mathrm{om}} \times 1.724$ (Lyman et al., 1990). [ $\mathrm{K}_{\mathrm{om}}$ value cited in Mackay et al. (1993)].

110 (or $\log \mathrm{K}_{\mathrm{oc}}=2.04$ ) reported at $25^{\circ} \mathrm{C}$ by Schwarzenbach and Westall (1981). [Also cited in Howard et al. (1990) and in Mackay et al. (1993)].

209 (or $\log \mathrm{K}_{\mathrm{oc}}=2.32$ ) reported at $25^{\circ} \mathrm{C}$ by Chiou et al. (1979). [Also cited in Mackay et al. (1993)].

281 (or $\log \mathrm{K}_{\mathrm{oc}}=2.45$ ) reported at $25^{\circ} \mathrm{C}$ for surface soil by Pignatello (1990). [Also cited in Mackay et al. (1993)].

344 derived from a $\log \mathrm{K}_{\mathrm{om}}$ of 2.30 for A-horizon Marlette soil treated with DDTMA reported at $25^{\circ} \mathrm{C}$ by Lee et al. (1989) and the assumption that $\mathrm{K}_{\mathrm{oc}}=\mathrm{K}_{\mathrm{om}} \times 1.724$ (Lyman et al., 1990). [ $\mathrm{K}_{\mathrm{om}}$ value cited in Mackay et al. (1993)]. 
363 (or $\log \mathrm{K}_{\mathrm{oc}}=2.56$ ) reported at $25^{\circ} \mathrm{C}$ for soil by Chiou et al. (1988). [Also cited in Mackay et al. (1993)].

437 (or $\log \mathrm{K}_{\mathrm{oc}}=2.64$ ) reported at $20^{\circ} \mathrm{C}$ for soil, sand, and loess by Grathwohl (1990). [Also cited in Mackay et al. (1993)].

626 derived from a $\log \mathrm{K}_{\mathrm{om}}$ of 2.56 for A-horizon Marlette soil treated with HDTMA reported at $25^{\circ} \mathrm{C}$ by Lee et al. (1989) and the assumption that $\mathrm{K}_{\mathrm{oc}}=\mathrm{K}_{\mathrm{om}} \times 1.724$ (Lyman et al., 1990). [ $\mathrm{K}_{\mathrm{om}}$ value cited in Mackay et al. (1993)].

750 derived from a $\log \mathrm{K}_{\mathrm{om}}$ of 2.64 for $\mathrm{B}_{\mathrm{t}}$-horizon Marlette soil treated with DDTMA reported at $25^{\circ} \mathrm{C}$ by Lee et al. (1989) and the assumption that $\mathrm{K}_{\mathrm{oc}}=\mathrm{K}_{\mathrm{om}} \times 1.724$ (Lyman et al., 1990). [ $\mathrm{K}_{\mathrm{om}}$ value cited in Mackay et al. (1993)].

970 derived from a $\log \mathrm{K}_{\mathrm{om}}$ of 2.75 for $\mathrm{B}_{\mathrm{t}}$-horizon Marlette soil treated with HDTMA reported at $25^{\circ} \mathrm{C}$ by Lee et al. (1989) and the assumption that $\mathrm{K}_{\mathrm{oc}}=\mathrm{K}_{\mathrm{om}} \times 1.724$ (Lyman et al., 1990). [ $\mathrm{K}_{\mathrm{om}}$ value cited in Mackay et al. (1993)].

1950 (or $\log \mathrm{K}_{\mathrm{oc}}=3.29$ ) reported at $20^{\circ} \mathrm{C}$ for weathered shale and mudrock by Grathwohl (1990). [Also cited in Mackay et al. (1993)].

3980 (or $\log \mathrm{K}_{\mathrm{oc}}=3.60$ ) reported at $25^{\circ} \mathrm{C}$ for Borden organic phase with no mineral sorption by Ball and Roberts (1991). [Also cited in Mackay et al. (1993)].

10700 (or $\log \mathrm{K}_{\mathrm{oc}}=4.03$ ) reported at $20^{\circ} \mathrm{C}$ for unweathered shale and mudrock by Grathwohl (1990). [Also cited in Mackay et al. (1993)].

Recommended value, based on the log-mean value of the 13 measured values reported above; (the high $\mathrm{K}_{\mathrm{oc}}$ value reported for unweathered shale and mudrock is excluded because it is assumed not be relevant for soils):

$$
\begin{aligned}
& \log K_{o c}=2.6 \pm 0.5 \\
& K_{o c}=400 \times \text { or } \div 3.2
\end{aligned}
$$

Diffusion coefficient in water

Based on the Wilke and Chang (1955) method described in Reid et al. (198\%), the diffusion coefficient in $\mathrm{m}^{2} / \mathrm{d}$ in water is given by 


$$
\begin{aligned}
& \text { 颜 } \\
& \text { 萂 }
\end{aligned}
$$

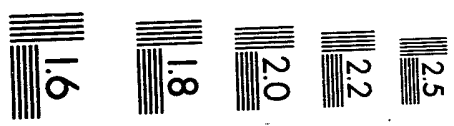



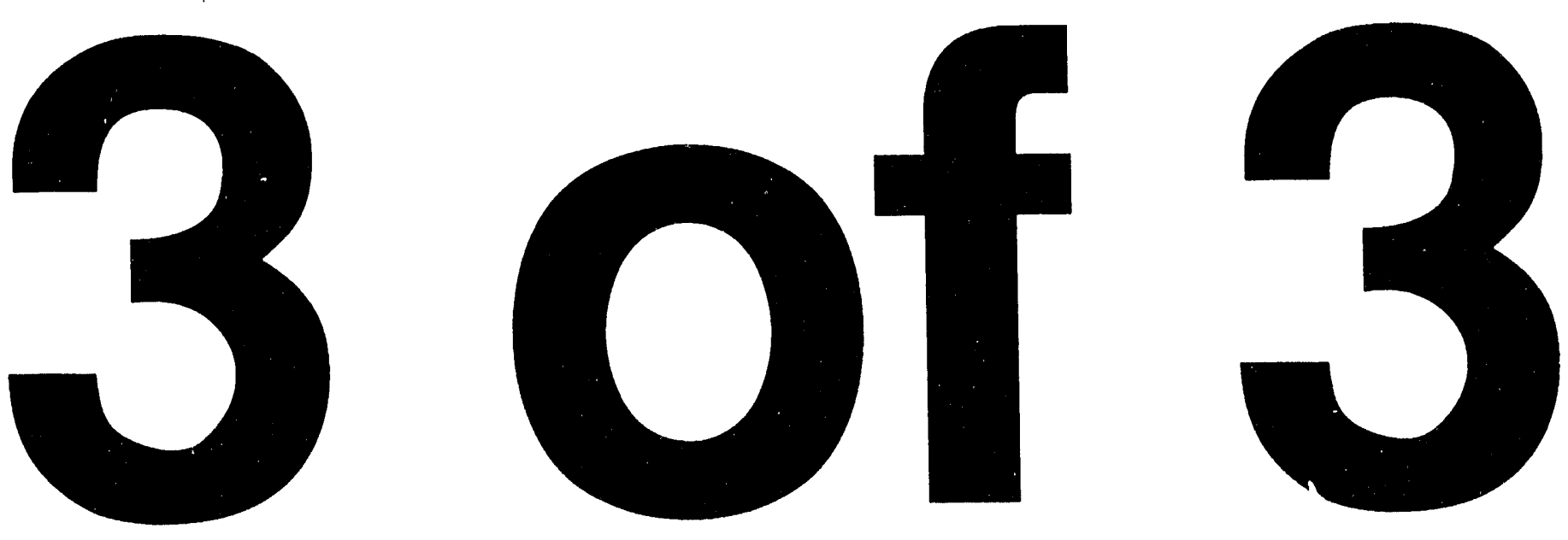


$$
D_{x y}=\frac{6.5 \times 10^{-7}\left(\phi M_{y}\right)^{1 / 2} \mathrm{~T}}{\eta_{y} V_{x}^{0.6}}
$$

The molecular weight $\mathrm{M}_{\mathrm{y}}$ of water is $18 \mathrm{~g} / \mathrm{mol}$. Wilke and Chang (1955) recommend an association factor, $\phi$, of 2.6 when the solvent is water. The viscosity of water, $\eta_{y}$, is $0.89 \mathrm{cP}$ at $25^{\circ} \mathrm{C}$. Molecular volume can be estimated by the Le Bas incremental method as described in Lyman et al. (1990). With the molecular volume $V_{x}$ of $P C E$ equal to $111 \mathrm{~cm}^{3} / \mathrm{mol}$, this expression gives

Recommended value:

$$
D_{\text {water }}=3.0 \times 10^{-7} \mathrm{~T} \mathrm{~m}^{2} / \mathrm{d}=8.8 \times 10^{-5} \mathrm{~m}^{2} / \mathrm{d} \text { or } 1.0 \times 10^{-9} \mathrm{~m}^{2} / \mathrm{s} @ 25^{\circ} \mathrm{C}
$$

Diffusion coefficient in air

Based on the Fuller et al. (1966) method described in Lyman et al. (1990), the diffusion coefficient in $\mathrm{m}^{2} / \mathrm{d}$ in air is given by

$$
D_{\text {air }}=8.6 \times 10^{-3} \mathrm{~T}^{1.75} \frac{\sqrt{\frac{\left(29+\mathrm{M}_{\mathrm{x}}\right)}{29 \mathrm{M}_{\mathrm{x}}}}}{\left[2.7+\left(V_{\mathrm{x}}\right)^{1 / 3}\right]^{2}}
$$

With the molecular volume, $\mathrm{V}_{\mathrm{x}}$, of PCE of $111 \mathrm{~cm}^{3} / \mathrm{mol}$ and a molecular weight of $166 \mathrm{~g} / \mathrm{mol}$, the above expression gives (with $\mathrm{T}$ in kelvins)

Recommended value:

$$
\mathrm{D}_{\text {air }}=3.1 \times 10^{-5} \mathrm{~T}^{1.75} \mathrm{~m}^{2} / \mathrm{d}=0.66 \mathrm{~m}^{2} / \mathrm{d} \text { or } 7.6 \times 10^{-6} \mathrm{~m}^{2} / \mathrm{s} @ 25^{\circ} \mathrm{C} .
$$

Bioconcentration factors for plant tissue concentration relative to soil concentration No reported measurements of plant-root bioconcentration for PCE in soils are available in the current literature. Estimation methods for this parameter are considered below. 
The partition factor from surface soil to edible plant parts due to rainsplash, $\mathrm{K}_{\mathrm{ps}}^{\text {rain }}$ is equal to $0.0034 \mathrm{~kg}$ (soil) $/ \mathrm{kg}$ (plant) with a CV of 1 (Dreicer et al. 1984). This partition factor applies plant fresh-mass concentration relative to soil concentration.

Based on the Briggs et al. (1982, 1983) estimation equation for uptake of contaminants by roots from soil solution, we calculate the RCF (which represents the ratio of contaminant concentration in root, $\mathrm{mg} / \mathrm{kg}$ [fresh mass], to contaminant concentration in soil solution, $\mathrm{mg} / \mathrm{L}$ ) for PCE as

$$
\mathrm{RCF}=0.82+0.03 \mathrm{~K}_{\mathrm{ow}}^{0.77}=3.4 \text { to } 15
$$

When this factor is divided by the sorption coefficient, $\mathrm{K}_{\mathrm{D}}=\mathrm{f}_{\mathrm{oc}} \times \mathrm{K}_{\mathrm{OC}}=(0.01$ to $0.02) \times \mathrm{K}_{\mathrm{oc}}$ (from above), we obtain the ratio of contaminant concentration in roots, $\mathrm{mg} / \mathrm{kg}$ (fresh mass) to contaminant concentration in soil solids, $\mathrm{mg} / \mathrm{kg}$, which we refer to as $\mathrm{K}_{\mathrm{ps}}$ (roots) and estimate it as being in the range

$$
\mathrm{K}_{\mathrm{ps}}(\text { roots })=0.04 \text { to } 20
$$

Based on the regression of $K_{p s}$ (roots) with $K_{o c}$ from Topp et al. (1986), and based on the range of $\mathrm{K}_{\mathrm{oc}}$ values listed above, we obtain

$$
\begin{aligned}
& \text { (recommended range for root crops) } \\
& \mathrm{K}_{\mathrm{ps}} \text { (roots) }=664 \mathrm{~K}_{\mathrm{oc}}^{-0.622}=3.8 \text { to } 38 \text { (reflecting the range in } \mathrm{K}_{\mathrm{oc}} \text { ) }
\end{aligned}
$$

Based on the Travis and Arms (1988) correlation for plant-soil bioconcentration we obtain for the total plant (not jir 4 , roots) the following soil/plant partition coefficient

$$
\begin{aligned}
\mathrm{K}_{\mathrm{ps}}=7.7 \mathrm{~K}_{\mathrm{ow}}^{-0.58}=0.14 \times \text { or } \div 5.3 & \begin{array}{l}
\text { (recommended value for exposed } \\
\text { produce reflecting estimation error) }
\end{array}
\end{aligned}
$$

Steady-state bioconcentration factors for plant leaf concentration relative to air concentration

No reported measurements of plant-air bioconcentration for PCE in air are available in the current literature. Estimation methods for this parameter are considered below.

Based on the model of Riederer (1990) for foliar uptake of gases in plant leaves, we estimate a steady-state plant-air partition coefficient of 


$$
\begin{aligned}
& \mathrm{K}_{\mathrm{pa}}^{\mathrm{gs}}=\left[0.5+\left(0.4+0.01 \times \mathrm{K}_{\mathrm{ow}}\right) \times \frac{\mathrm{RT}}{\mathrm{H}}\right] \times 10^{-3} \frac{\mathrm{m}^{3}}{\mathrm{~kg}}=0.02 \mathrm{~m}^{3} / \mathrm{kg} \times \text { or } \div 2.2 \\
& \text { (recommended value). }
\end{aligned}
$$

We could find no study in which the estimation error of this partition coefficient has been considered, but we assume the $\mathrm{CV}$ associated with it is on the order of 1 .

Bioconcentration factors for fish concentration relative to water/or sediment concentrations

39 (or $\log$ BCF of 1.59) reported for trout muscle by Neely et al. (1974). [Also cited in Mackay (1982), in Howard et al. (1990), and in Mackay et al. (1993)].

49 (or log BCF of 1.69) reported for bluegill sunfish by Barrows et al. (1980). [Also cited in Howard et al. (1990) and in Mackay et al. (1993)].

49 (or log BCF of 1.69) reported for bluegill sunfish by Veith et al. (1980). [Also in Mackay et al. (1993)].

62 (or $\log$ BCF of 1.79) reported for rainbow trout by Saito et al. (1992). [Also in Mackay et al. (1993)].

115 (or log BCF of 2.06) reported for. rainbow trout by Veith and Kosian (1983). [Also in Mackay et al. (1993)].

16 to 144 Based the \pm one-standard-deviation range of the $K_{o w}$ values above and the estimation method based on $K_{\text {ow }}$ of Mackay (1982).

Recommended BCF value, based on the arithmetic mean values of the five measured values and the predicted range of values for log BCF above:

$\log \mathrm{BCF}($ fish $)=1.74 \pm 0.3$

$\mathrm{BCF}($ fish $)=55 \times$ or $\div 2$

Steady-state biotransfer factors for milk or dairy-product concentration relative to contaminant intake by cattle

No reported measurements of milk-diet biotransfer for toluene are available in the current literature for PCE. 
Based on the geometric mean regression of milk-to-diet biotransfer against $\mathrm{K}_{\mathrm{ow}}$ developed by Travis and Arms (1988) we estimate the milk biotransfer factor for PCE as

$$
\mathrm{B}_{\mathrm{k}}=7.9 \times 10^{-9} \mathrm{~K}_{\mathrm{ow}} \times 10^{( \pm 0.84)}=7.9 \times 10^{-6} \times \text { or } \div 7 \text { (recommended value) }
$$

The estimation error in this expression corresponds to a CVs of 6 .

Steady-state biotransfer factors for meat concentration relative to contaminant intake by cattle, pigs, and chickens

No reported measurements of meat-diet biotransfer for PCE are available in the current literature.

Based on the geometric mean regression of meat-to-diet biotransfer against $\mathrm{K}_{\mathrm{ow}}$ developed by Travis and Arms (1988) we estimate the meat biotransfer factor for PCE as

$$
\mathrm{B}_{\mathrm{t}}=2.5 \times 10^{-8} \mathrm{~K}_{\mathrm{ow}} \times 10^{( \pm 0.952)}=2.5 \times 10^{-5} \times \text { or } \div 9 \text { (recommended value) }
$$

The estimation error in this expression corresponds to a CV of 11.

Steady-state biotransfer factors for egg concentration relative to contaminant intake by chickens

No reported measurements of egg-diet biotransfer for PCE are available in the current literature.

Based on the geometric mean regression of egg-to-diet biotransfer against $\mathrm{K}_{\mathrm{ow}}$ developed above, we estimate the egg biotransfer factor for PCE as

$$
B_{e}=7.9 \times 10^{-6} K_{o w} \times 10^{( \pm 1)}=7.9 \times 10^{-3} \times \text { or } \div 10 \text { (recommended value) }
$$

The estimation error in this expression corresponds to a CV of 14.

\section{Contaminant biodegradation factors in soil}

Based on the aqueous aerobic biodegradation half life of PCE measured by Mudder (1981) and by Jensen and Rosenberg (1975), Howard et al. (1991) estimate the soil half life due to aerobic degradation to be in the range of 180 to $360 \mathrm{~d}$. [This range is also cited in Mackay et al. (1993)]. This range corresponds to an aerobic biodegradation rate constant in the range 0.00193 to $0.00385 \mathrm{~d}^{-1}$. The anaerobic half life of PCE has been estimated to be in the range 100 to $1640 \mathrm{~d}$ by Howard et al. (1991) based on anaerobic screening test data from Bouwer et al. (1981). This range corresponds to an anaerobic biodegradation rate constant in the range 0.000423 to $0.0069 \mathrm{~d}^{-1}$. 
Recommended soil biodegradation rate constants, based on the log mean and log range of the soil half life ranges above:

aerobic soil biodegradation rate constant $=0.0027 \mathrm{~d}^{-1} \times$ or $\div 1.2$

anaerobic soil biodegradation rate constant $=0.0017 \mathrm{~d}^{-1} \times$ or $\div 2.2$

Media-specific half lives for air, soil, and surface water

Air. Based on measurements by Atkinson (1985) of the vapor-phase reaction of PCE with hydroxyl radicals, Howard et al. (1991) estimate the half life of PCE in lower atmosphere is in the range of 16 to $160 \mathrm{~d}$. [This range is also cited in Mackay et al. (1993).] Based on the rate of disappearance of PCE due to reaction with hydroxyl radicals, Yung et al. (1975) report a half-life of $10 \mathrm{~d}$. [This range is also cited in Mackay et al. (1993)].

Soil Based on the aqueous aerobic biodegradation half life of PCE measured by Mudder (1981) and by Jensen and Rosenberg (1975), Howard et al. (1991) estimate the soil half life due to aerobic degradation to be in the range of 180 to $360 \mathrm{~d}$. [This range is also cited in Mackay et al. (1993)]. The anaerobic half life of PCE has been estimated to be in the range 100 to $1640 \mathrm{~d}$ by Howard et al. (1991) based on anaerobic screening test data from Bouwer et al. (1981).

Water Based on the aqueous aerobic river "die-away" test data measured by Mudder (1981) and on saltwater grab-sample data by Jensen and Rosenberg (1975), Howard et al. (1991) estimate the surface-water half life due to aerobic degradation to be in the range of 180 to $360 \mathrm{~d}$. [This range is also cited in Mackay et al. (1993).] Based on the concentration reduction between sample points on the Rhine River and a lake in the Rhine basin, Zoetemann et al. (1980) estimate respective PCE half lives to be 10 and $32 \mathrm{~d}$. These values are cited in Mackay et al. (1993) and in Howard et al. (1990). These latter rate constants reflect processes other than biodegradation, such as volatilization and deposition. 


Recommended half lives (in days), based on the geometric mean of the
half-life range and the geometric range of the values, 32 to 360 (the
lowest value is excluded because of its likely association with transport
processes:
Air $\quad 40 \mathrm{~d} \times$ or $\div 2.2$
Soil $\quad 404 \mathrm{~d} \times$ or $\div 2.2$
Water $\quad 130 \mathrm{~d} \times$ or $\div 3.5$

\section{References for Tetrachloroethylene (PCE)}

Antropov, L. I., V.E. Pogulyai, V.D. Simonov, and T.M. Shamsutdinov (1972), Russ. J. Phyhs. Chem. 46(2), 311-312 (VINITI N2. 3739-71).

Archer, W. L., V.L. and Stevens (1977), Ind. Eng. Chem. Prod. Res. Dev. 16(4), 319.

Ashworth, R.A., et al. (1986), "Air-Water Partitioning Coefficients of Organics in Dilute Aqueous Solutions," paper presented at the American Institute of Chemical Engineers 1986 National Meeting, Boston, MA.

Atkinson, R. (1985), "Kinetics and Mechanisms of the Gas Phase Reaction of Hydroxyl Radical with Organic Compounds Under Atmospheric Conditions," Chem. Rev. 85, 69-201.

Ball, W.P., and P.V. Roberts (1991), "Long Term Sorption of Halogenated Organic Chemicals by Aquifer Materials. 1. Equilibrium," Environ. Sci. Technol. 25(7), 12231237.

Banerjee, S., S.H. Yalkowsky, and S.C. Valvani (1980), "Water Solubility and Octanol/Water Partition Coefficient of Organics. Limitations of Solubility-Partition Coefficient Correlation," Environ. Sci. Technol. 14(10), 1227-1229.

Barrows, M.E., S.R. Petrocelli, and K.J. Macek (1980), "Bioconcentraion and Elimination of Selected Water Pollutants by Bluegill Sunfish (Lepomis machrochirus)," in Dynamic, Exposure, Hazard Assessment of Toxic Chemicals, R. Haque, Ed. (Ann Arbor Science Publishers, Inc., Ann Arbor, Mn), pp. 379-392.

Boublik, T., V. Fried, and E. Hála (1984), The Vapour Pressures of Pure Substances: Selected Values of the Temperature Dependence of the Vapour Pressures of Some Pure Substances in the Normal and Low Pressure Region (Second Revised Edition), Physical sciences data; 17 (Elsevier Science Publishers, Amsterdam, The Netherlands). 
Bouwer, E.J., B. Rittman, and P.L. McCarty (1981), "Anaerobic Degradation of 1- and 2-Carbon Halogenated Aliphatic Organic Compounds," Environ. Sci. Technol. 15, 596-599.

Briggs, G.G., R.H. Bromilow, and A.A. Evans (1982), “Relationships Between Lipophilicity and Root Uptake and Translocation of Non-Ionized Chemicals by Barley," Pestic. Sci. 13, 495-504.

Briggs, G.G., R.H. Bromilow, A.A. Evans, and M. Williams (1983), "Relationships Between Lipophilicity and the Distribution of Non-Ionized Chemicals in Barley Shoots Following Uptake by the Roots," Pestic. Sci. 14, 492-500.

Chiou, C.T., V.H. Freed, D.W. Schmedding, and R.L. Kohnert (1977), "Partition Coefficient and Bioaccumulation of Selected Organic Chemicals," Environ. Sci. Technol. 11(5), 475-478.

Chiou, C.T., L.J. Peters, and A.H. Freed (1979), "A Physical Concept of Soil-Water Equilibria for Nonionic Organic Compounds," Science 206, 831-832.

Chiou, C.T., D.E. Kile, and R.L. Malcolm (1988), "Soprtion of Vapors of Some Organic Liquids on Soil Humic Acid and Its Relation to Partitioning of Organic Compounds in Soil Organic Matter," Environ. Sci. Technol. 22(3), 298-303.

Coca, J. and R. Diaz (1980), J. Chem. Eng. Data 25(1), 80-83.

Daubert, T.E., and R.P. Danner (1985), Data Compilation Tables of Properties of Pure Compounds, Am. Institute of Chem. Engineers, pp. 450.

Dean, J.D., Ed. (1985), Lang's Handbook of Chemistry (McGraw-Hill, Inc., New York City, NY), 13th ed.

Dilling, W. L. (1977), Environ. Sci. Technol. 11(4), 405-409.

Dreicer, M., T.E. Hakonson, G.C. White, and F.W. Whicker (1984), "Rainsplash as a Mechanism for Soil Contamination of Plant Surfaces," Health Phys. 46, 177-187.

du Pont de Nemours \& Company (1966), Solvent Properties Comparison Chart, Freon Aerosol Report FA-26, Wilmington, Del. 6 pp.

Ethyl Corporation (1958), Chlorinated Solvents, Rep. ICD-1006 (58), New York, NY. 12 pp.

Fuller, E.N., P.D. Schettler, and J.C. Giddings (1966), "A New Method for Prediction of Binary Gas-Phase Diffusion Coefficients," Ind. Eng. Chem. 58, 19-27.

Gladis, G. P. (1960), Chem. Eng. Prog. 56(10), 43-51.

Gossett, J.M. (1987), “Measurement of Henry's Law Constants for $C_{1}$ and $C_{2}$ Chlorinated Hydrocarbons," Environ. Sci. Technol. 21, 202-208.

Grathwohl, P. (1990), "Influence of Organic Matter From Soils and Sediments From Various Origins on the Sorption of Some Chlorinated Aliphatic Hydrocarbons: Implications on $K_{o c}$ Correlations," Environ. Sci. Technol. 24, 1687-1693. 
Gunther, F. A., W.E. Westlake, and P.S. Jaglan (1968), Residue Rev. 20, 1-148.

Hancock, E. G., Ed. (1973), Propylene and Its Industrial Derivatives, Ernest Benn, London, UK. 517 pp.

Hansch, C., and A. Leo (1985), "The Log P and Related Parameters Database, created and updated by the Medicinal Chemistry Project at Pomona College under the direction of Corwin Hansch and Albert Leo - 1985 Printout," in Medchem Project Issue №. 26, Pomona College, Claremont, CA.

Hansch, C., and A. Leo (1987), "The Log P and Related Parameters Database," created and updated by the Medicinal Chemistry Project at Pomona College, Claremont, CA, under the direction of Corwin Hansch and Albert Leo - 1987 Printout.

Hooker Chemical Corp. (1966), Hooker Perchloroethylene for Industrial Uses, Bull. N. 190, Niagara Falls, NY.

Horvath, A. L. (1982), Halogenated Hydrocarbons, Solubility-Miscibility with Water (Marcel Dekker, Inc., New York City, NY).

Howard, P.H., G.W. Sage, W.F. Jarvis, and D.A. Gray, Eds. (1990), Handbook of Environmental Fate and Exposure Data for Organic Chemicals. Volume II. Solvents (Lewis Publishers, Inc., Chelsea, MI).

Howard, P. H., R. S. Boethling, W. F. Jarvis, W. M. Meylan, and E. M. Michalenko, Eds. (1991), Handbook of Environmental Degradation Rates (Lewis Publishers, Inc, Chelsea, MI)

Imperial Chemical Industries (1972), Brixham Lab. Rep. BL/B/1417, Brixham, England (August).

Interdyne, Inc. (1976), Solvent Data Sheet, SDS -104, Indianapolis, Ind., 2 pp.

Jensen, S., and R. Rosenberg (1975), "Degradability of Some Chlorinated Aliphatic Hydrocarbons in Seawater and Sterilized Water," Water Res. 9, 659-661.

Kenaga, E. E., and C. A. I. Goring (1980), "Relationship Between Water Solubility, Soil Sorption, Octanol-Water Partitioning, and Concentration of Chemicals in Biota," in Aquatic Toxicology, ASTM STP 707, J. G. Eaton, P. R. Parrish, and

A. C. Hendricks, Eds. (American Society for Testing and Materials, Philadelphia, PA) pp. 78-115.

Kirk-Othmer Encyclopedia of Chemical Technology (1964), Chlorocarbons and Chlorohydrocarbons, Vol. 5 (2nd ed.), Wiley, New York, NY. pp. 100-363.

Lee, J.F., J.R. Crum, and S.A. Boyd (1989), “Enhanced Retention of Organic Contaminants by Soils Exchanged with Organic Cations," Environ. Sci. Technol. 23, 1365-1372.

Leighton, D.T., and J.M. Calo (1981), "Distribution Coefficients of Chlorinated Hydrocarbons in Dilute Air-Water Syustems for Groundwater Contamination Applications," J. Chem. Eng. Data 26, 382-385. 
Lincolff, A.H., and J.M. Gossett (1984), "The Determination of Henry's law Constant for Volatile Organics by Equilibrium Partitioning in Closed Systems," in

Gas Transfer at Water Surfaces, W. Brutsaert, and G.H. Jirka, Eds. (Reidel Publishing Company, Dordrecht, The Netherlands), pp. 17-25.

Lyman, W. J., W. F. Reehl, and D. H. Rosenblatt (1990), Handbook of Chemical Property Estimation Methods: Environmental Beharior of Organic Compounds (American Chemical Society, Washington, DC).

Mackay, D. (1982), "Correlation of Bioconcentration Factors," Environ. Sci. Technol. 16, 274-278.

Mackay, D., W.-Y. Shiu, and K.-C. Ma (1993), Illustrated Handbook of Physical-Chemical Properties and Environmental Fate for Organic Chemicals. Volume III. Volatile Organic Chemicals (Lewis Publishers, Inc., Boca Raton, FL).

Mackay, D., W.-Y. Shiu, and R.P. Sutherland (1979), “Determination of Air-Water Henry's law Constants for Hydrophobic Pollutants," Environ. Sci. Technol. 13, 333337.

Marsden, C., Ed. (1963), Solvents Guide (2nd ed.), Cleaver-Hume, London, UK.

Matthews, P. J. (1975), Effl. Water Treat. J. 15(11), 565-567 and 626-627.

Matthews, P. J. (1979), "Use of Vapor-Liquid Equilibrium Data for Estimating Trade Effluent Limits," Proc. Natl. Phys. Lab. Conf. on Chemical Thermodynamic Data on Fluids and Fluid Mixtures. Teddington, Sept. 11-12, 1978. IPC Science and Technology Press, Guildford, England, UK. pp. 53-61.

MoConnell, G., D.M. Ferguson, and C.R. Pearson (1975), "Chlorinated Hydrocarbons and the Environment," Endeavour XXXVI, 13-18.

McGovern, E. W. (1943), Ind. Eng. Chem. 35(12), 1230-1239.

Miller, S. A., Ed. (1969), Ethylene and Its Industrial Derivatives, Ernest Benn, London, UK. $1321 \mathrm{pp}$.

Mitchell, J. and Smith, D. M. (1977), Aquametry, Part 1: A Treatise on Methods for the Determination of Water (2nd ed.), Wiley, New York, NY. 632 pp.

Moiseeva, L. M., Stepanov, G. G., and Pukhonto, A. N. (1977), Khim. Prom., NN.6, 435-437.

Mudder, T. (1981), "Development of Empirical Structure-Biodegradability Relationships and Testing Protocol for Slightly Soluble and Volatile Priority Pollutants," Diss. Abstr. Int. B. 42, 1804.

Munz, C., and P.V. Roberts (1982), Technical Report №. 262, Department of Civil Engineering, Stanford University, Stanford, CA.

Munz, C., and P.V. Roberts (1987), "Air-Water Phase Equilibria of Volatile Organic Solutes," J. Am. Water Works Assoc., 62-69. 
Nathan, M. F. (1978), Chem. Eng. 85(3), 93-100.

Neely, W.B., D.R. Branson, and G.E. Blau (1974), "Partition Coefficient to Measure Bioconcentration Potential of Organic Chemicals in Fish," Environ. Sci. Technol. 8, 1113-1115.

O'Connel, W. L. (1963), Trans. Am. Inst. Mech. Eng. 226(2), 126-132.

Pearson, C. R., and G. McConnell (1975), Proc. Roy. Soc. Lond. Ser. B 189, 305-332.

Pignatello, J.J. (1990), "Slow Reversible Sorption of Aliphatic Hydrocarbons in Soils:

I. Formation of Residual Fractions," Environ. Toxicol. Chem. 9, 1107-1115.

Pittsburgh Plate Glass Industries (1971), Perchloroethylene, Bull. 35C (A-1020, 5M, 471), Pittsburgh, PA, 2 pp.

Reid, R. C., J. M. Prausnitz, and B. E. Poling (1987), The Properties of Gases and Liquids (McGraw Hill, New York City, NY), 4th ed.

Reiderer, M. (1990), "Estimating Partitioning and Transport of Organic Chemicals in the Foliage/Atmosphere System: Discussion of a Fugacity-Based Model," Environ. Scil. Technol. 24, 829-837.

Riddick, J. A., and W.B. Bunger (1970), Orgaric Solvents. Physical Properties and Methods of Purification (3rd ed.), Vol. 2, Wiley-Interscience, New York, IJY. 603 pp.

Saito, S., A. Tanoue, and M. Matsuo (1992), "Applicability of I/O-Characters to a Quantitative Description of Bioconcentration of Organic Chemicals in Fish," Chemosphere 24(1), 81-87.

Schwarzenbach, R.P., E. Molnar-Kubica, W. Gieger, and S.G. Wakeham (1979), "Distribution, Residence Time, and Fluxes of Tetrachloroethylene and 1,4-Dichlorobenzene in Lake Zurich, Switzerland," Environ. Sci. Technol. 13(11), 1367-1373.

Schwarzenbach, R.P., and J. Westall (1981), "Transport of Nonpolar Compounds from Surface Water to Groundwater. Laboratory Sorption Studies," Environ. Sci. Technol. 11, 1360-1367.

Sconce, J. S., Ed. (1962), Chlorine: Its Manufacture, Properties, and Uses, Reinhold, New York, NY. 901 pp.

Selenka, F., and U. Bauer (1978), "Detection of Readily Volatile Organochloride Compounds in Water," Org. Verunreinig. Umwelt: Erkennen, Bewerten. pp. 242255 (CA 91:62457s).

Siminov, V. D., T. M. Shamsutdinov, V.E. Pogulyai, and L.N. Popova (1974), Russ. J. Phys. Chem. 48(11), 1573-1575.

Stull, D. R. (1947), "Vapor Pressure of Pure Substances: Organic Compounds," Ind. Eng. Chem. 39, 517-540. 
Tancréde, M.V., and Y. Yanagisawa (1990), "An Analytical Method to Determine Henry's law Constant for Selected Volatile Organic Compounds at Concentrations and Temperatures Corresponding to Tap Water Use," J. Air Waste Nianage. Assoc. 40, 1658-1663.

Topp, E., I. Scheunert, A. Attar, and F. Korte (1986), "Factors Affecting the Uptake of 14C-Labeled Organic Chemicals by Plants From Soil," Ecotoxicol. Environ. Saf. 11, 219-228.

Travis, C. C., and A. D. Arms (1988), "Bioconcentration of Organics in Beef, Milk, and Vegetation," Environ. Sci. Technol. 22, 271-274.

Urano, K., and C. Murata (1985), "Adsorption of Principal Chlorinated Organic Compounds on Soil," Chemosphere 14(3/4), 293-299.

Vallaud, A., V. Raymond, and P. Salmon (1957), Les Solvants Chlores et L'Hygiene Industrielle, Inst. Natl. Securite pour le Prevention des Accidents du Travail et des Maladies Professionelles, Paris, France. 356 pp.

Veith, G.D., and P. Kosian (1983), "Estimating Bioconcentration Potential from Octanol/Water Partition Coefficients," in Physical Behavior of PCBs in the Great Lakes, D. Mackay, S. Paterson, S.J. Eisenreich, and M.S. Simmons, Eds. (Ann Arbor Science Publishers, Ann Arbor, MI), pp. 269-282.

Veith, G.D., K.J. Macek, S.R. Petrocelli, and J. Caroll (1980), "An Evaluation of Using Partition Coefficients and Water Solubility to Estimate Bioconcentration Factors for Organic Chemicals in Fish," in Aquatic Toxicology, ASTM STP 707, J. G. Eaton, P. R. Parrish, and A. C. Hendricks, Eds. (American Society for Testing and Materials, Philadelphia, PA) pp. 117-119.

Verschueren, K. (1983), Handbook of Environmental Data on Organic Chemicals, Second Edition (Van Nostrand Reinhold Company Inc., New York City, NY).

Weast, R. C., M.J. Astle, and W.H. Beyer, Eds. (1986), CRC Handbook of Chemistry and Physics: A Ready Reference Book of Chemical and Physical Data, 67th Edition (CRC Press, Inc., Boca Raton, FL).

Weast, R.C., and J.G. Grasselli, Eds. (1989), Handbook of Data on Organic Compounds, 2nd Edition, Volume IV (CRC Press, Inc., Boca Raton, FL).

Wilke, C.R., and P. Chang (1955), "Correlation of Diffusion Coefficients in Dilute Solutions," AIChE J. 1, 264-270.

Windholz, M., S. Budavari, R. F. Blumetti, and E. S. Otterbein, Eds. (1983), The Merck Index: An Encyclopedia of Chemicals, Drugs, and Biologicals, 10th Edition (Merck \& Co., Inc., Rahway, NJ).

Wright, W. H. and Schaffer, J. M. (1932), Am. J. Hyg. 16(2), 325-428.

Yung, Y.L., M.B. McElroy, and S.C. Wofsy (1975), “Atmospheric Halocarbons: A Discussion with Emphasis on Chloroform," Geophys. Res. Lett. 2(9), 397-399. 
Yurteri, C., D.F. Ryan, J.J. Callow, and J.J. Gurol (1987), "The Effect of Chemical Composition of Water on Henry's law Constant," J. Water Pollut. Control Fed. 59, 950-956.

Zoeteman, B.C.J., K.M. Harmsen, and J.B.H.J. Linders (1980), "Persistent Organic Pollutants in River Water and Groundwater of the Netherlands," Chemosphere 9, 231-249. 
Tetrachloroethylene

- 198 - 


\section{Toluene}

Other names: Methyl benzene, phenylmethane, toluol, methyl benzol., methacide CAS Registry Number: 108-88-3

Toluene is used in the manufacture of benzene derivatives, saccharin, medicines, dyes, perfumes, detergents and explosives. Also, it is used in solvent recovery plants, as a component of gasoline. Additionally, toluene is a solvent for paints and coatings, for gums, resins, and rubber, and it is used as an adhesive solvent in plastic toys. Toluene is released to the atmosphere principally from the volatilization of petroleum fuels and toluene-based solvents and thinners, and from motor-vehicle exhaust. Toluene is obtained mainly from petroleum refining and coal tar distillation. Natural sources of toluene are coal tar, crude oil, volcanoes and forest fires.

Formula: $\mathrm{C}_{7} \mathrm{H}_{8}$

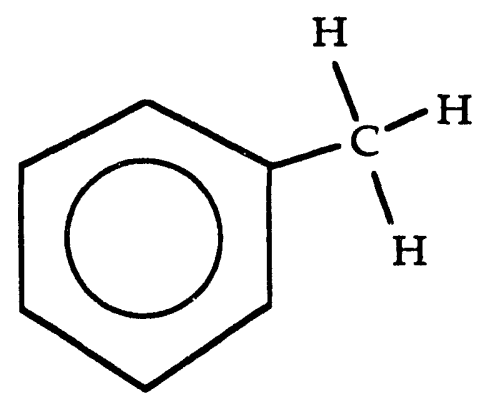

Molecular weight

$92.1{ }^{\circ} \mathrm{C}$ (Verschueren, 1983)

$92.13{ }^{\circ} \mathrm{C}$ (Weast et al., 1986; Mackay et al., 1992; Howard et al., 1990; Windholz et al., 1983)

Melting Point

$-95{ }^{\circ} \mathrm{C}$ (Weast et al., 1986; Mackay et al., 1992; Howard et al., 1990

Octanol-water partition coefficient $\left(K_{o w}\right)$

129 derived from a $\log \mathrm{K}_{\mathrm{ow}}$ of 2.11 reported by Hansch and Leo (1985) based on the value measured by Rogers and Cammarata (1969). [Also cited in Mackay et al. (1992)].

162 derived from a $\log K_{o w}$ of 2.21 reported by Hansch and Leo (1985) based on the value measured by Banerjee et al. (1980). [Also cited in Mackay et al. (1992)]. 
389 derived from a $\log \mathrm{K}_{\mathrm{ow}}$ of 2.59 based on the value measured by Hanai et al. (1981). [Also cited in Mackay et al. (1992)].

407 derived from a $\log \mathrm{K}_{\text {ow }}$ of 2.61 reported by Hansch and Leo (1985) based on the value measured by Tayar et al. (1984).

417 derived from a $\log \mathrm{K}_{\mathrm{ow}}$ of 2.62 based on the value measured by Miyake and Terada (1982). [Also cited in Mackay et al. (1992)].

447 derived from a $\log \mathrm{K}_{\mathrm{ow}}$ of 2.65 reported by Hansch and Leo (1985) based on the value measured by Tewari et al. (1982a). [Also cited in Mackay et al. (1992)].

447 derived from a $\log \mathrm{K}_{\mathrm{ow}}$ of 2.65 as measured by Wasik et al. (1983). [Also cited in Mackay et al. (1992)].

447 derived from a $\log \mathrm{K}_{\mathrm{ow}}$ of 2.65 as measured by Eadsforth and Moser (1983). [Also cited in Mackay et al. (1992)].

447 derived from a $\log \mathrm{K}_{\mathrm{ow}}$ of 2.65 as measured by Schantz and Martire (1987). [Also cited in Mackay et al. (1992)].

479 derived from a $\log \mathrm{K}_{\mathrm{ow}}$ of 2.68 reported by Hansch and Leo (1985) based on the value measured by Nahum and Horvath (1980). [Also cited in Mackay et al. (1992)].

490 derived from a $\log \mathrm{K}_{\mathrm{ow}}$ of 2.69 reported by Hansch and Leo (1985) based on the value measured by Fujita et al. (1964). [Also cited in Verschueren (1983) and in Mackay et al. (1992)].

525 derived from a $\log \mathrm{K}_{\mathrm{ow}}$ of 2.72 as measured by Garst and Wilson (1984). [Also cited in Mackay et al. (1992)].

537 derived from a $\log \mathrm{K}_{\mathrm{ow}}$ of 2.73 reported by Hansch and Leo (1985) based on the value measured by Church and Hansch at Pamona College in Claremont, CA (unpublished data). [Also cited in Howard et al. (1990)].

550 derived from a $\log \mathrm{K}_{\mathrm{ow}}$ of 2.74 as measured by Hafkanscheid and Tomlinson (1983). [Also cited in Mackay et al. (1992)].

602 derived from a $\log \mathrm{K}_{\mathrm{ow}}$ of 2.78 as measured by Hammers et al. (1982). [Also cited in Mackay et al. (1992)].

603 derived from a $\log \mathrm{K}_{\mathrm{ow}}$ of 2.59 as measured by Burkhard et al. (1985). [Also cited in Mackay et al. (1992)].

611 derived from a $\log \mathrm{K}_{\mathrm{ow}}$ of 2.786 as measured by De Bruijn et al. (1989). [Also cited in Mackay et al. (1992)].

631 derived from a $\log K_{o w}$ of 2.8 reported by Hansch and Leo (1985) based on a private communication from $\mathrm{M}$. Tichy and $\mathrm{K}$. Bocek. 
645 derived from a $\log \mathrm{K}_{\mathrm{ow}}$ of 2.81 as measured by Doucette and Andren (1988). [Also cited in Mackay et al. (1992)].

759 derived from a $\log \mathrm{K}_{\mathrm{ow}}$ of 2.88 as measured by Eadsforth and Moser (1983). [Also cited in Mackay et al. (1992)].

779 derived from a $\log \mathrm{K}_{\mathrm{ow}}$ of 2.89 as measured by Rapaport and Eisenreich (1984). [Also cited in Mackay et al. (1992)].

870 derived from a $\log K_{o w}$ of 2.94 reported by Hansch and Leo (1985) based on the value measured by Konemann et al. (1979).

933 derived from a $\log \mathrm{K}_{\mathrm{ow}}$ of 2.97 as measured by McDuffie (1981). [Also cited in Mackay et al. (1992)].

1000 derived from a $\log \mathrm{K}_{\mathrm{ow}}$ of 3.00 as measured by De Kock and Lord (1987). [Also cited in Mackay et al. (1992)].

Recommended value, based on the log-mean value of the 24 measured values reported above:

$$
\begin{aligned}
& \log K_{o w}=2.70 \pm 0.20 \\
& K_{o w}=501 \times \text { or } \div 1.6
\end{aligned}
$$

\section{Vapor pressure at standard temperatures}

$3.79 \mathrm{kPa}$ at $25^{\circ} \mathrm{C}$ reported by Daubert and Danner (1985). [Also cited in Howard et al. (1990) and in Mackay et al. (1992)].

The Merck Index (Windholz et al., 1983) reports a boiling point of $110.6^{\circ} \mathrm{C}$

Stull (1947) reports the following vapor pressures for toluene.

$\begin{array}{ccc}\text { Temperature }\left({ }^{\circ} \mathrm{C}\right) & \text { Vapor Pressure }(\mathrm{mm}) & \text { Vapor Pressure }(\mathrm{kPa}) \\ -4.4 & 5 & 0.667 \\ 6.4 & 10 & 1.33 \\ 18.4 & 20 & 2.67 \\ 31.8 & 40 & 5.33 \\ 40.3 & 60 & 8.00 \\ 51.9 & 100 & 13.3 \\ 69.5 & 200 & 26.7 \\ 89.5 & 400 & 53.3 \\ 110.6 & 760 & 101\end{array}$


Interpolating from the above data gives $\mathrm{VP}$ at $25^{\circ} \mathrm{C}=3.69 \mathrm{kPa}$

Verschueren (1983) reports the following vapor pressures for toluene.

Temperature $\left({ }^{\circ} \mathrm{C}\right) \quad$ Vapor Pressure $(\mathrm{mm})$ Vapor Pressure $(\mathrm{kPa})$

6.4

20

31.8

110.6
10

22

40

760
1.33

2.93

5.33

Interpolating from this data give VP at $25^{\circ} \mathrm{C}=3.71 \mathrm{kPa}$

The following Antoine equations have been published for estimating the vapor pressure of toluene in $\mathrm{kPa}$

$$
\log _{10}(\mathrm{VP})=6.0844-\frac{1347.6}{219.79+\mathrm{T}} \text { for } 35^{\circ} \mathrm{C}<\mathrm{T}<110^{\circ} \mathrm{C} \text { from }
$$

Boublik et al. (1984),

which gives $\mathrm{VP}=3.79 \mathrm{kPa}$ at $25^{\circ} \mathrm{C}$ and

$$
\log _{10}(\mathrm{VP})=6.0795-\frac{1344.8}{219.48+\mathrm{T}} \text { for } 6^{\circ} \mathrm{C}<\mathrm{T}<137^{\circ} \mathrm{C} \text { from Wilhoit and }
$$

Zwolinski (1971) and from Dean (1985),

which also gives $\mathrm{VP}=3.79 \mathrm{kPa}$ at $25^{\circ} \mathrm{C}$.

The Antoine equation above in the temperature range $6^{\circ} \mathrm{C}<\mathrm{T}<137^{\circ} \mathrm{C}$ proposed by Wilhoit and Zwolinski (1971) for VP versus temperature is plotted below.

Recommended value for the temperature range -10 to $40^{\circ} \mathrm{C}$, based on the Antoine equation of Wilhoit and Zwolinski (1971) above:

$$
\operatorname{VP}(\mathrm{kPa})=10^{[6.0795-1344.8 /(219.48+\mathrm{T})]} \pm 0.05 \text { for }-10^{\circ} \mathrm{C}<\mathrm{T}<40^{\circ} \mathrm{C}
$$

Recommended value for the temperature $25^{\circ} \mathrm{C}$, based on the mean of the four values above

$$
\operatorname{VP}(\mathrm{kPa})=3.75 \pm 0.05 @ 25^{\circ} \mathrm{C}
$$




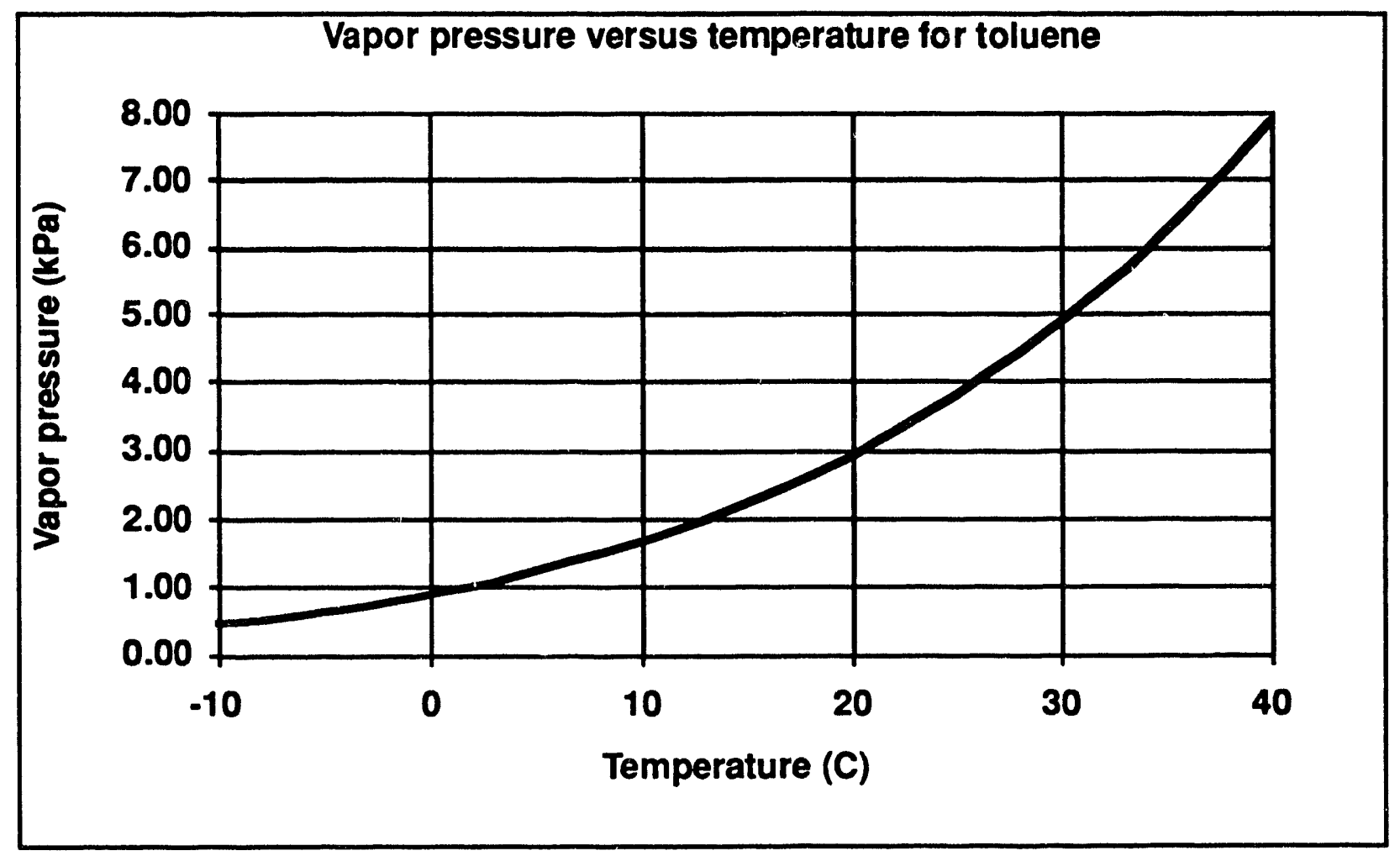

\section{Solubility in water}

$470 \mathrm{mg} / \mathrm{L}$ at $16^{\circ} \mathrm{C}$ reported by Verschueren (1983).

$515 \mathrm{mg} / \mathrm{L}$ at $20^{\circ} \mathrm{C}$ reported by Verschueren (1983).

$479 \mathrm{mg} / \mathrm{L}$ at $21^{\circ} \mathrm{C}$ measured by Chey and Calder (1972). [Also cited in Mackay et al. (1992)].

$347 \mathrm{mg} / \mathrm{L}$ at $25^{\circ} \mathrm{C}$ measured by Booth and Everson (1948). [Also cited in Mackay et al. (1992)].

$470 \mathrm{mg} / \mathrm{L}$ at $25^{\circ} \mathrm{C}$ measured by Fühner (1924). [Also cited in Mackay et al. (1992)].

$488 \mathrm{mg} / \mathrm{L}$ at $25^{\circ} \mathrm{C}$ measured by Sada et al (1975). [Also cited in Mackay et al. (1992)].

$500 \mathrm{mg} / \mathrm{L}$ at $25^{\circ} \mathrm{C}$ measured by Klevens (1950). [Also cited in Mackay et al. (1992)].

$507 \mathrm{mg} / \mathrm{L}$ at $25^{\circ} \mathrm{C}$ measured by Rossi and Thomas (1981). [Also cited in Mackay et al. (1992)].

$515 \mathrm{mg} / \mathrm{L}$ at $25^{\circ} \mathrm{C}$ measured by McAuliffe (1966). [Also cited in Mackay et al. (1992)]. 
Toluene

$517 \mathrm{mg} / \mathrm{L}$ at $25^{\circ} \mathrm{C}$ measured by Mackay and Wolkoff (1973) [Also cited in Mackay et al. (1992)].

$517 \mathrm{mg} / \mathrm{L}$ at $25^{\circ} \mathrm{C}$ measured by Mackay et al. (1975). [Also cited in Mackay et al. (1992)].

$520 \mathrm{mg} / \mathrm{L}$ at $25^{\circ} \mathrm{C}$ measured by Mackay and Shiu (1975). [Also cited in Mackay et al. (1992)].

$524 \mathrm{mg} / \mathrm{L}$ ai $25^{\circ} \mathrm{C}$ measured by Banerjee (1984). [Also cited in Mackay et al. (1992)].

$534 \mathrm{mg} / \mathrm{L}$ at $25^{\circ} \mathrm{C}$ measured by Schwarz (1977). [Also cited in Mackay et al. (1992)].

$534.8 \mathrm{mg} / \mathrm{L}$ at $25^{\circ} \mathrm{C}$ measured by Sutton and Calder (1975). [Also cited in Howard et al. (1990) and in Mackay et al. (1992)].

$538 \mathrm{mg} / \mathrm{L}$ at $25^{\circ} \mathrm{C}$ measured by McAuliffe (1963). [Also cited in Mackay et al. (1992)].

$538 \mathrm{mg} / \mathrm{L}$ at $25^{\circ} \mathrm{C}$ measured by Coutant and Keigley (1988). [Also cited in Mackay et al. (1992)].

$546 \mathrm{mg} / \mathrm{L}$ at $25^{\circ} \mathrm{C}$ measured by Morrison and Billett (1952). [Also cited in Mackay et al. (1992)].

$550 \mathrm{mg} / \mathrm{L}$ at $25^{\circ} \mathrm{C}$ measured by Dreisbach (1955). [Also cited in Mackay et al. (1992)].

$554 \mathrm{mg} / \mathrm{L}$ at $25^{\circ} \mathrm{C}$ measured by Price (1976). [Also cited in Mackay et al. (1992)].

$573 \mathrm{mg} / \mathrm{L}$ at $25^{\circ} \mathrm{C}$ measured by Polack and Lu (1973). [Also cited in Mackay et al. (1992)].

$578 \mathrm{mg} / \mathrm{L}$ at $25^{\circ} \mathrm{C}$ measured by Tewari et al. (1982b). [Also cited in Mackay et al. (1992)].

$580 \mathrm{mg} / \mathrm{L}$ at $25^{\circ} \mathrm{C}$ measured by Wasik et al. (1983). [Also cited in Mackay et al. (1992)].

$580 \mathrm{mg} / \mathrm{L}$ at $25^{\circ} \mathrm{C}$ measured by Keeley et al. (1988). [Also cited in Mackay et al. (1992)].

$585 \mathrm{mg} / \mathrm{L}$ at $25^{\circ} \mathrm{C}$ measured by Tewari et al. (1982c). [Also cited in Mackay et al. (1992)].

$627 \mathrm{mg} / \mathrm{L}$ at $25^{\circ} \mathrm{C}$ measured by Bohon and Claussen (1951). [Also cited in Mackay et al. (1992)].

$627 \mathrm{mg} / \mathrm{L}$ at $25^{\circ} \mathrm{C}$ measured by Vesala (1974). [Also cited in Mackay et al. (1992)]. 
$570 \mathrm{mg} / \mathrm{L}$ at $30^{\circ} \mathrm{C}$ measured by Gross and Saylor (1931) [Also cited in Mackay et al. (1992)].

Recommended value based on the arithmetic mean of the measured values above:

$$
\begin{aligned}
W S= & 535 \pm 55 \mathrm{mg} / \mathrm{L} \text { at } 25^{\circ} \mathrm{C} \\
& 5.81 \pm 0.6 \mathrm{~mol} / \mathrm{m}^{3} \text { at } 25^{\circ} \mathrm{C}
\end{aligned}
$$

Henry's law constant (dimensionless form, i.e. H/RT)

0.240 reported at $20^{\circ} \mathrm{C}$ by Yurteri et al. (1987) based on EPICS. [Also cited in Mackay et al. (1992)].

0.243 reported at $25^{\circ} \mathrm{C}$ by Shen (1982). [Also cited in Howard et al. (1990) and in Mackay et al. (1992)].

0.244 reported at $25^{\circ} \mathrm{C}$ by Keeley at al. (1988) based on concentration ratios. [Also cited in Mackay et al. (1992)].

0.261 reported at $25^{\circ} \mathrm{C}$ by Leighton and Calo (1981) based on concentration ratios. [Also cited in Mackay et al. (1992)].

0.261 reported at $25^{\circ} \mathrm{C}$ by Garbarini and Lion (1985) based on EPICS. [Also cited in Mackay et al. (1992)].

0.263 reported at $25^{\circ} \mathrm{C}$ by Ashworth et al. (1988) based on EPICS. [Also cited in Mackay et al. (1992)].

0.272 reported at $25^{\circ} \mathrm{C}$ by Mackay et al. (1979) based on batch striping. [Also cited in Mackay and Shiu (1981) and Mackay et al. (1992)].

0.274 reported at $25^{\circ} \mathrm{C}$ by Suntio et al. (1988) based on batch stripping. [Also cited in Mackay et al. (1992)].

0.275 reported at $25^{\circ} \mathrm{C}$ by as an experimental value by Hine and Mookerjee (1975). [Also cited in Mackay et al. (1992)].

$0.260 \pm 0.03$ obtained by taking the ratio of VP/WS divided by RT, where VP and WS are the values recommended above.

Recommended value at $25^{\circ} \mathrm{C}$ based on the arithmetic mean of the the values above:

$\mathrm{H} / \mathrm{RT}=0.26 \pm 0.01 @ 25^{\circ} \mathrm{C}$ 
The figure below is the plot of the dimensionless Henry's law constant based on the ratio of temperature-dependent vapor pressure to solubility as recommended in sections above.

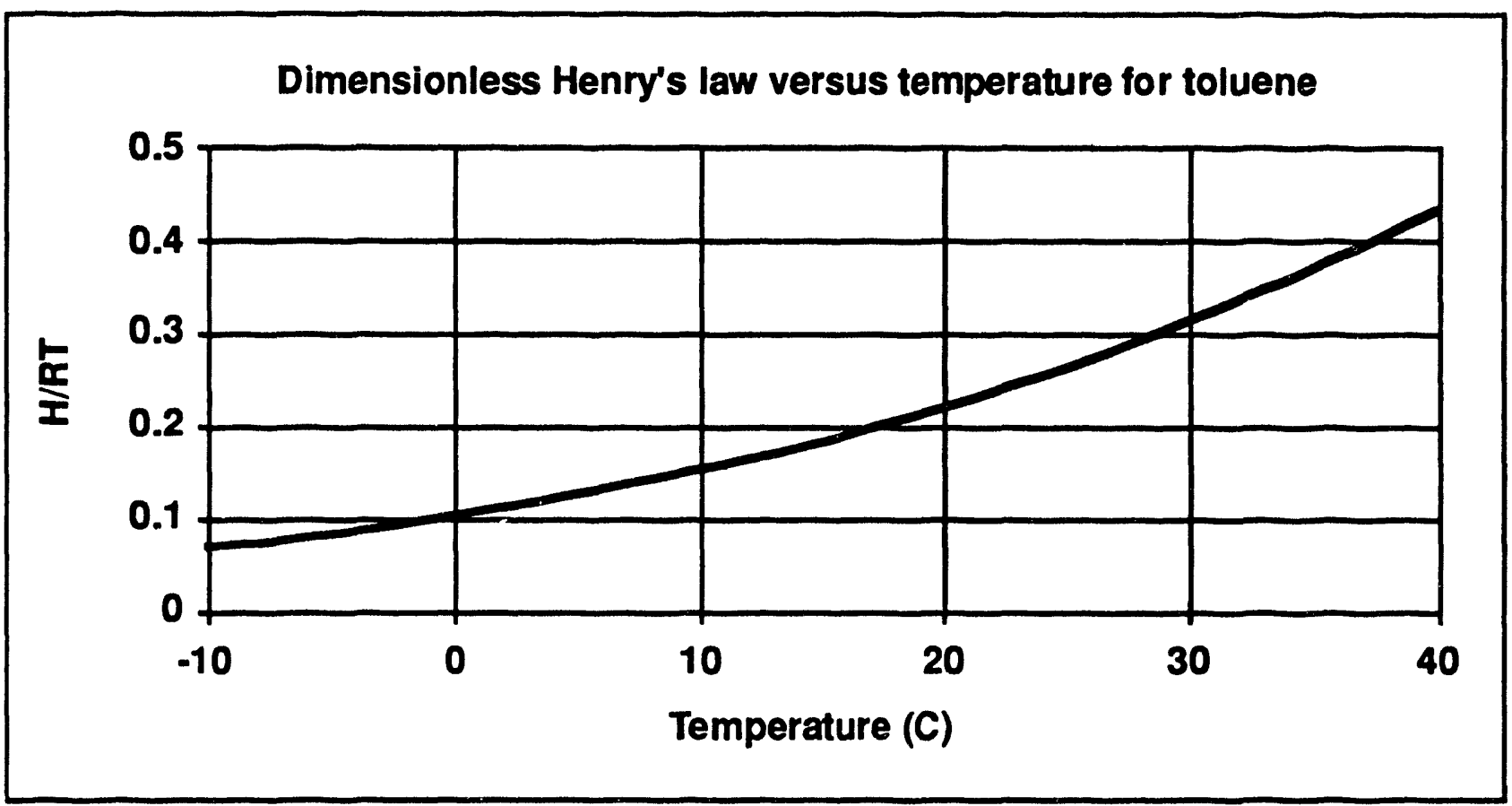

Organic-carbon partition coefficient $\left(K_{o c}\right)$

34 derived from a $\log \mathrm{K}_{\mathrm{om}}$ of 1.29 for untreated soils reported by Lee et al. (1989) and the assumption that $\mathrm{K}_{\mathrm{oc}}=\mathrm{K}_{\mathrm{om}} \times 1.724$ (Lyman et al., 1990). [ $\mathrm{K}_{\mathrm{om}}$ value cited in Mackay et al. (1992)].

37 based on a $K_{0 m}$ of 21.7 reported for Wendover silty loam by Nathwani and Phillips (1977) and the assumption that $\mathrm{K}_{\mathrm{oc}}=\mathrm{K}_{\mathrm{om}} \times 1.724$ (Lyman et al., 1990). [Also cited in Howard et al. (1990)].

42.3 derived from a $\log \mathrm{K}_{\mathrm{om}}$ of 1.39 for untreated soils reported by Lee et al. (1989) and the assumption that $\mathrm{K}_{\mathrm{oc}}=\mathrm{K}_{\mathrm{om}} \times 1.724$ (Lyman et al., 1990). [ $\mathrm{K}_{\mathrm{om}}$ value cited in Mackay et al. (1992)].

46 based on a $K_{o m}$ of 26.9 reported for Vaudreil sandy loam by Nathwani and Phillips (1977) and the assumption that $\mathrm{K}_{\mathrm{oc}}=\mathrm{K}_{\mathrm{om}} \times 1.724$ (Lyman et al., 1990). [Also cited in Howard et al. (1990)].

75 to 131 based on a $\log K_{D}$ of $0.60 \pm 12$ measured by Vowles and Mantoura (1987) using HPLC retention factors in soils with $4 \%$ organic carbon. 
77 to 191 reported for soils by Garbarini and Lion (1985). [Also cited in Mackay et al. (1992)].

151 measured by Garbarini and Lion (1986) for soil using a headspace technique.

160 based on a $\mathrm{K}_{\mathrm{om}}$ of 93.05 reported for Grimsby silt loam by Nathwani and Phillips (1977) and the assumption that $\mathrm{K}_{\mathrm{oc}}=\mathrm{K}_{\mathrm{om}} \times 1.724$ (Lyman et al., 1990). [Also cited in Howard et al. (1990) and in Mackay et al. (1992)].

$\sim 176$ based on measurements by Wilson et. al (1981) of retardation velocities in low-organic carbon, sandy soils. [Also cited as 178 in Howard et al. (1990) and in Mackay et al. (1992)].

178 derived from a $\log \mathrm{K}_{o c}$ of 2.25 from reported by Wilson et al. (1981). [Also cited in Mackay et al. (1992)].

182 derived from a $\log \mathrm{K}_{\mathrm{oc}}$ of 2.26 reported by Szabo et al. (1990a,b). [Also cited in Mackay et al. (1992)].

245 derived from a $\log \mathrm{K}_{\mathrm{oc}}$ of 2.39 reported for soils by Schwarzenbach and Westall (1981). [Also cited in Mackay et al. (1992)].

249 to 1340 derived from a $\log \mathrm{K}_{\mathrm{om}}$ of 2.16 to 2.89 for cation-treated soils reported by Lee et al. (1989) and the assumption that $\mathrm{K}_{\mathrm{oc}}=\mathrm{K}_{\mathrm{om}} \times 1.724$ (Lyman et al., 1990). [ $\mathrm{K}_{\mathrm{om}}$ values cited in Mackay et al. (1992)].

Recommended value, based on the log-mean value of the 16 measured values reported above:

$$
\begin{aligned}
& \log K_{o C}=2.1 \pm 0.41 \\
& K_{o C}=130 \times \text { or } \div 2.6
\end{aligned}
$$

\section{Diffusion coefficient in water}

Based on the Wilke and Chang (1955) method described in Reid et al. (1987), the diffusion coefficient in $\mathrm{m}^{2} / \mathrm{d}$ in water is given by

$$
D_{\mathrm{xy}}=\frac{6.5 \times 10^{-7}\left(\phi M_{\mathrm{y}}\right)^{1 / 2} \mathrm{~T}}{\eta_{\mathrm{y}} V_{\mathrm{x}}^{0.6}} \text {. }
$$

The molecular weight $\mathrm{M}_{\mathrm{y}}$ of water is $18 \mathrm{~g} / \mathrm{mol}$. Wilke and Chang (1955) recommend an association factor, $\phi$, of 2.6 when the solvent is water. The 
viscosity of water, $\eta_{y}$, is $0.89 \mathrm{cP}$ at $25^{\circ} \mathrm{C}$. Molecular volume can be estimated by the LeBas incremental method as described in Lyman et al. (1990). With the molecular volume $V_{x}$ of toluene equal to $103 \mathrm{~cm}^{3} / \mathrm{mol}$, this expression gives

Recommended value:

$$
D_{\text {water }}=3.1 \times 10^{-7} \mathrm{~T} \mathrm{~m}^{2} / \mathrm{d}=9.2 \times 10^{-5} \mathrm{~m}^{2} / \mathrm{d} \text { or } 1.1 \times 10^{-9} \mathrm{~m}^{2} / \mathrm{s} @ 25^{\circ} \mathrm{C}
$$

Diffusion coefficient in air

Based on the Fuller et al. (1966) method described in Lyman et al. (1990), the diffusion coefficient in $\mathrm{m}^{2} / \mathrm{d}$ in air is given by

$$
D_{\text {air }}=8.6 \times 10^{-3} \mathrm{~T}^{1.75} \frac{\sqrt{\frac{\left(29+\mathrm{M}_{x}\right)}{29 \mathrm{M}_{x}}}}{\left[2.7+\left(V_{x}\right)^{1 / 3}\right]^{2}}
$$

With the molecular volume, $\mathrm{V}_{\mathrm{x}}$, of toluene of $103 \mathrm{~cm}^{3} / \mathrm{mol}$ and a molecular weight of $92.1 \mathrm{~g} / \mathrm{mol}$, the above expression gives (with $\mathrm{T}$ in kelvins)

Recommended value:

$$
D_{\text {air }}=3.4 \times 10^{-5} \mathrm{~T}^{1.75} \mathrm{~m}^{2} / \mathrm{d}=0.72 \mathrm{~m}^{2} / \mathrm{d} \text { or } 8.3 \times 10^{-6} \mathrm{~m}^{2} / \mathrm{s} @ 25^{\circ} \mathrm{C} \text {. }
$$

Bioconcentration factors for plant root concentration relative to soil concentration

No reported measurements of plant-root bioconcentration for toluene in soils are available in the current literature. Estimation methods for this parameter are considered below.

The partition factor from surface soil to edible plant parts due to rainsplash, $\mathrm{K}_{\mathrm{ps}}^{\text {rain }}$ is equal to $0.0034 \mathrm{~kg}$ (soil) $/ \mathrm{kg}$ (plant) with a CV of 1 (Dreicer et al. 1984). This partition factor applies plant fresh mass concentration relative to soil concentration.

Based on the Briggs et al. $(1982,1983)$ estimation equation for uptake of contaminants by roots from soil solution, we calculate the RCF (which represents the ratio of contaminant concentration in root, $\mathrm{mg} / \mathrm{kg}$ [fresh mass], to contaminant concentration in soil solution, $\mathrm{mg} / \mathrm{L}$ ) for toluene as 


$$
\mathrm{RCF}=0.82+0.03 \mathrm{~K}_{\mathrm{ow}}^{0.77}=3.3 \text { to } 6
$$

When this factor is divided by the sorption coefficient, $K_{D}=f_{O C} \times K_{o c}=(0.01$ to $0.02) \times K_{o c}$ (from above), we obtain the ratio of contaminant concentration in roots, $\mathrm{mg} / \mathrm{kg}$ (fresh mass) to contaminant concentration in soil solids, $\mathrm{mg} / \mathrm{kg}$, which we refer to as $K_{p s}$ (roots) and estimate it as being in the range

$$
\mathrm{K}_{\mathrm{ps}}(\text { roots })=0.5 \text { to } 12
$$

Based the regression of $K_{p s}$ (roots) with $K_{o c}$ from Topp et al. (1986), and based on the range of $\mathrm{K}_{\mathrm{oc}}$ values listed above, we obtain

$$
\mathrm{K}_{\mathrm{ps}}(\text { roots })=664 \mathrm{~K}_{\propto}^{-0.622}=7.5 \text { to } 74 \text { (recommended range for }
$$
root crops)

Based on the Travis and Arms (1988) correlation for plant-soil bioconcentration we obtain for total plant (not just roots) the following soil/plant partition coefficient

$$
\begin{array}{r}
K_{p s}=7.7 K_{o w}^{-0.58}=0.21 \times \text { or } \div 5.3 \text { (recommended value for } \\
\text { exposed produce) }
\end{array}
$$

Steady-state bioconcentration factors for plant leaf concentration relative to air concentration

No reported measurements of plant-air bioconcentration for toluene in air are available in the current literature. Estimation methods for this parameter are considered below.

Based on the model of Riederer (1990) for foliar uptake of gases in plant leaves, we estimate a steady-state plant-air partition coefficient of

$$
\begin{aligned}
& \text { Recommended value, } \\
& \mathrm{K}_{\mathrm{pa}}^{\mathrm{gs}}=\left[0.5+\left(0.4+0.01 \times \mathrm{K}_{\mathrm{ow}}\right) \times \frac{\mathrm{RT}}{\mathrm{H}}\right] \times 10^{-3} \frac{\mathrm{m}^{3}}{\mathrm{~kg}}=0.02 \mathrm{~m}^{3} / \mathrm{kg} \times \text { or } \div 2.2
\end{aligned}
$$

We could find no study in which the estimation error of this partition coefficient has been considered, but we assume the $\mathrm{CV}$ associated with it is on the order of 1 . 
Bioconcentration factors for fish concentration relative to water/or sediment concentrations

13.2 (or $\log$ BCF of 1.12) reported for eels by Ogata and Miyake (1978). [Also cited in Howard et al. (1990) and in Mackay et al. (1992)].

1.7 (or log BCF of 0.22) reported for Manila clam by Nunes and Benville (1979). [Also cited in Howard et al. (1990) and in Mackay et al. (1992)].

4.2 (or $\log$ BCF of 0.62 ) reported for mussels by Geyer et al. (1982). [Also cited in Howard et al. (1990) and in Mackay et al. (1992)].

8.3 (or $\log$ BCF of 0.92) reported for goldfish by Ogata et al. (1984). [Also cited in Mackay et al. (1992)].

90 (or $\log$ BCF of 1.95) reported for golden ide fish by Freitag et al. (1985). [Also cited in Howard et al. (1990) and in Mackay et al. (1992)].

98 (or $\log \mathrm{BCF}$ of 1.99 ) reported for s. capricornutum by Herman et al. (1991). [Also cited in Mackay et al. (1992)].

15 to 39 Based the two-standard-deviation range of the $\mathrm{K}_{\mathrm{ow}}$ values above and the estimation method based on $\mathrm{K}_{\mathrm{ow}}$ of Mackay (1982).

Recommended value, based on the log-mean value of the three measured values and one predicted value reported above:

$\log B C F($ fish $)=1.14 \pm 0.7$

$\mathrm{BCF}($ fish $)=14 \times$ or $\div 5$

Steady-state biotransfer factors for milk or dairy-product concentration relative to contaminant intake by cattle

No reported measurements of milk-diet biotransfer for toluene are available in the current literature.

Based on the geometric mean regression of milk-to-diet biotransfer against $\mathrm{K}_{\mathrm{ow}}$ developed by Travis and Arms (1988) we estimate the milk biotransfer factor for toluene as

$$
B_{k}=7.9 \times 10^{-9} K_{o w} \times 10^{( \pm 0.84)}=4.0 \times 10^{-6} \times \text { or } \div 7 \text { (recommended value) }
$$

The estimation error in this expression corresponds to a CVs of 6. 
Steady-state biotransfer factors for meat concentration relative to contaminant intake by cattle, pigs, and chickens

No reported measurements of meat-diet biotransfer for toluene are available in the current literature.

Based on the geometric mean regression of meat-to-diet biotransfer against $\mathrm{K}_{\mathrm{ow}}$ developed by Travis and Arms (1988) we estimate the meat biotransfer factor for toluene as

$$
B_{t}=2.5 \times 10^{-8} K_{o w} \times 10^{( \pm 0.952)}=1.3 \times 10^{-5} \times \text { or } \div 9 \text { (recommended value) }
$$

The estimation error in this expression corresponds to a CV of 11.

Steady-state biotransfer factors for egg concentration relative to contaminant intake by chickens

No reported measurements of egg-diet biotransfer for toluene are available in the current literature.

Based on the geometric mean regsession of egg-to-diet biotransfer against $\mathrm{K}_{\mathrm{ow}}$ developed above, we estimate the egg biotransfer factor for toluene as

$$
\mathrm{B}_{\mathrm{e}}=7.9 \times 10^{-6} \mathrm{~K}_{\mathrm{ow}} \times 10^{( \pm 1)}=4.0 \times 10^{-3} \times \text { or } \div 10 \text { (recommended value) }
$$

The estimation error in this expression corresponds to a CV of 14.

\section{Contaminant biodegradation factors in soil}

Based on the aqueous aerobic biodegradation half life of toluene measured by Wakeham et al. (1983), Howard et al. (1991) estimate the soil half life due to aerobic degradation to be in the range of 4 to $22 \mathrm{~d}$. This range is also cited in Mackay et al. (1992). This range corresponds to an aerobic biodegradation rate constant in the range 0.032 to $0.17 \mathrm{~d}^{-1}$. The anaerobic half life of toluene has been estimated to be in the range 56 to $210 \mathrm{~d}$ by Howard et al. (1991) based on anaerobic sediment grab-sample data from Horowitz et al. (1982). This range corresponds to an anaerobic biodegradation rate constant in the range 0.0033 to $0.012 \mathrm{~d}^{-1}$.

Recommended soil biodegradation rate constants, based on the log mean and log range of the soil half life ranges above:

aerobic soil biodegradation rate constant $=0.074 \mathrm{~d}^{-1} \times$ or $\div 1.6$

anerobic soil biodegradation rate constant $=0.0063 \mathrm{~d}^{-1} \times$ or $\div 1.5$ 
Media-specific half lives for air, soil, and surface water

Air. Based on measurements of Atkinson (1985), Howard et al. (1991) estimate the half life of toluene in lower atmosphere is in the range of 0.42 to $4.3 \mathrm{~d}$ based on photo-oxidation as a removal process. [This range is also cited in Mackay et al. (1992).] Based on the rate of disappearance of toluene due to reaction with hydroxyl radicals, Doyle et al. (1975) report a half life of $0.2 \mathrm{~d}$ and Darnall et al. report a half life in the range 0.1 to $1 \mathrm{~d}$.

Soil Based on the aqueous aerobic biodegradation half life of toluene measured by Wakeham et al. (1983), Howard et al. (1991) estimate the soil half life due to aerobic degradation to be in the range of 4 to $22 \mathrm{~d}$. This range is also cited in Mackay et al. (1992). The anaerobic half-live of toluene has been estimated to be in the range 56 to $210 \mathrm{~d}$ by Howard et al. (1991) based on anaerobic sediment grab-sample data from Horowitz et al. (1982).

Anderson et al. (1991) report a disappearance half life of toluene from test soils of less than $2 \mathrm{~d}$. This value is also cited in Mackay et al. (1992).

Water Based on the aqueous aerobic biodegradation half life of toluene measured by Wakeham et al. (1983), Howard et al. (1991) estimate the surface-water half life due to aerobic degradation to be in the range of 4 to $22 \mathrm{~d}$. This range is also cited in Mackay et al. (1992).

Recommended half lives (in days), based on the geometric mean of the half lives and the geometric range of the values:

$$
\begin{array}{ll}
\text { Air } & 2.1 \times \text { or } \div 3.0 \mathrm{~d} \\
\text { Soil } & 20 \times \text { or } \div 3.8 \mathrm{~d} \\
\text { Water } & 9.4 \times \text { or } \div 1.6 \mathrm{~d}
\end{array}
$$

\section{References for Toluene}

Anderson, T.A., J.J. Beauchamp, B.T. Walton (1991), "Organic Chemicals in the Environment," J. Environ. Qual. 20, 420-424.

Ashworth, R.A., G.B. Howe, M.E. Mullins, and T.N. Rogers (1988), "Air-Water Partitioning Coefficients of Organics in Dilute Aqueous Solutions," J. Hazard. Mater. 18, 25-36.

Atkinson, R. (1985), "Kinetics and Mechansims of the Gas Phase Reaction of Hydroxy Radicals with Organic Compounds Under Atmospheric Conditions," Chem. Rev. 85, 69-201. 
Banerjee, S. (1984), "Solubility of Organic Mixture in Water," Environ. Sci. Technol. $18,587-591$.

Banerjee, S., Yalkowsky, S. H., and Valvani, S. C. (1980), "Water Solubility and Octanol/Water Partition Coefficient of Organics. Limitations of Solubility-Partition Coefficient Correlation," Environ. Sci. Technol. 14(10), 1227-1229.

Briggs, G.G., R.H. Bromilow, and A.A. Evans (1982), "Relationships Between Lipophilicity and Root Uptake and Translocation of Non-Ionized Chemicals by Barley," Pestic. Sci. 13, 495-504.

Briggs, G.G., R.H. Bromilow, A.A. Evans, and M. Williams (1983), "Relationships Between Lipophilicity and the Distribution of Non-Ionized Chemicals in Barley Shoots Following Uptake by the Roots," Pestic. Sci. 14, 492-500.

Bohon, R.L., and W.F. Claussen (1951), "The Solubility of Aromatic Hydrocarbons in Water," J. Am. Chem. Soc. 72, 1571-1576.

Booth, H.S., and H.E. Everson (1948), "Hydrotropic Solubilities: Solubilities in 40 Per Cent Sodium Xylenesulfonate," Ind. Eng. Chem. 40(8), 1491-1493.

Boublík, T., Fried, V., and Hála, E. (1984), The Vapour Pressures of Pure Substances: Selected Values of the Temperature Dependence of the Vapour Pressures of Some Pure Substances in the Normal and Low Pressure Region (Second Revised Edition), Physical sciences data; 17 (Elsevier Science Publishers, Amsterdam, The Netherlands).

Burkhard, L.P., D.W. Kuehl, and G.D. Veith (1985), "Evaluation of Reversed-Phase Liquid Chromatography/Mass Spectrometry for Estimation of n-Octanol/Water Partition Coefficients Organic Chemicals," Chemosphere 14(10), 1551-1560.

Chey, W., and G.V. Calder (1972), "Method for Determining Solubility of Slightly Soluble Organic Compounds," J. Chem. Eng. Data 17(2), 199-200.

Coutant, R.W., and G.W. Keigley (1988), "An Alternative Method for Gas Chromatographic Determination of Volatile Organic Compounds in Water," Anal. Chem. 60, 2436-2537.

Daubert, T.E., and R.P. Danner (1985), Data Compilation Tables of Properties of Pure Compounds, Am. Institute of Chem. Engineers, pp. 450.

Dean, J.D., Ed. (1985), Lang's Handbook of Chemistry (McGraw-Hill, Inc., New York City, NY), 13th ed.

DeBruijn, J., F. Busser, W. Seinen, and J. Hermens (1989), "Determination of Octanol/Water Partition Coefficient for Hydrophobic Organic Chemicals with the 'Slow-Stirring' Method,' Envieron. Toxicol. Chem. 8, 499-512.

DeKock, A.C., and D.A. Lord (1987), "A Simple Procedure for Determining Octanol-Water Partition Coefficients Using Reversed Phase High Performance Liquid Chromatography (RPHPLC)," Chemosphere 16(1), 133-142. 
Doucette, W.J., and A.W. Andren (1988), "Estimation of Octanol/Water Partition Coefficients: Evaluation of Six Methods for Highly Hydrophobic Aromatic Hydrocarbons," Chemosphere 17, 345-359.

Doyle, G.J., A.C. Lloyd, K.R. Darnall, A.M. Winer, and J.N. Pitts, Jr.(1975), "Gas Phase Kinetic Study of Relative Rates of Reaction of Selected Aromatic Compounds with Hydroxy Radicals in an Environmental Chamber," Environ. Sci. Technol. 9(3), 237-241.

Dreicer, M., T.E. Hakonson, G.C. White, and F.W. Whicker (1984), "Rainsplash as a Mechanism for Soil Contamination of Plant Surfaces," Health Phys. 46, 177-187.

Dreisbach, R.R. (1955), "Physical Properties of Chemical Compounds," Adv. Chem. Ser. 15, 134.

Eadsforth, C.V., and P. Moser (1983), "Assessments of Reversed Phase Chromatographic Methods for Determining Partition Coefficients," Chemosphere 12, 1459-1475.

Fühner, H. (1924), "Die Wasserlöslichkeit in Homologen Reihen," Chem. Ber. 57, 510-515.

Fujita, T., J. Iwasu, and C. Hansch (1964), "A New Substituent Constant, "Pi" Derived from Partition Coeficients,"J. Am. Chem. Soc. 86, 5175-5180.

Fuller, E.N., P.D. Schettler, and J.C. Giddings (1966), "A New Method for Prediction of Binary Gas-Phase Diffusion Coefficients," Ind. Eng. Chem. 58, 19-27.

Freitag, D., L. Ballhorn, H. Geyer, and F. Korte (1985), "Environmental Hazard Profile of Organic Chemicals. An Experimental Method for the Assessment of the Behaviour of Organic Chemicals in the Ecosphere by Means of Simple Laboratory Tests with ${ }^{14} \mathrm{C}$ Labelled Chemicals," Chemosphere 14, 1589-1616.

Garbarini, D.R., and L.W. Lion (1985), "Evaluation of Sorptive Partitioning of Nonionic Pollutants in Closed Systems by Headspace Analysis," Environ. Sci. Technol. 19, 1122-1128.

Garbarini, D.R., and L.W. Lion (1986), "Influence of the Nature of Soil Organics on the Sorption of Toluene and Trichloroethylene," Environ. Sci. Technol. 20, 12631269.

Garst, J.E., and W.C. Wilson (1984), "Accurate, Wide Range, Automated, High Performance Liquid Chromatographic Method for the Estimation of Octanol/Water Partition Coefficients. II: Effects of Chromatographic Method and Procedure Variables on Accuracy and Reproducibility of the Method," J. Pharm. Sci. 73(11), 1616-1623.

Geyer, H., P. Sheenhan, D. Kotzias, D. Freitag, and F. Korte (1982), "Prediction of Ecotoxicological Behaviour of Chemicals: Relationship Between Physico-Chemical Properties and Bioaccumulation of Organic Chemicals in the Mussel Mytilus edulis," Chemosphere 11, 1121-1134. 
Gross, P.M., and J.H. Saylor (1931), "The Solubilities of Certain Slightly Soluble Organic Compounds in Water," J. Am. Chem. Soc. 53, 1744-1751.

Hafkenscheid, T.L., and E. Tomlinson (1983), "Correlations Between Alkane/Water and Octan-1-ol/Water Distribution Coefficients and Isocratic Reversed-Phase Liquid Chromatographic Capacity Factor of Acids, Bases and Neutrals," Int. J. Pharm. 16, 225-240.

Hammers, W.E., G.J. Meurs, and C.L. DeLigny (1982), "Correlations Between Liquid Chromatographic Capacity Ratio Data on Lichrosorb RP-18 and Partition Coefficients in the Octanol-Water System," J. Chromatogr. 247, 1-13.

Hanai, T., C. Tran, and J. Hubert (1981), "An Approach to the Prediction of Retention Times in Liquid Chromatography," J. HRC \& CC 4, 454-460.

Hansch, C., and A. Leo (1985), "The Log P and Related Parameters Database, created and updated by the Medicinal Chemistry Project at Pomona College under the direction of Corwin Hansch and Albert Leo - 1985 Printout," in Medchem Project Issue No. 26, Pomona College, Claremont, CA.

Herman, D.C., C.I. Mayfield, and W.E. Innis (1991), "The Relationship Between Toxicity and Bioconcentration of Volatile Aromatic Hydrocarbons by the Alga Selenastrum capricornutum," Chemosphere 22(7), 665-676.

Hine, J. and P.K. Mookerjee (1975), "The Intrinsic Hydrophilic Character of Organic Compounds. Correlations in Terms of Structural Contributions," J. Org. Chem. 40, 292-298.

Horowitz, A., D.R. Shelton, C.P. Cornell, and J.M. Tiedje (1982), "Anaerobic Degradation of Aromatic Compounds in Sediment and Digested Sludge," Dev. Ind. Microbiol. 23, 435-444.

Howard, P.H., G.W. Sage, W.F. Jarvis, and D.A. Gray, Eds. (1990), Handbook of Environmental Fate and Exposure Data for Organic Chemicals. Volume II. Solvents (Lewis Publishers, Inc., Chelsea, MI).

Howard, P. H., R. S. Boethling, W. F. Jarvis, W. M. Meylan, and E. M. Michalenko, Eds. (1991), Handbook of Environmental Degradation Rates (Lewis Publishers, Inc, Chelsea, MI).

Keeley, D.F., M.A. Hoffpauir, and J.R. Meriweather (1988), "Solubility of Aromatic Hydrocarbons in Water and Sodium Chloride Solutions of Different Ionic Strengths: Benzene and Toluene,"J. Chem. Eng. Data 33, 87-89.

Klevens, H.B. (1950), "Solubilization of Polycyclic Hydrocarbons," J. Phys. Colloid Chem. 54, 283-298.

Könemann, H., et al. (1979), J. Chromatogr. 178, 559. 
Lee, J.F., J.R. Crum, and S.A. Boyd (1989), "Enhanced Retention of Organic Contaminants by Soils Exchanged with Organic Cations," Environ. Sci. Technol. 23, 1365-1372.

Leighton, D.T., and J.M. Calo (1981), "Distribution Coefficients of Chlorinated Hydrocarbons in Dilute Air-Water Syustems for Groundwater Contamination Applications," J. Chem. Eng. Data 26, 381-385.

Lyman, W. J., W. F. Reehl, and D. H. Rosenblatt (1990), Handbook of Chemical Property Estimation Methods: Environmental Behavior of Organic Compounds (American Chemical Society, Washington, DC).

Mackay, D. (1982), "Correlation of Bioconcentration Factors," Environ. Sci. Technol. 16, 274-278.

Mackay, D., and W.-Y. Shiu (1975), "The Aqueous Solubility and Air-Water Exchange Characteristics of Hydrocarbons Under Environmental Conditions," in Chemistry and Physics of Aqueous Gas Solutions, W.A. Adams, G. Greer, J.E. Desnoyers, G. Atkinson, K.B. Kell, K.B. Oldham, and J. Walkey, Eds. (Electrochem. Soc., Inc., Princeton, NJ), pp. 93-110.

Mackay, D., and W.-Y. Shiu (1981), "A Critical Review of Henry's law Constants for Chemicals of Environmental Interest," J. Phys. Chem. Ref. Data 10, 1175-1199.

Mackay, D., W.-Y. Shiu, and K.-C. Ma (1992), Illustrated Handbook of Physical-Chemical Properties and Environmental Fate for Organic Chemicals. Volume 1. Monoaromatic Hydrocarbons, Chlorobenzenes, and PCBs (Lewis Publishers, Inc., Chelsea, MI).

Mackay, D., W.-Y. Shiu, and R.P. Sutherland (1979), "Determination of Air-Water Henry's law Constants for Hydrophobic Pollutants," Environ. Sci. Technol. 13, 333337.

Mackay, D., W.-Y. Shiu, and A.W. Wolkoff (1975), "Gas Chromatographic Determination of Low Concentrations of Hydrocarbons in Water by Vapor Phase Extraction," Water Quality Parameters, ASTM STP 573 (Am. Soc. Testing and Materials, Philadelphia, PA), pp. 251-258.

Mackay, D., and A.W. Wolkoff (1973), "Rate of Evaporation of Low-Solubility Contaminants from Water Bodies to Atmosphere," Environ. Sci. Technol.7, 611614.

McAuliffe, C. (1963), "Solubility in Water of $\mathrm{C}_{1}-\mathrm{C}_{9}$ Hydrocarrbons," Nature(London) 200, 1092-1093.

McAuliffe, C. (1966), "Solubility in Water of Paraffin, Cycloparaffin, Olegin, Acetylene, Cycloolefin, and Aromatic Hydrocarbons," J. Phys. Chem. 70, 1267-1275.

McDuffie, B. (1981), "Estimation of Octanol/Water Partition Coefficients for Organic Pollutants Using Reversed Phase HPLC," Chemosphere 10, 73-83. 
Miyake, K., and H. Terada (1982), 'Determination of Partition Coefficients of Very Hydrophobic Compounds by High Performance Liquid Chromatography on Glyceryl-Coated Controlled-Pore Glass," J. Chromatogr. 240, 9-20.

Morrison, T.J., and F. Billett (1952), "The Salting Out of Non-Electrolytes.

Part II. The Effects of Variation in Non-Electrolyte," J. Chem. Soc. 3819-3822.

Nahum, A., and C. Horvath (1980), "Evaluation of Octanol-Water Partition Coefficients by Using High-Performance Liquid Chromatography," J. Chomatogr. 192, 315-322.

Nathwani, J.S., and C.R. Phillips (1977), "Absorption-Desorption of Selected Hydrocarbons in Crude Oils on Soils," Chemosphere 6(4), 157-162.

Nunes, P., and P.E. Benville, Jr. (1979), "Uptake and Depuration of Petroleum Hydrocarbons in the Manila Clams, Tapes semidecussata Reeve," Bull. Environ. Contam. Toxicol. 21, 719-724.

Ogata, M., K. Fujisawa, Y. Ogino, and E. Mano (1984), "Partition Coefficients as a Measure of Bioconcentration Potential of Crude Oil Compounds in Fish and Shellfish," Bull. Environ. Contam. Toxicol. 33, 561-567.

Ogata,M., and Y. Miyake (1978), "Disappearance of Aromatic Hydrocarbons and Organic Sulfur Compounds from Fish Flesh Reared in Crude Oil Suspension," Water Res. 12, 10411044.

Polak, J., and B.C.Y. Lu (1973), "Mutual Solubilities of Hydrocarbons and Water at $0^{\circ}$ and $25^{\circ} \mathrm{C}$," Can. J. Chem. 51, 4018-4023.

Price, L.C. (1976), "Aqueous Solubility of Petroleum as Applied to its Origin and Primary Migration," Am. Assoc. Petrol. Geol. Bull. 60, 213-244.

Rappaport, R.A., and S. Eisenreich (1984), "Chromatographic Determination of Octanol-Water Partition Coefficients ( $\mathrm{K}_{\mathrm{ow}}$ 's) for 58 PCB Congeners," Environ. Sci. Technol. 18, 163-170.

Reid, R. C., J. M. Prausnitz, and B. E. Poling (1987), The Properties of Gases and Liquids (McGraw Hill, New York City, NY), 4th ed.

Reiderer, M. (1990), "Estimating Partitioning and Transport of Organic Chemicals in the Foliage/Atmosphere System: Discussion of a Fugacity-Based Model," Environ. Scil. Technol. 24, 829-837.

Rogers, K.S., and A. Cammarata (1969), "Superdelocalizability and Charge Density. A Correlation with Partition Coefficients," J. Med. Chem. 12, 692-693.

Rossi, S.S., and W.H. Thomas (1981), "Solubility Behavior of Three Aromatic Hydrocarbons in Distilled Water and Natural Seawater," Environ. Sci. Technol. 15, 715-716.

Sada, E., S. Kito, and Y. Ito (1975), "Solubility of Toluene in Aqueous Salt Solutions," J. Chem. Eng. Data 20(4), 373-375. 
Toluene

Schantz, M.M., and D.E. Martire (1987), "Determination of Hydrocarbon-Water Partition Coefficients from Chromatographic Data and Based on Solution Thermodyncamics and Theory," J. Chromatogr. 391, 35.

Schwarz, F.P. (1977), "Determination of Temperature Dependence of Solubilities of Polycyclic Aromatic Hydrocarbons in Aqueous Solutions by a Fluorescence Method," J. Chem. Eng. Data 22, 273-277.

Schwarzenbach, R.P., and J. Westall (1981), "Transport of Nonpolar Compounds from Surface Water to Groundwater. Laboratory Sorption Studies," Environ. Sci. Technol. 11, 1360-1367.

Shen, T.T. (1982), "Estimation of Organic Compound Emissions from Water Lagoons," J. Pollut. Control Assoc. 32, 79-82.

Stull, D. R. (1947), "Vapor Pressure of Pure Substances: Organic Compounds," Ind. Eng. Chem. 39, 517-540.

Suntio, L.R., W.-Y. Shiu, and D. Mackay (1988), "A Review of the Nature and Properties of Chemicals Present in Pulp Mill Effluents," Chemosphere 17, 1249-1290.

Sutton, C., and J.A. Calder (1975), "Solubility of Alkybenzenes in Distilled Water and Seawater at $25^{\circ} \mathrm{C}$," J. Chem. Eng. Data 20, 320-322.

Szabo, G., S.L. Prosser, and R.A. Bulman (1990a), "Prediction of the Adsorption Coefficient $\left(\mathrm{K}_{\mathrm{oc}}\right)$ for Soil by a Chemically Immobilized Humic Acid Column Using RP-HPLC," Chemosphere 21, 729-740.

Szabo, G., S.L. Prosser, and R.A. Bulman (1990b), "Determination of the Adsorption Coefficient $\left(\mathrm{K}_{\mathrm{oc}}\right)$ of Some Aromatics for Soil by RP-HPLC on Two Immobilized Humic Acid Phases," Chemosphere 21, 777-788.

Tayar, N., et al. (1984), Int. J. Pharmaceut. 19, 271.

Tewari, Y.B., M.M. Miller, S.P. Wasik, and D.E. Martire (1982a), "Aqueous Solubility and Octanol/Water Partition Coefficient of Organic Compounds at $25.0^{\circ} \mathrm{C}$," J. Chem. Eng. Data 27, 451-454.

Tewari, Y.B., D.E. Martire, S.P. Wasik, and M.M. Miller (1982b), "Aqueous Solubilities and Octanol/Water Partition Coefficients of Binary Liquid Mixtures of Organic Compounds at $25.0^{\circ} \mathrm{C}$," J. Solution Chem. 11, 435-445.

Tewari, Y.B., M.M. Miller, and S.P. Wasik (1982c), "Calculation of Aqueous Solubilities of Organic Compounds," NBS J. Res. 87, 155-158.

Topp, E., I. Scheunert, A. Attar, and F. Korte (1986), "Factors Affecting the Uptake of 14C-Labeled Organic Chemicals by Plants From Soil," Ecotoxicol. Environ. Saf. 11, 219-228.

Travis, C. C., and A. D. Arms (1988), "Bioconcentration of Organics in Beef, Milk, and Vegetation," Environ. Sci. Technol. 22, 271-274. 
Verschueren, K. (1983), Handbook of Environmer al Data on Organic Chemicals, Second Edition (Van Nostrand Reinhold Company Inc., New York City, NY).

Vesala, A. (1974), "Thermodynamics of Transfer Nonelectrolytes From Light and Heavy Water. I. Linear Free Energy Correlations of Free Energy of Transfer with Solubility and Heat of Melting of Nonelectrolyte," Acta Chem. Scand. 28A(8), 839845 .

Vowles, P.D., and R.F.C. Mantoura (1987), "Sediment-Water Partition Coefficients and HPLC Retention Factors of Aromatic Hydrocarbons," Chemosphere 16, 109-116.

Wakeham, S.G., A.C. Davis, and J.L. Karas (1983), "Microcosm Experiments to Determine the Fate and Persistence of Volatile Organic Compounds in Coastal Seawater,"Environ. Sci. Technol.17, 611-617.

Wasik, S.P., M.M. Miller, Y.B. Tewari, W.E. May, W.J. Sonnefeld, H. DeVoe, and W.H. Zoller (1983), 'Determination of the Vapor Pressure, Aqueous Solubility, and Octanol/Water Partition Coefficient of Hydrophobic Substances by Coupled Generator Column/Liquid Chromatographic Methods," Res. Rev. 85, 29-42.

Weast, R. C., M. J. Astle, and W. H. Beyer, Eds. (1986), CRC Handbook of Chemistry and Physics: A Ready Reference Book of Chemical and Physical Data, 67th Edition (CRC Press, Inc., Boca Raton, FL).

Wilhoit, R.C., and B.J. Zwolinski (1971), Handbook of Vapor Pressures and Heats of Vaporization of Hydrocarbons and Related Compounds, Thermodynamics Research Center, Texas A\&M University, College Station, TX.

Wilke, C.R., and P. Chang (1955), "Correlation of Diffusion Coefficients in Dilute Solutions," AIChE J. 1, 264-270.

Wilson, J.T., C.G. Enfield, W.J. Dunlap, R.L. Cosby, D.A. Foster, and L.B. Baskin (1981), "Transport and Fate of Selected Organic Pollutants in a Sandy Soil," J. Environ. Qual. 10(4), 501-506.

Windholz, M., S. Budavari, R. F. Blumetti, and E. S. Otterbein, Eds. (1983), The Merck Index: An Encyclopedia of Chemicals, Drugs, and Biologicals, 10th Edition (Merck \& Co., Inc., Rahway, NJ).

Yurteri, C., D.F. Ryan, J.J. Callow, and J.J. Gurol (1987), "The Effect of Chemical Composition of Water on Henry's law Constant," J. Water Pollut. Control Fed. 59, 950-956. 


\section{Toluene}

-220 - 


\section{Toluene-2,4-Diisocyanate}

Other names: 2,4-diisocyanato-1-methylbenzene; 2,4-diisocyanatoluene; 2,4-TDI; tolyene-2-4-diisocyanate; naconate 100

\section{CAS Registr" Number: 584-84-9}

Toluene-2,4-diisocyanate (2,4-TDI) is a white liquid used in the manufacture of polyurethane foams and other elastomers. 2,4-TDI constitutes roughly $80 \%$ of the commercial toluene diisocyanate (TDI) used in the U.S., the other $20 \%$ being the isomer, 2,6-TDI (Howard, 1989). TDI is released to the environment as a fugitive emission from stack exhaust during the production, transport, and use of TDI in the manufacture of polyurethane-foam products. Both 2,4- and 2,6TDI are reactive with any compound having active hydrogens, i.e. water, acids, alcohols. According to Roegler (1985), the 2,4-isomer is about 1.4 times as reactive with water as the 2,6-isomer. The reactivity of the TDI isomers makes it impossible to define solubilities for these compounds in either water or octanol or in any compound or environmental medium containing water or hydrogendonor compounds. Because of their high reactivity, TDI isomers are not found in nature. TDI isomers are fully miscible (i.e., infinitely soluble) in alcohol (with decomposition), ether, acetone, carbon tetrachloride, benzene, chlorobenzene, kerosene, and olive oil.

Formula: $\mathrm{C}_{9} \mathrm{H}_{6} \mathrm{~N}_{2} \mathrm{O}_{2}$

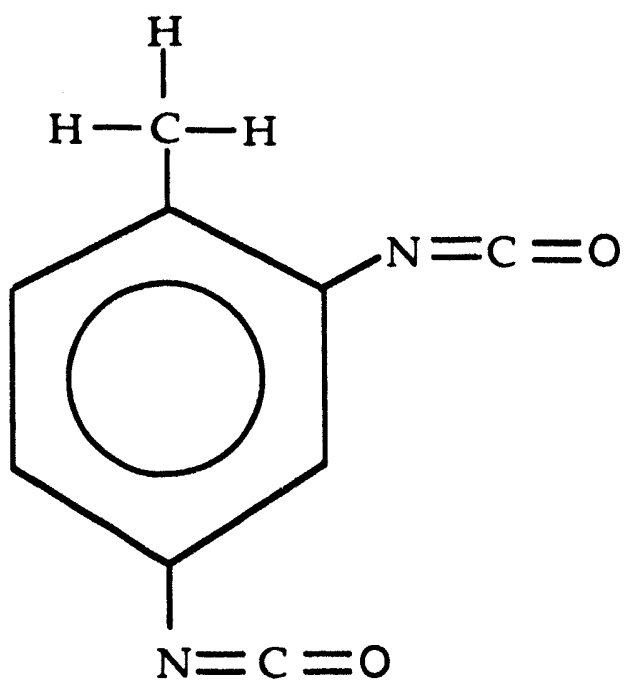

Molecular weight

174.15 (Windholz et al., 1983)

174.16 (Verschueren, 1983)

174.17 (Howard, 1989) 
174.2 (Roegler, 1985)

Melting Point

19.5 to $21.5^{\circ} \mathrm{C}$ (Howard, 1989)

Octanol-water partition coefficient $\left(K_{o w}\right)$

Because of its reactivity with water, 2,4-TDI cannot be characterized has having an octanol-water partition coefficient. However, because it is fully miscible in olive oil, it is expected to be fully miscible in octanol. If it is fully miscible in octanol, then it has no solubility limit, and it makes little sense to propose an octanol-water partition coefficient. If at low concentrations, TDI behaves as miscible with water before it reacts, then its $\mathrm{K}_{\mathrm{ow}}$ is essentially unity; otherwise, it is infinite. Based on the QSAR method of fragment contribution as proposed by Leo et al. (1971), one can estimate the $K_{o w}$ for 2,4-TDI, but the miscibility of TDI in organic solvents and its reactivity in water makes such estimates suspect. Nonetheless, such fragment estimating methods indicate that the $\log \mathrm{K}_{\mathrm{ow}}$ of 2,4-TDI is less than zero, indicating a high relative solubility in water.

No recommended $\mathrm{K}_{\mathrm{ow}}$. Bioconcentration for TDI cannot be estimated using $\mathbf{K}_{\text {ow }}$.

Vapor pressure at standard temperatures

1.33 $\mathrm{Pa}$ at $20^{\circ} \mathrm{C}$ reported by LARC (1979). [Also cited in Howard (1989).]

The Merck Index (Windholz et al., 1983) and Howard (1989) report a boiling point of $251^{\circ} \mathrm{C}$

Verschueren (1983) reports the following vapor pressures (VPs) for 2,4-TDI.

Temperature $\left({ }^{\circ} \mathrm{C}\right) \quad$ Vapor Pressure $(\mathrm{mm})$ Vapor Pressure $(\mathrm{Pa})$

20

0.01

1.33

80

1

133

251

760

101,300

Interpolating from this data give VP at $25^{\circ} \mathrm{C}=2.3 \mathrm{~Pa}$

The following Antoine equation has been published for estimating the vapor pressure of 2,4-TDI in $\mathrm{kPa}$ 
$\log _{10}(\mathrm{VP})=6.63416-\frac{2097.536}{201.33+\mathrm{T}} \pm 0.006$ for $20^{\circ} \mathrm{C}<\mathrm{T}<170^{\circ} \mathrm{C}$ from

Boublik et al. (1984),

which gives $\mathrm{VP}=2.3 \mathrm{~Pa}$ at $25^{\circ} \mathrm{C}$.

The relationship between VP and temperature is plotted below, using the Antoine equation shown above.

Recommended values:

$$
\begin{gathered}
\mathrm{VP}(\mathrm{Pa})=10^{[6.63416-2097.536 /(201.33+\mathrm{T})]} \times \text { or } \div 1.014 \\
\text { for } 20^{\circ} \mathrm{C}<\mathrm{T}<170^{\circ} \mathrm{C}
\end{gathered}
$$

Recommended value @ $25^{\circ} \mathrm{C}$ :

$$
\mathrm{VP}(\mathrm{Pa})=2.3 \pm 0.03 @ 25^{\circ} \mathrm{C}
$$

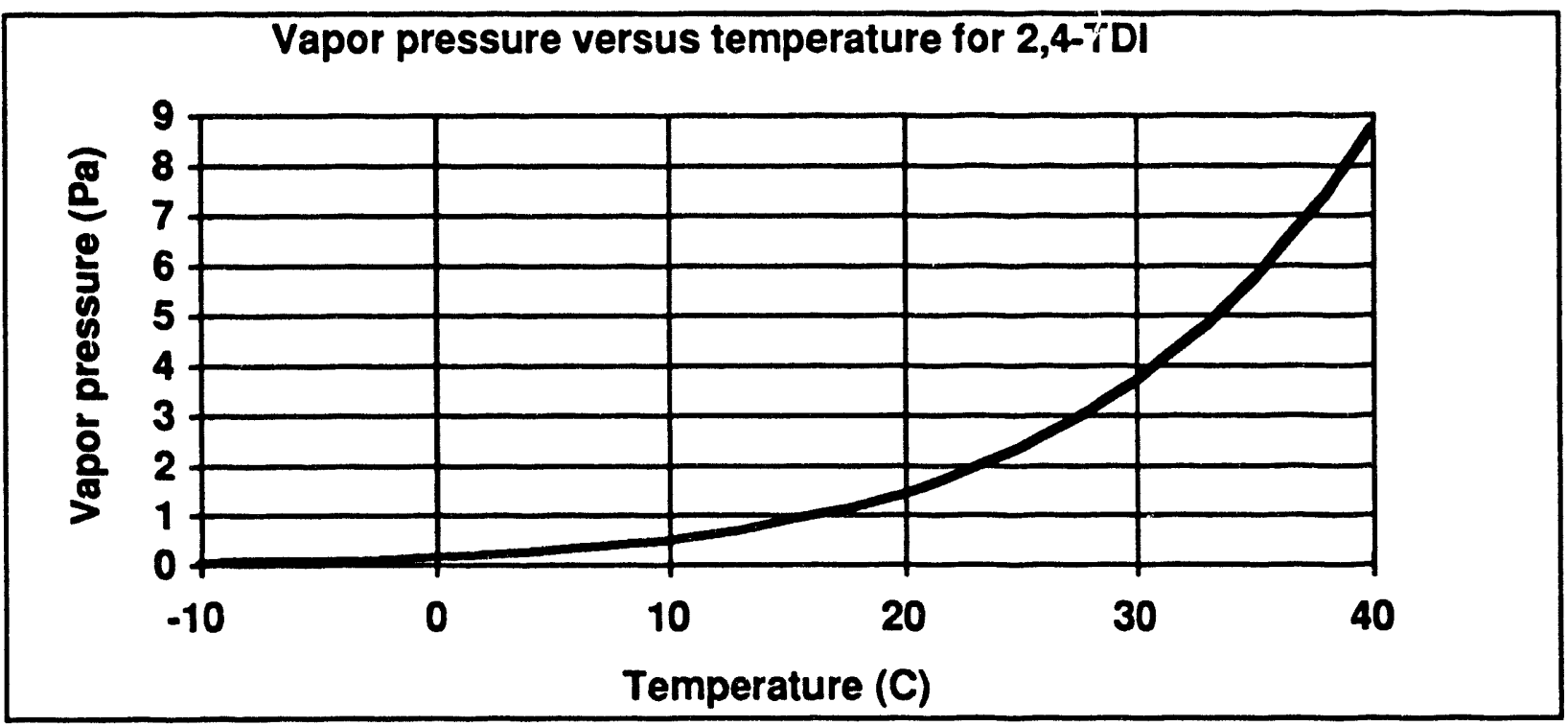

Solubility in water

No measurements of TDI solubility in water are available in the current literature. Because of its reactivity in water, it is not possible for TDI to estimate water solubility for TDI. As noted above, TDI isomers are fully miscible (i.e., 
infinitely soluble) in alcohol (with decomposition), ether, acetone, carbon tetrachloride, benzene, chlorobenzene, kerosene, and olive oil.

As discussed by Howard (1989), Brochhagen and Grieveson (1984) added $0.5 \mathrm{~L}$ of TDI to $20 \mathrm{~L}$ of stagnant water and observed the formation of a hard compact crust at the water/TDI interface, as well as the subsequent disappearance of TDI due to hydrolysis.

No recommended solubility. Inter-phase partitioning for TDI cannot be estimated using water solubility.

\section{Henry's law constant}

No measurements of Henry's law constants are available for TDI in the current literature. Because of its reactivity in water, it is not possible to estimate Henry's law partitioning for TDI. However, at low concentrations, the ratio of air to water concentration in air and water environments that are in contact can be estimated as

$$
C_{w} / C_{a}=A \times v_{d} /\left(V_{w} \times R_{w^{\prime}}\right)
$$

where $C_{w}$ is the TDI concentration in a given water body, $\mathrm{mol} / \mathrm{m}^{3} ; \mathrm{C}_{\mathrm{a}}$ is the TDI concentration in air above the water body, $\mathrm{mol} / \mathrm{m}^{3} ; \mathrm{v}_{\mathrm{d}}$ is the deposition velocity that represents the rate of TDI transfer from air to water, $\mathrm{m} / \mathrm{d} ; \mathrm{A}$ is the contact area between the air and water, $\mathrm{m}^{2} ; \mathrm{V}_{\mathrm{w}}$ is the volume of the water body, $\mathrm{m}^{3}$; and $R_{w}$ is the first-order rate constant that accounts for all TDI removals from water (i.e. hydrolysis), day ${ }^{-1}$.

\section{Organic-carbon partition coefficient $\left(K_{o c}\right)$}

No measurements of TDI $K_{\mathrm{oc}}$ values are available in the current literature. Because of its reactivity in water, it is not possible to make an estimate for TDI of soil-water partitioning.

At low concentrations, the ratio of soil to air concentration in air and soil environments that are in contact, can be estimated as

$$
\mathrm{C}_{\mathrm{s}} / \mathrm{C}_{\mathrm{a}}=\mathrm{A} \times \mathrm{v}_{\mathrm{d}} /\left(\mathrm{V}_{\mathrm{s}} \times \mathrm{R}_{\mathrm{s}}\right)
$$

where $C_{s}$ is TDI concentration in the soil below a contaminated air mass, $\mathrm{mol} / \mathrm{m}^{3} ; \mathrm{C}_{\mathrm{a}}$ is the TDI concentration in air above the soil, $\mathrm{mol} / \mathrm{m}^{3} ; \mathrm{v}_{\mathrm{d}}$ is the deposition velocity that represents the rate of TDI transfer from air to land, $\mathrm{m} / \mathrm{d}$; $A$ is the contact area between the air and land, $\mathrm{m}^{2} ; \mathrm{V}_{\mathrm{s}}$ is the volume of the soil compartment, $\mathrm{m}^{3}$; and $\mathrm{R}_{\mathrm{S}}$ is the first-order rate constant that accounts for all TDI removals from soil (i.e. hydrolysis), day ${ }^{-1}$. 
Diffusion coefficient in water

Based on the Wilke and Chang (1955) method described in Reid et al. (1987), the diffusion coefficient in $\mathrm{m}^{2} / \mathrm{d}$ in water is given by

$$
D_{\mathrm{xy}}=\frac{6.5 \times 10^{-7}\left(\phi M_{\mathrm{y}}\right)^{1 / 2} \mathrm{~T}}{\eta_{\mathrm{y}} V_{\mathrm{x}}^{0.6}} .
$$

The molecular weight $M_{y}$ of water is $18 \mathrm{~g} / \mathrm{mol}$. Wilke and Chang (1955) recommend an association factor, $\phi$, of 2.6 when the solvent is water. The viscosity of water, $\eta_{y}$, is $0.89 \mathrm{cP}$ at $25^{\circ} \mathrm{C}$. Molecular volume can be estimated by the LeBas incremental method as described in Lyman et al. (1990). With the molecular volume $V_{x}$ of $2.4-T D I$ equal to $162 \mathrm{~cm}^{3} / \mathrm{mol}$, this expression gives

Recommended value:

$$
D_{\text {water }}=2.4 \times 10^{-7} \mathrm{~T} \mathrm{~m}^{2} / \mathrm{d}=7.0 \times 10^{-5} \mathrm{~m}^{2} / \mathrm{d} \text { or } 8.1 \times 10^{-10} \mathrm{~m}^{2} / \mathrm{s} @ 25^{\circ} \mathrm{C}
$$

\section{Diffusion coefficient in air}

Based on the Fuller et al. (1966) method described in Lyman et al. (1990), the diffusion coefficient in $\mathrm{m}^{2} / \mathrm{d}$ in air is given by

$$
D_{\text {air }}=8.6 \times 10^{-3} T^{1.75} \frac{\sqrt{\frac{\left(29+j M_{x}\right.}{2 S_{1} / I_{x}}}}{\left[2.7+\left(V_{x}\right)^{1 / 3}\right]^{2}},
$$

where the molecular volume, $V_{x}$, of $2,4-T D I$ is $162 \mathrm{~cm}^{3} / \mathrm{mol}$; the molecular weight of TDI is $174 \mathrm{~g} / \mathrm{mol}$; and temperature (T) is expressed in kelvins. Then, the abo:e expression yields:

Recommended value:

$$
\mathrm{D}_{\text {air }}=2.6 \times 10^{-5} \mathrm{~T}^{1.75} \mathrm{~m}^{2} / \mathrm{d}=0.55 \mathrm{~m}^{2} / \mathrm{d} \text { or } 6.4 \times 10^{-6} \mathrm{~m}^{2} / \mathrm{s} @ 25^{\circ} \mathrm{C} .
$$


Bioconcentration factors for plant root concentration relative to soil concentration

No reported measurements of plant-root bioconcentration for 2,4-TDI in soils are available in the current literature. The reactive nature of the compound suggests that it is not likely to enter plants through the roots in appreciable quantities.

The partition factor from surface soil to edible plant parts due to rainsplash, $\mathrm{K}_{\mathrm{ps}}^{\text {rain }}$ is equal to $0.0034 \mathrm{~kg}$ (soil) $/ \mathrm{kg}$ (plant) with a CV of 1 (Dreicer et al. 1984). This partition factor yields plant fresh-mass concentration relative to soil concentration.

Recommended bioconcentration for TDI for plant roots relative to soil based on rainsplash only is $K_{p s}^{\text {rain }}=0.0034 \mathrm{~kg}$ (soil) $/ \mathrm{kg}$ (plant)

Steady-state bioconcentration factors for plant leaf concentration relative to air concentration

No reported measurements of plant-air bioconcentration for 2,4-TDI in air are available in the current literature. At low concentrations, the ratio of plant to air concentration of 2,4-TDI in air and plant environments that are in contact, can be estimated as

$$
C_{p} / C_{a}=A \times v_{d} /\left(V_{p} \times R_{p}\right)
$$

where $C_{p}$ is the TDI concentration in the plants in contact with contaminated air, $\mathrm{mol} / \mathrm{m}^{3} ; \mathrm{C}_{\mathrm{a}}$ is the TDI concentration in air above the plants, $\mathrm{mol} / \mathrm{m}^{3} ; \mathrm{v}_{\mathrm{d}}$ is the deposition velocity that represents the rate of TDI transfer from air to plant surfaces, $\mathrm{m} / \mathrm{d} ; \mathrm{A}$ is the contact area between the air and plants, $\mathrm{m}^{2} ; \mathrm{V}_{\mathrm{p}}$ is the volume of the plants compartment, $\mathrm{m}^{3}$; and $R_{\mathrm{p}}$ is the first-order rate constant that accounts for all TDI removals from plants (i.e. hydrolysis, photolysis, biodegradation, etc.), day ${ }^{-1}$.

Bioconcentration factors for fish concentration relative to water/or sediment concentrations

No reported measurements of fish-water bioconcentration for 2,4-TDI in water or sediments are available in the current literature.

No recommended bioconcentration for TDI between fish and water. 
Steady-state biotransfer factors for milk, dairy products, meat and egg concentrations relative to contaminant intake or dairy-product concentration relative to contaminant intake by food-producing animals

No reported measurements of milk-diet, meat-diet, or egg-diet biotransfer for 2,4-TDI are available in the current literature.

Using guinea pigs exposed to radio-labeled 2,4-TDI in air, Kennedy et al. (1989) have shown that the rate of 2,4-TDI uptake into blood increases linearly with time. They observed a half time for removal of TDI from blood on the order of 400 hours. This observation could be used to establish some preliminary estimate of biotransfer, if it is assumed that half times for removal can be used for other species, that is

$B_{i}=\frac{1}{R_{b} B W} \times$ or $\div 50$

where $B_{i}$ is the biotransfer factor from animal intake to milk, meat, or eggs, day $/ \mathrm{kg} ; \mathrm{R}_{\mathrm{b}}$ is the removal rate constant for 2,4-TDI from the animal, day ${ }^{-1}$ $\left(=0.693 / T_{1 / 2}\right)$; and BW is the animal body weight, $\mathrm{kg}$. The geometric standard deviation accounts for both the uncertainty associated with inter-species extapolation and the uncertainty associated with relating whole-body blood concentration to concentration in specific tissues. With adult cattle weights in the range 500 to $1000 \mathrm{~kg}$ (McKone and Ryan, 1989) and adult chicken weights in the range 1.8 to $2.5 \mathrm{~kg}$ (Altman and Dittmer, 1968), we estimate the following uncertain estimates of $B_{k}, B_{t}$, and $B_{e}$

$$
\mathrm{B}_{\mathrm{k}}=0.032 \mathrm{~d} / \mathrm{kg} \times \text { or } \div 50 \text { (recommended value for milk) }
$$

$$
B_{t}=0.032 \mathrm{~d} / \mathrm{kg} \times \text { or } \div 50 \text { (recommended value for meat) }
$$

$$
\mathrm{B}_{\mathrm{e}}=11 \mathrm{~d} / \mathrm{kg} \times \text { or } \div 50 \text { (recommended value for eggs) }
$$

\section{Contaminant biodegradation factors in soil}

Howard et al. (1991) estimate the unacclimated aqueous aerobic biodegradation half life of 2,6-TDI due to aerobic degradation to be in the range of 7 to $28 \mathrm{~d}$. This range corresponds to an aerobic biodegradation rate constant in the range 0.025 to $0.099 \mathrm{~d}^{-1}$. The unacclimated aqueous anaerobic half life for 2,6-TDI has been estimated by Howard et al. (1991) to be in the range of 28 to $112 \mathrm{~d}$. This range corresponds to an anaerobic biodegradation rate constant in the range 0.0057 to $0.025 \mathrm{~d}^{-1}$. 
Recommended soil biodegradation rate constants, based on the log mean and log range of the aqueous biodegradation half life ranges above and an uncertainty factor of 2 in going from 2,6- to 2,4-TDI:

aerobic soil biodegradation rate constant $=0.05 \mathrm{~d}^{-1} \times$ or $\div 5$

anaerobic soil biodegradation rate constant $=0.01 \mathrm{~d}^{-1} \times$ or $\div 5$

Media-specific half lives for air, soil, and surface water

Air Based on measurements by Atkinson (1987), Howard et al. (1991) estimate the half life of 2,6-TDI in lower atmosphere is in the range of 0.013 to $0.13 \mathrm{~d}$ based on photo-oxidation as a removal process.

Soil Based on the aqueous hydrolysis half-life in water, Howard et al. (1991) estimate the soil half life of 2,4-TDI to be in the range of 0.5 to $1 \mathrm{~d}$.

Water Based on the disappearance due to hydrolysis observed by Duff (1983) of a mixture of 2,4- and 2,6-TDI in a model river, Howard et al. (1991) estimate the half-life of 2,6-TDI in surface water to be in the range 0.5 to $1 \mathrm{~d}$. According to Roegler (1985), the 2,4-isomer is about 1.4 times as reactive with water as the 2,6-isomer.

Recommended half lives (in days), based on geometric mean of the half-lives range and geometric range of the values and an uncertainty factor of 2 in going from 2,6- to 2,4-TDI:
Air
$0.04 \times$ or $\div 7 d$
Soil
$0.7 \times$ or $\div 4 \mathrm{~d}$
Water
$0.7 \times$ or $\div 4 \mathrm{~d}$ 


\section{References for Toluene-2,4-diisocyanate}

Altman, P.L., and D.S. Dittmer (1968), Metabolism (Federation of American Societies for Experimental Biology, Bethesda, Maryland, pp 98-103, 551-552).

Atkinson, R. (1987), "Estimation of OH Radical Rate Constants and Atmospheric Lifetimes for Polychlorobiphenyls, Dibenzo-p-dioxins," Environ. Sci. Technol. 21, 305-307.

Boublik, T., Fried, V., and Hála, E. (1984), The Vapour Pressures of Pure Substances: Selected Values of the Temperature Dependence of the Vapour Pressures of Some Pure Substances in the Normal and Low Pressure Region (Second Revised Edition), Physical sciences data; 17 (Elsevier Science Publishers, Amsterdam, The Netherlands).

Brochhagen F.K., and B. M. Grieveson (1984), Cellular Polymers 3, 11-17.

Dreicer, M., T.E. Hakonson, G.C. White, and F.W. Whicker (1984), "Rainsplash as a Mechanism for Soil Contamination of Plant Surfaces," Health Phys. 46, 177-187.

Duff, P. B. (1983), "The Fate of TDI in the Environment," in Polyurethane: New Paths to Progress - Marketing - Technology, Proc. SPI 6th Inter. Tech. Marketing Conf., pp. 408-412

Fuller, E. N., P.D. Schettler, and J. C. Giddings (1966), "A New Method for Prediction of Binary Gas-Phase Diffusion Coefficients," Ind. Eng. Chem. 58, 19-27.

Howard, P. H., Ed. (1989), Handbook of Fate and Exposure Data for Organic Chemicals. Vol. I. Large Production and Priority Pollutants (Lewis Publishers, Chelsea, MI).

Howard, P. H., R. S. Boethling, W. F. Jarvis, W. M. Meylan, and E. M. Michalenko, Eds. (1991), Handbook of Environmental Degradation Rates (Lewis Publishers, Inc, Chelsea, MI).

International Agency for Research on Cancer (IARC) (1979), "2,4- and 2,6-Toluene Diisocyanates, 1,5-Naphthalene Diisocyanate, 4,4'-Methylenediphenyl Diisocyanate and Polymethylene Polyphenyl Isocyanate and Flexible and Rigid Polyurethane Foams," in IARC Monographs on the Evaluation of the Carcinogenic Risk of Chemicals to Humans: Some Monomers, Plastics and Synthetic Elastomers, and Acrolein, Volume 19 (International Agency for Research on Cancer, Lyon, France), pp. 303-340; Views and opinions of an IARC Working Group which met 7-13 February 1978, in Lyon, France.

Kennedy, A. L., M. F. Stock, Y. Alarie, and W. E. Brown (1989), “Uptake and Distribution of ${ }^{14} \mathrm{C}$ During and Following Inhalation Exposure to Radioactive Toluene Diisocyanate," Toxicol. Appl. Pharmacol. 100, 280-292.

Leo, A., C. Hansch, and D. Elkins (1971), "Partition Coefficients and Their Uses," Chem. Rev. 71, 525-616. 
Lyman, W. J., W. F. Reehl, and D. H. Rosenblatt (1990), Handbook of Chemical Property Estimation Methods: Environmental Behavior of Organic Compounds (American Chemical Society, Washington, DC).

McKone, T.E., P.B. Ryan (1989), "Human Exposures to Chemicals through Food Chains: An Uncertainty Analysis," Environ. Sci. Technol.23, 1154-1163.

Reid, R. C., J. M. Prausnitz, and B. E. Poling (1987), The Properties of Gases and Liquids (McGraw Hill, New York City, NY), 4th ed.

Roegler, M. (1985), "Slabstock Foams," in Polyurethane Handbook: Chemistry Raw Materials - Processing - Application - Properties, G. Oertel, Ed. (Carl Hanser Verlag, Munich, Germany), pp. 162-197.

Verschueren, K. (1983), Handbook of Environmental Data on Organic Chemicals, Second Edition (Van Nostrand Reinhold Company Inc., New York City, NY).

Wilke, C. R., and P. Chang (1955), "Correlation of Diffusion Coefficients in Dilute Solutions," A.I.Ch.E. J. 1(2), 264-270.

Windholz, M., S. Budavari, R. F. Blumetti, and E. S. Otterbein, Eds. (1983), The Merck Index: An Encyclopedia of Chemicals, Drugs, and Biologicals, 10th Edition (Merck \& Co., Inc., Rahway, NJ). 


\section{1,3-Xylene}

Other names: meta xylene, m-xylene, 3-xylene, 1,3-dimethylbenzene, m-xylol

CAS Registry Number: 108-38-3

$1,3-x y l e n e$ is the predominant isomeric form $(60 \%)$ of the technical grade of xylenes (mixed xylenes) which contains the three isomers and ethylbenzene. Mixed xylenes is produced primarily from petroleum, smaller amounts are produced from coal tar. It is also a by-product of olefin manufacture. Mixed xylenes are ranked 22 nd in production volume of top commercial products. Approximately $92 \%$ of all mixed xylenes are incorporated into gasoline. The remainder is used in solvent, cleaning agent, and degreaser applications.

Individual isomers are used to produce specific industrial chemicals. $\mathrm{m}$-xylene is used for the production of isophthalic acid which is an intermediate in the manufacture of polyester resins. Environmental fate and distribution of mixed xylenes is estimated to be $99.1 \%$ through its release into the air from the gasoline fuel emission and solvent waste.

Formula:: $\mathrm{C}_{8} \mathrm{H}_{10}$ or $\mathrm{C}_{6} \mathrm{H}_{4}\left(\mathrm{CH}_{3}\right)_{2}$

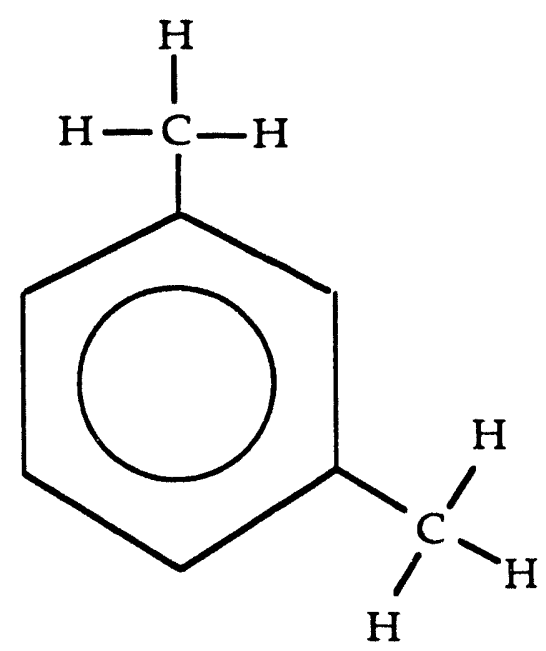

Molecular weight

106.16 (Windholz et al., 1983)

106.17 (Weast et al., 1986; Howard et al., 1990)

106.2 (Mackay et al., 1992)

Recommended molecular weight for m-xylene, 106.2 
Melting point

-47.4 (Howard et al., 1990)

Octanol-water partition coefficient $\left(K_{o w}\right)$

$1.51 \times 10^{3}$ derived from a $\log \mathrm{K}_{\mathrm{ow}}$ of 3.18 reported by Mackay et al. (1992) based on the value measured using generator-column techniques by Wasik et al. (1981).

$1.95 \times 10^{3}$ derived from a $\log \mathrm{K}_{\mathrm{ow}}$ of 3.29 reported by Mackay et al. (1992) based on the value measured using HPLC-k' by Hammers et al. (1982).

$1.35 \times 10^{3}$ derived from a $\log \mathrm{K}_{\mathrm{ow}}$ of 3.13 reported by Mackay et al. 1992) based on the value measured using generator-column, HPLC/UV by Tewari et al. (1982a,b).

$1.91 \times 10^{3}$ derived from a $\log \mathrm{K}_{\mathrm{ow}}$ of 3.28 reported by Mackay et al. (1992) based on the value measured using HPLC/RV by Garst and Wilson (1984).

$1.58 \times 10^{3}$ derived from a $\log \mathrm{K}_{\mathrm{ow}}$ of 3.20 reported by Mackay et al. (1992) based on the value measured using generator-column-HPLC/UV by Wasik et al. (1983).

$2.34 \times 10^{3}$ derived from a $\log \mathrm{K}_{\mathrm{ow}}$ of 3.37 reported by Mackay et al. (1992) based on the value measured using HPLC-k' by Haky and Young (1984).

$1.51 \times 10^{3}$ derived from a $\log \mathrm{K}_{\mathrm{ow}}$ of 3.18 reported by Mackay et al. (1992) based on the value measured by Doucette and Andren (1988).

Recommended value based on the log-mean value of the seven measured values reported above:

$\log \mathrm{K}_{\mathrm{ow}}=3.23 \pm 0.08$

$\mathrm{K}_{\mathrm{ow}}=1.7 \times 10^{3} \times$ or $\div 1.2$

Vapor pressure in $\mathrm{kPa}$ at standard temperatures

Stull (1947) reports the boiling point of $\mathrm{m}$-xylene as $139.1^{\circ} \mathrm{C}$.

Verschueren (1983) reports the boiling point of $\mathrm{m}$-xylene as $139^{\circ} \mathrm{C}$.

Howard et al. (1990) reports the boiling point of m-xylene as $139.3^{\circ} \mathrm{C}$. 
Stull (1947) reports the following vapor pressures for $m-x y l e n e$.

$\begin{array}{ccc}\text { Temperature }\left({ }^{\circ} \mathrm{C}\right) & \text { Vapor Pressure }(\mathrm{mm}) & \text { Vapor Pressure }(\mathrm{kPa}) \\ -6.9 & 1 & 0.13 \\ 16.8 & 5 & 0.67 \\ 28.3 & 10 & 1.3 \\ 41.1 & 20 & 2.7 \\ 55.3 & 40 & 5.3 \\ 64.4 & 60 & 8.0\end{array}$

Interpolating from these data gives $\mathrm{VP}$ at $25^{\circ} \mathrm{C}=1.08 \mathrm{kPa}$

Verschueren (1983) reports the following vapor pressures for m-xylene.

Temperature (C) Vapor Pressure (mm) Vapor Pressure (kPa)

20

30

139
6 11 760
8.0

1.5

101

Interpolating from these data give VP at $25^{\circ} \mathrm{C}=1.09 \mathrm{kPa}$

Other reported values:

1.10 reported at $25^{\circ} \mathrm{C}$ by Mackay et al. (1982), [Also cited in Mackay et al. (1992)].

1.11 reported at $25^{\circ} \mathrm{C}$ by Riddick et al. (1986). [Also cited in Mackay et al. (1992) and Howard et al. (1990)].

1.11 extrapolated by Mackay et al. (1992) at $25^{\circ} \mathrm{C}$ from the Antoine equation of Stephenson and Malanowski (1987).

1.11 quoted at $25^{\circ} \mathrm{C}$ by Hine and Mookerjee (1975). [Also cited in Mackay et al.(1992)].

The following Antoine equations have been published for estimating the vapor pressure of $\mathrm{m}$-xylene in $\mathrm{kPa}$ :

$$
\log _{10}(\mathrm{VP})=6.4629-\frac{1641.63}{230.9+\mathrm{T}} \pm 0.006 \mathrm{kPa}
$$


for $0^{\circ} \mathrm{C}<\mathrm{T}<60^{\circ} \mathrm{C}$ from Pitzer and Scott (1943) and cited in Boublik et al. (1984) that gives $\mathrm{VP}=1.12 \mathrm{kPa}$ at $25^{\circ} \mathrm{C}$,

$$
\log _{10}(\mathrm{VP})=6.1339-\frac{1462.27}{215.11+\mathrm{T}} \mathrm{kPa}
$$

for $28^{\circ} \mathrm{C}<\mathrm{T}<166^{\circ} \mathrm{C}$ from Wilhoit and Zwolinski (1971) and Dean (1985) that gives $\mathrm{VP}=1.11 \mathrm{kPa}$ at $25^{\circ} \mathrm{C}$.

The Antoine equation above proposed by Pitzer and Scott (1943) for VP versus temperature is plotted below.

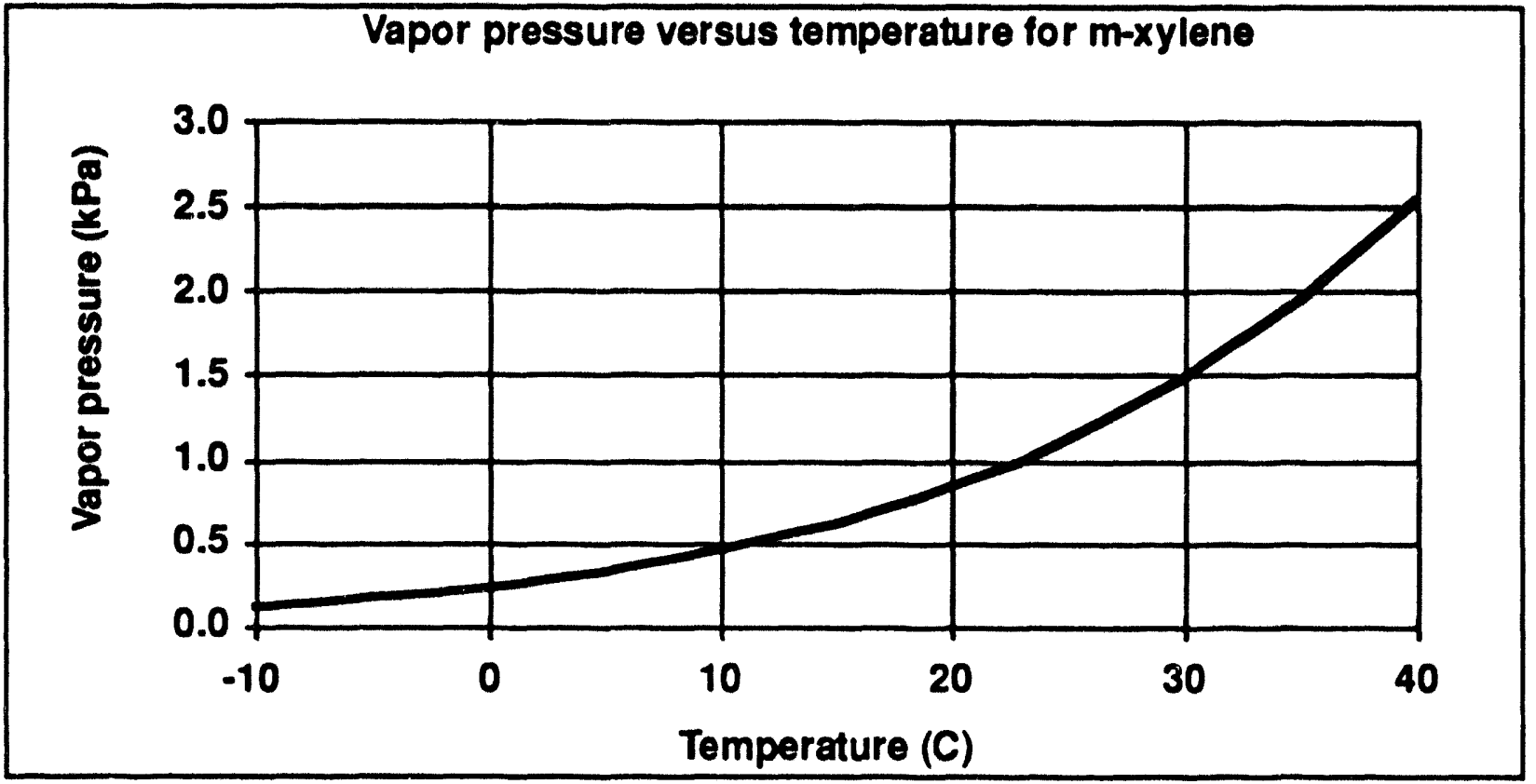

Recommended values for the temperature range 0 to $60^{\circ} \mathrm{C}$, based on the Antoine equation of Pitzer and Scott (1943) above:

$$
\operatorname{VP}(\mathrm{kPa})=10^{[6.4629-1641.63 /(230.9+\mathrm{T})]} \pm 1 \text { for } 0^{\circ} \mathrm{C}<\mathrm{T}<60^{\circ} \mathrm{C}
$$

Recommended value @ $25^{\circ} \mathrm{C}$, based all values above:

$$
\operatorname{VP}(\mathrm{kPa})=1.10 \pm 0.013 @ 25^{\circ} \mathrm{C}
$$


Solubility in water

$134 \mathrm{mg} / \mathrm{L}$ at $25^{\circ} \mathrm{C}$ reported by Mackay et al. (1992) based on the value measured using shake flask-GC by Price (1976).

$146 \mathrm{mg} / \mathrm{L}$ at $25^{\circ} \mathrm{C}$ reported by Mackay et al. (1992) based on the value measured using shake flask-GC by Sutton and Calder (1975).

$146 \mathrm{mg} / \mathrm{L}$ at $25^{\circ} \mathrm{C}$ reported by Mackay et al. (1992) based on the value reported by Riddick et al. (1986).

$157 \mathrm{mg} / \mathrm{L}$ at $25^{\circ} \mathrm{C}$ reported by Mackay et al. (1992) based on the value measured using shake flask-GC by Hermann (1972).

$159 \mathrm{mg} / \mathrm{L}$ at $25^{\circ} \mathrm{C}$ reported by Mackay et al. (1992) based on the value measured using generator column-HPLC/UV by Tewari et al. (1982a).

$160 \mathrm{mg} / \mathrm{L}$ at $25^{\circ} \mathrm{C}$ reported by Mackay et al. (1992) based on the value measured using shake generator column-HPLC by Wasik et al. (1983), as cited by Shiu et al. (1990).

$162 \mathrm{mg} / \mathrm{L}$ at $25^{\circ} \mathrm{C}$ reported by Mackay et al. (1992) based on the value measured using shake flask-GC by Polak and Lu (1973).

$173 \mathrm{mg} / \mathrm{L}$ at $25^{\circ} \mathrm{C}$ reported by Mackay et al. (1992) based on the value measured using shake flask-UV by Andrews and Keefer (1949).

$196 \mathrm{mg} / \mathrm{L}$ at $25^{\circ} \mathrm{C}$ reported by Mackay et al. (1992) based on the value measured using shake flask-UV by Bohon and Claussen (1951).

$206 \mathrm{mg} / \mathrm{L}$ at $25^{\circ} \mathrm{C}$ reported by Mackay et al. (1992) based on the value measured using shake flask-UV by Vesala (1974).

Recommended value based on the arithmetic mean of the ten measured values above:

$$
\begin{aligned}
\text { WS } & =164 \pm 22 \mathrm{mg} / \mathrm{L} @ 25^{\circ} \mathrm{C} \\
& =1.55 \pm 0.21 \mathrm{~mol} / \mathrm{m}^{3} @ 25^{\circ} \mathrm{C}
\end{aligned}
$$


Henry's law constant (dimensionless form, i.e. $H / R T$ )

0.26 reported at $25^{\circ} \mathrm{C}$ by Nirmalakhandan and Speece (1988). [Also cited in Mackay et al. (1992)].

0.29 reported at $25^{\circ} \mathrm{C}$ by Pankow and Rosen (1988). [Also cited in Mackay et al. (1992)].

0.31 reported at $25^{\circ} \mathrm{C}$ by Ashworth et al. (1988). [Also cited in Mackay et al. (1992)]. This value is also reported in Howard et al. (1990) who attributes it to National Academy of Sciences (NAS, 1980) report.

0.286 obtained by taking the ratio of VP/WS divided by RT, where VP and WS are the values recommended above.

Recommended value based on the arithmetic mean of the four values above:

$$
\mathrm{H} / \mathrm{RT}=0.29 \pm 0.02 @ 25^{\circ} \mathrm{C}
$$

The figure below is the plot of the dimensionless Henry's law constant based on the ratio of temperature-dependent vapor pressure to solubility as recommended in sections above

\section{Dimensionless Henry's law versus temperature for $\mathbf{m - x y l e n e}$}

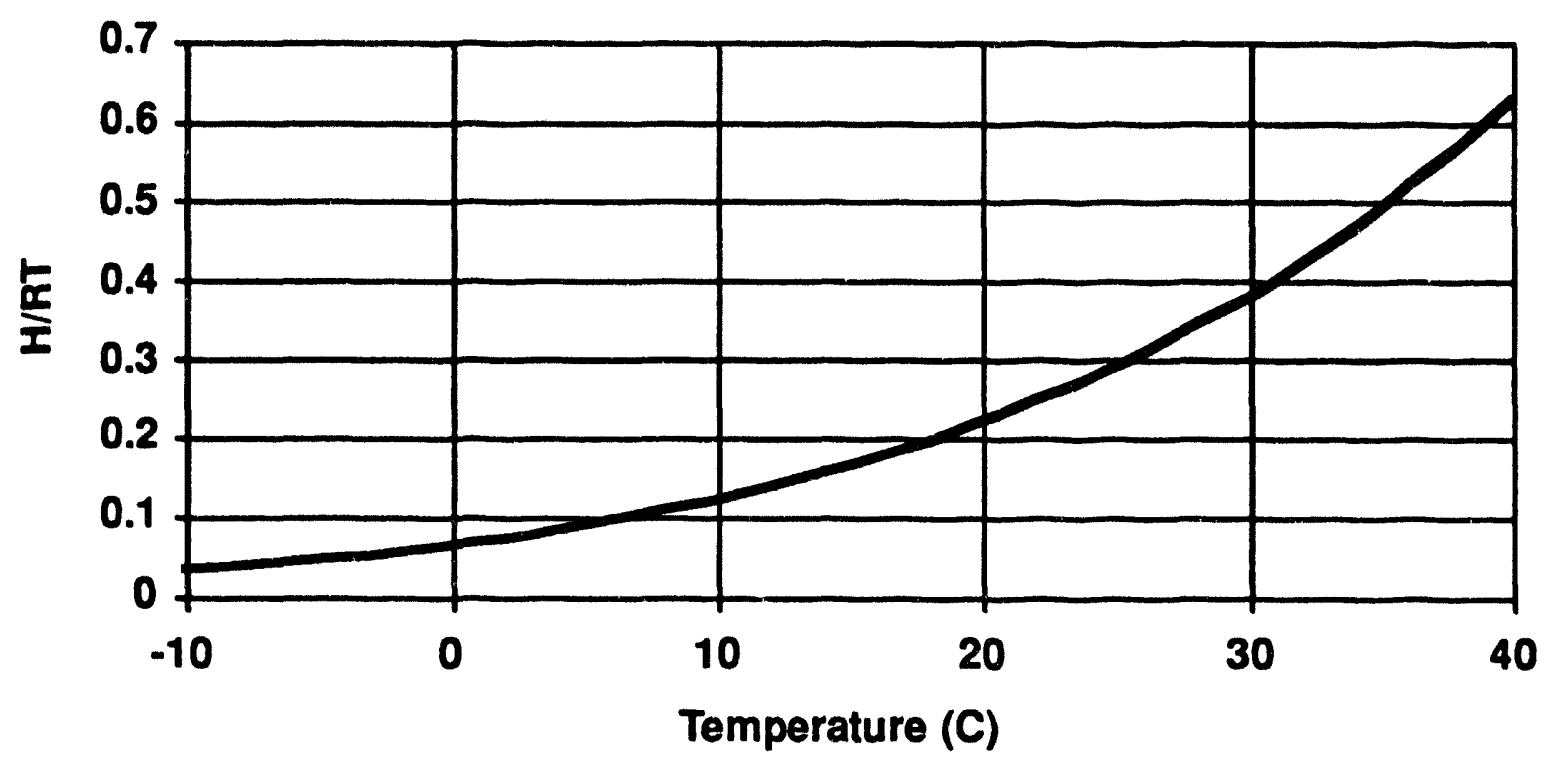


Organic-carbon partition coefficient $\left(K_{o c}\right)$

$1.82 \times 10^{2}$ derived from a $\log \mathrm{K}_{\mathrm{oc}}$ of 2.25 measured by Seip et al. (1986). [also cited by Mackay et al. (1992)].

$2.51 \times 10^{2}$ derived from a $\log \mathrm{K}_{\mathrm{oc}}$ of 2.40 measured by Szabo et al. (1990a,b) by using RP-HPLC on two immobilized humic acid phases. [Also cited by Mackay et al. (1992)].

$2.34 \times 10^{2}$ derived from a $\log K_{o c}$ of 2.37 measured by Szabo et al. (1990a,b) by using RP-HPLC on two immobilized humic acid phases. [Also cited by Mackay et al. (1992)].

Recommended value, based on the log-mean value of the three values
reported above:
$\log \mathrm{K}_{\mathrm{OC}}=2.34 \pm 0.07$
$\mathrm{~K}_{\mathrm{oc}}=2.20 \times 10^{2} \times$ or $\div 1.18$

Diffusion coefficient in water

Based on the Wilke and Chang (1955) method described in Reid et al. (1987), the diffusion coefficient in $\mathrm{m}^{2} / \mathrm{d}$ in water is given by

$$
D_{x y}=\frac{6.5 \times 10^{-7}\left(\phi M_{y}\right)^{1 / 2} \mathrm{~T}}{\eta_{y} V_{x}^{0.6}} \text {. }
$$

The molecular weight $\mathrm{M}_{\mathrm{y}}$ of water is $18 \mathrm{~g} / \mathrm{mol}$. Wilke and Chang (1955) recommend an association factor, $\phi$, of 2.6 when the solvent is water. The viscosity of water, $\eta_{y}$, is $0.89 \mathrm{cP}$ at $25^{\circ} \mathrm{C}$. Molecular volume can be estimated by the LeBas incremental method as described in Lyman et al. (1990). With the molecular volume $V_{x}$ of $m$-xylene equal to $123 \mathrm{~cm}^{3} / \mathrm{mol}$, this expression gives

Recommended value:

$$
D_{\text {water }}=2.8 \times 10^{-7} \mathrm{~T} \mathrm{~m}^{2} / \mathrm{d}=8.3 \times 10^{-5} \mathrm{~m}^{2} / \mathrm{d} \text { or } 9.7 \times 10^{-10} \mathrm{~m}^{2} / \mathrm{s} @ 25^{\circ} \mathrm{C}
$$


Diffusion coefficient in air

Based on the Fuller et al. (1966) method described in Lyman et al. (1990), the diffusion coefficient in $\mathrm{m}^{2} / \mathrm{d}$ in air is given by

$$
D_{\text {air }}=8.6 \times 10^{-3} \mathrm{~T}^{1.75} \frac{\sqrt{\frac{\left(29+\mathrm{M}_{x}\right)}{29 \mathrm{M}_{\mathrm{x}}}}}{\left[2.7+\left(V_{\mathrm{x}}\right)^{1 / 3}\right]^{2}}
$$

With the molecular volume, $v_{x}$ of $m-x y l e n e$ of $123 \mathrm{~cm}^{3} / \mathrm{mol}$ and a molecular weight of $106.2 \mathrm{~g} / \mathrm{mol}$, the above expression gives (with $\mathrm{T}$ in kelvins)

Recommended value:

$$
D_{\text {air }}=3.1 \times 10^{-5} \mathrm{~T}^{1.75} \mathrm{~m}^{2} / \mathrm{d}=0.65 \mathrm{~m}^{2} / \mathrm{d} \text { or } 7.6 \times 10^{-6} \mathrm{~m}^{2} / \mathrm{s} @ 25^{\circ} \mathrm{C}
$$

Bioconcentration factors for plant root concentration relative to soil concentration

No reported measurements of plant-root bioconcentration for $\mathrm{m}$-xylene in soils are available in the current literature. Estimation methods for this parameter are considered below.

The partition factor from surface soil to edible plant parts due to rainsplash, $\mathrm{K}_{\mathrm{ps}}^{\text {rain }}$ is equal to $0.0034 \mathrm{~kg}$ (soil) $/ \mathrm{kg}$ (plant) with a CV of 1 (Dreicer et al. 1984). This partition factor applies plant fresh mass concentration relative to soil concentration.

Based on the Briggs et al. $(1982,1983)$ estimation equation for uptake of contaminants by roots from soil solution, we calculate the RCF (which represents the ratio of contaminant concentration in root, $\mathrm{mg} / \mathrm{kg}$ [fresh mass], to contaminant concentration in soil solution, $\mathrm{mg} / \mathrm{L}$ ) for $\mathrm{m}$-xylene as

$$
\mathrm{RCF}=10
$$

When this factor is divided by the sorption coefficient, $K_{D}=f_{o c} \times K_{o c}=(0.01$ to $0.02) \times \mathrm{K}_{\mathrm{oc}}$ (from above), we obtain the ratio of contaminant concentration in roots, $\mathrm{mg} / \mathrm{kg}$ (fresh mass) to contaminant concentration in soil solids, $\mathrm{mg} / \mathrm{kg}$, which we refer to as $\mathrm{K}_{\mathrm{ps}}$ (roots) and estimate it as being in the range

$$
\mathrm{K}_{\mathrm{ps}}(\text { roots })=2.3 \text { to } 4.5
$$


Based the regression of $K_{p s}$ (roots) with $K_{o c}$ from Topp et al. (1986), and based on the range of $K_{o c}$ values listed above, we obtain

(recommended range for root crops)

$$
\mathrm{K}_{\mathrm{ps}}(\mathrm{roots})=664 \mathrm{~K}_{\mathrm{OC}}^{-0.622}=22 \text { to } 26 \text { (reflecting the range in } \mathrm{K}_{\mathrm{oc}} \text { ) }
$$

Based on the Travis and Arms (1988) correlation for plant-soil bioconcentration we obtain for total plant (not just roots) the following soil/plant partition coefficient

$$
\begin{array}{r}
\mathrm{K}_{\mathrm{ps}}=7.7 \mathrm{~K}_{\mathrm{ow}}^{-0.58}=0.51 \times \text { or } \div 5.3 \begin{array}{c}
\text { (recommended value for exposed } \\
\text { produce reflecting estimation error) }
\end{array}
\end{array}
$$

Steady-state bioconcentration factors for piant leaf concentration relative to air concentration

No reported measurements of plant-air bioconcentration for $m$-xylene in air are available in the current literature. Estimation methods for this parameter are considered below.

Based on the model of Riederer (1990) for foliar uptake of gases in plant leaves, we estimate a steady-state plant-air partition coefficient of

$$
\begin{gathered}
\mathrm{K}_{\mathrm{pa}}^{\mathrm{gs}}=\left[0.5+\left(0.4+0.01 \times \mathrm{K}_{\mathrm{ow}}\right) \times \frac{\mathrm{RT}}{\mathrm{H}}\right] \times 10^{-3} \frac{\mathrm{m}^{3}}{\mathrm{~kg}}=0.06 \mathrm{~m}^{3} / \mathrm{kg} \\
\text { (recommended value) }
\end{gathered}
$$

We could find no study in which the estimation error of this partition coefficient has been considered, but we assume the CV associated with it is on the order of 1 .

Bioconcentration factors for fish concentration relative to water/or sediment concentrations

23.44 derived from an eel/water ( $50 \mathrm{ppm}$ ) log BCF of 1.37 reported by Ogata and Miyake (1978).

15.14 derived from a goldfish/water log BCF of 1.18 reported by Ogata et al. (1984).

6.03 derived from a clam tissue/water $\log B C F$ of 0.78 reported by Nunes and Benville (1979). 
81 Based the $\mathrm{K}_{\mathrm{ow}}$ value and the correlation of Mackay (1982).

Recommended value, based on the log-mean value of the three measured values and one predicted value reported above:

$\log \mathrm{BCF}($ fish $)=1.3 \pm 0.5$

$\mathrm{BCF}(\mathrm{fish})=20 \times$ or $\div 3$

Steady-state biotransfer factors for milk or dairy-product concentration relative to contaminant intake by cattle

No reported measurements of milk-diet biotransfer for $m$-xylene are available in the current literature.

Based on the geometric mean regression of milk-to-diet biotransfer against $\mathrm{K}_{\mathrm{ow}}$ developed by Travis and Arms (1988) we estimate the milk biotransfer factor for m-xylene as

$$
B_{k}=7.9 \times 10^{-9} \mathrm{~K}_{\mathrm{ow}} \times 10^{( \pm 0.84)}=1.3 \times 10^{-5} \times \text { or } \div 7 \text { (recommended value) }
$$

The estimation error in this expression corresponds to a CVs of 6 .

Steady-state biotransfer factors for meat concentration relative to contaminant intake by cattle, pigs, and chickens

No reported measurements of meat-diet biotransfer for $m$-xylene are available in the current literature.

Based on the geometric mean regression of meat-to-diet biotransfer against $\mathrm{K}_{\mathrm{ow}}$ developed by Travis and Arms (1988) we estimate the meat biotransfer factor for m-xylene as

$$
B_{t}=2.5 \times 10^{-8} K_{o w} \times 10^{( \pm 0.952)}=4.3 \times 10^{-5} \times \text { or } \div 9 \text { (recommended value) }
$$

The estimation error in this expression corresponds to a CV of 11 .

Steady-state biotransfer factors for egg concentration relative to contaminant intake by chickens

No reported measurements of egg-diet biotransfer for $m$-xylene are available in the current literature. 
Based on the geometric mean regression of egg-to-diet biotransfer against $\mathrm{K}_{\mathrm{ow}}$ developed above, we estimate the egg biotransfer factor for $\mathrm{m}$-xylene as

$$
\mathrm{B}_{\mathrm{e}}=7.9 \times 10^{-6} \mathrm{~K}_{\mathrm{ow}} \times 10^{( \pm 1)}=1.3 \times 10^{-2} \times \text { or }+10 \text { (recommended value) }
$$

The estimation error in this expression corresponds to a CV of 14 .

Contaminant biodegradation factors in soil

Kappeler and Wuhrmann (1978) report 100\% degradation of m-xylene in 192 hours (8 days) in a soil (sampled at 20 and $90 \mathrm{~cm}$ depth) column study simulating an aerobic ground water infiltration system at $10^{\circ} \mathrm{C}$. This can be interpreted as a residence time and corresponds to a degradation rate of 0.125 day $^{-1}$.

Jamison et al. (1976) also reported $100 \%$ degradation of m-xylene in 192 hours at $13^{\circ} \mathrm{C}$.

Bridie et al. (1979) and Howard et al. (1991) both reported the aqueous, aerobic biodegradation half-life of $\mathrm{m}$-xylene in unacclimated soil grab samples in the range 168 to 672 hours ( 7 to 28 days). [This study is also cited in Mackay et al. (1992)]. This range of soil half-lives corresponds to a soil biodegradation rate constant of 0.099 day $^{-1}$ to 0.025 day $^{-1}$.

Kuhn et al. (1985) and Howard et al. (1991) both reported the aqueous, aerobic biodegradation half-life of $m$-xylene in unacclimated soil grab samples from which an aqueous anaerobic biodegradation half-life in the range 672 to 2688 hours (28 to 112 days) is derived. [This study is also cited in Mackay et al. (1992)]. This range of soil half-lives corresponds to a soil biodegradation rate constant of 0.025 to 0.00026 day $^{-1}$.

Olsen and Davis (1990) report a biodegradation half time of 0.7 hours (0.03) days. [This study is also cited in Mackay et al. (1992)]. This half-life corresponds to a soil biodegradation rate constant of 23.1 day $^{-1}$.

Recommended values, based on log mean of the soil degradation rate constants:

aerobic soil biodegradation rate constant $=0.24$ day $^{-1} \times$ or $\div 12$ anaerobic soil biodegradation rate constant $=0.0025$ day $^{-1} \times$ or $\div 4$ 
Media-specific half lives for air, soil, and surface water

Air Atkinson (1985) estimated the half life of m-xylene in the lower atmosphere to be 2.6 to 26 hours ( 0.1 to 1.1 ) days based on an measured rate data for vapor phase reacton with hydroxy radicals in air. [Also reported by Howard et al. (1991) and cited by Mackay et al. (1992)].

Singh et al. (1981) estimated the half life of $m$-xylene in urban lower atmospher to be 7.2 hours (0.3) days based on an measured rate data for vapor phase reacton with hydroxy radicals at $27^{\circ} \mathrm{C}$.

Doyle et al. (1975) estimated the half life of $m$-xylene in ambient LA basin to be 0.83 hour based on an measured reacton with hydroxy radicals at $27^{\circ} \mathrm{C}$. [Also cited by Mackay et al. (1992)].

Brice and Derwent (1978) estimated the half life of $m$-xylene in the lower atmosphere under smog in S.E. England to be 1.5 hours (0.06) days. [also reported by Perry et al. (1977), and cited by Mackay et al. (1992)].

Ravishankara et al. (1978) estimated the half life of $m$-xylene in the troposphere to be 1.0 hours $(0.042)$ day for summer and 9.7 hours $(0.4)$ day for winter based on an measured rate data for vapor phase reacton with hydroxy radicals at $25^{\circ} \mathrm{C}$.

Soil Howard et al. (1991) have estimated the half-live of $m$-xylene in soil due to aerobic biodegradation to be in the range of 168 to 672 hours ( 7 to 28 days). [also reported by Bridie et al. (1979), and cited by Mackay et al. (1992)].

Water Howard et al. (1991) have estimated the half-live of $m$-xylene in surface water due to aerobic biodegradation to be in the range of 168 to 672 hours ( 7 to 28 days).

Recommended half-life values, based on arithmetic mean of the half lives and geometric range of the values:
Air $\quad 0.3 \mathrm{~d} \times$ or $\div 2.6$
Soil $\quad 18 \mathrm{~d} \times$ or $\div 1.5$
Surface Water $18 \mathrm{~d} \times$ or $\div 1.5$ 


\section{References for 1,3-Xylene}

Andrews, L.J., and R.M. Keefer (1949), "Cation Complexs of Compounds Containing Carbon-Carbon Couble Conds. IV. The Argentation of Aromatic Hydrocarbons," J. Am. Chem. Soc. 71, 3644-3647.

Ashworth, R.A., G.B. Howe, M.E. Mullins, and T.N. Rogers (1988), "Air-Water Partitioning Coefficients of Organics in Dilute Aqueous Solutions," J. Hazard. Mater. 18, 25-36.

Atkinson, R. (1985), "Kinetics and Mechansims of the Gas Phase Reaction of Hydroxy Radicals with Organic Compounds Under Atmospheric Conditions," Chem. Rev. 85, 69-201.

Bohon, R.L., and W.F. Claussen (1951), "The Solubility of Aromatic Hydrocarbons in Water," J. Am. Chem. Soc. 72, 1571-1576.

Boublik, T., V. Fried, and E. Hála (1984), The Vapour Pressures of Pure Substances: Selected Values of the Temperature Dependence of the Vapour Pressures of Some Pure Substances in the Normal and Low Pressure Region (Second Revised Edition), Physical sciences data; 17 (Elsevier Science Publishers, Amsterdam, The Netherlands).

Brice, K.A., and R.G. Derwent (1978), "Emissions Inventory for Hydrocarbons in United Kingdom," Atom. Environ. 12, 2045-2054.

Bridie, A.L., C.J.M. Wolff, and M. Winter (1979), “BOD and COD of Some Petrochemicals," Water Res. 13, 627-630.

Briggs, G.G., R.H. Bromilow, and A.A. Evans (1982), "Relationships Between Lipophilicity and Root Uptake and Translocation of Non-Ionized Chemicals by Barley," Pestic. Sci. 13, 495-504.

Briggs, G.G., R.H. Bromilow, A.A. Evans, and M. Williams (1983), "Relationships Between Lipophilicity and the Distribution of Non-Ionized Chemicals in Barley Shoots Following Uptake by the Roots," Pestic. Sci. 14, 492-500.

Dean, J.D., Ed. (1985), Lang's Handbook of Chemistry (McGraw-Hill, Inc., New York City, NY), 13th ed.

Doucette, W. J., and A. W. Andren (1988), "Estimation of Octanol/Water Partition Coefficients: Evaluation of Six Methods for Highly Hydrophobic Aromatic Hydrocarbons," Chemosphere 17, 345-359.

Doyle, G.J., A.C. Lloyd, K.R. Darnall, A.M. Winer, and J.N. Pitts, Jr.(1975), "Gas Phase Kinetic Study of Relative Rates of Reaction of Selected Aromatic Compounds with Hydroxy Radicals in an Environmental Chamber," Environ. Sci. Technol. 9(3), 237-241.

Dreicer, M., T.E. Hakonson, G.C. White, and F.W. Whicker (1984), "Rainsplash as a Mechanism for Soil Contamination of Plant Surfaces," Health Phys. 46, 177-187. 
Fuller, E.N., P.D. Schettler, and J.C. Giddings (1966), "A New Method for Prediction of Binary Gas-Phase Diffusion Coefficients," Ind. Eng. Chem. 58, 19-27.

Garst, J.E., and W.C. Wilson (1984), "Accurate, Wide Range, Automated, High Performance Liquid Chromatographic Method for the Estimation of Octanol/Water Partition Coefficients. II: Effects of Chromatographic Method and Procedure Variables on Accuracy and Reproducibility of the Method," J. Pharm. Sci. 73(11), 1616-1623.

Haky, J.E., and A.M. Young (1984), "Evaluation of a Simple HPLC Correlation Method for the Estimation of the Octanol-Water Partition Coefficients of Organic Compounds," J. Liq. Chromatogr. 7, 675-689.

Hammers, W.E., G.J. Meurs, and C.L. DeLigny (1982), “Correlations Between Liquid Chromatographic Capacity Ratio Data on Lichrosorb RP-18 and Partition Coefficients in the Octanol-Water System," J. Chromatogr. 247, 1-13.

Hermann, R.B. (1972), "Theory of Hydrophobic Bonding. II. The Correlation of Hydrocarbon Solubility in Water with Solvent Cavitly Surface Area," J. Phys. Chem. 76, 2754-2758.

Hine, J., and P.K. Mookerjee (1975), "The Intrinsic Hydrophilic Character of Organic Compounds. Correlations in Terms of Structural Contributions," J. Org. Chem. 40, 292-298.

Howard, P.H., G.W. Sage, W.F. Jarvis, and D.A. Gray, Eds. (1990), Handbook of Environmental Fate and Exposure Data for Organic Chemicals. Volume II. Solvents (Lewis Publishers, Inc., Chelsea, MI).

Howard, P. H., R. S. Boethling, W. F. Jarvis, W. M. Meylan, and E. M. Michalenko, Eds. (1991), Handbook of Environmental Degradation Rates (Lewis Publishers, Inc, Chelsea, MI).

Jamison, V.W., R.L. Raymond, and J.O. Hudson (1976), "Biodegradation of High Octane Gasoline," in Proceedings of The Third International Biodegradation Symposium, L.M. Sharply, and A.M. Kaplan Eds., pp. 187-196.

Kappeler, T., and K. Wuhrmann (1978), "Microbial Degradation of the Water Soluble Fraction of Gas Oil," Water Res. 12, 327-333.

Kuhn, E.P., P.J. Coldgerg, J.L. Schnoor, O. Waner, A.J.B. Zehnder, and R.P. Schwarzenbach (1985), "Microbial Transformation of Substituted Benzenes During Infiltration of River Water to Ground Water: Laboratory Column Studies,"Environ. Sci. Technol. 19, 961-968.

Lyman, W. J., W. F. Reehl, and D. H. Rosenblatt (1990), Handbook of Chemical Property Estimation Methods: Environmental Behavior of Organic Compounds (American Chemical Society, Washington, DC).

Mackay, D. (1982), "Correlation of Bioconcentration Factors," Environ. Sci. Technol. 16, 274-278. 
Mackay, D., A.M. Bobra, D.W. Chan, and W.Y. Shiu (1982), "Vapor Pressure Correlation for Low-Volatility Environmental Chemicals," Environ. Sci. Technol. 16, 645-649.

Mackay, D., W.-Y. Shiu, and K.-C. Ma (1992), Illustrated Handbook of Physical-Chemical Properties and Environmental Fate for Organic Chemicals. Volume 1. Monoaromatic Hydrocarbons, Chlorobenzenes, and PCBs (Lewis Publishers, Inc., Chelsea, MI).

National Academy of Sciences (NAS) (1980), The Alkyl Benzenes (National Academy Press, Washington, DC), pp. II-1 to II-51.

Nirmalakhandan, N. N., and R. E. Speece (1988), “QSAR Model for Predicting Henry's Law Constant," Environ. Sci. Technol. 22, 1349-1357.

Nunes, P., and P.E. Benville, Jr. (1979), "Uptake and Depuration of Petroleum Hydrocarbons in the Manila Clams, Tapes semidecussata Reeve," Bull. Environ. Contam. Toxicol. 21, 719-724.

Ogata, M., K. Fujisawa, Y. Ogino, and E. Mano (1984), "Partition Coefficients as a Measure of Bioconcentration Potential of Crude Oil Compounds in Fish and Shellfish," Bull. Environ. Contam. Toxicol. 33, 561-567.

Ogata,M., and Y. Miyake (1978), "Disappearance of Aromatic Hydrocarbons and Organic Sulfur Compounds from Fish Flesh Reared in Crude Oil Suspension," Water Res. 12, 10411044.

Olsen R.L., and A. Davis (1990), "Predicting the Fate and Transport of Organic Compounds in Groundwater," Hazard. Mat. Control 3, 40-64.

Pankow, J.F., and M.E. Rosen (1988), "Determination of Volatile Compounds in Water by Purging Directly to a Capillary Column with Whole Column Cryotrapping," Environ. Sci. Technol. 18, 398-405.

Perry, R.A., R. Atkinson, and J.N. Pitts (1977), "Kinetics and Mechanisms of the Gas Phase Reaction of the Hydroxy Radicals with Aromatic Hydrocarbons Over Temperature Range 296-473 ${ }^{\circ} \mathrm{K}, "$ J. Phys. Chem. 81, 296-304.

Pitzer, K.S., and D.W. Scott (1943), J. Am. Chem. Soc. 65, 803.

Polak, J., and B.C.Y. Lu (1973), "Mutual Solubilities of Hydrocarbons and Water at $0^{\circ}$ and $25^{\circ} \mathrm{C}$," Can. J. Chem. 51, 4018-4023.

Price, L.C. (1976), "Aqueous Solubility of Petroleum as Applied to its Origin and Primary Migration," Am. Assoc. Petrol. Geol. Bull. 60, 213-244.

Ravishankara et al. (1978), "A Kinetic Study of the Reactions of Hydroxyl with Several Aromatic and Olefinic Compounds," Int. J. Chem. Kinet. 10, 783-804.

Reid, R. C., J. M. Prausnitz, and B. E. Poling (1987), The Properties of Gases and Liquids (McGraw Hill, New York City, NY), 4th ed. 
Reiderer, M. (1990), "Estimating Partitioning and Transport of Organic Chemicals in the Foliage/Atmosphere System: Discussion of a Fugacity-Based Model," Environ. Scil. Technol. 24, 829-837.

Riddick, J.A. et al. (1986), Organic Solvents (Wiley Intercsience. New York City, NY).

Seip, H.M., J. Alstad, G.E. Carlberg, K. Martinsen, and P. Skaane (1986),

"Measurement of Mobility of Organic Compounds in Soils," Sci. Total Environ. 50, 87-101.

Shiu, W.Y., K.C. Ma, D. Mackay, J.N. Seiber, and R.D. Wauchope (1990), “Solubilities of Pesticides in Water. Part I: Environmental Physical Chemistry; and Part II. Data Compilation," Rev. Environ. Contam. Toxicol. 116, 1-187.

Singh et al. (1981), "Measurements of Some Potentially Hazardous Organic Chemicals in Urban Environments," Atmos. Environ. 15, 601-612.

Stephenson, R.M., and S. Malanowski (1987), Handbook of the Thermodynamics of Organic Compounds (Elesvier Science Publishing Co., Inc., New York City, NY).

Stull, D. R. (1947), "Vapor Pressure of Pure Substances: Organic Compounds," Ind. Eng. Chem. 39, 517-540.

Sutton, C., and J.A. Calder (1975), "Solubility of Alkybenzenes in Distilled Water and Seawater at $25^{\circ} \mathrm{C}, " \mathrm{~J}$. Chem. Eng. Data 20, 320-322.

Szabo, G., S.L. Prosser, and R.A. Bulman (1990a), "Prediction of the Adsorption Coefficient $\left(\mathrm{K}_{\mathrm{oc}}\right)$ for Soil by a Chemically Immobilized Humic Acid Column Using RP-HPLC," Chemosphere 21, 729-740.

Szabo, G., S.L. Prosser, and R.A. Bulman (1990b), "Determination of the Adsorption Coefficient $\left(\mathrm{K}_{\mathrm{OC}}\right)$ of Some Aromatics for Soil by RP-HPLC on Two Immobilized Humic Acid Phases," Chemosphere 21, 777-788.

Tewari, Y.B., M.M. Miller, S.P. Wasik, and D.E. Martire (1982a), "Aqueous Solubility and Octanol/Water Partition Coefficient of Organic Compounds at $25.0^{\circ} \mathrm{C}$," J. Chem. Eng. Data 27, 451-454.

Tewari, Y.B., M.M. Miller, and S.P. Wasik (1982b), "Calculation of Aqueous Solubilities of Organic Compounds," NBS J. Res. 87, 155-158.

Topp, E., I. Scheunert, A. Attar, and F. Korte (1986), "Factors Affecting the Uptake of 14C-Labeled Organic Chemicals by Plants From Soil," Ecotoxicol. Environ. Saf. 11, 219-228.

Travis, C. C., and A. D. Arms (1988), "Bioconcentration of Organics in Beef, Milk, and Vegetation," Environ. Sci. Technol. 22, 271-274.

Verschueren, K. (1983), Handbook of Environmental Data on Organic Chemicals, Second Edition (Van Nostrand Reinhold Company Inc., New York City, NY). 
Vesala, A. (1974), "Thermodynamics of Transfer Nonelectrolytes From Light and Heavy Water. I. Linear Free Energy Correlations of Free Energy of Transfer with Solubility and Heat of Melting of Nonelectrolyte," Acta Chem. Scand. 28A(8), 839845.

Wasik, S.P., M.M. Miller, Y.B. Tewari, W.E. May, W.J. Sonnefeld, H.DeVoe, and W.H. Zoeller (1983), "Determination of the Vapor Pressure, Aqueous Solubility, and Octanol/Water Partition Coefficient of Hydrophobic Substances by Coupled Generator Column/Liquid Chromatographic Methods," Res. Reo. 85, 29-42.

Wasik, S.P., Y.B. Tewari, M.M. Miller, and D.E. Martire (1981), Octanol/Water Partition Coefficients and Aqueous Solubilities of Organic Compounds, U.S. Environmental Protection Agency, Washington, DC, PB82-141797.

Weast, R. C., M. J. Astle, and W. H. Beyer, Eds. (1986), CRC Handbook of Chemistry and Physics: A Ready Reference Book of Chemical and Physical Data, 67th Edition (CRC Press, Inc., Boca Raton, FL).

Wilhoit, R.C., and B.J. Zwolinski (1971), Handbook of Vapor Pressures and Heats of Vaporization of Hydrocarbons and Related Compounds, Thermodynamics Research Center, Texas A\&M University, College Station, TX.

Wilke, C.R., and P. Chang (1955), "Correlation of Diffusion Coefficients in Dilute Solutions," AIChE J. 1, 264-270.

Windholz, M., S. Budavari, R. F. Blumetti, and E. S. Otterbein, Eds. (1983), The Merck Index: An Encyclopedia of Chemicals, Drugs, and Biologicals, 10th Edition (Merck \& Co., Inc., Rahway, NJ). 


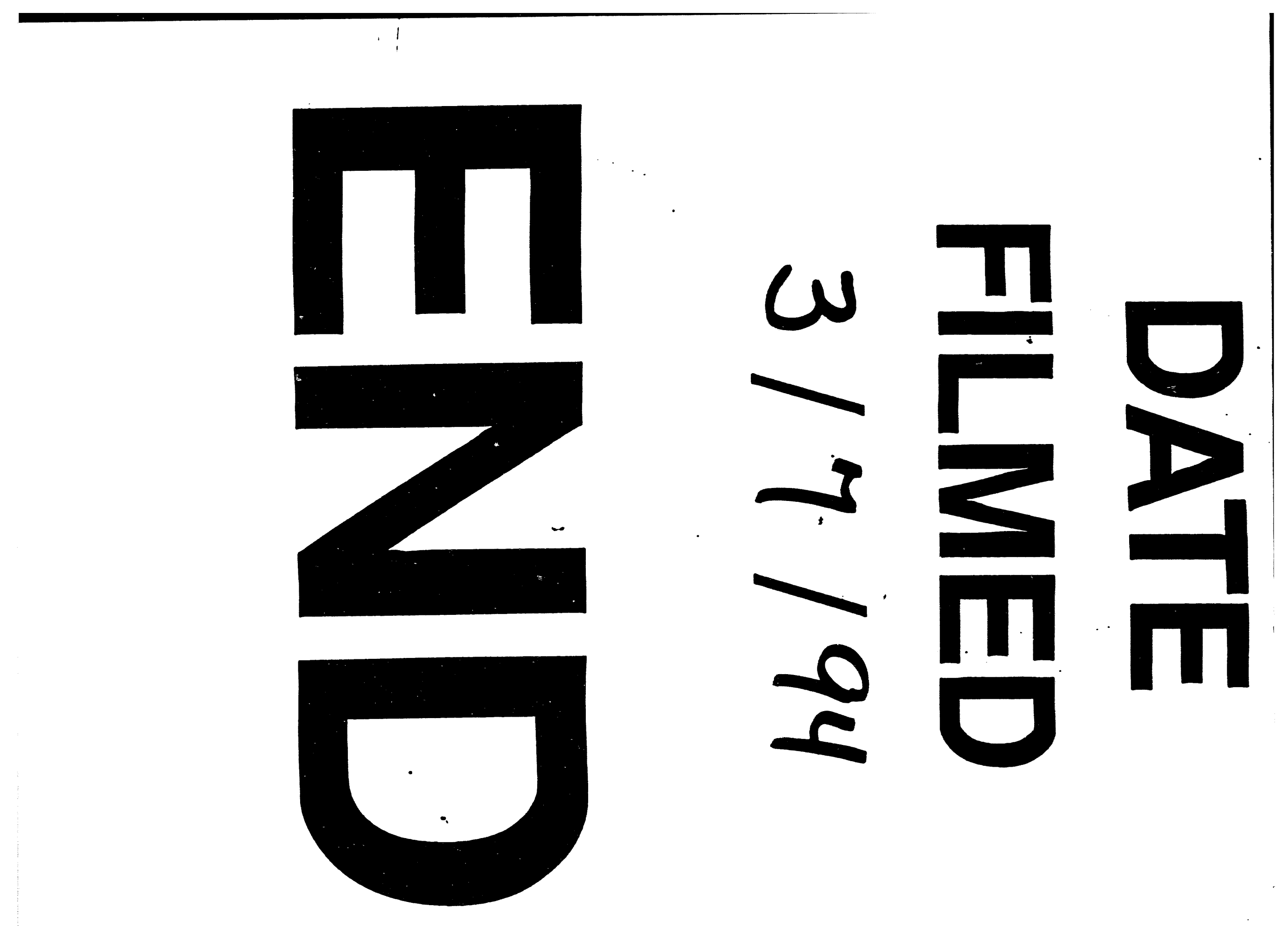


